DOC.20041005.0003

QA: QA

ANL-EBS-MD-000002 REV 02

September 2004

BBCHTEL SAIC COANILC

\title{
Aging and Phase Stability of Waste Package Outer
} Barrier

Prepared for:

U.S. Department of Energy

Office of Civilian Radioactive Waste Management

Office of Repository Development

1551 Hillshire Drive

Las Vegas, Nevada 89134-6321

Prepared by:

Bechtel SAIC Company, LLC

1180 Town Center Drive

Las Vegas, Nevada 89144

Under Contract Number

DE-AC28-01RW12101 


\section{DISCLAIMER}

This report was prepared as an account of work sponsored by an agency of the United States Government. Neither the United States Government nor any agency thereof, nor any of their employees, nor any of their contractors, subcontractors or their employees, makes any warranty, express or implied, or assumes any legal liability or responsibility for the accuracy, completeness, or any third party's use or the results of such use of any information, apparatus, product, or process disclosed, or represents that its use would not infringe privately owned rights. Reference herein to any specific commercial product, process, or service by trade name, trademark, manufacturer, or otherwise, does not necessarily constitute or imply its endorsement, recommendation, or favoring by the United States Government or any agency thereof or its contractors or subcontractors. The views and opinions of authors expressed herein do not necessarily state or reflect those of the United States Government or any agency thereof. 
QA: QA

Aging and Phase Stability of Waste Package Outer Barrier ANL-EBS-MD-000002 REV 02

September 2004 


\section{OCRWM Model Signature Page/Change History}

2. Type of Mathematical Model

$\triangle$ Process Model

Abstraction Model

System Model

Describe Intended Use of Model

This model is to be used as reference information for the General and Localized Corrosion Model of the Waste Package Outer Barrier.

3. Title

Aging and Phase Stability of Waste Package Outer Barrier

4. DI (including Rev. No., if applicable):

ANL-EBS-MD-000002 REV 02

\begin{tabular}{|c|c|c|c|}
\hline \multicolumn{2}{|l|}{$\begin{array}{l}\text { 5. Total Appendices } \\
\text { None }\end{array}$} & \multicolumn{2}{|c|}{$\begin{array}{l}\text { 6. No. of Pages in Each Appendix } \\
\text { N/A }\end{array}$} \\
\hline & Printed Name & Signature & Date \\
\hline 7. Originator & Frank Wong & $\forall$. & 24 SEP-OL \\
\hline $\begin{array}{l}\text { 8. Independent Technical } \\
\text { Reviewer }\end{array}$ & Pasu Pasupathi & & $9 / 2) / 04$ \\
\hline 9. Checker & David Stahl & & $9 / 27 / 04$ \\
\hline 10. QER & Charlie Warren & & $9 / 28 / 04$ \\
\hline 11. Responsible Manager/Lead & Dennis Thomas & & $4 \longdiv { 2 8 1 0 4 }$ \\
\hline 12. Responsible Manager & Neil Brown & & 9128104 \\
\hline
\end{tabular}

13. Remarks

The author gratefully acknowledges the efforts and contributions of Dr. Patrice Turchi and Sharon Torres. Dr. Turchi developed the computational thermodynamic and kinetics model, conducted the computational analyses, and documented the model formulation, results, and validation (Sections 3.1, 6.5, 6.6.1 through 6.6.4, 6.7.1.2, 7.1 through 7.4, and 8.1). Ms. Torres conducted and documented the volume fraction (Section 6.6.5) and microhardness (Section 6.6.6) measurements on many aged samples and also contributed the heat lot data (Section 8.2) of Alloy 22 material tested to date. The author would also like to thank Dr. Turchi and Ms. Torres for the many insightful and helpful discussions during the preparation of this Model Document.

The author also gratefully acknowledges the efforts of Dr. Ted Koppenaal who provided much valuable assistance in addressing and resolving the checker and reviewer comments during the preparation of Revision 2 of this document. The author would like to thank Dr. Koppenaal for the many helpful suggestions and timely contributions, which were very beneficial in the preparation of Revision 2 of this Model Document.

\begin{tabular}{|c|l|}
\hline \multicolumn{2}{|c|}{ Change History } \\
\hline 14. Revision No. & \multicolumn{1}{|c|}{ 15. Description of Change } \\
\hline 00 & Initial issue. \\
\hline $00 / 01$ & $\begin{array}{l}\text { The purpose of this ICN is to remove data-affiliated TBVs attached to Rev 00 of this AMR following } \\
\text { guidelines provided in TWP-MGR-MD-000004 REV 01, Technical Work Plan for: Integrated Management of } \\
\text { Technical Product Input Department (BSC 2001, Addendum B). } \\
\text { Changes made are indicated by vertical bars in the right margin. New DTN: LL010107712251.012 has been } \\
\text { used to replace DTN: LL000115905924.113 in the case of nonwelded aged Alloy 22 samples both in the } \\
\text { revised document and in the DIRS report. The remaining part of DTN: LL000115905924.113 representing } \\
\text { welded Alloy 22 samples are reference only so; that no TBVs exist in this ICN. Also, updated text in Sections } \\
5,6.2, \text { and 7, and references added in Section 8. In addition, figure captions in Section 4 and Table of Contents } \\
\text { modified and DIRS updated. }\end{array}$ \\
\hline
\end{tabular}


3. Title

Aging and Phase Stability of Waste Package Outer Barrier

4. DI (including Rev. No., if applicable):

ANL-EBS-MD-000002 REV 02

\begin{tabular}{|c|c|}
\hline & Change History \\
\hline 14. Revision No. & 15. Description of Change \\
\hline 01 & $\begin{array}{l}\text { The purpose of this revision is to include new information, data, and results pertinent to aging and phase } \\
\text { stability studies for Alloy } 22 \text {. Most of the sections in this AMR have been rewritten with new information, and } \\
\text { as a result, the changes were too extensive to use Revision Bars per Section 5.9d of AP-SIII.10Q. The few } \\
\text { sections noted below have undergone minor changes as noted: } \\
\text { Section 4.1.1: Figures Removed: } 9 \text { through } 27 ; 33,34 \text {, and } 36 \text { (from Rev } 00 \text { ICN 1) } \\
\text { Section 4.1.2: Figures Removed: } 49 \text { through 54; and } 59 \text { (from Rev } 00 \text { ICN 1) } \\
\text { Section 4.1.3: Figure Removed: } 72 \text { (from Rev00 ICN 1) } \\
\text { Section 4.1.4: Figures Removed: } 87 \text { through } 95 \text { (from Rev } 00 \text { ICN 1) } \\
\text { Section 5.1: editorial updates: (a) "assumes two things: (1) the phases that are thermodynamically stable at high } \\
\text { temperatures are also stable at lower temperatures and"; (b) "A procedure for the quantification of the } \\
\text { individual amounts of } \mu \text { P, P, and carbide is currently being developed. Once this procedure is developed, this } \\
\text { assumption can be tested directly." Have been deleted. } \\
\text { Section 5.2: editorial updates: "These calculations will further support the use of this assumption or provide } \\
\text { means of calculating WPOB lifetime in the absence of this assumption." Has been deleted. } \\
\text { New Section } 6.3 .1 \text { Phase Identification and Preliminary Kinetic Observations in Alloy } 22 \text { combines (from Rev } \\
\text { 00 ICN1): } \\
\text { - Section } 6.1 \text { Phase Identification in Alloy } 22 \text { (some editing to update Figure numbers) } \\
\text { - Section } 6.2 \text { Kinetics of Intermetallic Precipitation in Alloy } 22 \text { Base Metal (some editing to update Figure } \\
\text { numbers; last three sentences deleted. } \\
\text { New Section } 6.6 .5 .2 .2 \text { consists of (Rev } 00 \text { ICN 1) Section } 6.2 .1 \text { Basis for Confidence that Bounding Case is } \\
\text { Conservative (with editorial updates) } \\
\text { New Section } 6.3 .3 \text { Weld Characteristics consists of (Rev } 00 \text { ICN 1) Section } 6.4 \text { Kinetics of Intermetallic } \\
\text { Precipitation in Alloy } 22 \text { Welds } \\
\text { New Section } 6.7 .2 \text { Model Confidence: Natural Analogues: Discussion on josephinite from Section } 5.2 \text { has been } \\
\text { moved to Section } 6.7 .2 \\
\text { Assumptions } 5.3 \text { and } 5.4 \text { from Rev } 00 \text { ICN } 1 \text { are no longer applicable and have been removed in Rev } 1\end{array}$ \\
\hline 02 & $\begin{array}{l}\text { The purpose of this revision is to update the AMR per guidance from the Repository Integration Team (RIT). } \\
\text { Most of the sections in this AMR have been rewritten with new information, and as a result, the changes were } \\
\text { too extensive to use Revision Bars per Section 5.9d of AP-SIII.10Q. The key revisions are: } \\
\text { - Elimination of statements related to future work commitments } \\
\text { - Adjusted the micrograph frame aspect ratios (Section 4) to correspond to micrographs in the TDMS } \\
\text { database } \\
\text { - Added text to reference the bounding repository thermal conditions are "less than } 300^{\circ} \mathrm{C} \text { for } 500 \text { years } \\
\text { followed less than } 200^{\circ} \mathrm{C} \text { for as long as } 9,500 \text { years (BSC } 2004 \text { [DIRS } 169565 \text { ], Figure } 6.3-57 \text { )" } \\
\text { - Added/modified text for clarity } \\
\text { - Revised summary of chemical compositions of Alloy } 22 \text { heats tests and ternary surrogate modeled to } \\
\text { note that the conclusions of this AMR agree well with the chemical compositional ranges of Ni, Cr, } \\
\text { Mo, and } \mathrm{W} \text {, the elements which contribute most significantly to Alloy } 22 \text { phase stability. }\end{array}$ \\
\hline & \\
\hline
\end{tabular}




\section{CONTENTS}

Page

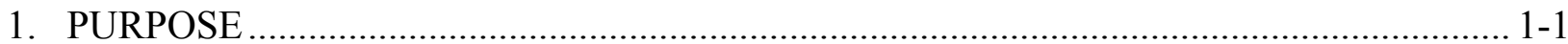

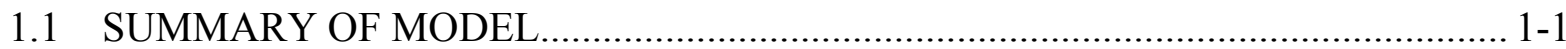

1.2 INTENDED USE OF MODEL …................................................................... 1-2

2. QUALITY ASSURANCE ................................................................................ 2-1

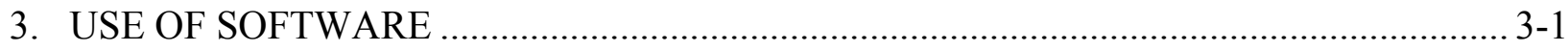

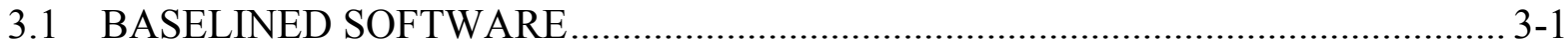

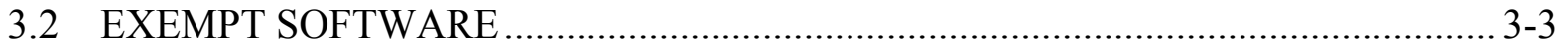

3.3 SUMMARY OF SOFTWARE USED ............................................................... 3-3

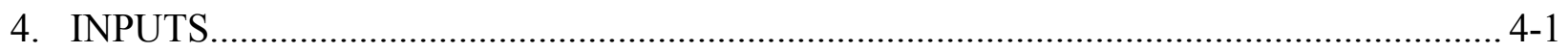

4.1 DIRECT INPUTS ..................................................................................... 4-1

4.1.1 Transmission Electron Microscopy Micrographs Used in Preliminary TCP and Carbide Phase Identification .............................................................. 4-2

4.1.2 Micrographs Showing Precipitation in Alloy 22 Beginning on and Covering Grain Boundaries, Beginning on Twin Boundaries, and Beginning Within the Grains .............................................................. 4-11

4.1.3 Micrographs Showing TCP Particles in Alloy 22 Welds ............................ 4-20

4.1.4 TEM Micrographs Showing When LRO Has Been Observed ....................... 4-25

4.1.5 SEM Micrographs Used for Quantification of Phases and LRO ................... 4-32

4.1.6 SEM Micrographs Showing Bulk Precipitation in Base Metal ..................... 4-32

4.1.7 SEM Micrographs Showing Precipitation in Weld Metal ........................... 4-37

4.1.8 Volume-Fraction Measurements................................................................... 4-41

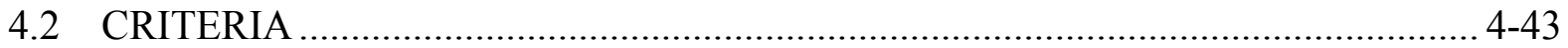

4.3 CODES AND STANDARDS ............................................................... $4-44$

5. ASSUMPTIONS .................................................................................................... $5-1$

5.1 KINETICS THE SAME FOR THE TCP AND CARBIDE PHASES IN

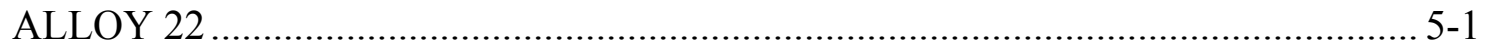

5.2 TRANSFORMATION MECHANISMS OPERATING AT THE HIGHER TEMPERATURES INVESTIGATED ALSO OPERATE AT THE LOWER EXPECTED REPOSITORY TEMPERATURES ................................................ 5-1

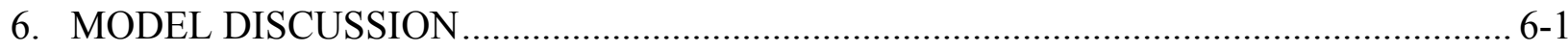

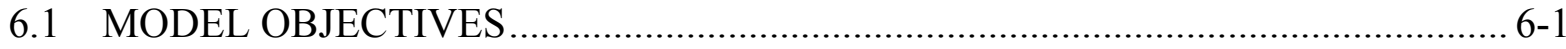

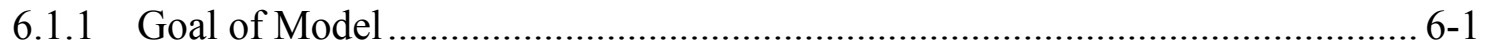

6.1.2 Background .......................................................................................... 6-1

6.2 FEATURES, EVENTS, AND PROCESSES (FEPS) INCLUDED IN MODEL........ 6-2

6.3 AGING AND PHASE STABILITY CONCEPTUAL MODEL .............................. 6-2

6.3.1 Phase Identification and Preliminary Kinetic Observations in Alloy 22 2........ 6-2

6.3.2 Kinetics of Phase Transformations in Alloy 22 .......................................... 6-4

6.3.3 Weld Characteristics ........................................................................ 6-5 


\section{CONTENTS (Continued)}

Page

6.4 CONSIDERATION OF ALTERNATIVE CONCEPTUAL MODELS ....................... 6-6

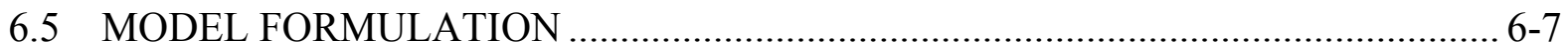

6.5.1 Background and Methodology ...................................................................... 6-7

6.5.2 Solidification According to the Scheil-Gulliver Approach ............................. 6-8

6.5.3 Computer Coupling of Phase Diagrams and Thermochemistry ....................... 6-9

6.5.4 Diffusion Modeling in Phase Transformations................................................ 6-11

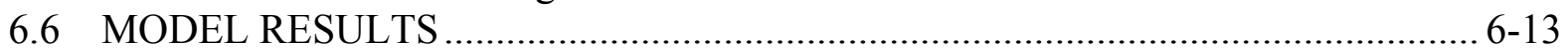

6.6.1 Property Diagrams of the Ni-Based Alloys ................................................. 6-13

6.6.2 Equivalent Alloys 22, 59, C-4, and C-276 ................................................ 6-18

6.6.3 Scheil-Gulliver Simulation of Solidification Processes in Ni-Based Alloys.. 6-19

6.6.4 Kinetic Properties of Nickel-Based Alloys ...................................................... 6-21

6.6.5 Volume-Fraction Measurements in Alloy 22 .............................................. 6-28

6.7 MODEL UNCERTAINTY AND CONFIDENCE .............................................. 6-32

6.7.1 Model Uncertainty ................................................................................. 6-32

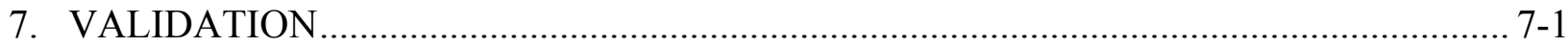

7.1 VALIDATION OF THE THERMO-CALC RESULTS FOR THE BINARY SUB-

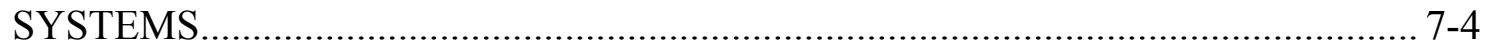

7.1.1 Modeling of the Ordered Phase oP6 ……................................................... 7-6

7.2 VALIDATION OF THE THERMO-CALC RESULTS FOR THE PSEUDO-

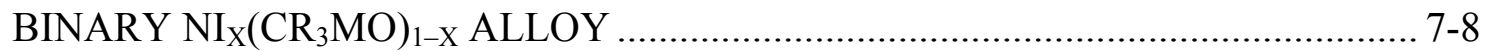

7.3 VALIDATION OF THE THERMO-CALC RESULTS FOR THE TERNARY NI-CR-MO ALLOY ………………………………................................ 7-10

7.4 VALIDATION OF THE TREATMENT OF MO AND W IN THE TERNARY

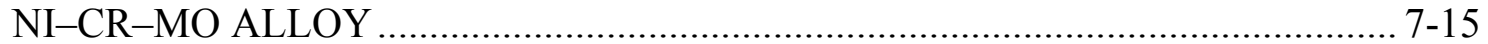

7.5 MODEL CONFIDENCE: NATURAL ANALOGUES ……………………….... 7-20

7.6 DISCUSSION OF MODEL VALIDATION ACTIVITIES ................................... 7-2

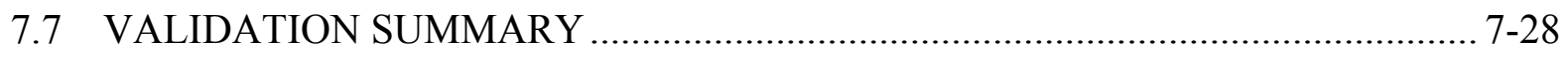

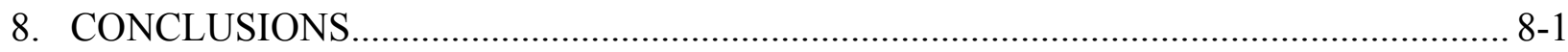

8.1 THE ROLE OF W IN THE STABILITY OF NICKEL-BASED ALLOYS................ 8-2

8.2 APPLICABILITY OF RANGES OF ALLOY 22 CHEMICAL COMPOSITION...... 8-2

8.3 SUMMARY OF DEVELOPED DATASETS ..................................................... 8-4

8.4 YUCCA MOUNTAIN REVIEW PLAN ACCEPTANCE CRITERIA …………........ 8-4

8.4.1 System Description and Demonstration of Multiple Barriers............................ 8-5

8.4.2 Degradation of Engineered Barriers ……………........................................ 8-6

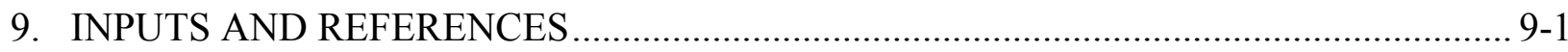

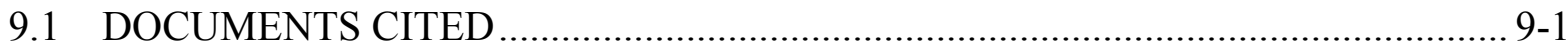

9.2 CODES, STANDARDS, REGULATIONS, AND PROCEDURES …………............. 9-7

9.3 SOURCE DATA, LISTED BY DATA TRACKING NUMBER ……………............. 9-8

9.4 OUTPUT DATA, LISTED BY DATA TRACKING NUMBER ………................... 9-8

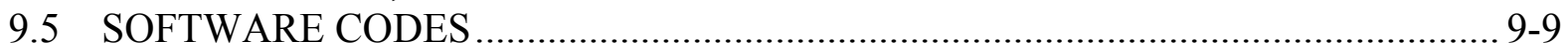




\section{FIGURES}

Page

1. Grain Boundary Precipitation in Alloy 22 Aged for 1,000 Hours at $593^{\circ} \mathrm{C}$...................... 4-2

2. $\quad$ Dark-Field Image Corresponding to Figure 1 ……...................................................... 4-3

3. SAD Pattern from the Grain Boundary Precipitate Shown in Figure 1 and Figure 2......... 4-3

4. Grain Boundary Precipitation (P Phase) in Alloy 22 Aged for 16,000 Hours at $593^{\circ} \mathrm{C} \ldots . .4-4$

5. $\quad$ Dark-Field Image Corresponding to Figure 4 ............................................................. 4-4

6. SAD Pattern from the Grain Boundary Precipitate Shown in Figure 4 and Figure 5 ......... 4-5

7. Grain Boundary Precipitation (carbide) in Alloy 22 Aged for 16,000 Hours at $593^{\circ} \mathrm{C}$..... 4-5

8. SAD Pattern from the Grain Boundary Precipitate Labeled Carbide in Figure 7 ............... 4-6

9. Precipitate (P phase) in Alloy 22 Aged for 16,000 Hours at $760^{\circ} \mathrm{C}$.................................. 4-6

10. Dark-Field Image Corresponding to Figure 9 ……..................................................... 4-7

11. SAD Pattern from the P-Phase Precipitate Shown in Figure 9 and Figure 10.................... 4-7

12. Precipitation (Possibly $\mu$ Phase) in Alloy 22 Aged for 16,000 Hours at $760^{\circ} \mathrm{C}$.................. 4-8

13. SAD Pattern from the $\mu$-Phase Precipitate Shown in Figure 12 ...................................... 4-8

14. Grain Boundary Precipitation in Alloy 22 Aged for 16,000 Hours at $760^{\circ} \mathrm{C}$ Showing in $\mu$-Phase Precipitation .......................................................................................... 4-9

15. SAD Pattern from the $\mu$-Phase Precipitate Shown in Figure 14 ...................................... 4-9

16. Grain Boundary Precipitation in Alloy 22 Aged for 16,000 Hours at $760^{\circ} \mathrm{C}$................... 4-10

17. SAD Pattern from the $\sigma$-Phase Precipitate Shown in Figure 16..................................... 4-10

18. SEM Micrograph Showing Precipitation Just Beginning on Grain Boundaries after Aging Alloy 22 for 10 Hours at $593^{\circ} \mathrm{C}$.................................................................. 4-11

19. SEM Micrograph Showing Precipitation on Grain Boundaries after Aging Alloy 22 for 100 Hours at $593^{\circ} \mathrm{C}$......................................................................................... 4-12

20. Optical Micrograph Showing No Precipitation on Grain Boundaries after Aging Alloy 22 for 1 Hour at $649^{\circ} \mathrm{C}$............................................................................ 4-12

21. SEM Micrograph Showing Little or No Precipitation on Grain Boundaries after Aging Alloy 22 for 1 Hour at $649^{\circ} \mathrm{C}$..................................................................... 4-13

22. SEM Micrograph Showing Precipitation on Grain Boundaries after Aging Alloy 22 for 10 Hours at $649^{\circ} \mathrm{C}$

23. SEM Micrograph Showing Precipitation on Grain Boundaries after Aging Alloy 22 for 100 Hours at $649^{\circ} \mathrm{C}$.......................................................................................... 4-14

24. SEM Micrograph Showing Precipitation on Grain Boundaries after Aging Alloy 22 for 1,000 Hours at $649^{\circ} \mathrm{C}$

25. SEM Micrograph Showing Precipitation on Grain and on Twin Boundaries after Aging Alloy 22 for 1,000 Hours at $649^{\circ} \mathrm{C}$

26. SEM Micrograph Showing Precipitation on Grain Boundaries and within the Grains after Aging Alloy 22 for 16,000 Hours at $649^{\circ} \mathrm{C}$

27. Low-Magnification SEM Micrograph Showing that Grain Boundary Precipitation has Begun after Aging Alloy 22 for 1 Hour at $760^{\circ} \mathrm{C}$...................................................... 4-16

28. High-Magnification SEM Micrograph Showing that Grain Boundary Precipitation has Begun after Aging Alloy 22 for 1 Hour at $760^{\circ} \mathrm{C}$. $4-16$

29. SEM Micrograph Showing Significant Grain Boundary Precipitation after Aging Alloy 22 for 10 Hours at $760^{\circ} \mathrm{C}$ 


\section{FIGURES (Continued)}

30. SEM Micrograph Showing Significant Grain Boundary Precipitation and Precipitation on Twin Boundaries after Aging Alloy 22 for 119 Hours at $760^{\circ} \mathrm{C}$

31. SEM Micrograph Showing Significant Precipitation Within the Grains of Alloy 22

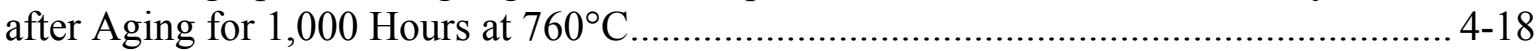

32. SEM Micrograph Showing Grain Boundary Precipitation in Alloy 22 after Aging for

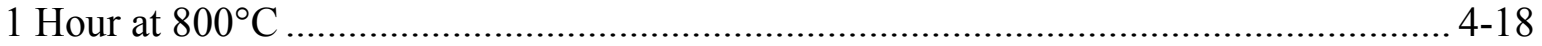

33. SEM Micrograph Showing Significant Grain Boundary Precipitation in Alloy 22 after Aging for 10 Hours at $800^{\circ} \mathrm{C}$.

34. SEM Micrograph Showing Precipitation on Grain Boundaries, on Twin Boundaries, and within the Grains after Aging Alloy 22 for 100 Hours at $800^{\circ} \mathrm{C}$

35. Low-Magnification (25×) Optical Micrograph of an Alloy 22 Multipass, Double-V Gas-Tungsten-Arc-Welding (GTAW) Weld with Matching Filler Metal (As-Welded) .. 4-20

36. SEM Micrograph of the Alloy 22 Weld Shown in Figure 35 Showing the Dendritic Structure Typical of Welds

37. SEM Micrograph of the Alloy 22 Weld Shown in Figure 35 Showing the Dendritic Structure Typical of Welds (Near Top of Plate; Center of Weld; Higher Magnification).

38. Low-Magnification Optical Micrograph of an Alloy 22 Weld and Aged for 40,000 Hours at $427^{\circ} \mathrm{C}$

39. SEM Micrograph of the Alloy 22 Weld Shown in Figure 38 at the Junction of Two Weld Passes

40. SEM Micrograph of the Alloy 22 Weld Shown in Figure 38 Showing the Dendritic Structure Typical of Welds ......................................................................................... 4-23

41. Optical Micrograph at the Fusion Line of the Alloy 22 Weld Shown in Figure 42 ........ 4-23

42. One of Few Precipitates Seen using TEM in the Alloy 22 Weld of Figure 38 Aged for 40,000 Hours at $427^{\circ} \mathrm{C}$

43. SAD Pattern from the Precipitate Shown in Figure 42 .................................................. 4-24

44. TEM Micrograph Showing a Precipitate, Possibly Carbide, in the HAZ of the Aged Alloy 22 Weld of Figure 38.

45. TEM Micrograph Showing LRO Domains in an Alloy 22 Base Metal Sample Aged for 16,000 Hours at $593^{\circ} \mathrm{C}$

46. Dark-Field Image Corresponding to Figure 45.

47. SAD Pattern from the Area Shown in Figure 45

48. TEM Micrograph from the Base Metal of an Alloy 22 Weld Sample Aged for 40,000 Hours at $427^{\circ} \mathrm{C}$.

49. Dark-Field Image from $1 / 3<220>$ Reflection.............................................................. 4-28

50. SAD Pattern from the Area Shown in Figure 48, Typical fcc $<110>$ Zone Axis............. 4-28

51. TEM Micrograph from the Weld Metal of an Alloy 22 Multipass, Double-V GTAW Weld with Matching Filler Metal Aged for 40,000 Hours at $427^{\circ} \mathrm{C}$................................ 4-29

52. Dark-Field Image Corresponding to Figure 51 ….................................................. 4-29

53. SAD Pattern from the Area Shown in Figure 51 ........................................................ 4-30

54. TEM Micrograph from the HAZ of the Alloy 22 Multipass, Double-V GTAW Weld with Matching Filler Metal Aged for 40,000 Hours at $427^{\circ} \mathrm{C}$. 


\section{FIGURES (Continued)}

Page

55. Dark-Field Image Corresponding to Figure 54, Taken from One of the $1 / 3<220>$ Reflections Shown in Figure 56.

56. SAD Pattern from the Area Shown in Figure 54, Showing $1 / 3<220>$ Superlattice Reflections

57. Base Metal Aged at $550^{\circ} \mathrm{C}$ for 21,052 Hours and Exhibits Ordered Matrix in Right-Hand Region

58. Base Metal aged at $649^{\circ} \mathrm{C}$ for 16,000 Hours ......................................................... 4-33

59. Base Metal Aged at $704^{\circ} \mathrm{C}$ for 16,000 Hours ......................................................... 4-33

60. Base Metal Aged at $760^{\circ} \mathrm{C}$ for 119 Hours ........................................................... 4-34

61. Base Metal Aged at $760^{\circ} \mathrm{C}$ for 1,000 Hours .............................................................. 4-34

62. Base Metal Aged at $760^{\circ} \mathrm{C}$ for 2,000 Hours ............................................................ 4-35

63. Base Metal Aged at $760^{\circ} \mathrm{C}$ for 16,000 Hours …….................................................. 4-35

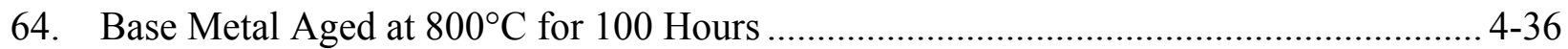

65. Base Metal Aged at $800^{\circ} \mathrm{C}$ for 1,002 Hours ............................................................ 4-36

66. Weld Metal, As-Welded Condition ..................................................................... 4-37

67. Weld Metal Aged at $593^{\circ} \mathrm{C}$ for 30 Hours ............................................................... 4-38

68. Weld Metal Aged at $593^{\circ} \mathrm{C}$ for 1,000 Hours .............................................................. 4-38

69. Weld Metal Aged at $704^{\circ} \mathrm{C}$ for 10 Hours ................................................................ 4-39

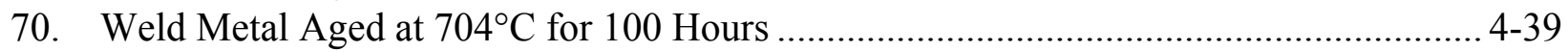

71. Weld Metal Aged at $760^{\circ} \mathrm{C}$ for 3 Hours .................................................................. $4-40$

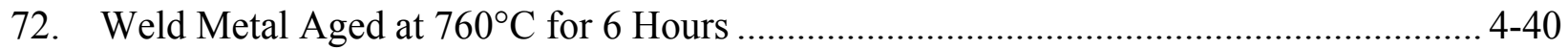

73. Weld Metal Aged at $760^{\circ} \mathrm{C}$ for 60 Hours ................................................................ 4-41

74. Schematic Description of Solidification According to the Scheil-Gulliver Approach........ 6-9

75. Schematic Flow Chart of Numerical Simulation of Phase Transformations ..................... 6-13

76. Calculated Property Diagrams of Alloy 22 .................................................................. 6-14

77. Calculated Property Diagrams of Alloy 22 with the Liquid, the fcc Matrix, and the $\sigma$ Phase (Left Panel), the P Phase (Central Panel), and the oP6-ordered Phase (Right Panel) Considered in the Calculations

78. Weight Fraction of Ni (Red), Cr (Blue), Mo (Green), W (Brown), and Fe (Black), Versus Temperature in the fcc Matrix, the oP6, and the P and $\sigma$ Phases for Alloy 22 at its Nominal Composition

79. Calculated Property Diagrams (Phase Fraction Versus Temperature) of Alloy 22, Alloy 59, C-4, and C-276 at Their Nominal Composition

80. Property Diagrams (Phase Fraction Versus Temperature) of the Equivalents of Alloy 22, 59, C-4, and C-276 at their Nominal Composition

81. Scheil-Gulliver Simulation Results for Alloy 22, Alloy 59, C-4, and C-276: Temperature Versus Weight Fraction of Solid Phase that Describes the Amount of Under-Cooling and the Succession of Phases During Cooling

82. Scheil-Gulliver Simulation Results of Weight Fraction of Ni (Red), Cr (Blue), and Mo (Green) in the fcc Matrix for Alloy 22, Alloy 59, C-4, and C-276 as Functions of Temperature, During Solidification 


\section{FIGURES (Continued)}

Page

83. Experimental Variation of the Lattice Parameter with Time at Fixed Isothermal Annealing for $\mathrm{Ni}_{2} \mathrm{Cr}$ Alloy.

84. Calculated Isothermal TTT Diagrams (Red Solid Circles) for an fcc-Based Matrix of a Binary $\mathrm{Ni}_{2} \mathrm{Cr}$ Alloy Transforming into the oP6-Ordered Phase, with Transformation Rate of $10 \%$

85. Property Diagram of Ni-24 at \% Cr-8 at \% Mo (or $20.78 \mathrm{wt} \% \mathrm{Cr}$ and $12.78 \mathrm{wt} \%$ Mo).

86. Calculated Isothermal TTT Diagrams for an fcc-Based Matrix of a Ternary Ni20.78Cr-12.78Mo (in wt \%) Cr Alloy Transforming into the oP6-Ordered Phase, with Transformation Rates of 5\%, $10 \%$, and $20 \%$

87. Property Diagram of $\mathrm{Ni}-21.1 \mathrm{wt} \% \mathrm{Cr}-13.5 \mathrm{wt} \% \mathrm{Mo}$ $6-25$

88. Calculated Isothermal TTT Diagram for an fcc-Based Matrix of a Ternary Ni21.1Cr-7.5Mo (in wt \%) Alloy (Surrogate for Alloy 22) Transforming into the oP6Ordered Phase, with Transformation Rates of $2 \%, 10 \%$, and $15 \%$

89. Calculated Isothermal TTT Diagram for an fcc-Based Matrix of a Ternary Ni-21.1Cr13.5Mo (in wt \%) Alloy (Surrogate for Alloy 22) Transforming into the P Phase, with Transformation Rates of $2 \%, 10 \%$, and $15 \%$.

90. Calculated Isothermal TTT Diagrams for an fcc-Based Matrix of a Ternary

Ni-21.1Cr-13.5Mo (in wt \%) Alloy (Surrogate for Alloy 22) Transforming into the $\sigma$ Phase, with Transformation Rates of $2 \%, 5 \%$, and $10 \%$

91. TCP Phase Precipitation on Alloy 22 Grain Boundaries as a Function of Time and Temperature

92. Time to Form $20 \%$ and $80 \%$ Grain Boundary Coverage of TCP Phases in Alloy 22 Base Metal as a Function of Aging Temperature

93. TCP-Phase Precipitation Kinetics in C-22 GTAW Welds as a Function of Temperature

94. Time to Form 1 and 5 vol \% TCP Phase in C-22 Welds as a Function of Aging Temperature

95. Comparison Between Experimentally Determined (Left) and Calculated (Right) Phase Diagrams of Ni-Cr, Ni-Mo, Ni-W, Cr-Mo, Cr-W, and Mo-W alloys, as Obtained with Thermo-Calc

96 Total Energy (In kj/mol) Versus Normalized Lattice Parameter (i.e., a $/ \mathrm{a}_{\mathrm{eq}}$, Where a is the Lattice Parameter and $\mathrm{a}_{\mathrm{eq}}$ is the Equilibrium Lattice Parameter) for the Three Ordered Compounds $\mathrm{Ni}_{2} \mathrm{Cr}_{2} \mathrm{Ni}_{2} \mathrm{Mo}$, and $\mathrm{Ni}_{2} \mathrm{~W}$ Of $\mathrm{Ni}_{2} \mathrm{Cr}$-Type (C11b or oP6) ..

97. Comparison of the Reference Ni-Cr-Phase Diagram (Left) with the Calculated Ni-CrPhase Diagram as Obtained with the Ordered Phase Modeled (Right) ............................. 7-8

98. Comparison Between the (a) Calculated (with Thermo-Calc) and (b) the Experimental Phase Diagrams of the Pseudo-Binary Alloy Ni- $\left(\mathrm{Cr}_{0.75} \mathrm{Mo}_{0.25}\right)$.

99. Calculated Isothermal Sections of the $\mathrm{Ni}-\mathrm{Cr}-\mathrm{Mo}$ Phase Diagram at 1,123 K, 1,323 K, and $1,523 \mathrm{~K}$

100. Calculated Isothermal Sections of the Ni-Cr-Mo Phase Diagram at $573 \mathrm{~K}, 773 \mathrm{~K}$, $893 \mathrm{~K}$, and $973 \mathrm{~K}$ 
FIGURES (Continued)

Page

101. Calculated fcc (or $\gamma$ ) Domain of Stability of the Ternary Ni-Cr-Mo Phase Diagram as a Function of Temperature from $1,250^{\circ} \mathrm{C}$ to $300^{\circ} \mathrm{C}$

102. Calculated Isothermal Sections of the Ternary Ni-Cr-Mo Phase Diagram at $893 \mathrm{~K}$, $873 \mathrm{~K}, 773 \mathrm{~K}$, and $573 \mathrm{~K}$....

103. Calculated Isopleths of the Ternary Ni-Cr-Mo Alloy at Fixed Mole Fraction of Ni of $0.625,0.645$, and 0.665

104. Phase Diagrams of $\mathrm{Ni}-\mathrm{Cr}-\mathrm{X}$, with $\mathrm{c}_{\mathrm{Cr}}+\mathrm{c}_{\mathrm{X}}=0.33$ Being Fixed, Where $\mathrm{X}=\mathrm{Mo}(\mathrm{a}), \mathrm{X}=\mathrm{W}$ (c)

105. (a) Micrograph of Platelet P-Phase Precipitate in an fcc Matrix, and Location of the (Red) Line Profile Along Which the Energy Dispersive X-ray (EDS) Analysis is Performed. (b) Variation of the Weight Fraction per Element Along the Line Profile, as Obtained from EDX Spectroscopy Analysis for Alloy 22 Annealed at $704^{\circ} \mathrm{C}$ for 16,000 hours.

106. (a) Property Diagram of Alloy 22. Weight Fraction of Ni (Red), Cr (Blue), Mo (Green), W (Brown), and Fe (Black), Versus Temperature in the fcc Matrix (b), and the P Phase (c) for Alloy 22.

107. TCP-Phase Precipitation in Alloy 22 Base Metal as a Function of Time and Temperature

108. Comparison of Phase Formation at $700^{\circ} \mathrm{C}$ for DICTRA Computational Results (P Phase) and Measured Data (TCP Phase) on Alloy 22 Base Metal

109. Comparison of Phase Formation at Approximately $750^{\circ} \mathrm{C}$ for DICTRA Computational Results (P phase) and Measured Data (TCP Phase) on Alloy 22 Base Metal

110. Microhardness (Hv) Measurements on Aged Alloy 22 Base Metal as a Function of Time and Temperature. 


\section{INTENTIONALLY LEFT BLANK}




\section{TABLES}

Page

1. Summary List of Software Used................................................................................... 3-3

2. Aging and Phase Stability of Waste Package Outer Barrier Analysis Direct Input Data... 4-1

3. Grain Boundary Precipitation Measurements (Grain Boundary Coverage Fraction)....... 4-42

4. Precipitation Area-Fraction Measurements on Weld Metal ............................................ 4-42

5. Features, Events, and Processes Excluded (Screened Out) in This Report ......................... 6-2

6. Phases Observed in Alloy 22 in TEM........................................................................ 6-4

7. Alternative Conceptual Model Considered.............................................................. 6-6

8. Nominal Chemical Compositions of Ni-Cr-Mo Alloys ................................................... 6-14

9. Bulk Precipitation Area-Fraction Measurements (\% Transformation)............................. 7-21

10. Microhardness (Hv) Measurements in Aged Base Metal ................................................ 7-24

11. Summary of Alloy 22 Chemical Composition of Heats Tested ........................................ 8-3

12. Summary of Alloy 22 Chemical Compositions (ASTM B575, Heats Tested, and Ternary Alloy 22 Surrogate) ...................................................................................... 8-4

13. Summary of Developed Datasets................................................................................. 8-4 


\section{INTENTIONALLY LEFT BLANK}




\section{ACRONYMS}

ASCII American Standard Code for Information Interchange

EBS Engineered Barrier System

GTAW gas-tungsten-arc welding

HAZ heat-affected zone

KP Kaufman binary alloys database

LRO long-range order

MOB mobility database

NRC Nuclear Regulatory Commission

QA quality assurance

SAD selected area diffraction

SGTE Scientific Group Thermodata Europe

SSOL Scientific Group Thermodata Europe solution database

SEM scanning electron microscopy

TBV to be verified

TCP tetrahedrally close-packed

TEM transmission electron microscopy

TSPA total system performance assessment

TTT time-temperature transformation

UNS unified numbering system 


\section{INTENTIONALLY LEFT BLANK}




\section{PURPOSE}

\subsection{SUMMARY OF MODEL}

This report was prepared in accordance with Technical Work Plan for: Regulatory Integration Modeling and Analysis of the Waste Form and Waste Package (BSC 2004 [DIRS 171583]). This report provides information on the phase stability of Alloy $22^{1}$, the current waste package outer barrier material. The goal of this model is to determine whether the single-phase solid solution is stable under repository conditions and, if not, how fast other phases may precipitate. The aging and phase stability model, which is based on fundamental thermodynamic and kinetic concepts and principles, will be used to provide predictive insight into the long-term metallurgical stability of Alloy 22 under relevant repository conditions. The results of this model are used by General Corrosion and Localized Corrosion of Waste Package Outer Barrier as reference-only information.

These phase stability studies are currently divided into three general areas:

- Tetrahedrally close-packed (TCP) phase and carbide precipitation in the base metal

- TCP and carbide precipitation in welded samples

- Long-range ordering reactions.

TCP-phase and carbide precipitates that form in Alloy 22 are generally rich in chromium $(\mathrm{Cr})$ and/or molybdenum (Mo) (Raghavan et al. 1984 [DIRS 154707]). Because these elements are responsible for the high corrosion resistance of Alloy 22, precipitation of TCP phases and carbides, especially at grain boundaries, can lead to an increased susceptibility to localized corrosion in the alloy. These phases are brittle and also tend to embrittle the alloy (Summers et al. 1999 [DIRS 146915]). They are known to form in Alloy 22 at temperatures greater than approximately $600^{\circ} \mathrm{C}$. Whether these phases also form at the lower temperatures expected in the repository during the 10,000-year regulatory period must be determined. The kinetics of this precipitation will be determined for both the base metal and the weld heataffected zone (HAZ).

The TCP phases (P, $\mu$, and $\sigma$ ) are present in the weld metal in the as-welded condition. It may be possible to eliminate these phases through a solution anneal heat treatment, but that may not be possible for the closure weld because the spent nuclear fuel cladding cannot be heated to more than $350^{\circ} \mathrm{C}$. The effects of any stress mitigation techniques (such as laser peening or solution heat treating) that may be used to reduce the tensile stresses on the closure welds must also be determined. Cold-work will cause an increase in dislocation density, and such an increase in dislocation density may cause an increase in diffusion rates that control precipitation kinetics (Porter et al. 1992 [DIRS 161265]; Tawancy et al. 1983 [DIRS 104991]).

1 The designation Alloy 22 is used in this report to indicate the alloy composition given by the Society of Automotive Engineers (SAE) - American Society of Testing and Materials (ASTM) Unified Numbering System (UNS) N06022. A number of manufacturers produce material within this UNS specification. This alloy is sold and often referred to in the technical literature by names such as Hastelloy Alloy C-22, Inconel Alloy 622, Allegheny Alloy AL-22, and possibly others. The designation Alloy 22 is, therefore, a generalized designation that covers all of these alloys. 
Long-range order (LRO) occurs in nickel (Ni)-Cr-Mo alloys (such as Alloy 22) at temperatures less than approximately $600^{\circ} \mathrm{C}$. This ordering has been linked to an increased susceptibility of $\mathrm{Ni}-\mathrm{Cr}-\mathrm{Mo}$ alloys to stress corrosion cracking and hydrogen embrittlement (Tawancy et al. 1983 [DIRS 104991]). These analyses provide information on the rate at which LRO may occur in Alloy 22 under repository conditions.

Determination of the kinetics of transformations through experimental techniques requires that the transformations being investigated be accelerated due to the fact that the expected service life is at least 10,000 years. Phase transformations are typically accelerated through an increase in temperature. The rate of transformation is determined at the higher temperature and is extrapolated to the lower temperatures of interest.

\subsection{INTENDED USE OF MODEL}

In the mill-annealed condition, Alloy 22 (UNS N06022) is primarily a single-phase, facecentered cubic ( $\mathrm{fcc}$ ), solid solution with excellent corrosion resistance over a wide range of environmental conditions. Over time, other phases (e.g., TCP/carbide and LRO) may precipitate and degrade both the mechanical properties and corrosion resistance of the alloy. The goal of this model is to determine whether the single-phase solid solution is stable under expected repository conditions, and if not, how fast other phases may precipitate. Precipitation kinetics in the annealed base metal, as well as in the annealed and laser-peened welds, are considered.

The objective of this aging and phase stability model is to provide a quantitative model that can be used to predict the amount of any phases forming as a function of both time and temperature. Due to the long time periods of interest (at least 10,000 years beyond permanent closure), it is not practical to obtain or generate data on the metallurgical stability of Alloy 22 using test durations of this magnitude. As a result, the aging and phase stability model, which is based on fundamental thermodynamic and kinetic concepts and principles, is used to provide predictive insight into the long-term metallurgical stability of Alloy 22 under relevant repository conditions. Thus, there are no direct inputs from the aging and phase stability model to the Total System Performance Assessment for the License Application (TSPA-LA).

This report also provides justification for excluding FEP 2.1.11.06.0A, Thermal sensitivity of waste package. Specifically, deleterious effects due to thermal aging and phase instability of the waste package outer barrier will not occur under repository temperature conditions in the first 10,000 years and this model report is, thus, a reference source for FEPs Screening of the Processes and Issues in the Waste Package and Drip Shield. 


\section{QUALITY ASSURANCE}

This report has been developed in accordance with AP-SIII.10Q, Models, under Technical Work Plan for: Regulatory Integration Modeling and Analysis of the Waste Form and Waste Package (BSC 2004 [DIRS 171583]), which, in turn, was developed in accordance with AP-2.27Q, Planning for Science Activities. The applicability of requirements frin Quality Assurance Requirements and Description (DOE 2004 [DIRS 171539]) is documented in Section 8 of Technical Work Plan for: Regulatory Integration Modeling and Analysis of the Waste Form and Waste Package (BSC 2004 [DIRS 171583]). All waste package configurations have been determined to be important to waste isolation in accordance with AP-2.22Q and, therefore, are classified as Safety Category (SC) in Q-List (BSC 2004 [DIRS 168361], Appendix A; BSC 2004 [DIRS 170992]). A process control evaluation was performed in accordance with AP-SV.1Q, Control of the Electronic Management of Information. Inputs and transfers of data were checked to assure completeness and accuracy in accordance with Supplement V requirements. Data were also protected from damage and password protected. 


\section{INTENTIONALLY LEFT BLANK}




\section{USE OF SOFTWARE}

\subsection{BASELINED SOFTWARE}

Thermo-Calc Version M (Thermo-Calc Version M, STN: 10170-M-00 [DIRS 163153]) is a commercially available software code that fulfills the need to provide critical modeling and analysis of data to:

- Produce, refine, and analyze multicomponent phase diagrams of alloys at repositoryrelevant temperatures for predicting phase stability properties

- Determine the solidification path and the effect of welding on stability and long-term aging of alloys selected for the barriers of the canisters used for storage of nuclear waste

- Generate isothermal sections of multicomponent alloy phase diagrams at repositoryrelevant temperature, isopleths, property diagrams (phase fractions as functions of temperature), and composition versus temperature diagrams for all stable and metastable phases formed

- Simulate phase transformations according to the Scheil-Gulliver model that use local equilibria, infinite diffusion in the liquid phase, and no back diffusion in the solid phase (Saunders and Miodownik 1998 [DIRS 104975]).

Thermo-Calc version $M$ is specially designed for systems with strongly nonideal phases and has gained a worldwide reputation as the best software application for the calculation of multicomponent phase diagrams. Thermo-Calc is the only software commercially available that can calculate arbitrary phase diagram sections with up to five independent variables in multicomponent systems. There are also modules to calculate many other types of properties, such as Scheil-Gulliver solidification simulations, Pourbaix diagrams, and partial pressures in gases.

Data generated with the Thermo-Calc software also provide the basis for more accurate predictions of diffusion kinetics and ultimately time-temperature transformation (TTT) diagrams with the DICTRA software (see below) by using diffusion both in the liquid and solid phases. The results of the equilibrium solidification and Scheil-Gulliver's simulations generated by Thermo-Calc correspond to the upper and lower bounds for the DICTRA results.

Thermo-Calc generates output in graphical or tabular form. Calculated values are generated by Thermo-Calc in a proprietary binary format; however, these files, when processed through various modules, produce tabulated data as ASCII text files and graphical data as encapsulated Postscript files.

DICTRA Version 20 (DICTRA V20, STN: 10391-20-00 [DIRS 163154]) is also commercially available software that is used in conjunction with Thermo-Calc to calculate the rate at which the relevant phase transformations occur. DICTRA Version 20 is used to predict the kinetics of phase transformation and evolution in candidate alloys for use in nuclear waste packages. In particular, this software application predicts TTT diagrams and, therefore, the aging behavior of 
complex Frank-Kasper phases (or TCP structures), such as the $\mathrm{P}$ and $\sigma$ phases, and of the ordered phase of the $\mathrm{Ni}_{2} \mathrm{Cr}$-type in Alloy 22 and other related alloys.

DICTRA version 20 fulfills the need to provide critical modeling and analysis of data to:

- Solve the diffusion equations

- Calculate thermodynamic equilibrium

- Solve the flux-balance equations

- Track the displacement of the phase-interface positions and adjust grid points during simulation as a function of time

- Analyze the kinetics of phase evolution in alloys selected for the barriers of the waste package by predicting TTT diagrams for the relevant phases forming as functions of time.

DICTRA interfaces with Thermo-Calc, which handles all thermodynamic calculations needed by DICTRA.

Data files used by Thermo-Calc and DICTRA are included with the purchase of the software and are considered to be from documented and substantiated established databases: KP (Kaufman binary alloys database), SSOL (Scientific Group Thermodata Europe, or SGTE, solution database), MOB (Mobility database), from published journals, and/or from qualified sources. The databases are included on the CD-R with the applications. Disaster recovery copies of these media are located in the project's Software Configuration Management system, and the original media are controlled by the user due to the vendor's licensing and copyright restrictions. The use of the data files per AP-SIII.10Q (Section 5.2.1k) are considered qualified for use within this report due to 1) reliability of the data source (databases have been reviewed and maintained for decades by world-renown experts affiliated with Thermo-calc and DICTRA applying these databases to a wide range of industrial applications) and 2) qualifications of personnel or organizations generating the data (the databases described above have been generated for decades by world-renown experts affiliated with Thermo-calc and DICTRA). Data files that are refined by comparing the output data of Thermo-Calc and DICTRA to known experimental data that are used to simulate Ni-Cr-Mo-W alloys in this study are described in Section 7.

The SSOL, KP, and MOB databases are provided in ASCII-text format and can be reviewed or edited with any standard text editor. Custom-generated input data can be created using any standard text editor to create an ASCII text file.

DICTRA uses the post-processor module from Thermo-Calc to generate output in graphical or tabular form. Calculated values are generated by DICTRA in a proprietary binary format; however, these files, when processed through various modules, can produce tabulated data as ASCII-text files and graphical data as encapsulated postscript files.

Thermo-Calc and DICTRA, which run on a Unix or Linux platform, are products of ThermoCalc AB. They were run on a Sun E450/Solaris 2.7. 
The use of the baselined software described in this section was consistent with its intended use and within the documented validation range of the software.

\subsection{EXEMPT SOFTWARE}

Microsoft Excel was used for graphing data, adding trend lines to the data, and manipulating data through the use of standard functions included in Excel. Excel is exempt from qualification in accordance with LP-SI.11Q-BSC, Sections 2.1.1, 2.1.2, and 2.1.6. When Excel is used for calculations and plots (Sections 6.6.5, 6.6.6, and 7.5), information required for an independent person to reproduce the work (including formula or algorithm used, listing of inputs, and listing of outputs) is provided.

Image-Pro Plus (Media Cybernetics) is a personal computer software package that is used for the analysis of digital images acquired from a transmission electron microscope (TEM), a scanning electron microscope (SEM), or an optical microscope. It is used as a quantitative metallographyanalysis tool and image processor/analyzer. Although there are many uses for Image-Pro Plus, the standard Measure menu commands are used primarily to perform analyses to acquire percent-area information. For the analyses presented in this report, these standard Measure commands were used to determine the extent of phase precipitation by measuring the appropriate image parameters (e.g., white areas) in a large number of SEM images. Details and results of these measurements are documented in the scientific notebooks associated with Data Tracking Numbers (DTNs) for phase precipitation measurements (Section 4.1.8). Image Pro-Plus software versions 4.0, 4.1, and 4.5.1 have been determined to be exempt from qualification in accordance with LP-SI.11Q-BSC, Sections 2.1.2 and 2.1.6.

KaleidaGraph version 3.5 (Synergy Software), ClarisDraw version 1.04, and Adobe Illustrator Version 8 were used for graphing data. The graphs are for visual representation of the data only, and all points plotted were checked by visual inspection. These software packages are exempt from qualification per LP-SI.11Q-BSC, Section 2.1.2. The actual tables of values plotted are presented in this document so that any approved software can be used to plot the data, if necessary.

\subsection{SUMMARY OF SOFTWARE USED}

A summary list of the software used in this model report is shown in Table 1.

Table 1. Summary List of Software Used

\begin{tabular}{|l|c|c|}
\hline \multicolumn{1}{|c|}{ Software Name } & Version Number & Software Tracking Number \\
\hline Thermo-Calc & $\mathrm{M}$ & $10170-\mathrm{M}-00$ \\
\hline DICTRA & 20 & $10391-20-00$ \\
\hline Image-Pro Plus & $4.0,4.1$, and 4.5 .1 & Exempt \\
\hline Excel & 2000 & Exempt \\
\hline KaleidaGraph & 3.5 & Exempt \\
\hline ClarisDraw & 1.04 & Exempt \\
\hline Adobe Illustrator & 8 & Exempt \\
\hline
\end{tabular}




\section{INTENTIONALLY LEFT BLANK}




\section{INPUTS}

\subsection{DIRECT INPUTS}

The input data used in this model report are summarized in Table 2. All micrographs and data are the result of waste package materials testing activities. A discussion of the uncertainty for these data can be found in Section 6.7.

Sections 4.1.1 through 4.1.4 present representative examples of micrographs that were used in the phase identification and kinetic observations that are described in Sections 6.3.1 and 6.3.3. Sections 4.1.5 through 4.1.7 present SEM micrographs that are representative examples of micrographs used in the area-fraction measurements presented in Section 4.1.8.

The input data presented here are appropriate for this study because scanning or tunneling electron microscopy are the most direct methods to determine the extent of phase precipitation after aging at specified times and temperatures. The micrographs and phase fraction measurements presented here are direct input for the direct metallurgical observations and insight trends supporting the Alloy 22 computational model as discussed in Section 6. Data used to validate the model may be found in Section 7. Data used for model development was not used for model validation.

Table 2. Aging and Phase Stability of Waste Package Outer Barrier Analysis Direct Input Data

\begin{tabular}{|c|c|c|c|}
\hline Data Name & Data Source & DTN & Data Use \\
\hline $\begin{array}{l}\text { Transmission Electron Microscopy } \\
\text { Micrographs Used in Preliminary TCP and } \\
\text { Carbide Phase Identification }\end{array}$ & $\begin{array}{l}\text { Waste Package } \\
\text { Materials Testing }\end{array}$ & $\begin{array}{l}\text { LL010107712251.012 } \\
\quad \text { [DIRS 155299] }\end{array}$ & Section 4.1 .1 \\
\hline $\begin{array}{l}\text { Micrographs Showing Precipitation in Alloy } \\
22 \text { Beginning on and Covering Grain } \\
\text { Boundaries, Beginning on Twin Boundaries, } \\
\text { and Beginning within the Grains }\end{array}$ & $\begin{array}{l}\text { Waste Package } \\
\text { Materials Testing }\end{array}$ & $\begin{array}{l}\text { LL010107712251.012 } \\
\quad \text { [DIRS 155299] }\end{array}$ & Section 4.1 .2 \\
\hline $\begin{array}{l}\text { Micrographs Showing TCP Particles in Alloy } \\
22 \text { Welds }\end{array}$ & $\begin{array}{l}\text { Waste Package } \\
\text { Materials Testing }\end{array}$ & $\begin{array}{l}\text { LL030301612251.040 } \\
\quad[\text { DIRS 162691] }\end{array}$ & Section 4.1 .3 \\
\hline $\begin{array}{l}\text { TEM Micrographs Showing When LRO Has } \\
\text { Been Observed }\end{array}$ & $\begin{array}{l}\text { Waste Package } \\
\text { Materials Testing }\end{array}$ & $\begin{array}{l}\text { LL010107712251.012 } \\
\text { [DIRS 155299] } \\
\text { LL030301612251.040 } \\
\text { [DIRS 162691] }\end{array}$ & Section 4.1 .4 \\
\hline $\begin{array}{l}\text { SEM Micrographs Used for Quantification of } \\
\text { Phases and LRO }\end{array}$ & $\begin{array}{l}\text { Waste Package } \\
\text { Materials Testing }\end{array}$ & $\begin{array}{l}\text { LL030104212251.012 } \\
\text { [DIRS 162009] }\end{array}$ & Section 4.1 .5 \\
\hline $\begin{array}{l}\text { SEM Micrographs Showing Bulk Precipitation } \\
\text { in Base Metal }\end{array}$ & $\begin{array}{l}\text { Waste Package } \\
\text { Materials Testing }\end{array}$ & $\begin{array}{l}\text { LL030103712251.007 } \\
\quad \text { [DIRS 163014] }\end{array}$ & Section 4.1 .6 \\
\hline $\begin{array}{l}\text { SEM Micrographs Showing Precipitation in } \\
\text { Weld Metal }\end{array}$ & $\begin{array}{l}\text { Waste Package } \\
\text { Materials Testing }\end{array}$ & $\begin{array}{l}\text { LL030104212251.012 } \\
\text { [DIRS 162009] } \\
\text { LL021009912251.003 } \\
\text { [DIRS 163013] }\end{array}$ & Section 4.1 .7 \\
\hline $\begin{array}{l}\text { Grain Boundary Precipitation Measurements } \\
\text { (Grain Boundary Coverage Fraction) }\end{array}$ & $\begin{array}{l}\text { Waste Package } \\
\text { Materials Testing }\end{array}$ & $\begin{array}{l}\text { LL030104012251.010 } \\
\quad \text { [DIRS 162468] }\end{array}$ & Section 4.1 .8 \\
\hline $\begin{array}{l}\text { Precipitation Area-Fraction Measurements on } \\
\text { Weld Metal }\end{array}$ & $\begin{array}{l}\text { Waste Package } \\
\text { Materials Testing }\end{array}$ & $\begin{array}{l}\text { LL030103612251.006 } \\
\text { [DIRS 162012] }\end{array}$ & Section 4.1 .8 \\
\hline
\end{tabular}




\subsubsection{Transmission Electron Microscopy Micrographs Used in Preliminary TCP and Carbide Phase Identification}

This section contains transmission electron microscopy (TEM) images and electron-selected area diffraction (SAD) patterns used to identify the phases that form in Alloy 22 base metal after aging in the temperature range of $593^{\circ} \mathrm{C}$ to $760^{\circ} \mathrm{C}$ (Figure 1 through Figure 15). Because of the structural similarity of the $\mu$ and $\mathrm{P}$ phases, some diffraction patterns could be indexed as either phase. For this reason, the phases forming in some cases are only tentatively identified. Several carbides form in Alloy 22, but they all have very similar structures. Although they are significantly different chemically, it is not possible to distinguish them in the work reported here. They are, therefore, simply called carbide.

The ambiguities in identifying the exact composition of the TCP phases or carbides have no impact on the aging and phase stability model because (1) the TCP phases are structurally similar, and (2) the carbides are structurally similar. Therefore, the phase kinetics among TCP phases and among carbides will also be similar. The effects of TCP/carbide phases on corrosion behavior are treated empirically as "TCP phase effects on aging" so specific identification of the individual TCP phases is not necessary.

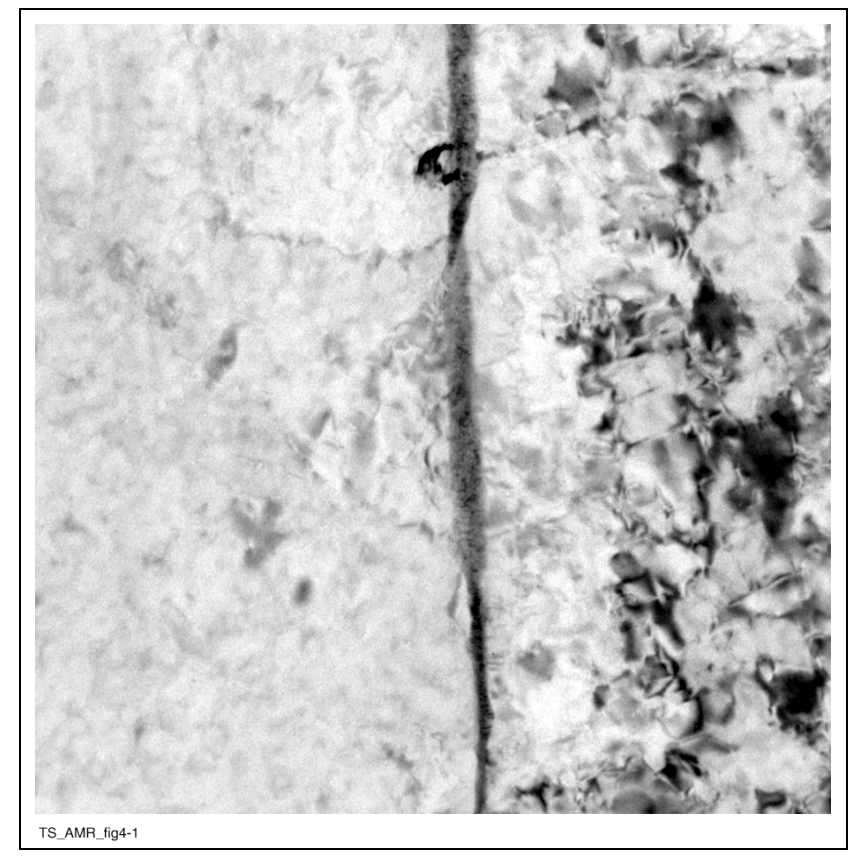

Source: DTN: LL010107712251.012 [DIRS 155299].

NOTE: This phase was identified as P phase (TS393-049b, Image S0244, 8/23/99, SN-LLNL-SCI-442, p. 19).

Figure 1. Grain Boundary Precipitation in Alloy 22 Aged for 1,000 Hours at $593^{\circ} \mathrm{C}$ 


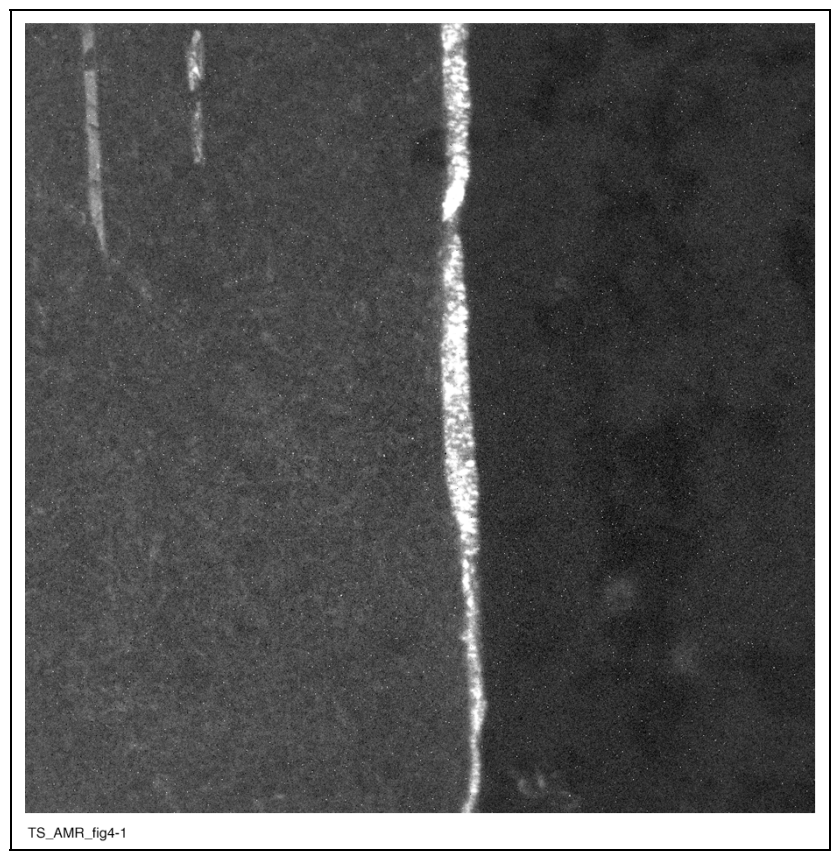

Source: DTN: LL010107712251.012 [DIRS 155299].

NOTE: $\quad$ The grain boundary precipitate identified as P appears light (TS393-049b, Image S0245, 8/23/99, SN-LLNL-SCl-442, p. 19).

Figure 2. Dark-Field Image Corresponding to Figure 1

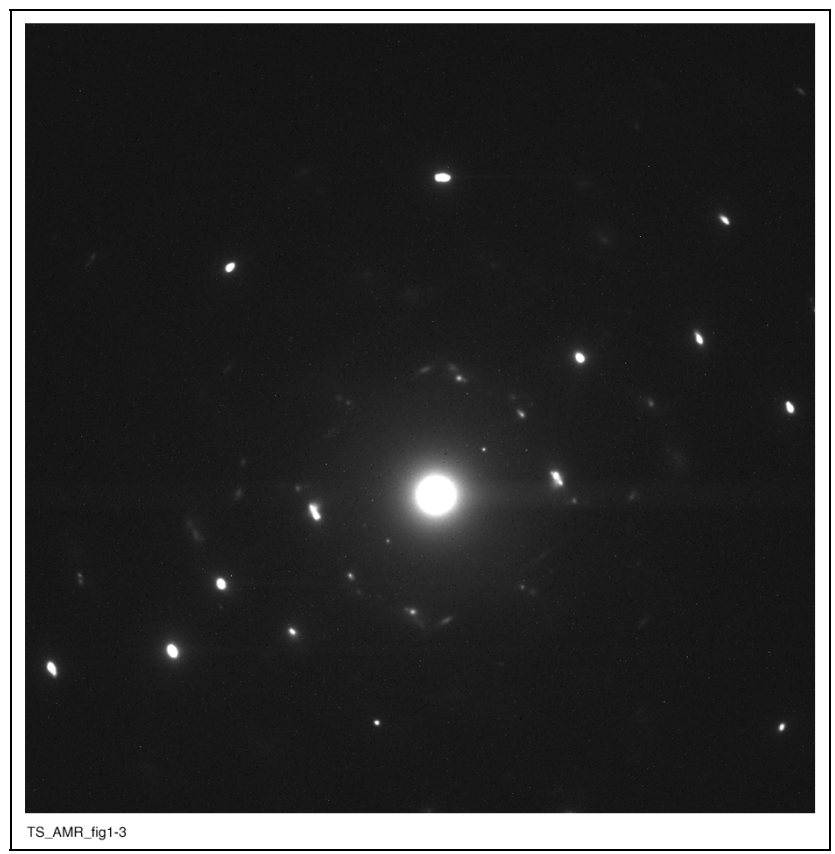

Source: DTN: LL010107712251.012 [DIRS 155299].

NOTE: This pattern was indexed as P phase (TS393-049b, Image S0246, 8/23/99, SN-LLNL-SCI-442, p. 20).

Figure 3. SAD Pattern from the Grain Boundary Precipitate Shown in Figure 1 and Figure 2 


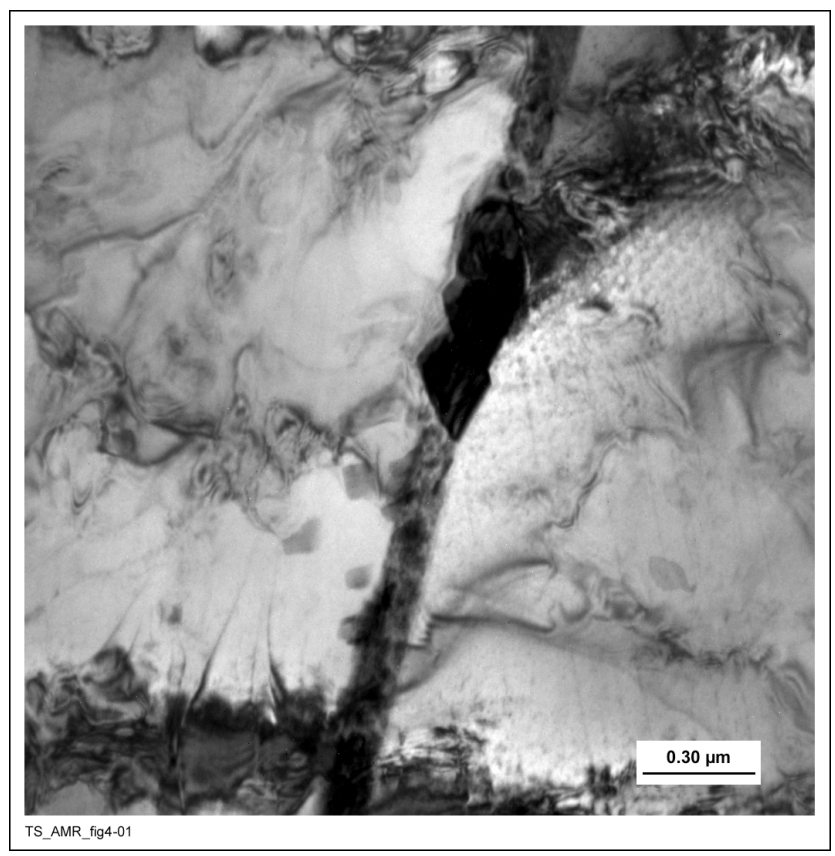

Source: DTN: LL010107712251.012 [DIRS 155299].

NOTE: This phase was identified as P phase (TS369-003a, Image S0125, 3/9/99, SN-LLNL-SCI-434, p. 41).

Figure 4. Grain Boundary Precipitation (P Phase) in Alloy 22 Aged for 16,000 Hours at $593^{\circ} \mathrm{C}$

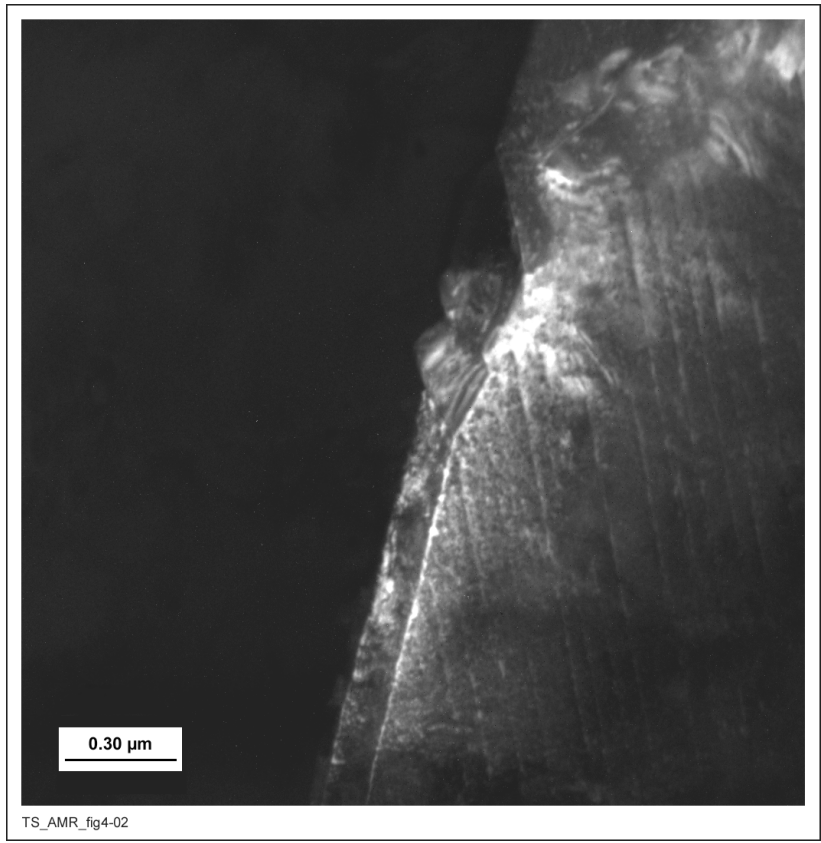

Source: DTN: LL010107712251.012 [DIRS 155299].

NOTE: The grain boundary precipitate identified as P appears light (TS369-003a, Image S0126, 3/9/99, SN-LLNLSCl-434, p. 42).

Figure 5. Dark-Field Image Corresponding to Figure 4 


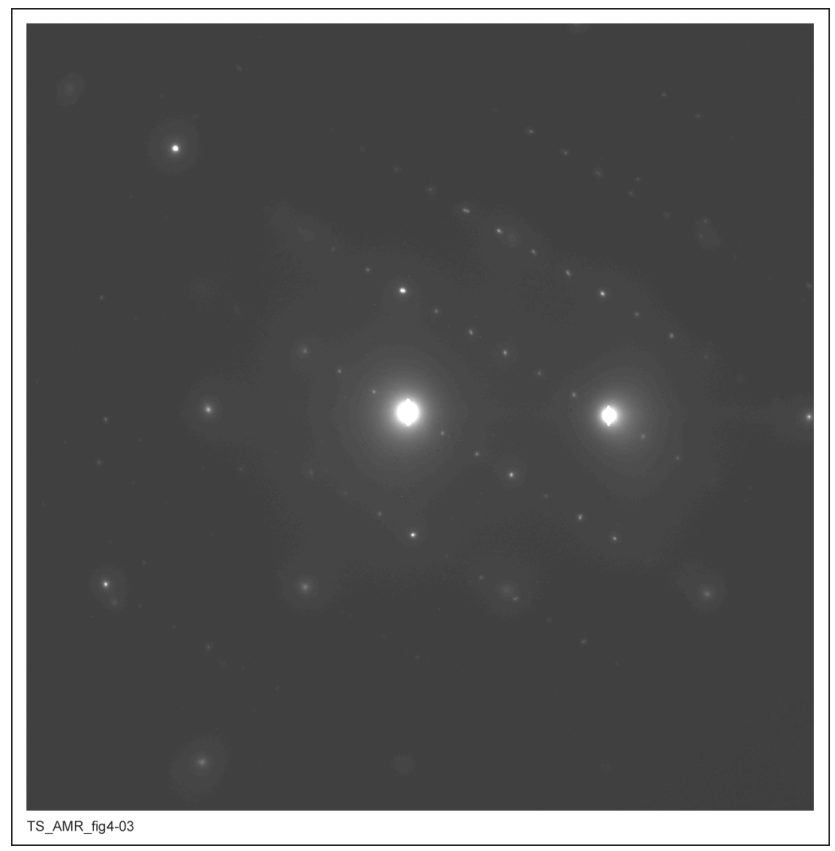

Source: DTN: LL010107712251.012 [DIRS 155299].

NOTE: This pattern was indexed as P phase (TS369-003a, Image S0124, 3/9/99, SN-LLNL-SCI-434, p. 43).

Figure 6. SAD Pattern from the Grain Boundary Precipitate Shown in Figure 4 and Figure 5

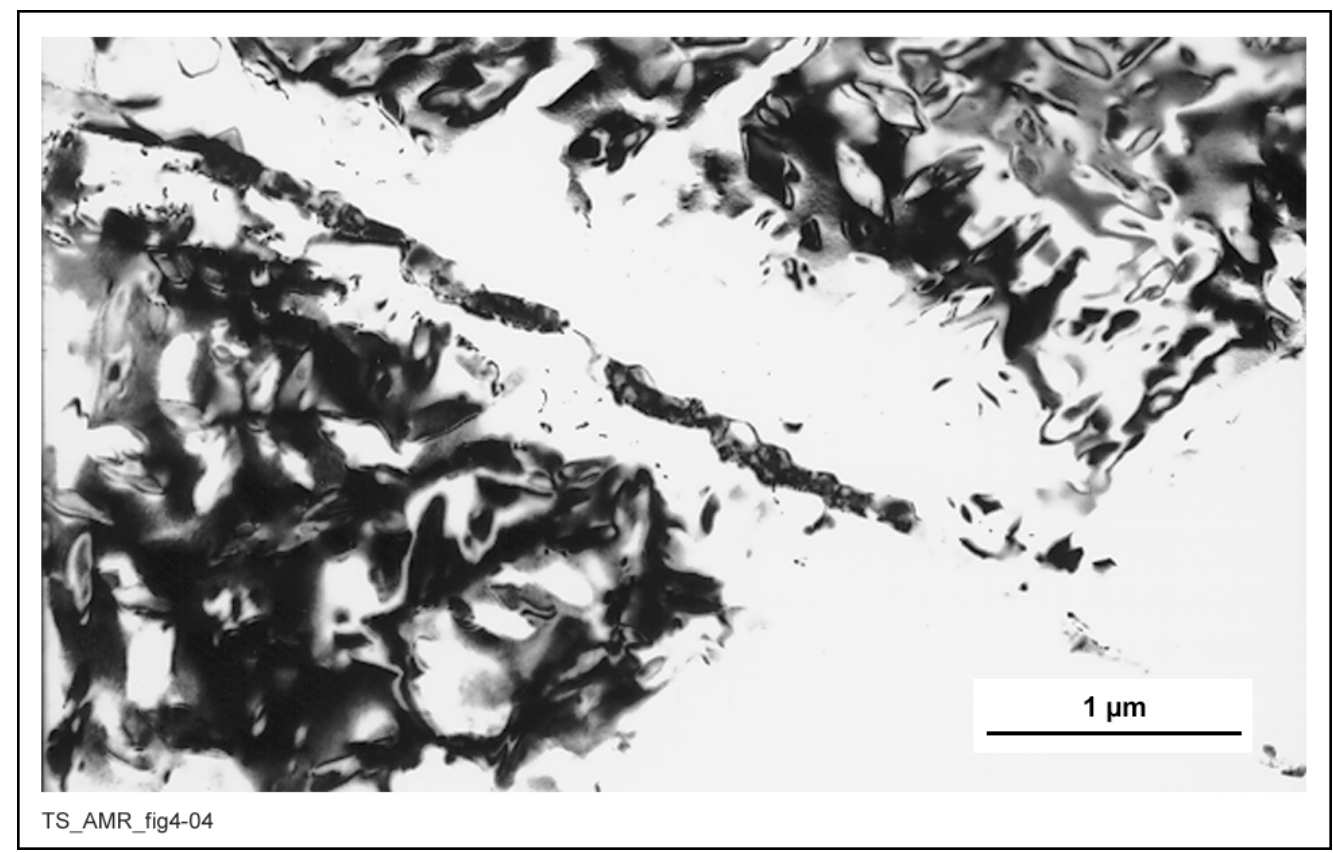

Source: DTN: LL010107712251.012 [DIRS 155299].

NOTE: This phase was identified as carbide (TS369-003a, Image 1490, 12/16/98, SN-LLNL-SCI-393, p. 66).

Figure 7. Grain Boundary Precipitation (carbide) in Alloy 22 Aged for 16,000 Hours at $593^{\circ} \mathrm{C}$ 


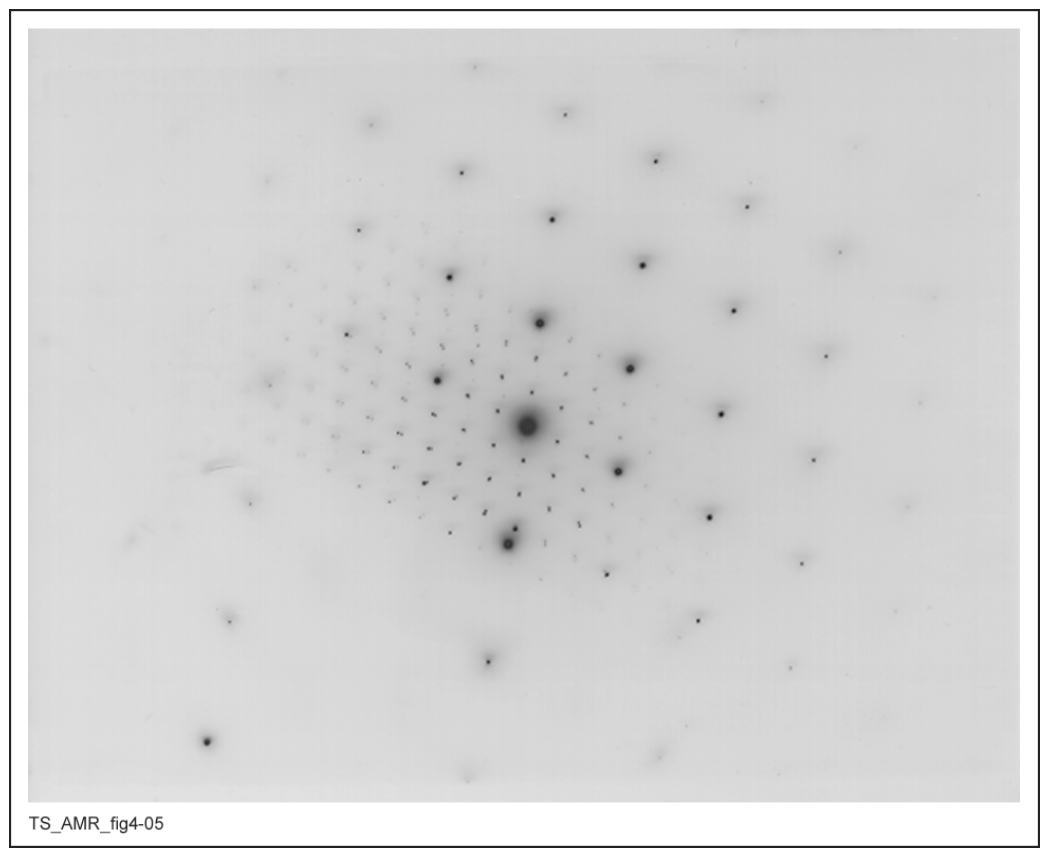

Source: DTN: LL010107712251.012 [DIRS 155299].

NOTE: This pattern was indexed as carbide (TS369-003a, Image 1489, 12/16/98, SN-LLNL-SCI-393, p. 66).

Figure 8. SAD Pattern from the Grain Boundary Precipitate Labeled Carbide in Figure 7

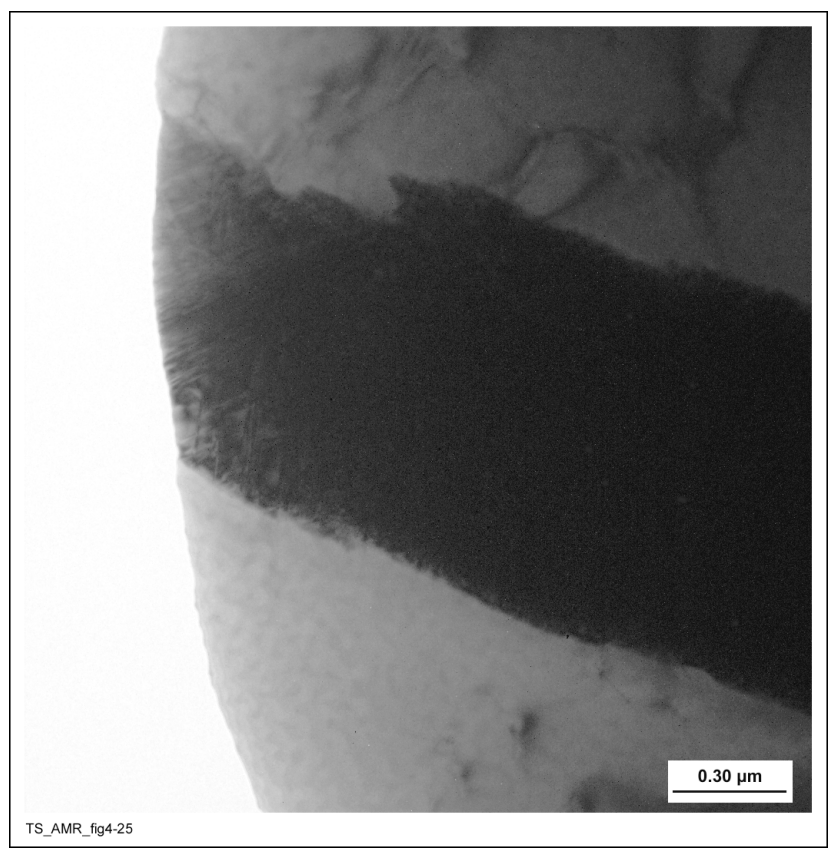

Source: DTN: LL010107712251.012 [DIRS 155299].

NOTE: This phase was identified as P phase (TS369-004a, Image S0037, 2/16/99, SN-LLNL-SCI-434, p. 63).

Figure 9. Precipitate (P phase) in Alloy 22 Aged for 16,000 Hours at $760^{\circ} \mathrm{C}$ 


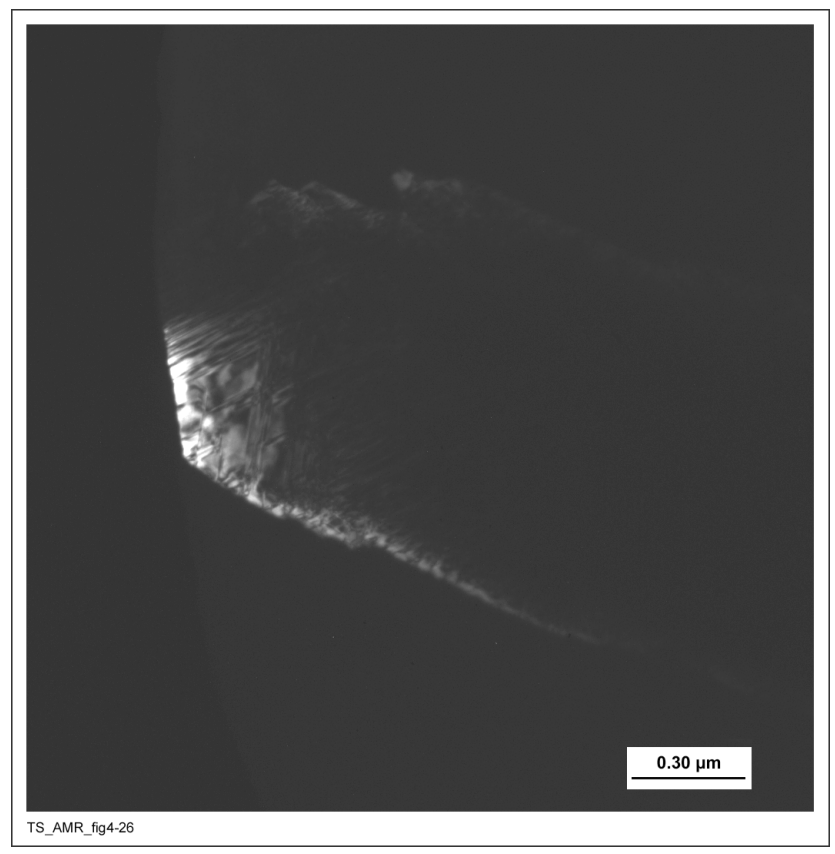

Source: DTN: LL010107712251.012 [DIRS 155299].

NOTE: The precipitate identified as P phase appears light (TS369-004a, Image S0038, 2/16/99, SN-LLNL-SCI-434, p. 63).

Figure 10. Dark-Field Image Corresponding to Figure 9

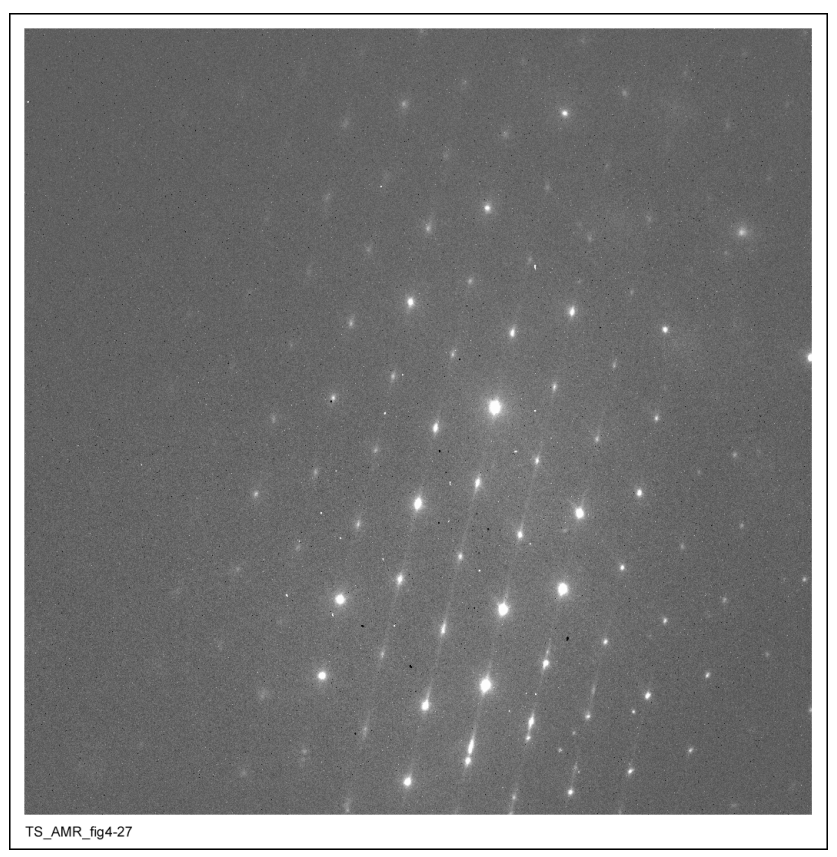

Source: DTN: LL010107712251.012 [DIRS 155299].

NOTE: (TS369-004a, Image S0036, 2/16/99, SN-LLNL-SCI-434, p. 64).

Figure 11. SAD Pattern from the P-Phase Precipitate Shown in Figure 9 and Figure 10 


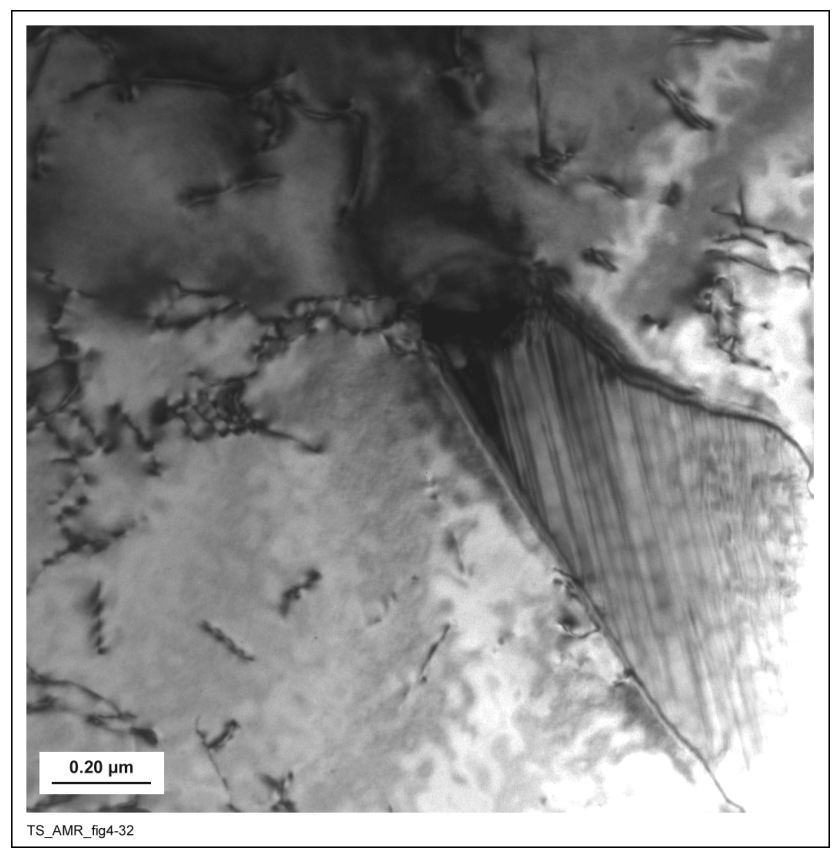

Source: DTN: LL010107712251.012 [DIRS 155299].

NOTE: This phase was tentatively identified as $\mu$ phase (TS369-004a, Image 1312, 3/14/98, SN-LLNL-SCI-393, p. 11).

Figure 12. Precipitation (Possibly $\mu$ Phase) in Alloy 22 Aged for 16,000 Hours at $760^{\circ} \mathrm{C}$

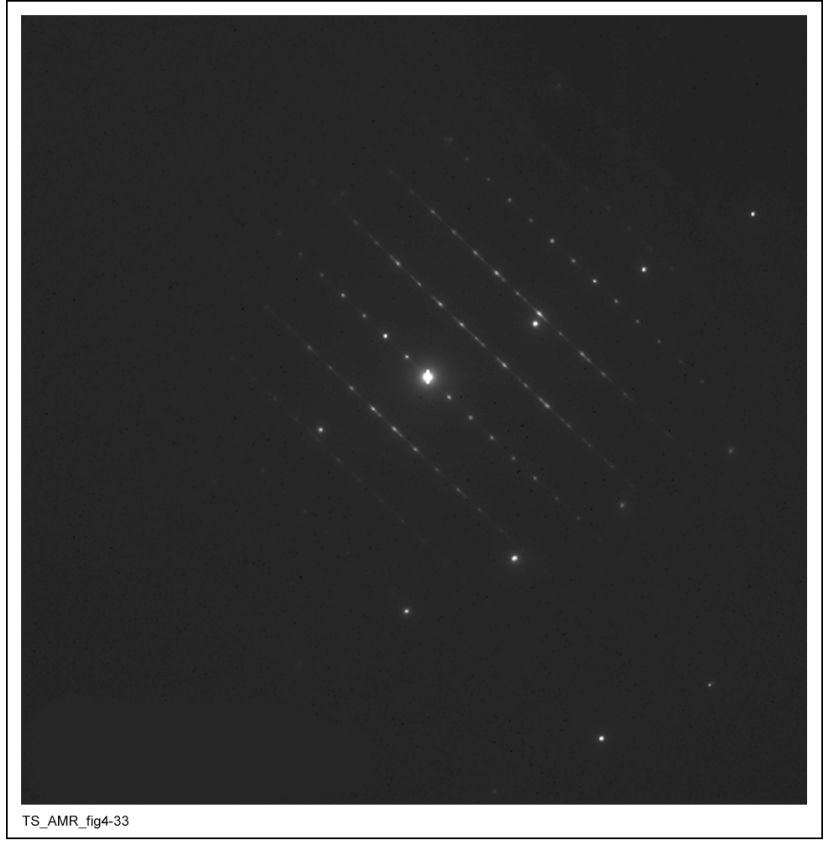

Source: DTN: LL010107712251.012 [DIRS 155299].

NOTE: (TS369-004a, Image 1314, 3/14/98, SN-LLNL-SCI-393, p. 13).

Figure 13. SAD Pattern from the $\mu$-Phase Precipitate Shown in Figure 12 


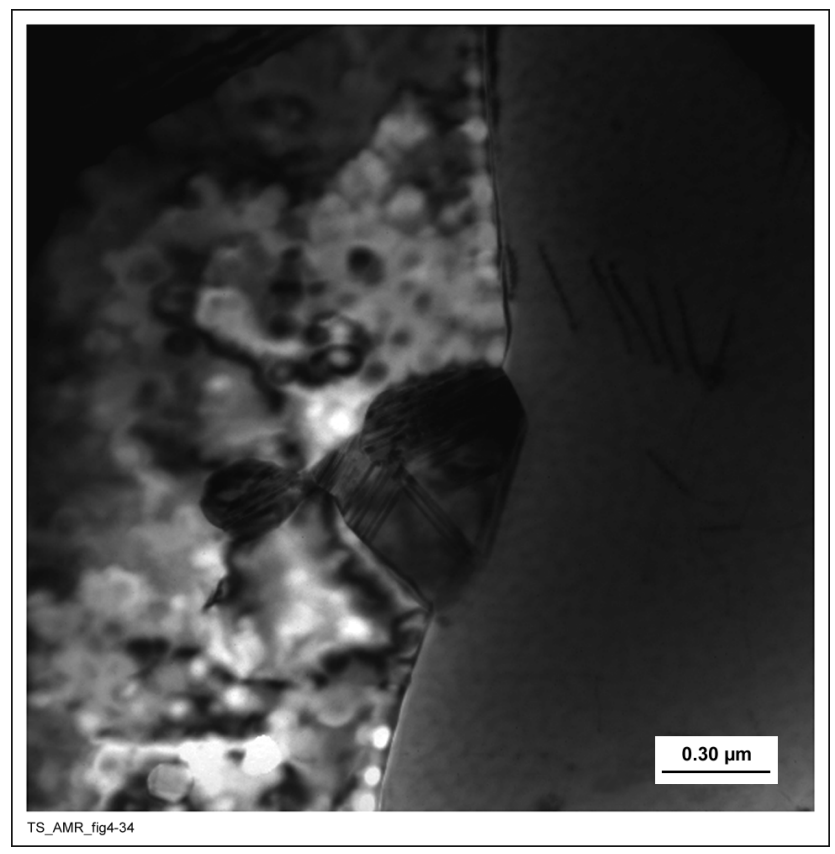

Source: DTN: LL010107712251.012 [DIRS 155299].

NOTE: This phase was identified as $\mu$ phase (TS369-004a, Image 1309, 3/14/98, SN-LLNL-SCI-369, p. 135).

Figure 14. Grain Boundary Precipitation in Alloy 22 Aged for 16,000 Hours at $760^{\circ} \mathrm{C}$ Showing in $\mu$-Phase Precipitation

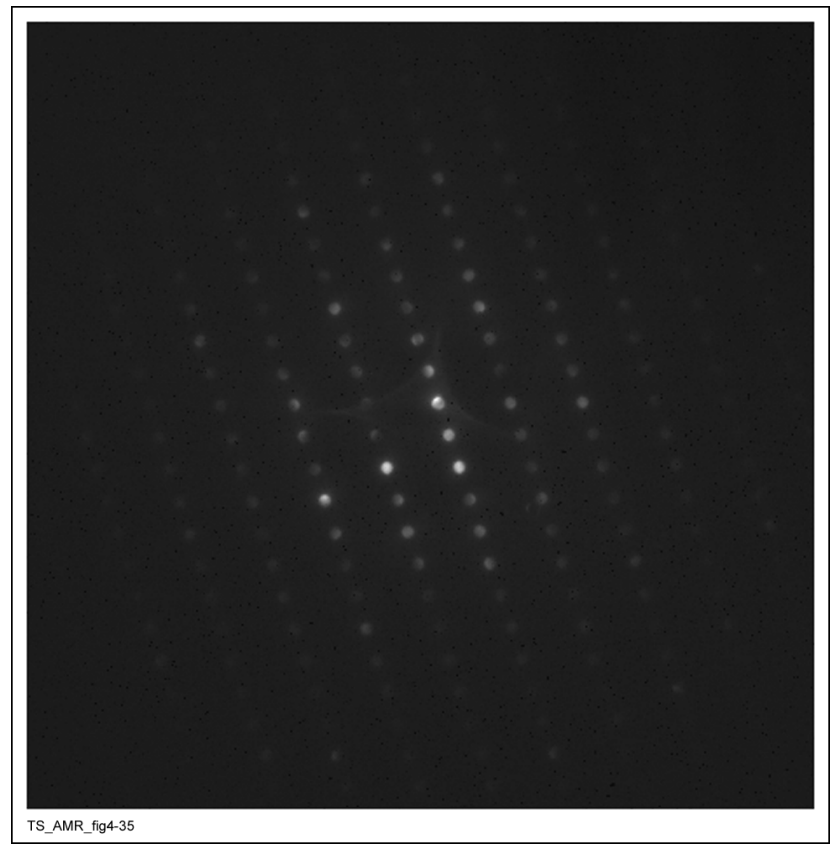

Source: DTN: LL010107712251.012 [DIRS 155299].

NOTE: (TS369-004a, Image 1310, 3/14/98, SN-LLNL-SCI-369, p. 150).

Figure 15. SAD Pattern from the $\mu$-Phase Precipitate Shown in Figure 14 


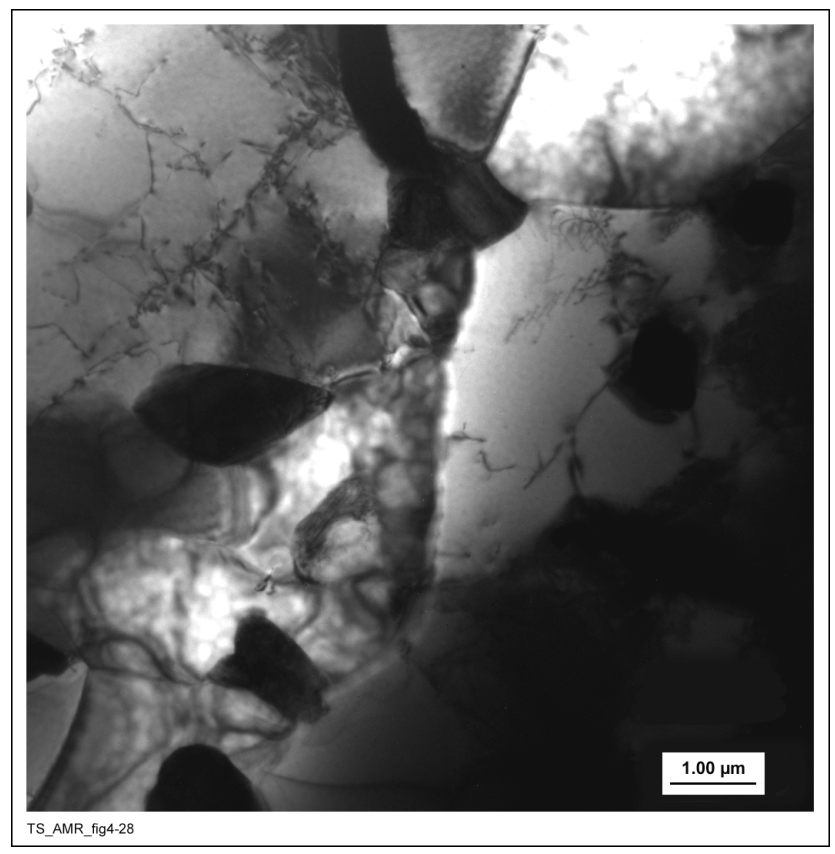

Source: DTN: LL010107712251.012 [DIRS 155299].

NOTE: The larger, brighter phase was identified as $\sigma$. The smaller precipitates are either $\mu$ or $\mathrm{P}$ phase (TS369-004a, Image 1300, 3/14/98, SN-LLNL-SCI-369, p. 66).

Figure 16. Grain Boundary Precipitation in Alloy 22 Aged for 16,000 Hours at $760^{\circ} \mathrm{C}$

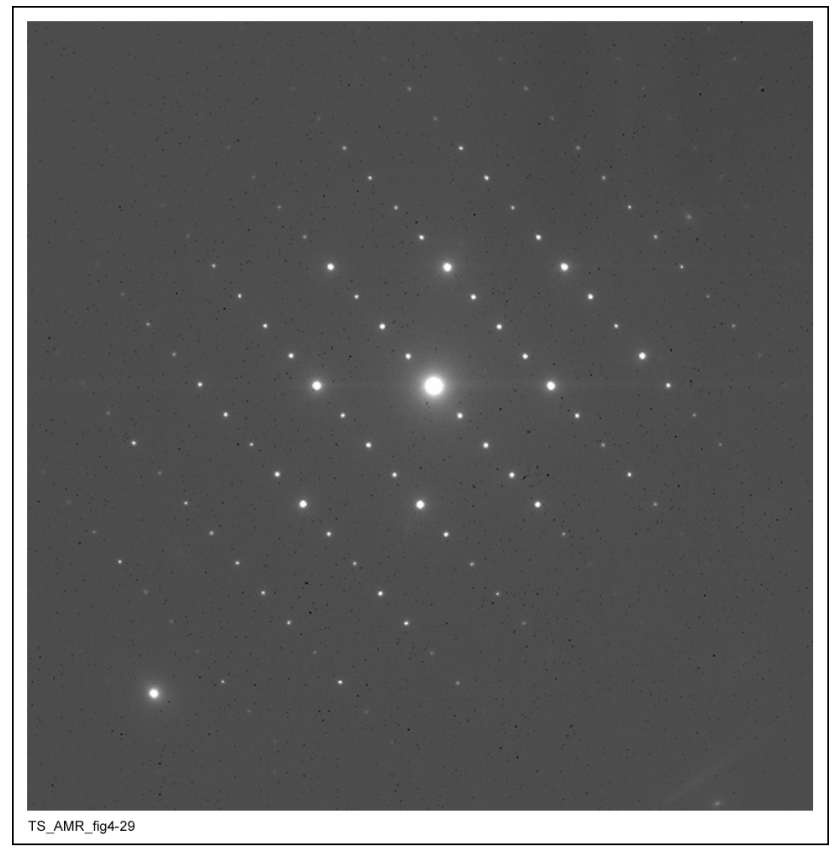

Source: DTN: LL010107712251.012 [DIRS 155299].

NOTE: (TS369-004a, Image 1306, tilted (-11,-9) from image 1300, 3/14/98, SN-LLNL-SCI-369, p. 98).

Figure 17. SAD Pattern from the $\sigma$-Phase Precipitate Shown in Figure 16 


\subsubsection{Micrographs Showing Precipitation in Alloy 22 Beginning on and Covering Grain Boundaries, Beginning on Twin Boundaries, and Beginning Within the Grains}

This section contains optical and scanning electron microscopy (SEM) images (Figure 18 through Figure 34) used to determine the times at which the various stages of TCP and carbide precipitation occur in Alloy 22 base metal after aging in the temperature range of $593^{\circ} \mathrm{C}$ to $800^{\circ} \mathrm{C}$ for durations ranging from 1 to 16,000 hours. No distinction has been made between the various TCP phases and the carbides that form in Alloy 22. The TCP phases $\mu, \mathrm{P}$, and $\sigma$ are virtually indistinguishable in the SEM (as shown in the preceding section, the phases are discernable in the TEM), and there is relatively little carbide precipitation.

Similar to the discussion in Section 4.1.1, the ambiguities in the exact composition of the TCP phases or carbides have no impact on the aging and phase stability model due to structural similarities among TCP phases and also among carbides. Thus, the phase kinetics among TCP phases and also among carbides will also be similar.

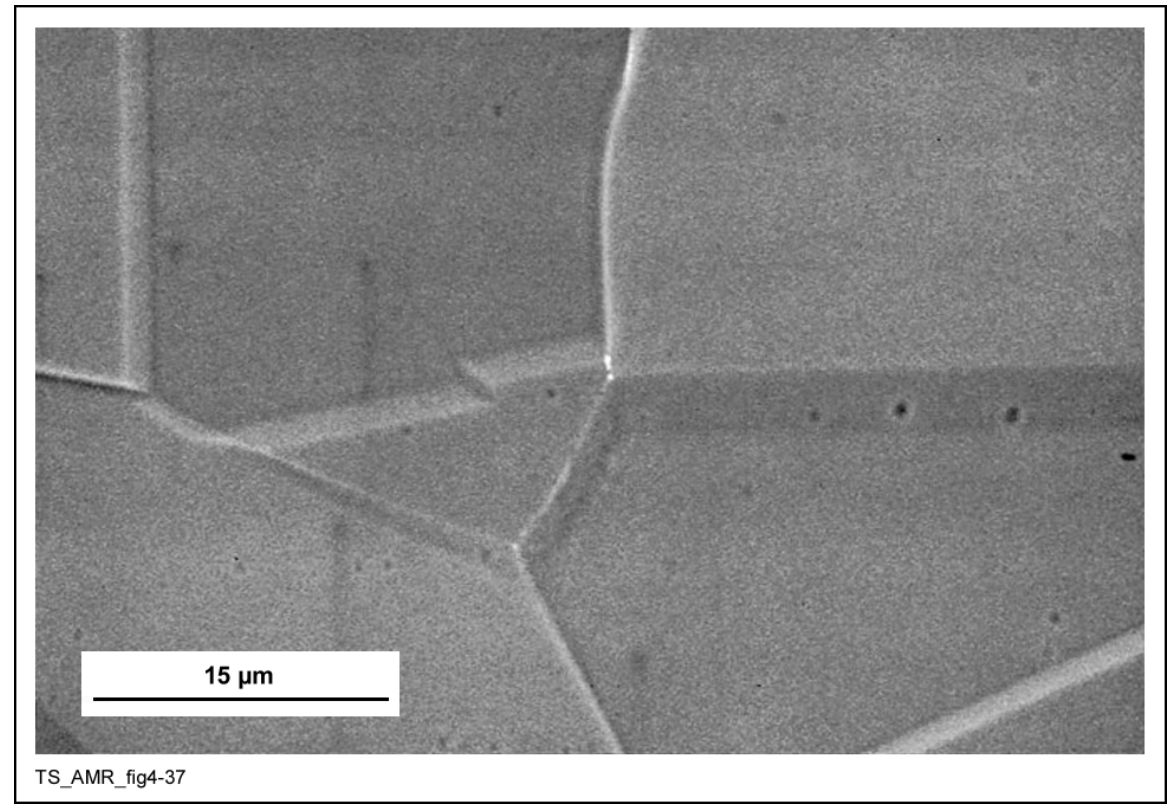

Source: DTN: LL010107712251.012 [DIRS 155299].

NOTE: (TS393-028a, 2/15/99, SN-LLNL-SCI-434, p. 7).

Figure 18. SEM Micrograph Showing Precipitation Just Beginning on Grain Boundaries after Aging Alloy 22 for 10 Hours at $593^{\circ} \mathrm{C}$ 


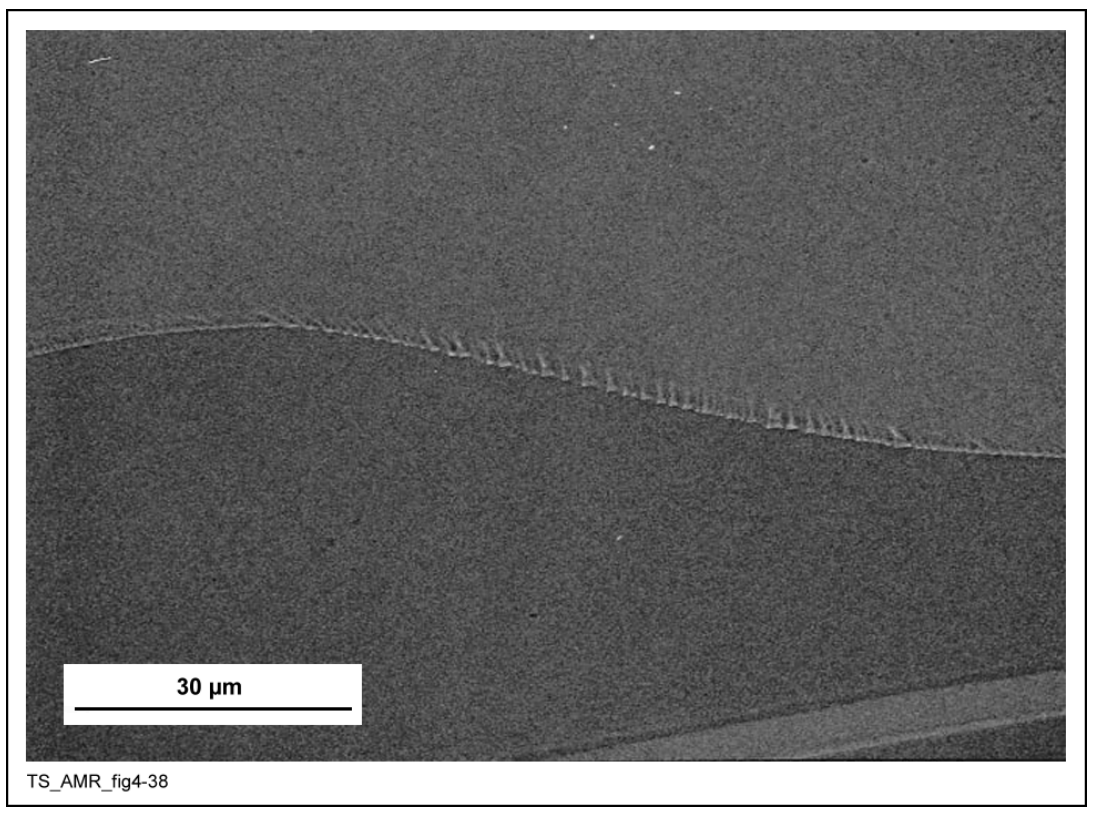

Source: DTN: LL010107712251.012 [DIRS 155299].

NOTE: (TS393-029a, 2/15/99, SN-LLNL-SCI-434, p. 8).

Figure 19. SEM Micrograph Showing Precipitation on Grain Boundaries after Aging Alloy 22 for 100 Hours at $593^{\circ} \mathrm{C}$

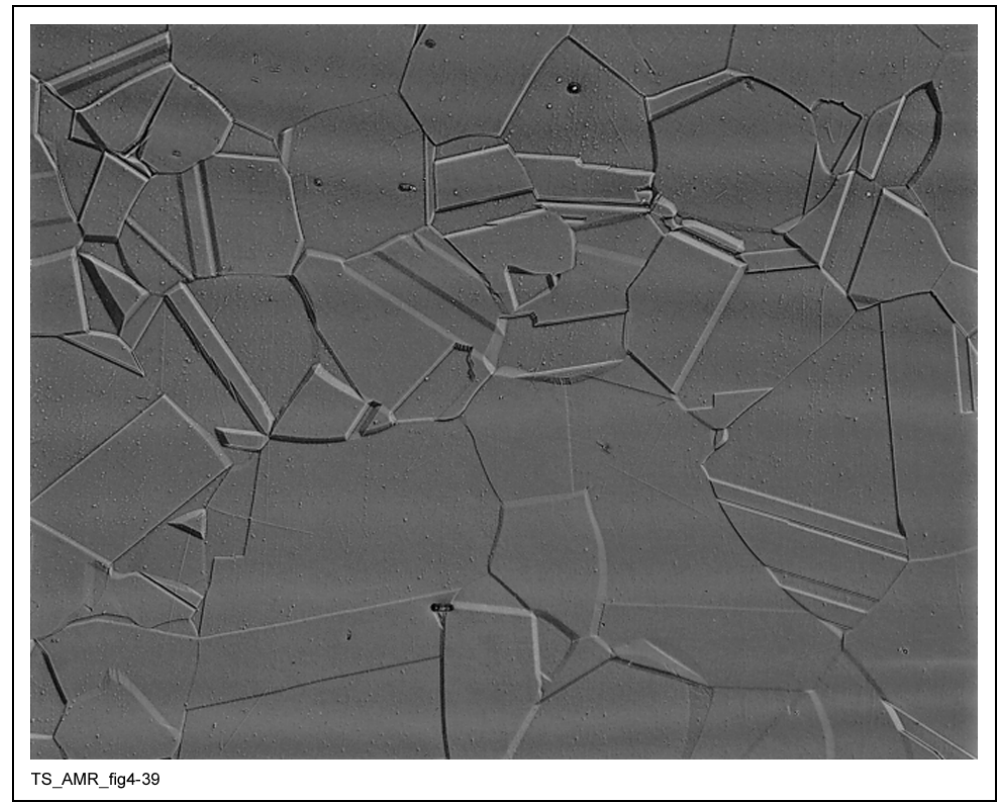

Source: DTN: LL010107712251.012 [DIRS 155299].

NOTE: (TS393-008a, 12/7/98, SN\#434, p. 10).

Figure 20. Optical Micrograph Showing No Precipitation on Grain Boundaries after Aging Alloy 22 for 1 Hour at $649^{\circ} \mathrm{C}$ 


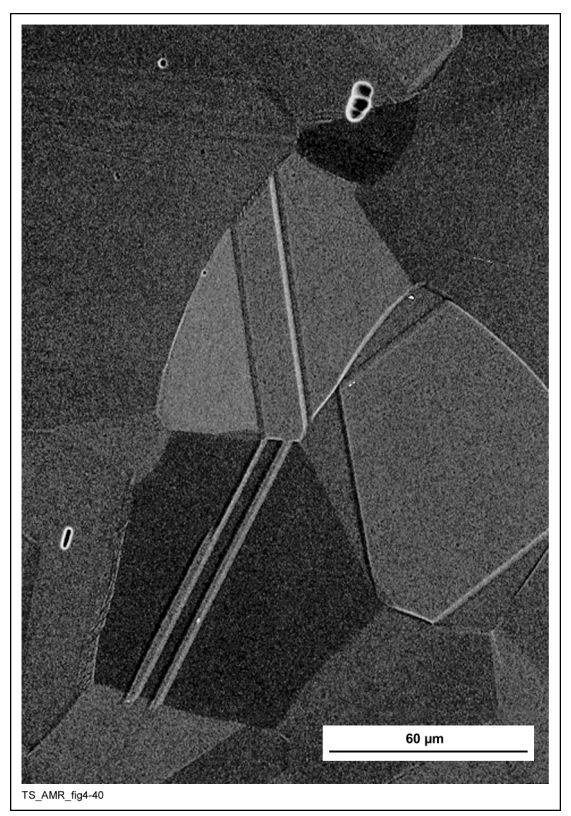

Source: DTN: LL010107712251.012 [DIRS 155299].

NOTE: (TS393-008a, 12/7/98, SN-LLNL-SCI-434, p. 10).

Figure 21. SEM Micrograph Showing Little or No Precipitation on Grain Boundaries after Aging Alloy 22 for 1 Hour at $649^{\circ} \mathrm{C}$

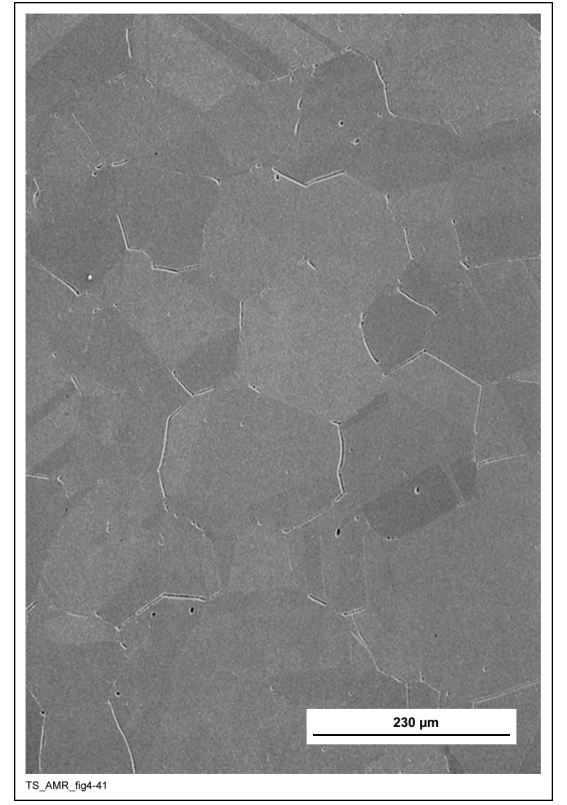

Source: DTN: LL010107712251.012 [DIRS 155299].

NOTE: (TS393-009a, 12/7/98, SN-LLNL-SCI-434, p. 11).

Figure 22. SEM Micrograph Showing Precipitation on Grain Boundaries after Aging Alloy 22 for 10 Hours at $649^{\circ} \mathrm{C}$ 


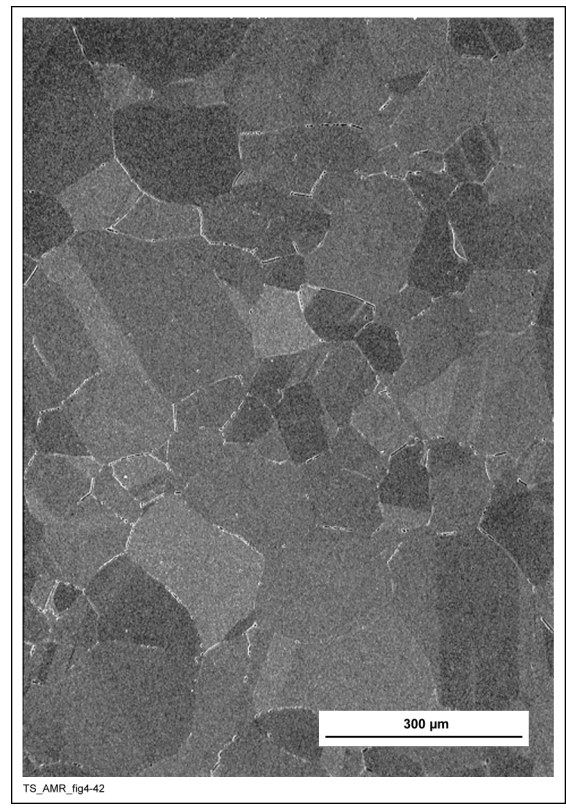

Source: DTN: LL010107712251.012 [DIRS 155299].

NOTE: (TS393-010a, 12/7/98, SN-LLNL-SCl-434, p. 12).

Figure 23. SEM Micrograph Showing Precipitation on Grain Boundaries after Aging Alloy 22 for 100 Hours at $649^{\circ} \mathrm{C}$

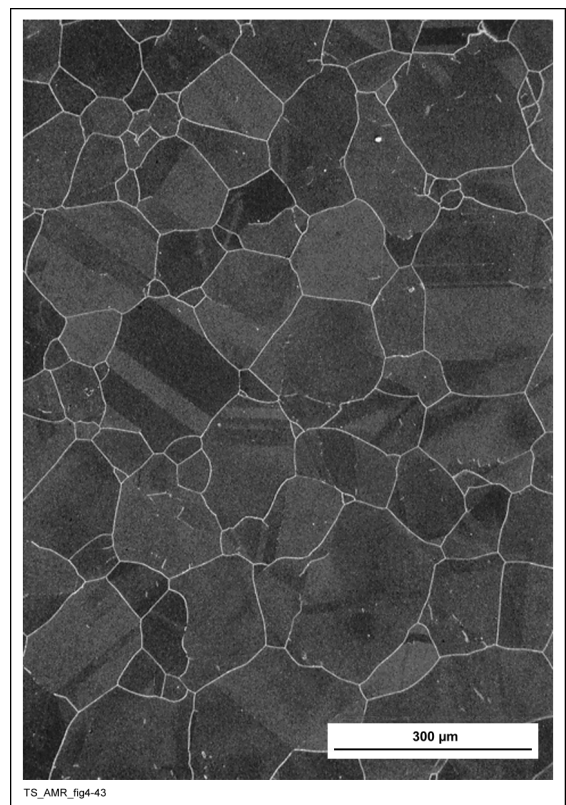

Source: DTN: LL010107712251.012 [DIRS 155299].

NOTE: (TS393-011a, 12/7/98, SN-LLNL-SCI-434, p. 12).

Figure 24. SEM Micrograph Showing Precipitation on Grain Boundaries after Aging Alloy 22 for 1,000 Hours at $649^{\circ} \mathrm{C}$ 


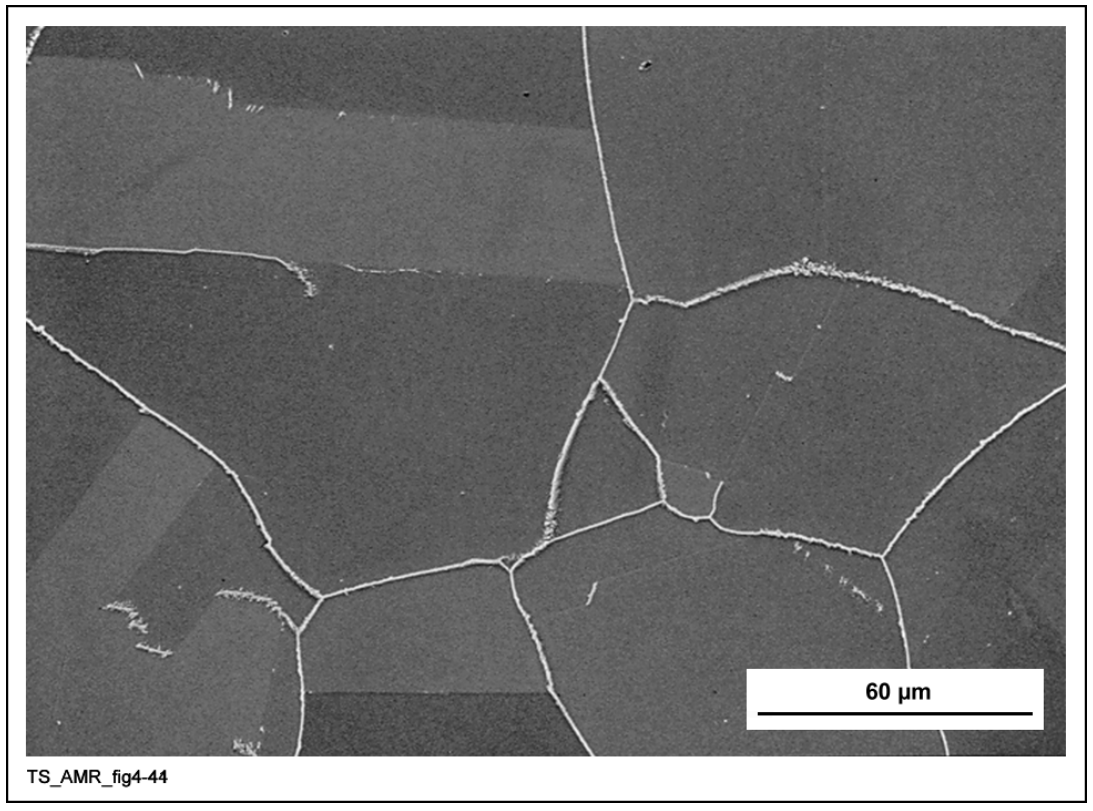

Source: DTN: LL010107712251.012 [DIRS 155299].

NOTE: (TS393-011a, 12/7/98, SN-LLNL-SCI-434, p. 13).

Figure 25. SEM Micrograph Showing Precipitation on Grain and on Twin Boundaries after Aging Alloy 22 for 1,000 Hours at $649^{\circ} \mathrm{C}$

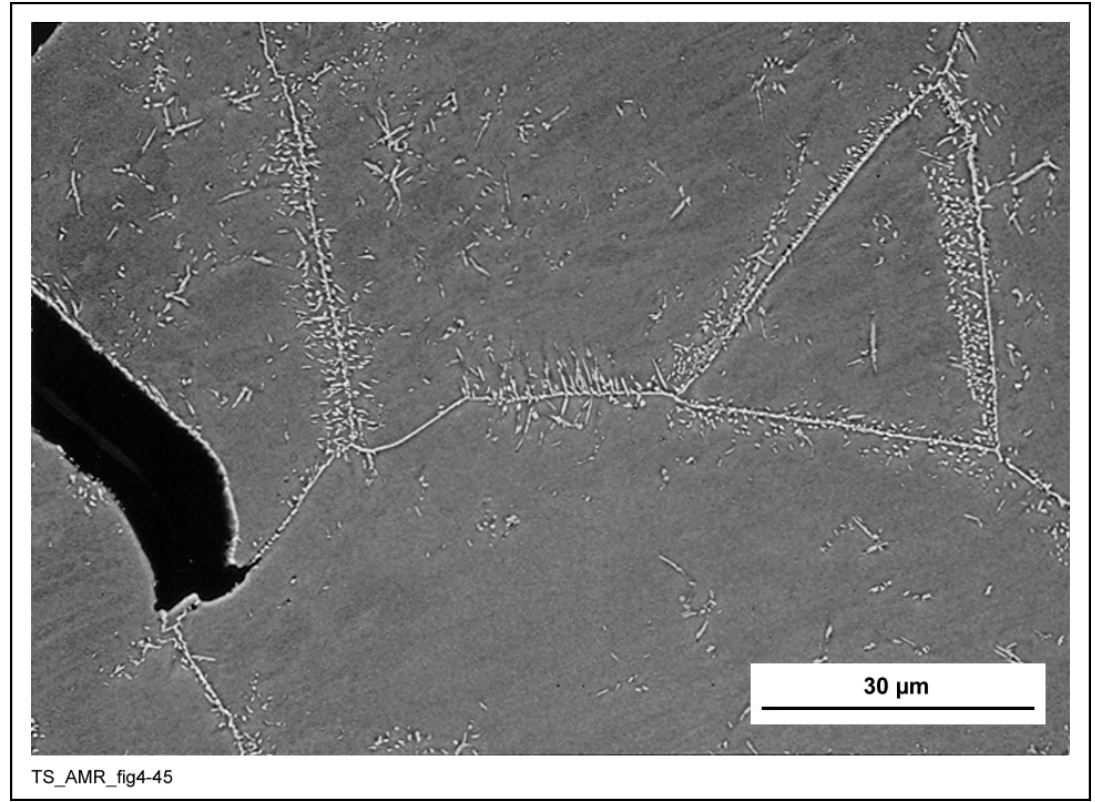

Source: DTN: LL010107712251.012 [DIRS 155299].

NOTE: (TS369-008b, 8/28/98, SN-LLNL-SCl-434, p. 14).

Figure 26. SEM Micrograph Showing Precipitation on Grain Boundaries and within the Grains after Aging Alloy 22 for 16,000 Hours at $649^{\circ} \mathrm{C}$ 


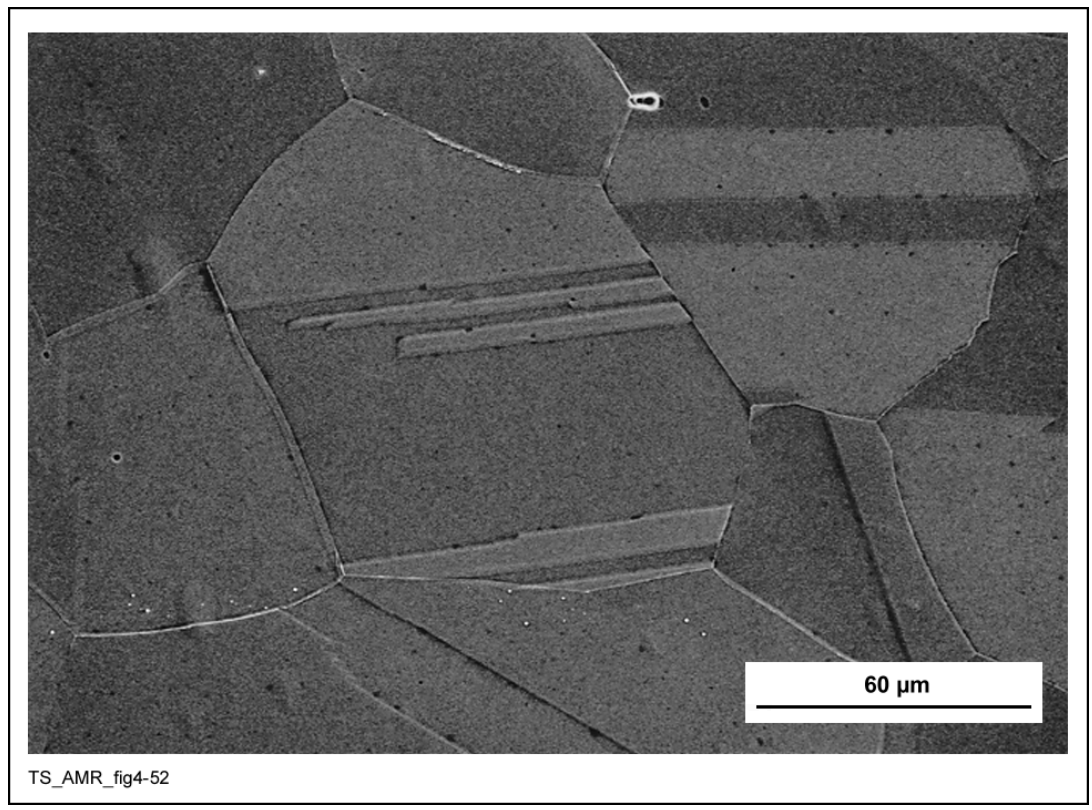

Source: DTN: LL010107712251.012 [DIRS 155299].

NOTE: (TS369-014, 11/30/98, SN-LLNL-SCI-434, p. 19).

Figure 27. Low-Magnification SEM Micrograph Showing that Grain Boundary Precipitation has Begun after Aging Alloy 22 for 1 Hour at $760^{\circ} \mathrm{C}$

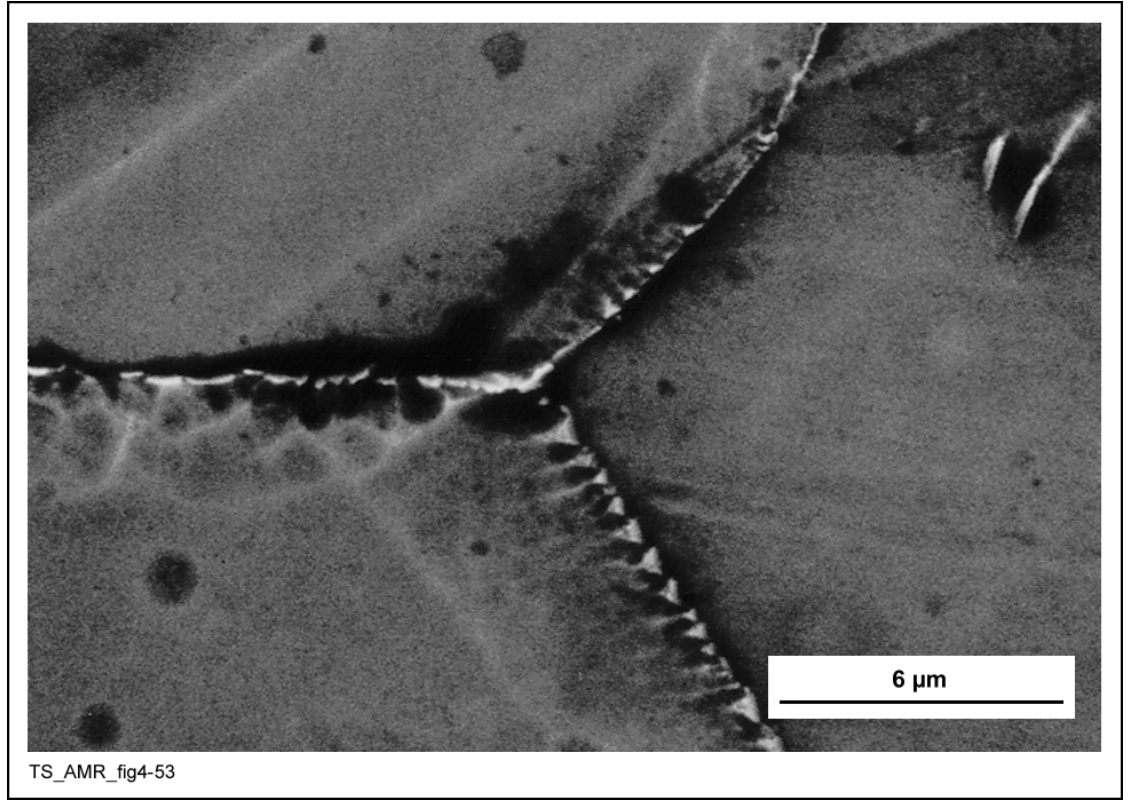

Source: DTN: LL010107712251.012 [DIRS 155299].

NOTE: (TS369-014, 11/30/98, SN-LLNL-SCI-434, p. 20).

Figure 28. High-Magnification SEM Micrograph Showing that Grain Boundary Precipitation has Begun after Aging Alloy 22 for 1 Hour at $760^{\circ} \mathrm{C}$ 


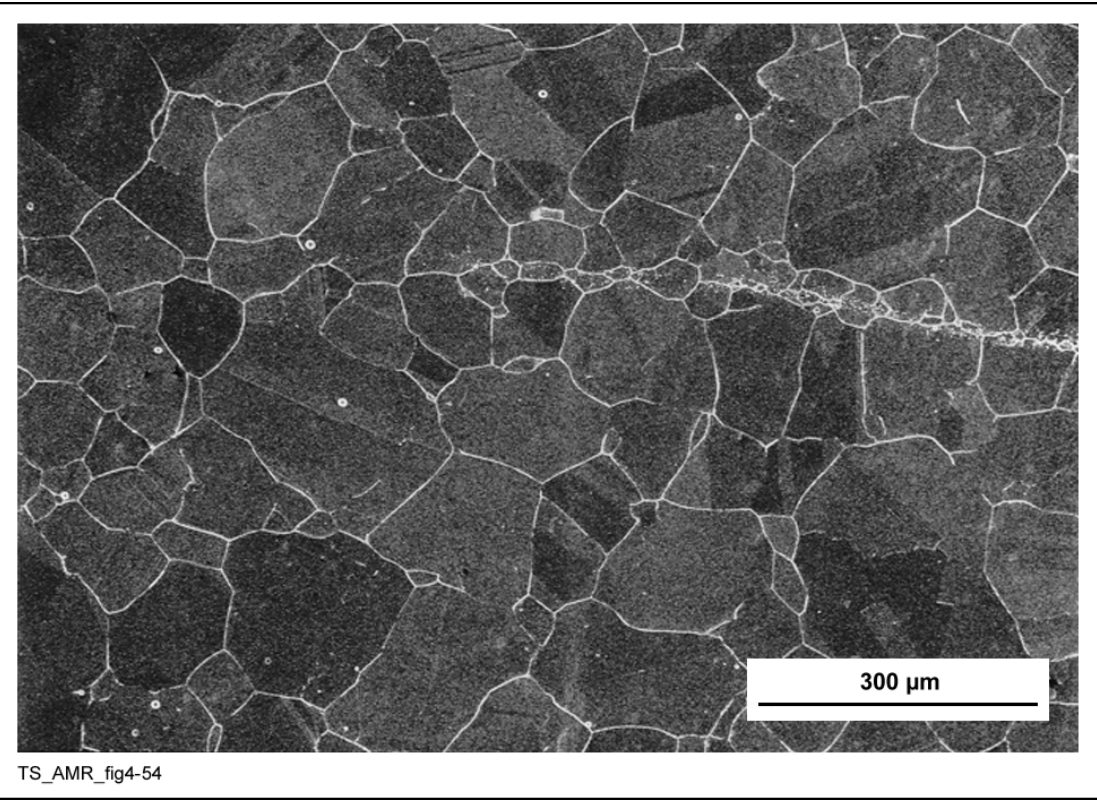

Source: DTN: LL010107712251.012 [DIRS 155299].

NOTE: (TS369-015, 11/30/98, SN-LLNL-SCI-434, p. 21).

Figure 29. SEM Micrograph Showing Significant Grain Boundary Precipitation after Aging Alloy 22 for 10 Hours at $760^{\circ} \mathrm{C}$

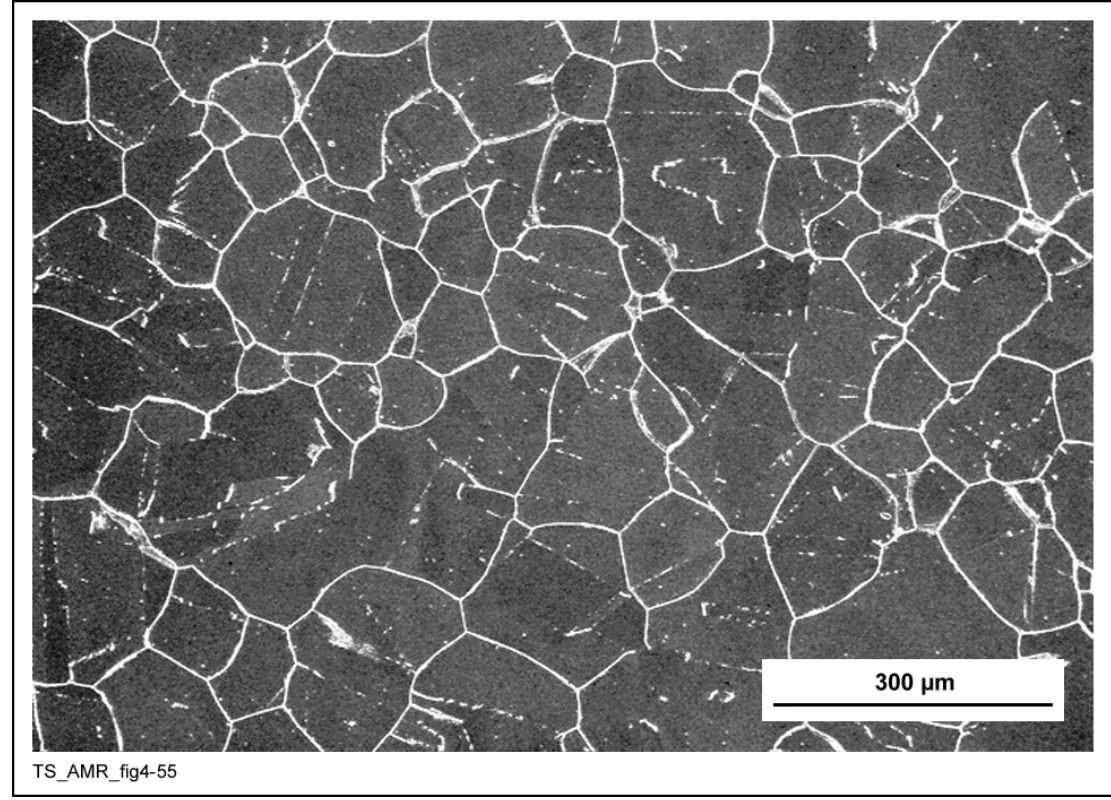

Source: DTN: LL010107712251.012 [DIRS 155299].

NOTE: (TS369-016, 11/30/98, SN-LLNL-SCI-434, p. 22).

Figure 30. SEM Micrograph Showing Significant Grain Boundary Precipitation and Precipitation on Twin Boundaries after Aging Alloy 22 for 119 Hours at $760^{\circ} \mathrm{C}$ 


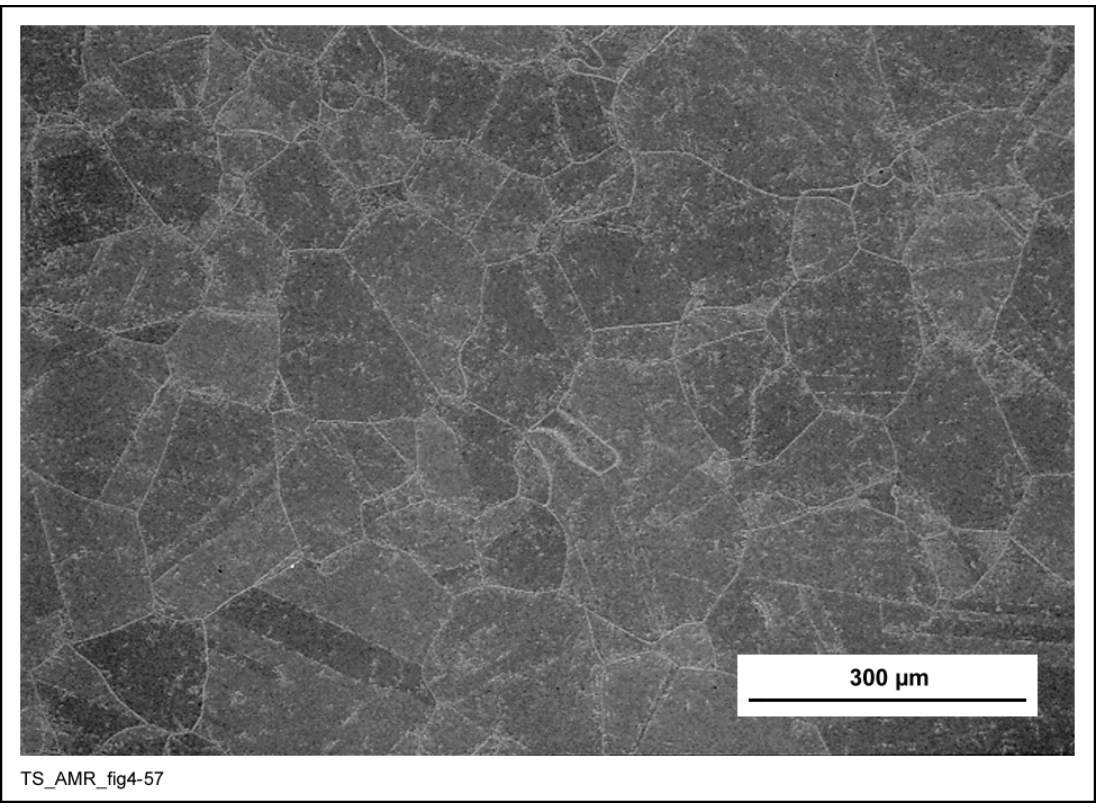

Source: DTN: LL010107712251.012 [DIRS 155299].

NOTE: (TS393-007a, 12/7/98, SN-LLNL-SCI-434, p. 22).

Figure 31. SEM Micrograph Showing Significant Precipitation Within the Grains of Alloy 22 after Aging for 1,000 Hours at $760^{\circ} \mathrm{C}$

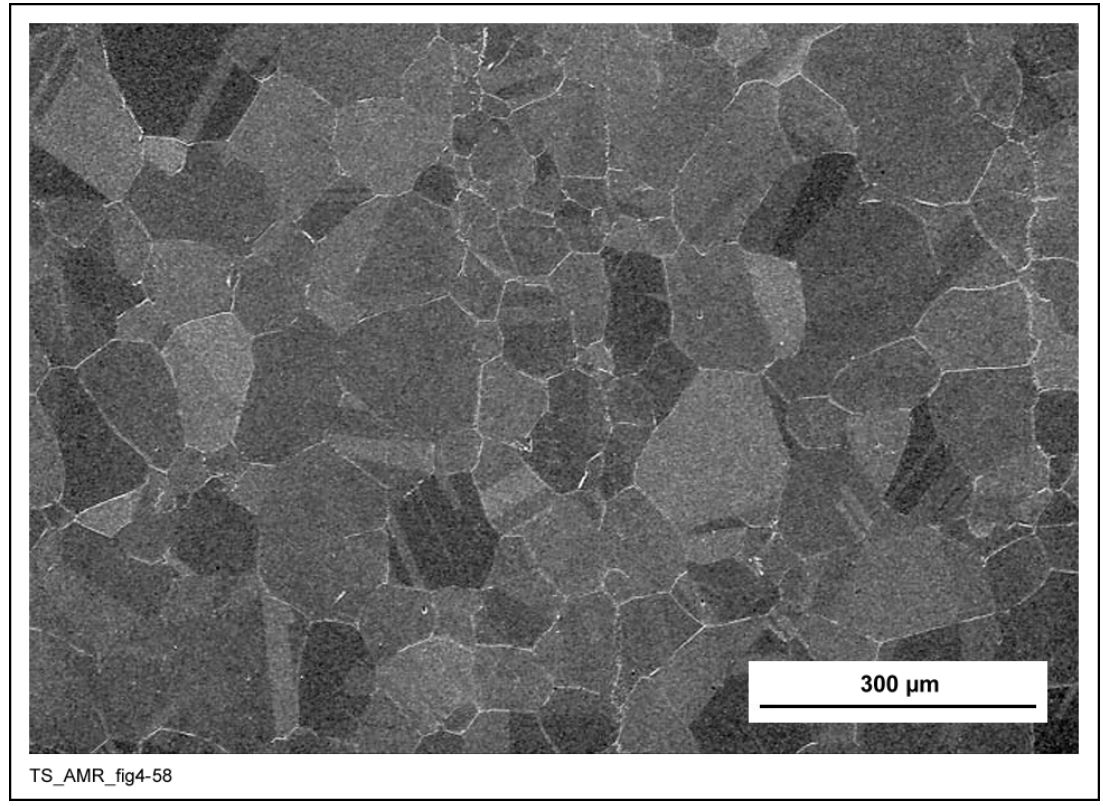

Source: DTN: LL010107712251.012 [DIRS 155299].

NOTE: (TS393-020a, 2/15/99, SN-LLNL-SCl-434, p. 25).

Figure 32. SEM Micrograph Showing Grain Boundary Precipitation in Alloy 22 after Aging for 1 Hour at $800^{\circ} \mathrm{C}$ 


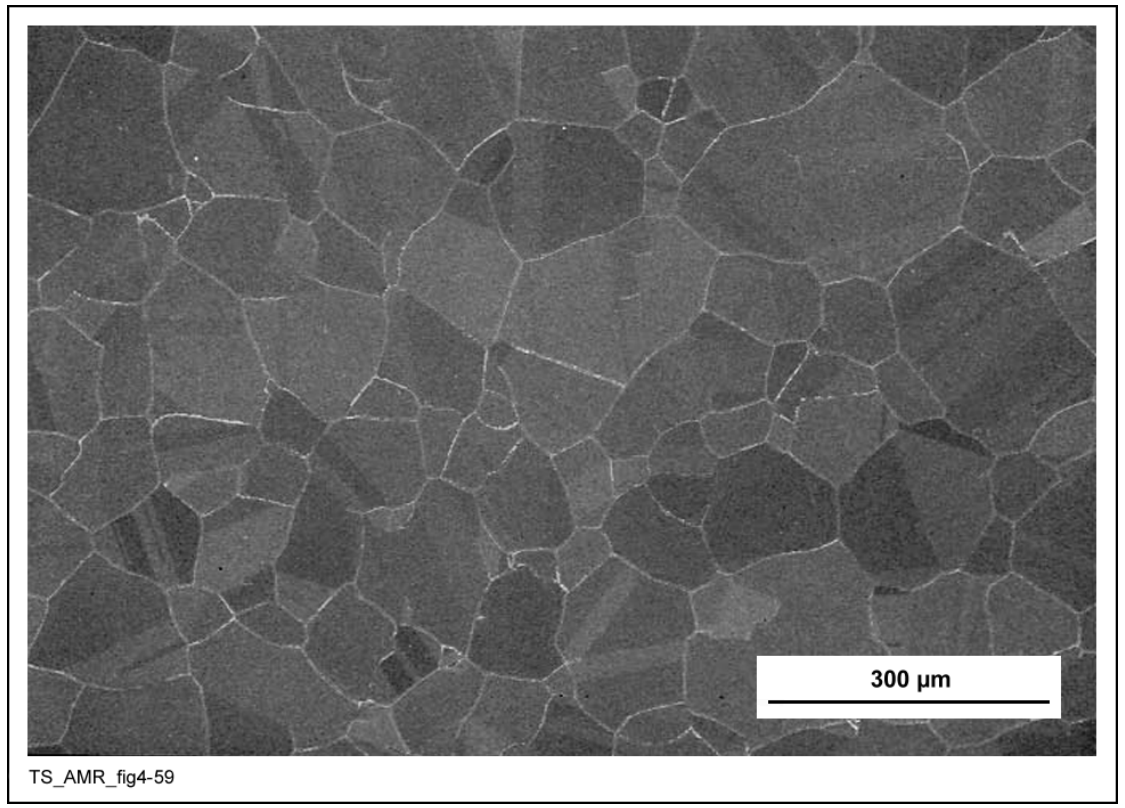

Source: DTN: LL010107712251.012 [DIRS 155299].

NOTE: (TS393-021a, 2/15/99, SN-LLNL-SCl-434, p. 26).

Figure 33. SEM Micrograph Showing Significant Grain Boundary Precipitation in Alloy 22 after Aging for 10 Hours at $800^{\circ} \mathrm{C}$

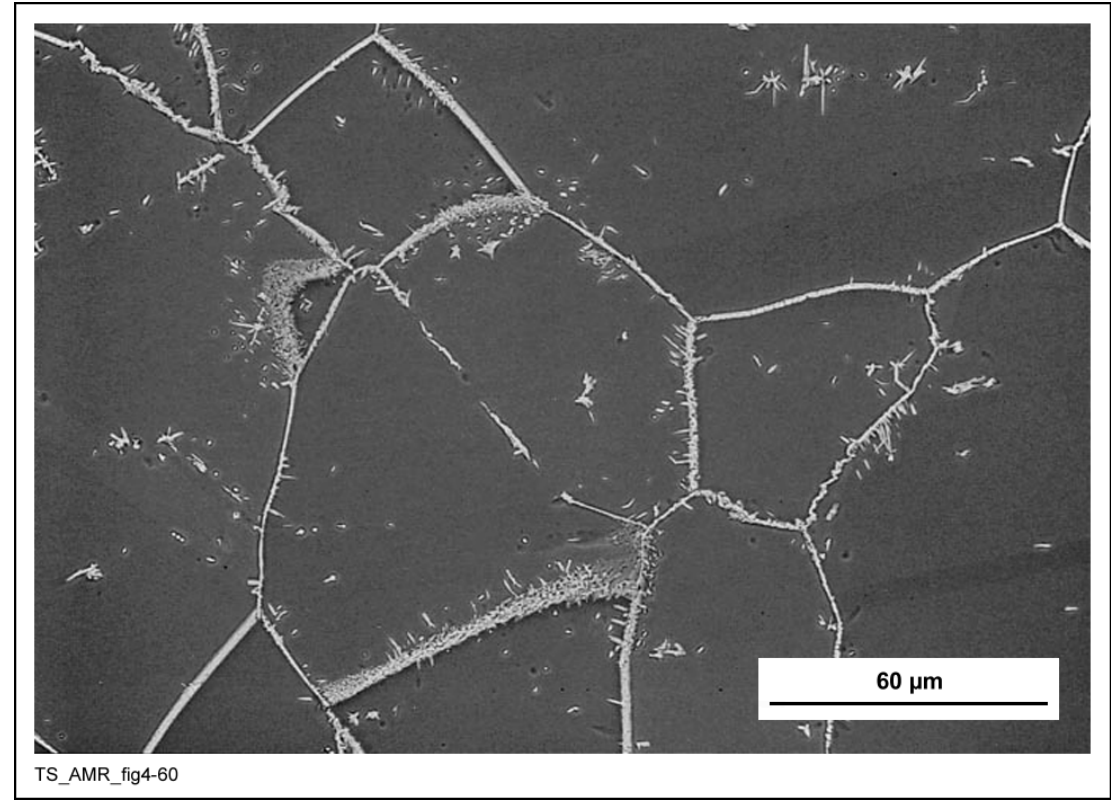

Source: DTN: LL010107712251.012 [DIRS 155299].

NOTE: (TS393-022a, 2/15/99, SN-LLNL-SCI-434, p. 27).

Figure 34. SEM Micrograph Showing Precipitation on Grain Boundaries, on Twin Boundaries, and within the Grains after Aging Alloy 22 for 100 Hours at $800^{\circ} \mathrm{C}$ 


\subsubsection{Micrographs Showing TCP Particles in Alloy 22 Welds}

The TCP phases $\mu, \mathrm{P}$, and $\sigma$ are known to form in Alloy 22 welds (Cieslak et al. 1986 [DIRS 104966], p. 2,041, paragraph 2). This section contains optical, SEM, and TEM images (Figure 35 through Figure 44) in the preliminary characterization of Alloy 22 welds. Two samples have been examined: one was examined in the as-welded condition; the other was aged for 40,000 hours at $427^{\circ} \mathrm{C}$. Although the two welds were produced in the same way, the aged sample did not come from the same weld, as did the unaged sample. Therefore, some variation is expected between the samples, and direct comparisons based on the small scale of differences seen between these samples should not be made.

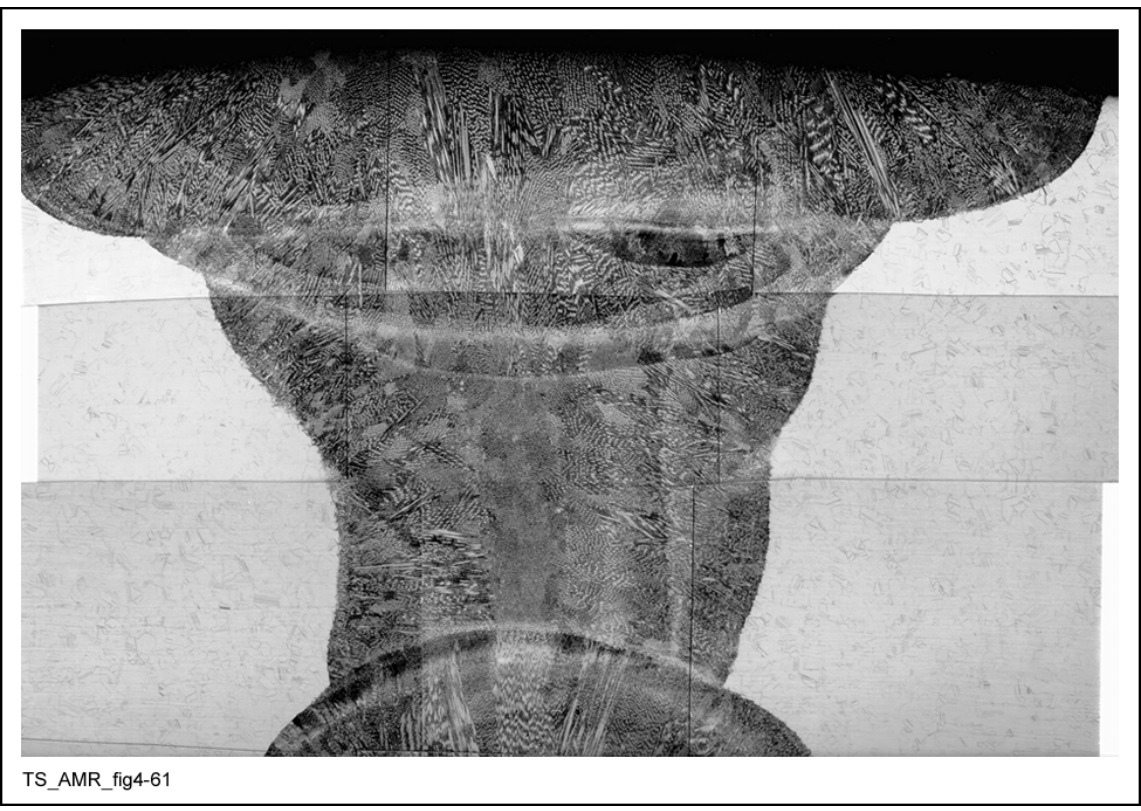

Source: DTN: LL030301612251.040 [DIRS 162691].

NOTE: Only approximately three-quarters of the half-inch plate is shown (TS369-019, 8/28/98, SN-LLNL-SCI-393, pp. 9 to 10$)$.

Figure 35. Low-Magnification (25×) Optical Micrograph of an Alloy 22 Multipass, Double-V Gas-Tungsten-Arc-Welding (GTAW) Weld with Matching Filler Metal (As-Welded) 


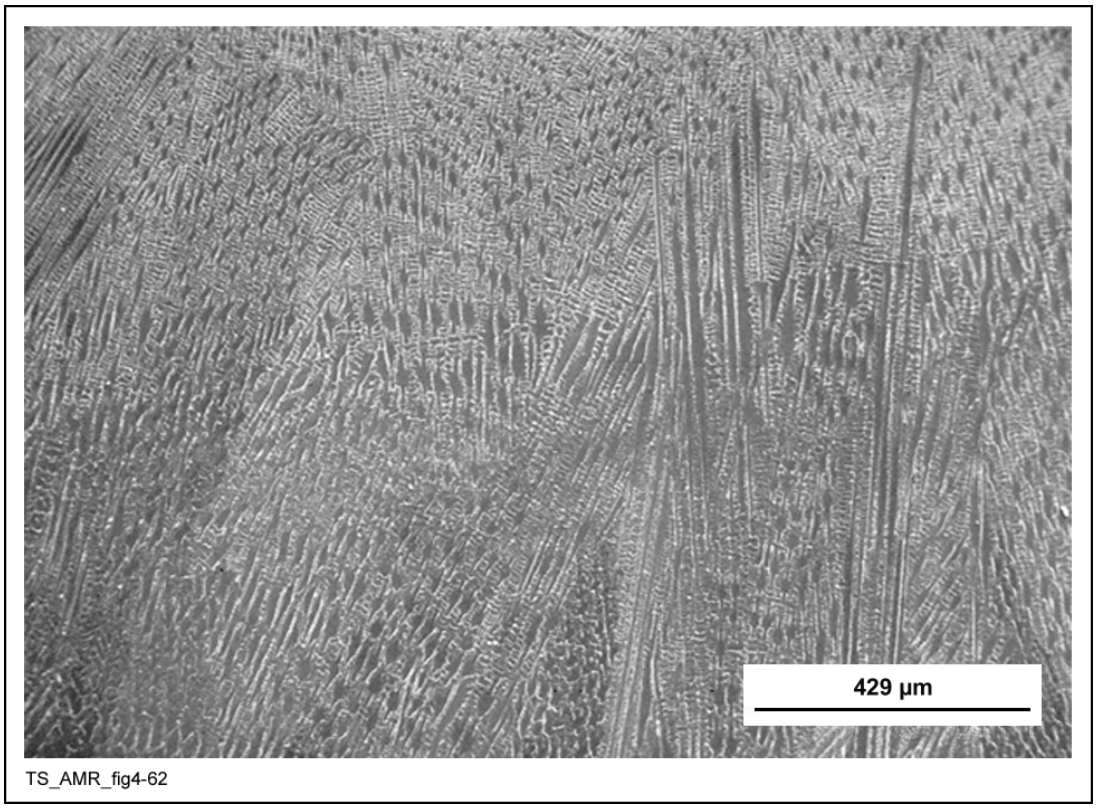

Source: DTN: LL030301612251.040 [DIRS 162691].

NOTE: (TS369-019, 8/28/98, SN-LLNL-SCI-393, p. 10).

Figure 36. SEM Micrograph of the Alloy 22 Weld Shown in Figure 35 Showing the Dendritic Structure Typical of Welds

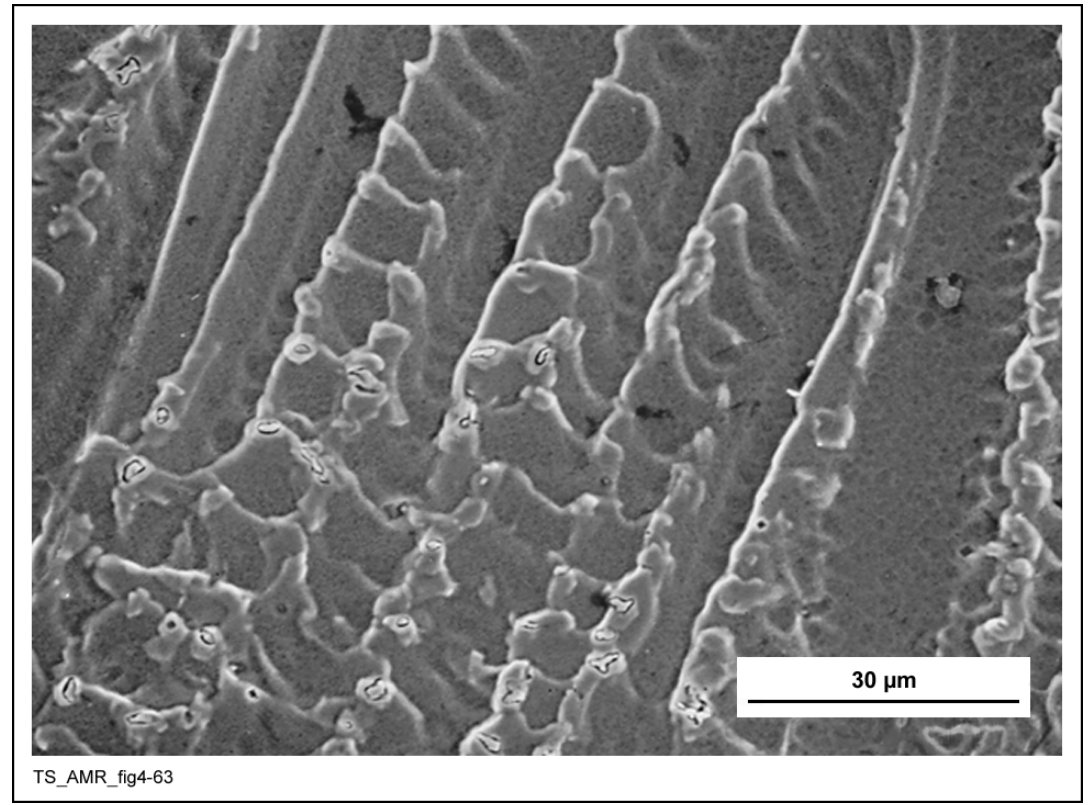

Source: DTN: LL030301612251.040 [DIRS 162691].

NOTE: TCP particles are seen to form in the interdendritic regions (TS369-019 SC11, 8/28/98, SN-LLNL-SCI-393, p. 10).

Figure 37. SEM Micrograph of the Alloy 22 Weld Shown in Figure 35 Showing the Dendritic Structure Typical of Welds (Near Top of Plate; Center of Weld; Higher Magnification) 


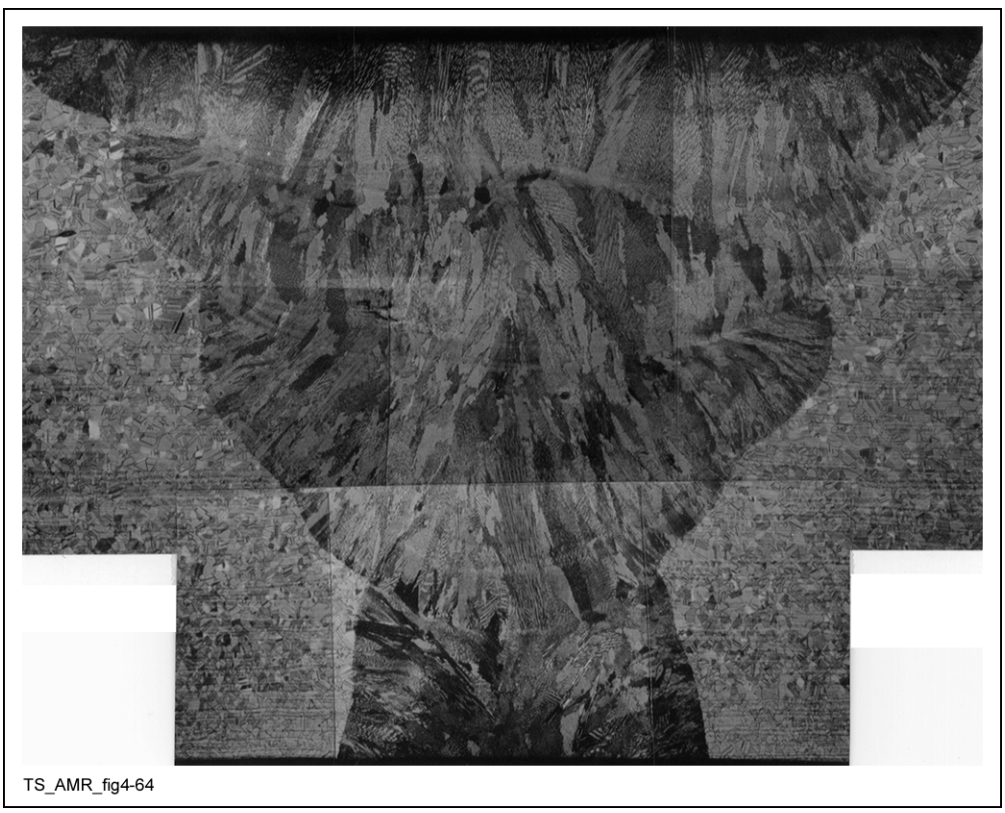

Source: DTN: LL030301612251.040 [DIRS 162691].

NOTE: Only approximately one-half of the half-inch plate is shown (TS369-005b, 5/12/98, SN-LLNL-SCI-369, p. 20).

Figure 38. Low-Magnification Optical Micrograph of an Alloy 22 Weld and Aged for 40,000 Hours at $427^{\circ} \mathrm{C}$

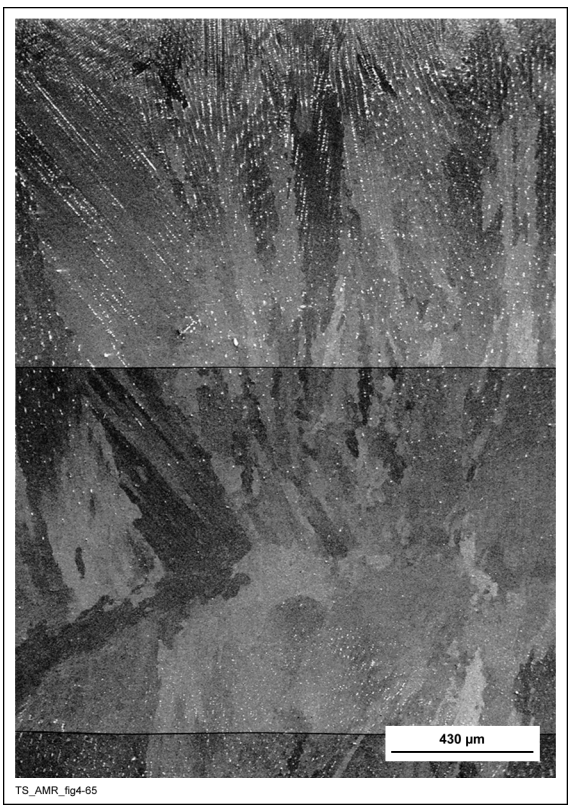

Source: DTN: LL030301612251.040 [DIRS 162691].

NOTE: The white TCP particles are distributed non-uniformly throughout the weld (TS369-005b, 5/12/98, SN-LLNL-SCl-369, p. 20).

Figure 39. SEM Micrograph of the Alloy 22 Weld Shown in Figure 38 at the Junction of Two Weld Passes 


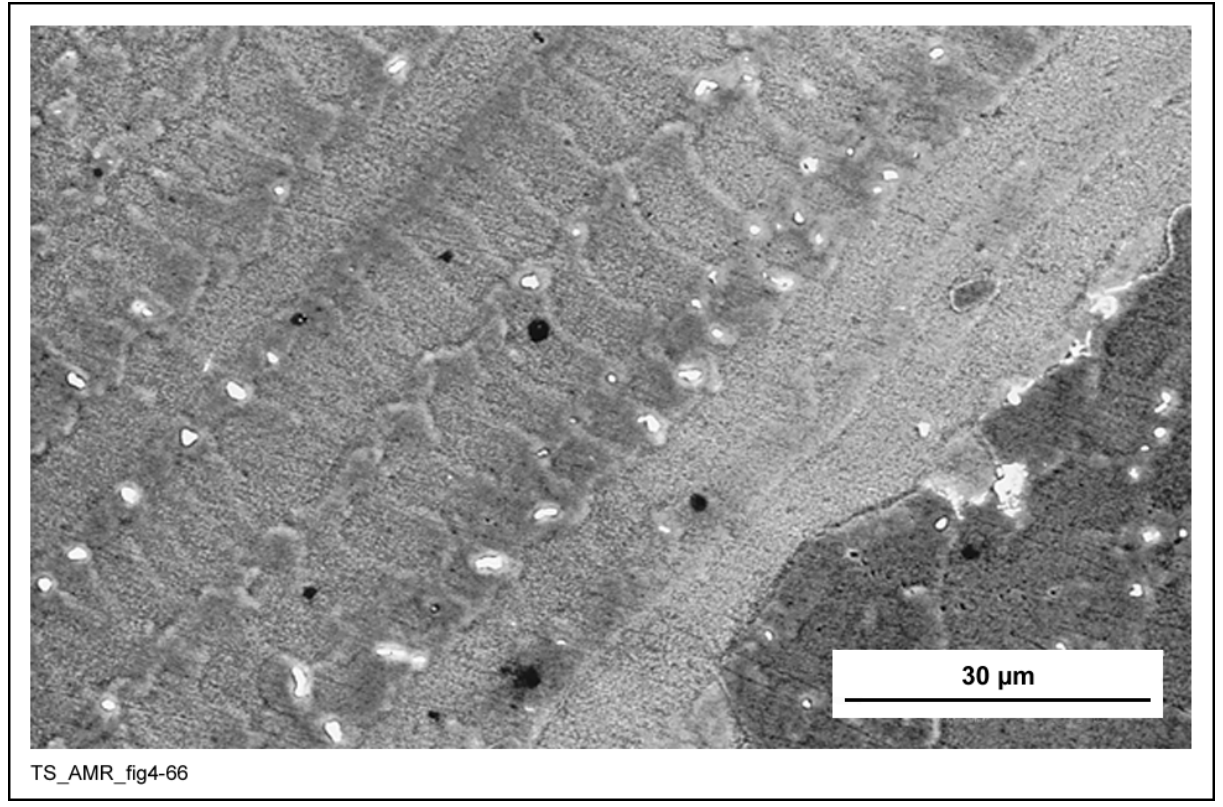

Source: DTN: LL030301612251.040 [DIRS 162691].

NOTE: TCP particles are seen to form in the interdendritic regions, as was seen in the unaged weld of Figure 37 (TS369-005b, 5/12/98, SN-LLNL-SCl-369, p. 20).

Figure 40. SEM Micrograph of the Alloy 22 Weld Shown in Figure 38 Showing the Dendritic Structure Typical of Welds

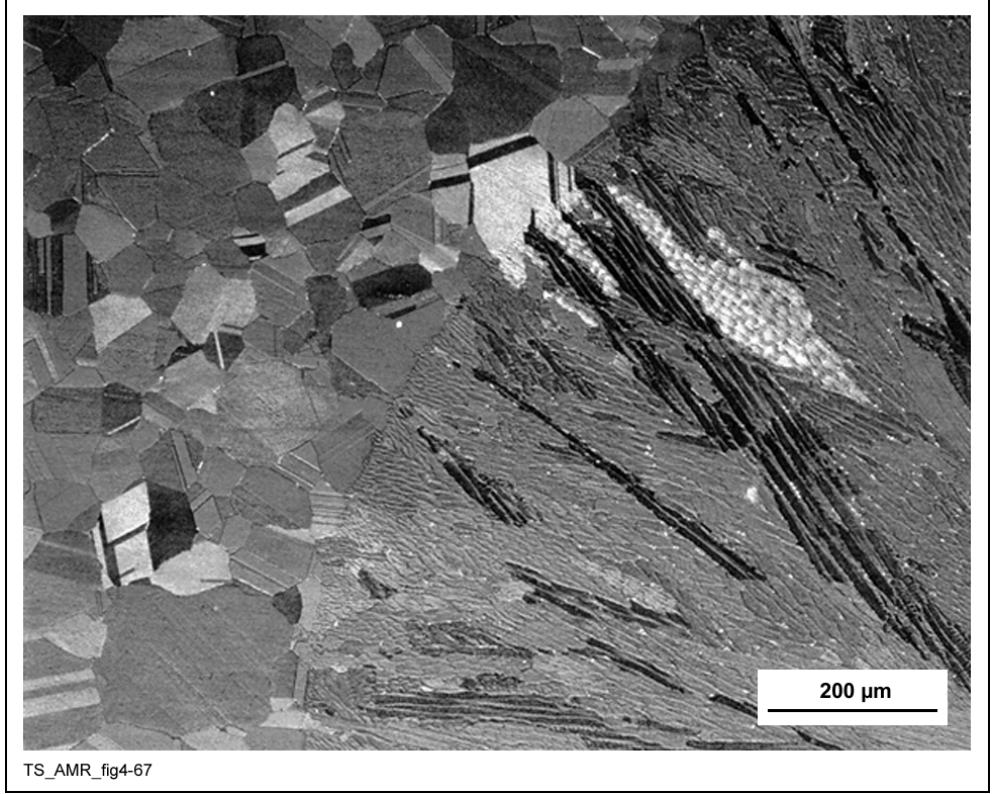

Source: DTN: LL030301612251.040 [DIRS 162691].

NOTE: Very few precipitates are noticeable (white "specks") in the Heat-Affected Zone (HAZ) of the aged weld (TS369-005b, 5/12/98, SN-LLNL-SCl-369, p. 20).

Figure 41. Optical Micrograph at the Fusion Line of the Alloy 22 Weld Shown in Figure 42 


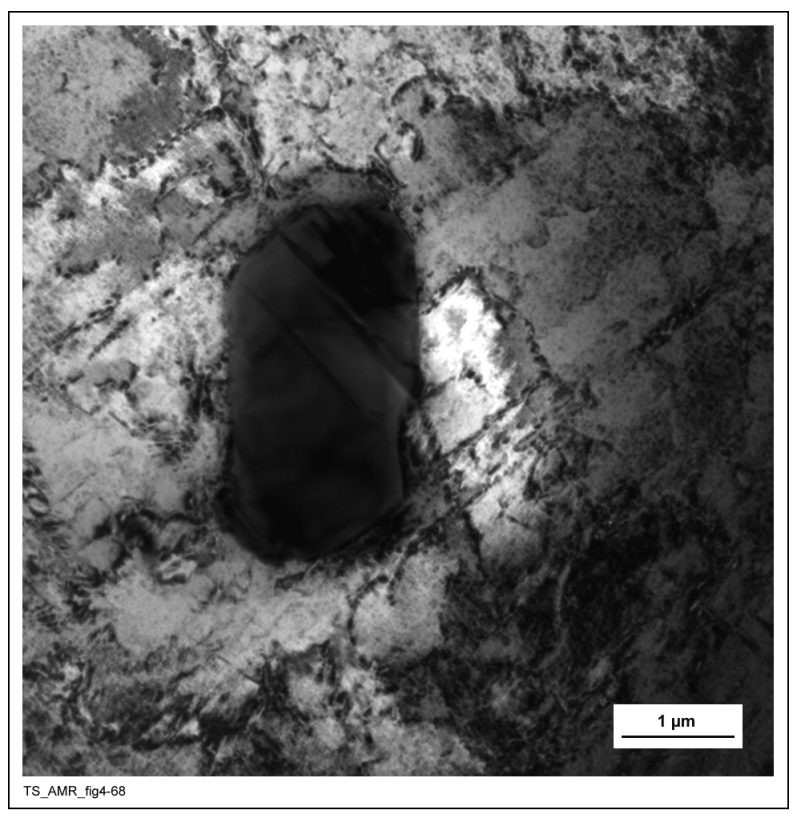

Source: DTN: LL030301612251.040 [DIRS 162691].

NOTE: $\quad$ This particle was not conclusively identified, but could be either $P$ or $\sigma$ (TS369-005a, Image 1373, 5/21/98, SN-LLNL-SCI-393, p. 27).

Figure 42. One of Few Precipitates Seen using TEM in the Alloy 22 Weld of Figure 38 Aged for 40,000 Hours at $427^{\circ} \mathrm{C}$

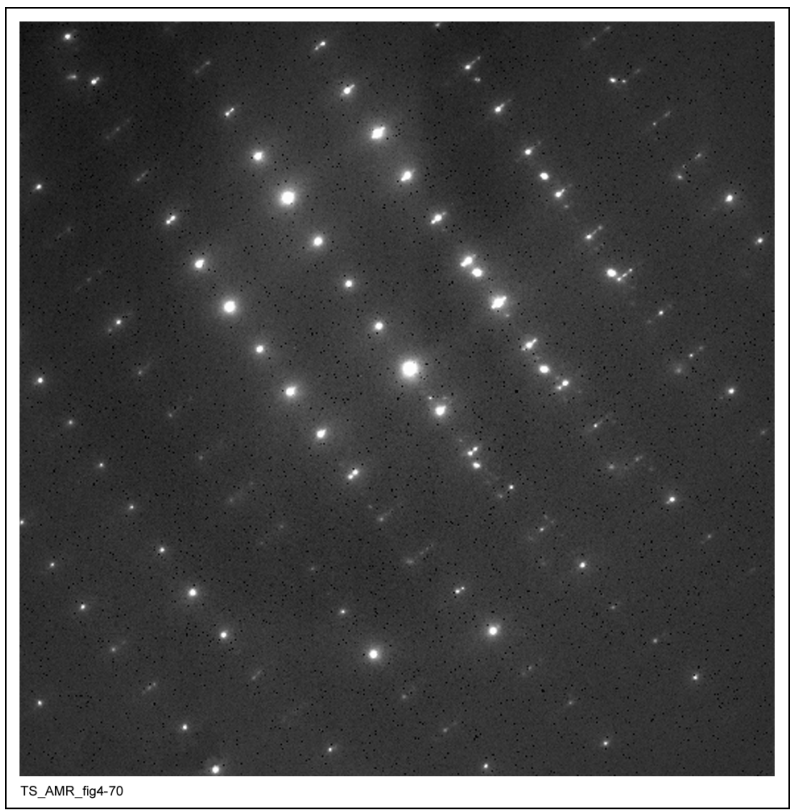

Source: DTN: LL030301612251.040 [DIRS 162691].

NOTE: This pattern could be indexed as either P phase or $\sigma$ (TS369-005a, Image 1375, 5/21/98, SN-LLNL-SCI393, p. 31).

Figure 43. SAD Pattern from the Precipitate Shown in Figure 42 


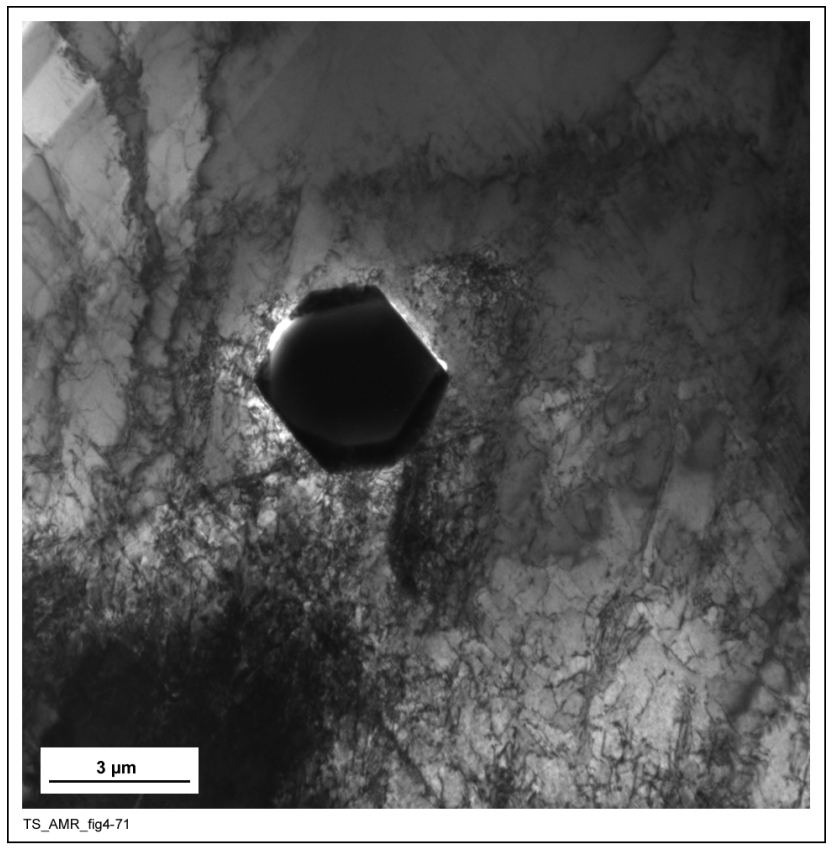

Source: DTN: LL030301612251.040 [DIRS 162691].

NOTE: A SAD pattern was not taken from this particle, but it appears to be a carbide and was probably present in the base metal prior to welding (TS369-005a, Image 1378, 5/22/98, SN-LLNL-SCI-393, p. 37).

Figure 44. TEM Micrograph Showing a Precipitate, Possibly Carbide, in the HAZ of the Aged Alloy 22 Weld of Figure 38

\subsubsection{TEM Micrographs Showing When LRO Has Been Observed}

This section contains a representative sampling of the TEM micrographs (Figure 45 through Figure 56) showing instances when LRO has been observed in aged Alloy 22 samples. In these sample micrographs, LRO has been observed in Alloy 22 base metal after aging for 16,000 hours at $593^{\circ} \mathrm{C}$ and in Alloy 22 welds after aging for 40,000 hours at $427^{\circ} \mathrm{C}$. 


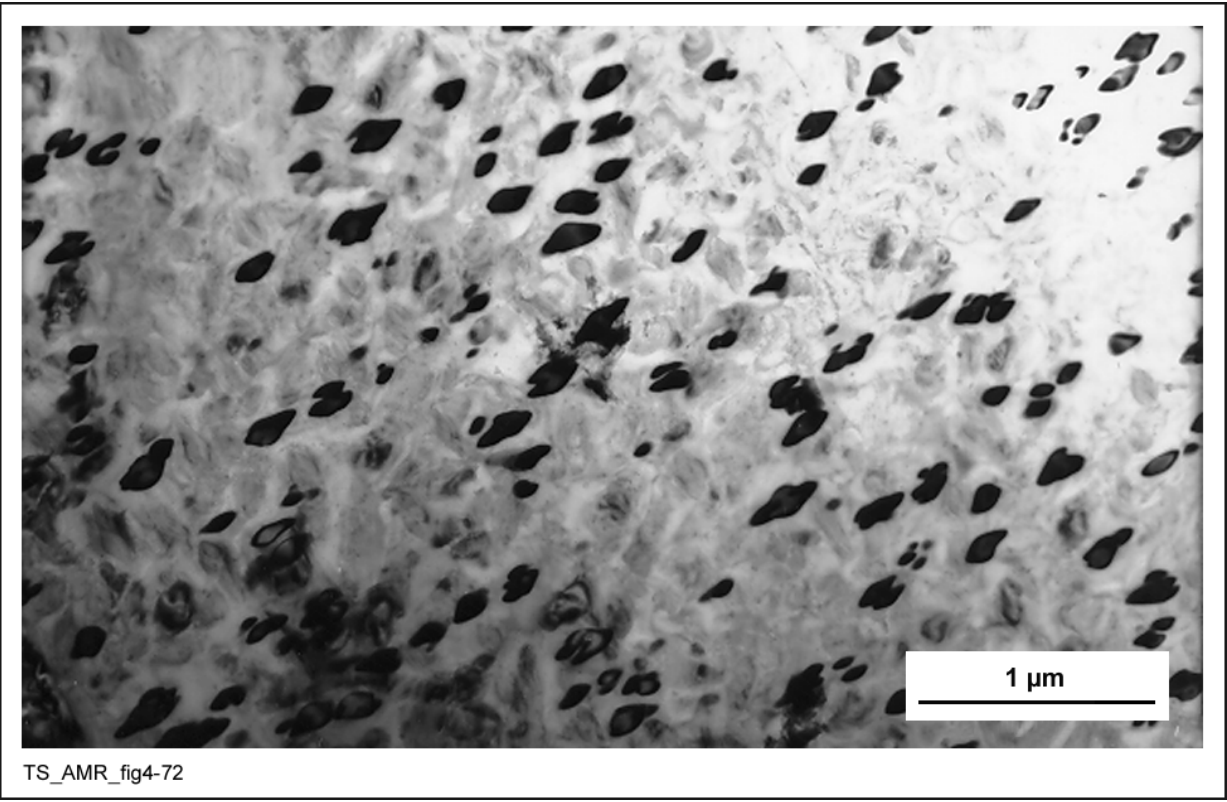

Source: DTN: LL010107712251.012 [DIRS 155299].

NOTE: (TS369-003a, Image 1484, 12/16/98, SN-LLNL-SCI-393, p. 61).

Figure 45. TEM Micrograph Showing LRO Domains in an Alloy 22 Base Metal Sample Aged for 16,000 Hours at $593^{\circ} \mathrm{C}$

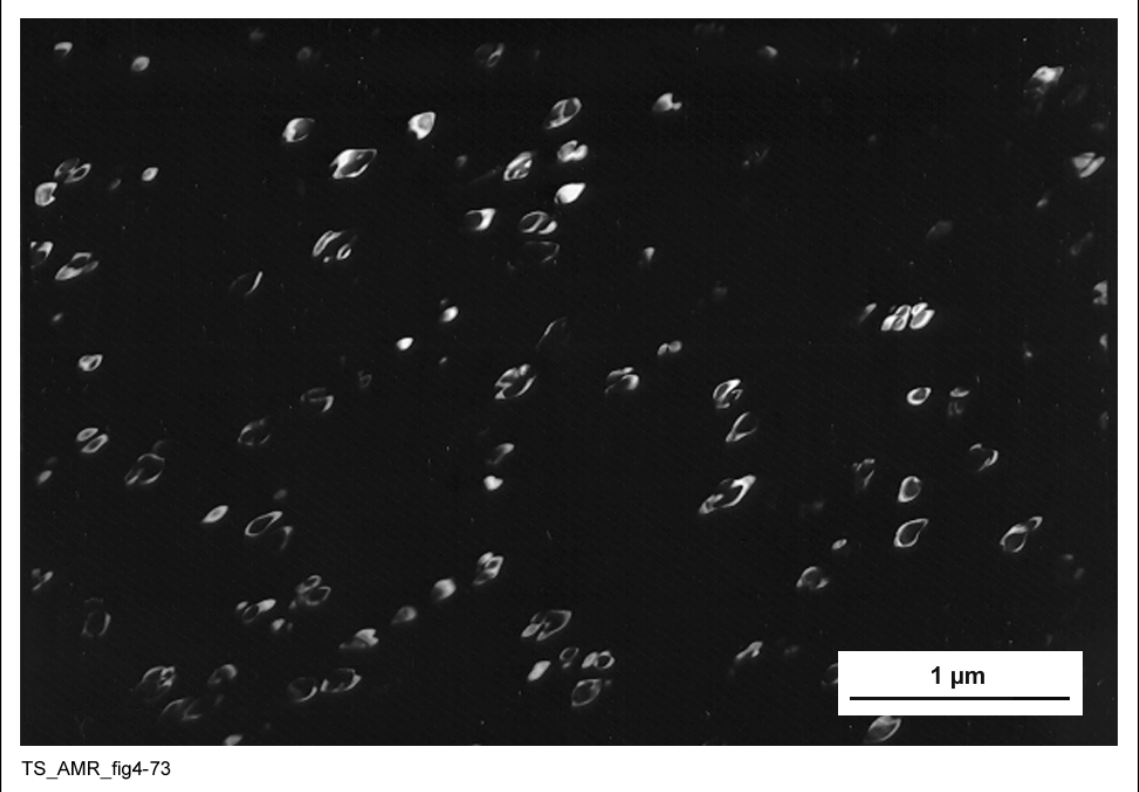

Source: DTN: LL010107712251.012 [DIRS 155299].

NOTE: One or more variants of the ordered domains appears light (TS369-003a, Image 1485, 12/16/98, SN-LLNL-SCI-393, p. 61).

Figure 46. Dark-Field Image Corresponding to Figure 45 


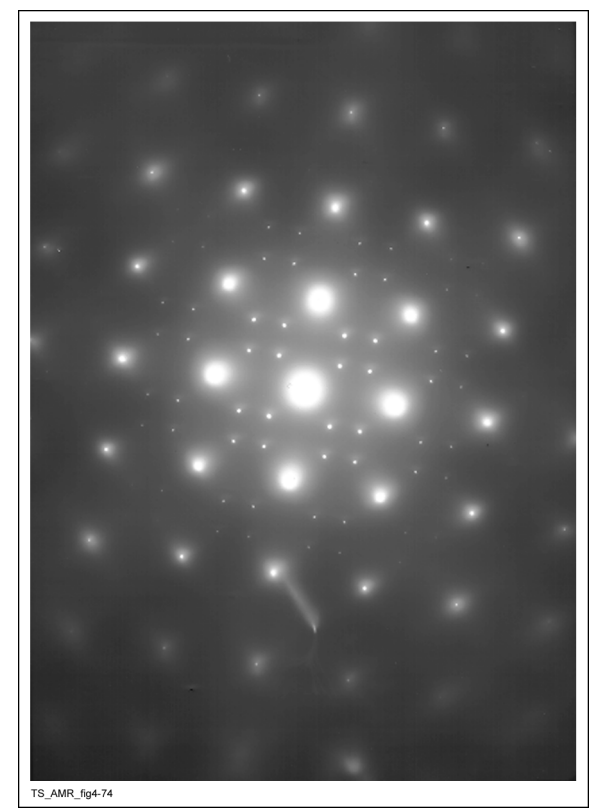

Source: DTN: LL010107712251.012 [DIRS 155299].

NOTE: The faint superlattice reflections are due to LRO (TS369-003a, Image 1483, 12/16/98, SN-LLNL-SCI-393, pp. 61 to 65$)$.

Figure 47. SAD Pattern from the Area Shown in Figure 45

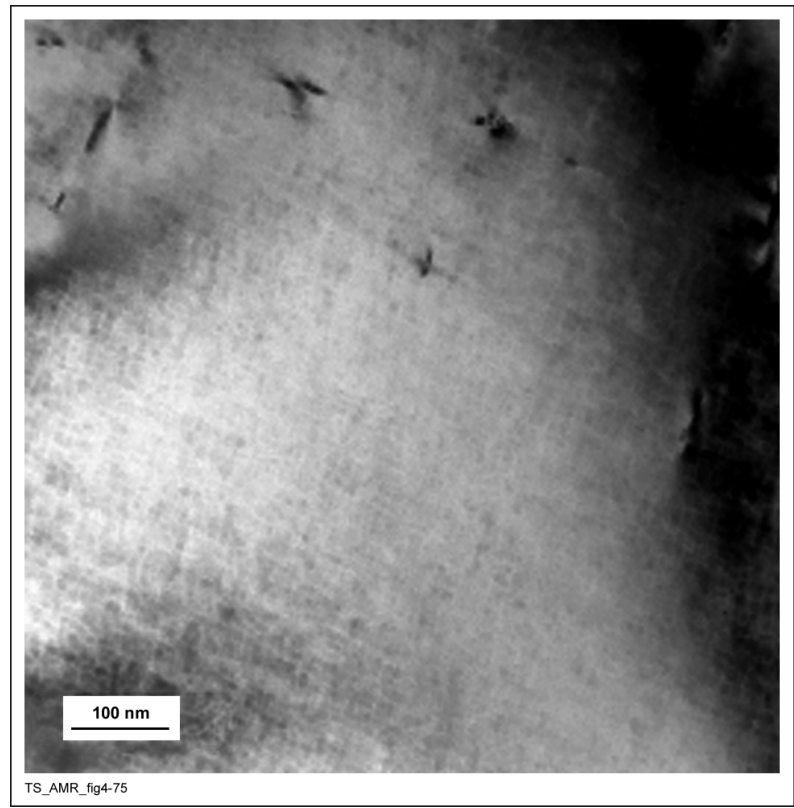

Source: DTN: LL030301612251.040 [DIRS 162691].

NOTE: (TS369-005a base metal, Image 1354, 3/20/98, SN-LLNL-SCI-369, p. 132) Bright field image from base-metal region of sample TS369-005a.

Figure 48. TEM Micrograph from the Base Metal of an Alloy 22 Weld Sample Aged for 40,000 Hours at $427^{\circ} \mathrm{C}$ 


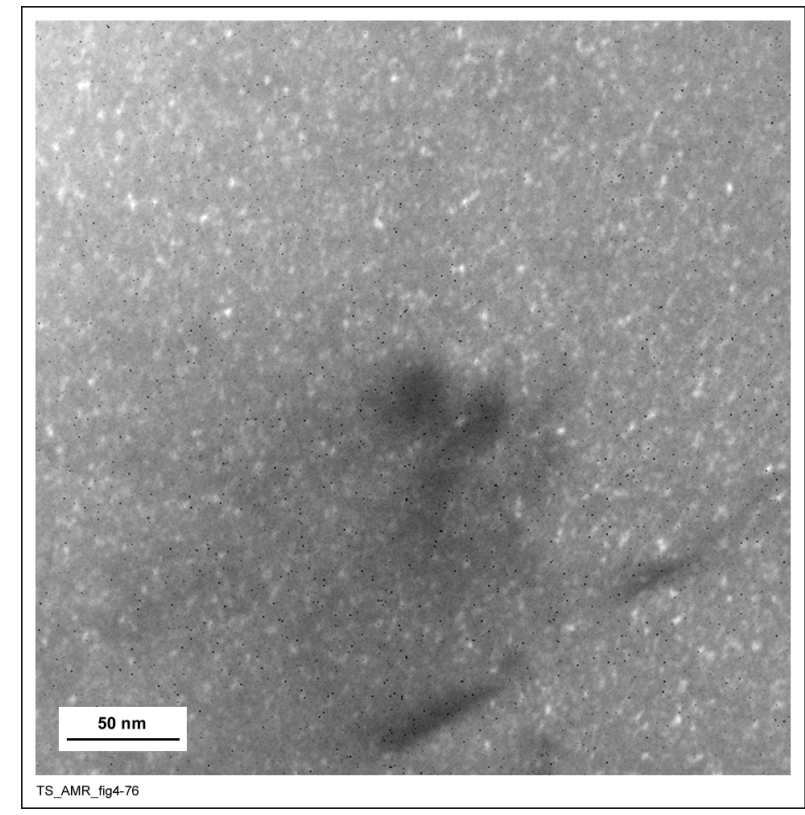

Source: DTN: LL030301612251.040 [DIRS 162691].

NOTE: One or more variants of the ordered domains appears light (TS369-005a base metal, Image 1356, 3/20/98, SN-LLNL-SCl-369, p. 133). White spots are ordered precipitates.

Figure 49. Dark-Field Image from $1 / 3<220>$ Reflection

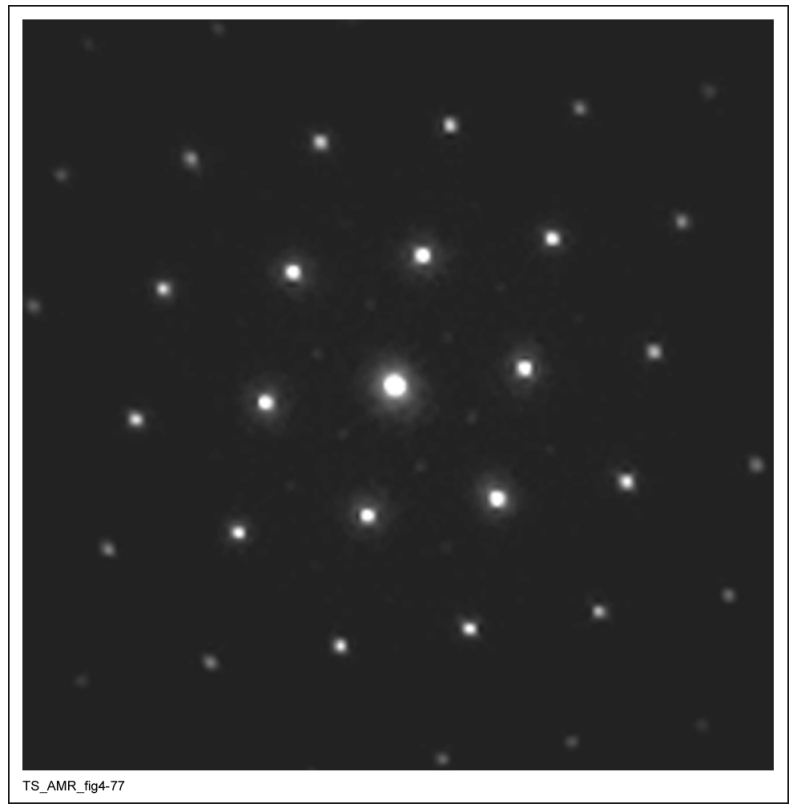

Source: DTN: LL030301612251.040 [DIRS 162691].

NOTE: The faint superlattice reflections are due to LRO (TS369-005a base metal, Image 1353, 3/20/98, SN-LLNL-SCI-369, p. 131). The faint spots occur at $1 / 3$ and $2 / 3<220>$.

Figure 50. SAD Pattern from the Area Shown in Figure 48, Typical fcc $<110>$ Zone Axis 


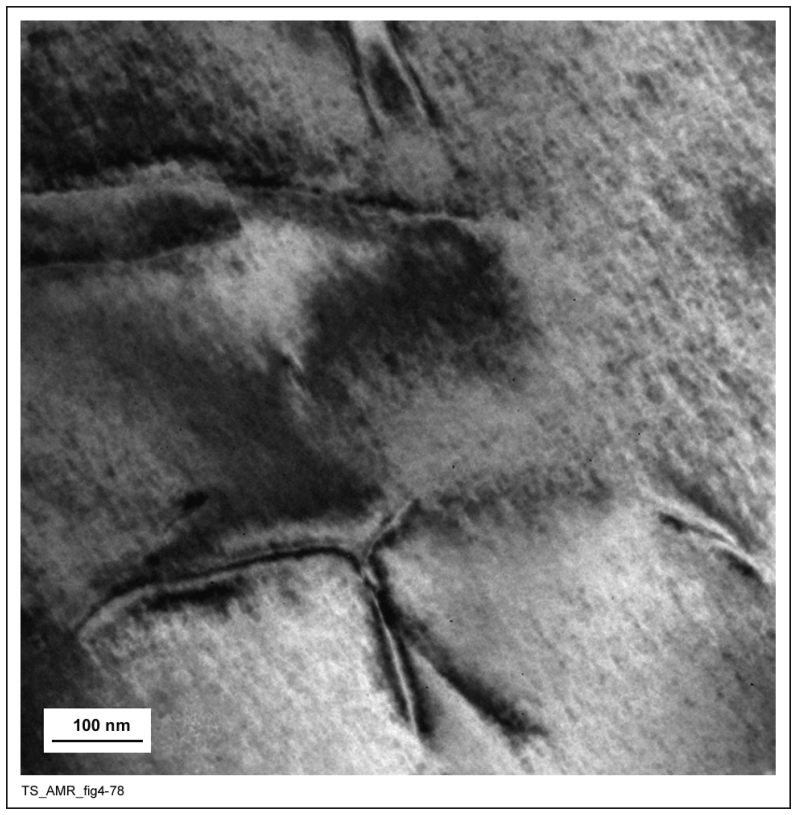

Source: DTN: LL030301612251.040 [DIRS 162691].

NOTE: (TS369-005a weld metal, Image 1371, 5/21/98, SN-LLNL-SCI-393, p. 26).

Figure 51. TEM Micrograph from the Weld Metal of an Alloy 22 Multipass, Double-V GTAW Weld with Matching Filler Metal Aged for 40,000 Hours at $427^{\circ} \mathrm{C}$

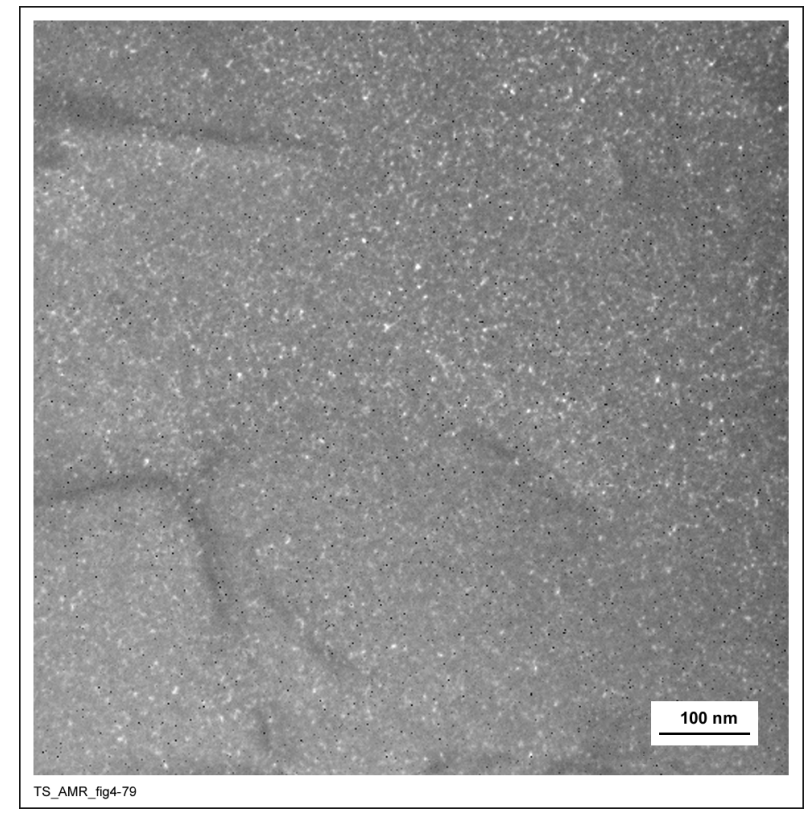

Source: DTN: LL030301612251.040 [DIRS 162691].

NOTE: The faint white regions are ordered domains (TS369-005a weld metal, Image 1372, 5/21/98, $\mathrm{SN}-\mathrm{LLNL}-\mathrm{SCl}-393$, p. 26). White spots are $\mathrm{Ni}_{2}(\mathrm{Cr}, \mathrm{Mo})$ precipitates.

Figure 52. Dark-Field Image Corresponding to Figure 51 


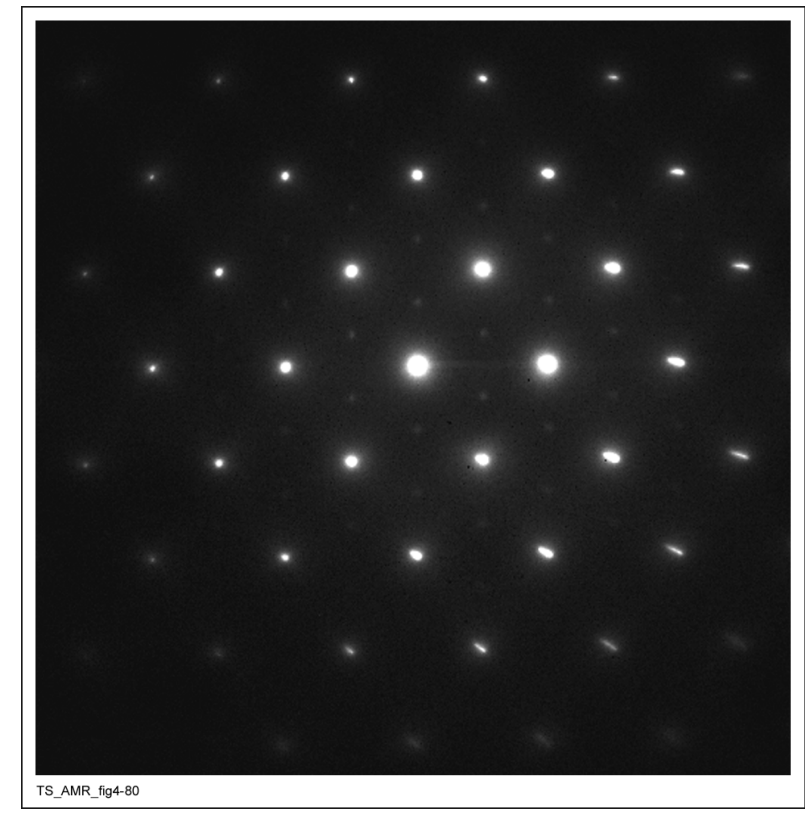

Source: DTN: LL030301612251.040 [DIRS 162691].

NOTE: The faint superlattice reflections indicate that ordering has occurred (TS369-005a weld metal, Image 1370, 5/21/98, SN-LLNL-SCl-393, p. 25).

Figure 53. SAD Pattern from the Area Shown in Figure 51

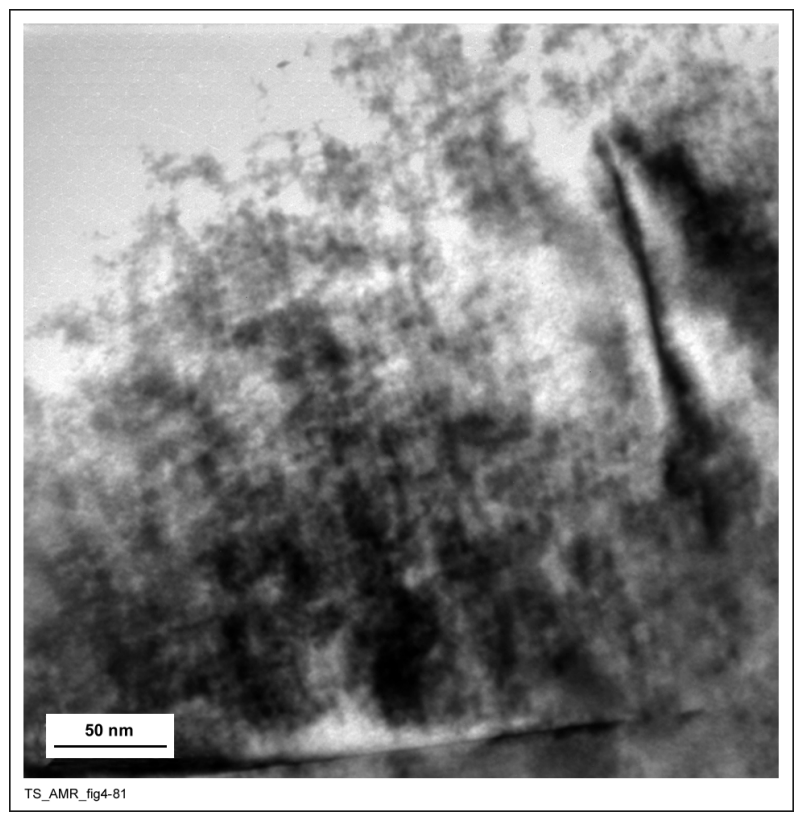

Source: DTN: LL030301612251.040 [DIRS 162691].

NOTE: (TS369-005a HAZ, Image 1379, 5/22/98, SN-LLNL-SCI-393, p. 38).

Figure 54. TEM Micrograph from the HAZ of the Alloy 22 Multipass, Double-V GTAW Weld with Matching Filler Metal Aged for 40,000 Hours at $427^{\circ} \mathrm{C}$ 


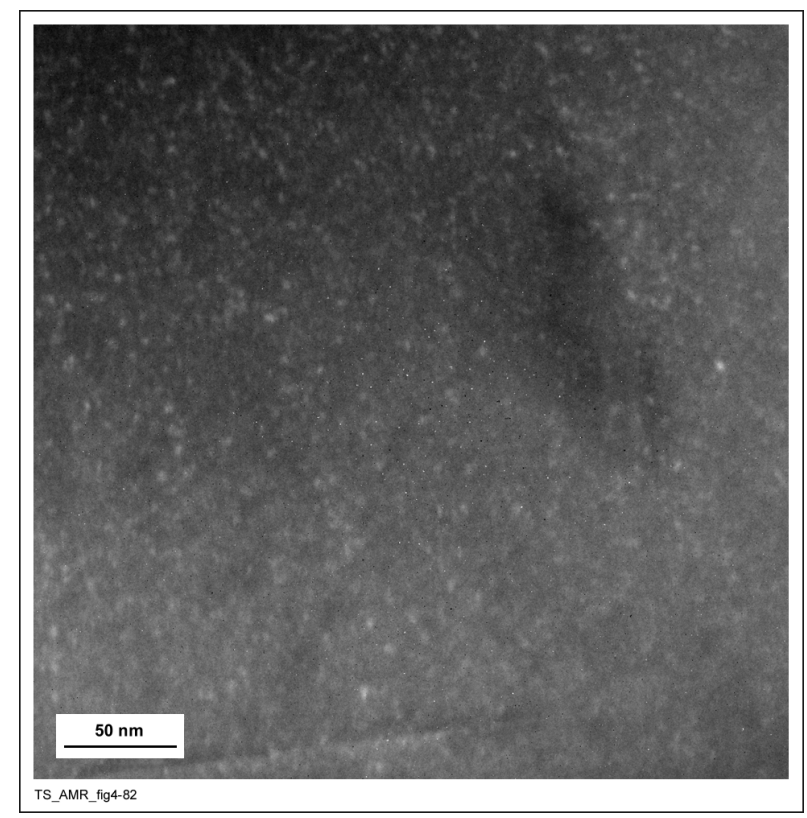

Source: DTN: LL030301612251.040 [DIRS 162691].

NOTE: The faint white regions are ordered domains (TS369-005a HAZ, Image 1380, 5/22/98, SN-LLNL-SCI-393, p. 39).

Figure 55. Dark-Field Image Corresponding to Figure 54, Taken from One of the $1 / 3<220>$ Reflections Shown in Figure 56

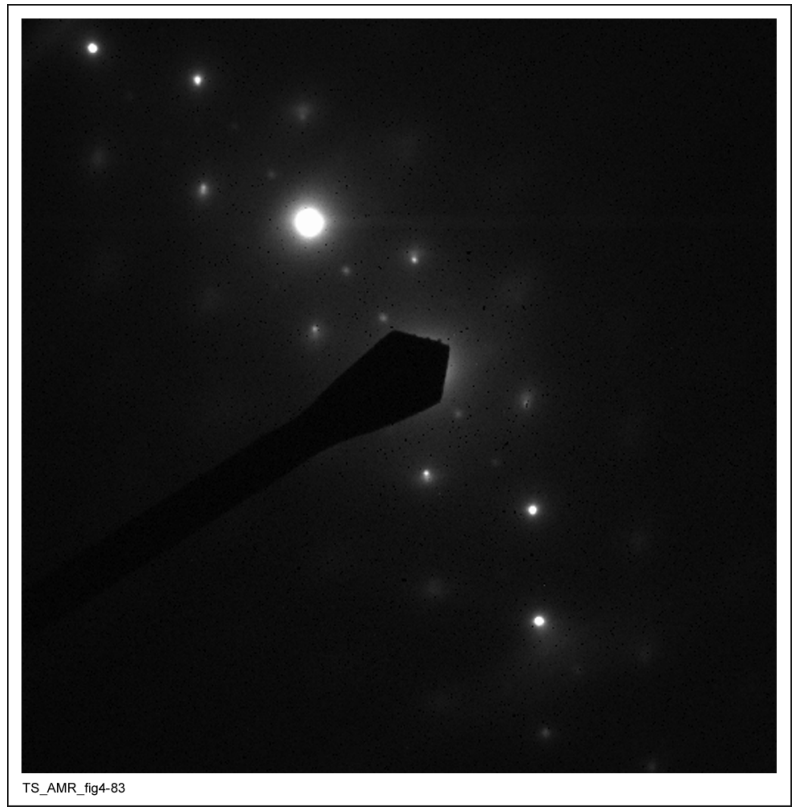

Source: DTN: LL030301612251.040 [DIRS 162691].

NOTE: The faint superlattice reflections are due to LRO (TS369-005a HAZ, Image 1381, 5/22/98, SN-LLNL-SCI-393, p. 39).

Figure 56. SAD Pattern from the Area Shown in Figure 54, Showing $1 / 3<220>$ Superlattice Reflections 


\subsubsection{SEM Micrographs Used for Quantification of Phases and LRO}

This section shows an example of a SEM micrograph used to quantify phases present at the onset of LRO. Figure 57 shows evidence of the onset of LRO (right-hand side of image) in base metal aged at $550^{\circ} \mathrm{C}$ for 21,052 hours. In addition, the Mo-rich $\mu$ and $\mathrm{P}$ phases are evident at the boundary (white areas).

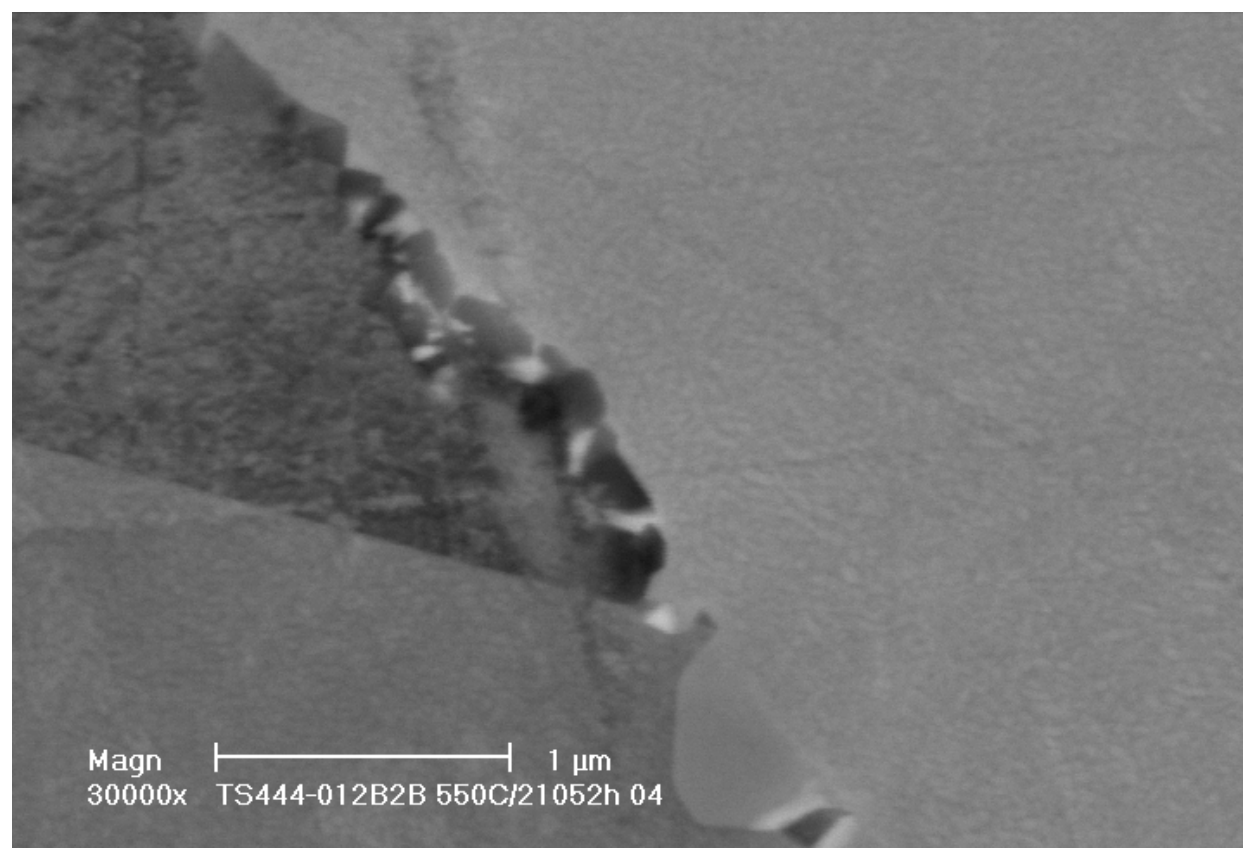

Source: DTN: LL030104212251.012 [DIRS 162009].

NOTE: Mo-rich $\mu$ and $P$ phases are also evident at interface (Sample No. TS444-012B2B).

Figure 57. Base Metal Aged at $550^{\circ} \mathrm{C}$ for 21,052 Hours and Exhibits Ordered Matrix in Right-Hand Region

\subsubsection{SEM Micrographs Showing Bulk Precipitation in Base Metal}

The micrographs in this section (Figure 58 through Figure 65) are representative of SEM micrographs that are used as input to determine area-fraction coverage in the bulk matrix of base metal as a function of time and temperature. The software package, Image-Pro Plus, analyzes the micrographs to determine area-fraction coverage. The volume fraction of precipitates (as function of time and temperature) is equivalent to the area-fraction measurement (Section 6.6.3) (Vander Voort 2000 [DIRS 161300], Hilliard and Cahn 1961 [DIRS 161454]). The area-fraction measurements on base metal are presented in Table 9. 


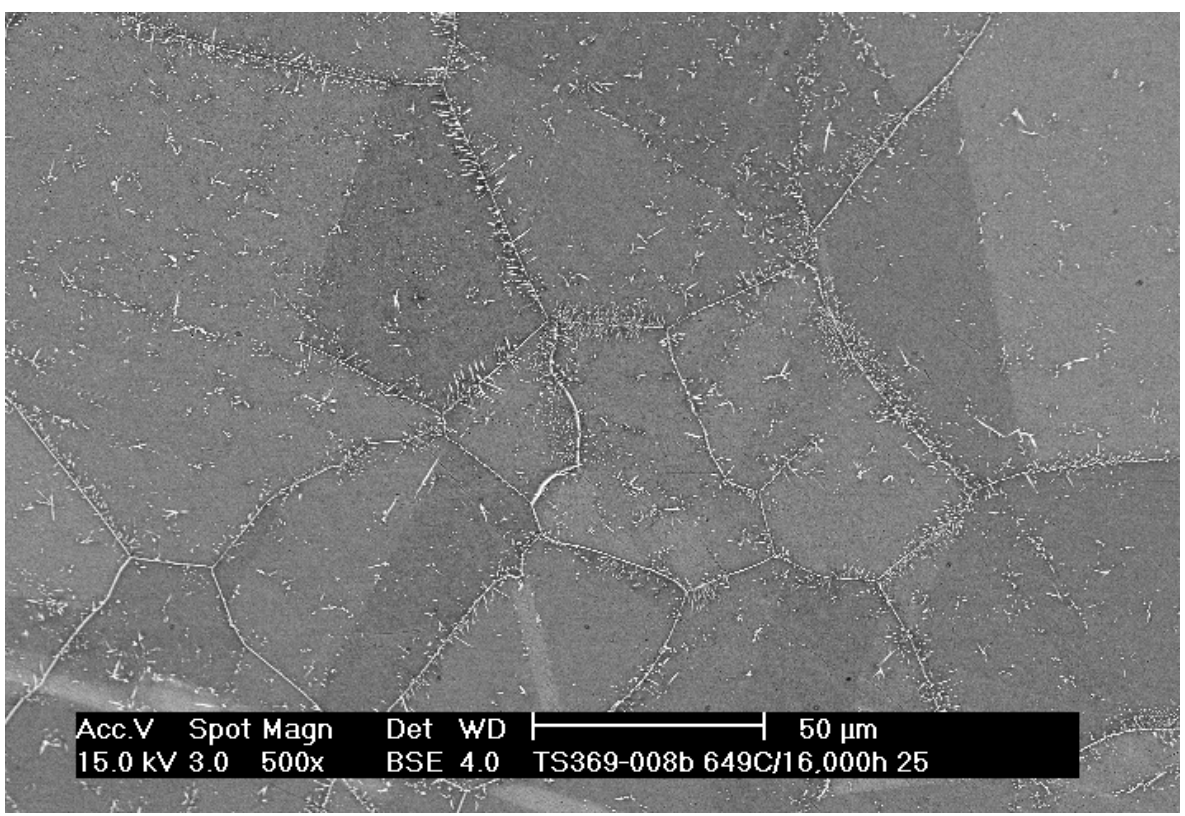

Source: DTN: LL030103712251.007 [DIRS 163014].

NOTE: $\quad$ Precipitates in the bulk matrix are noticeable (Sample No. TS369-008b).

Figure 58. Base Metal aged at $649^{\circ} \mathrm{C}$ for 16,000 Hours

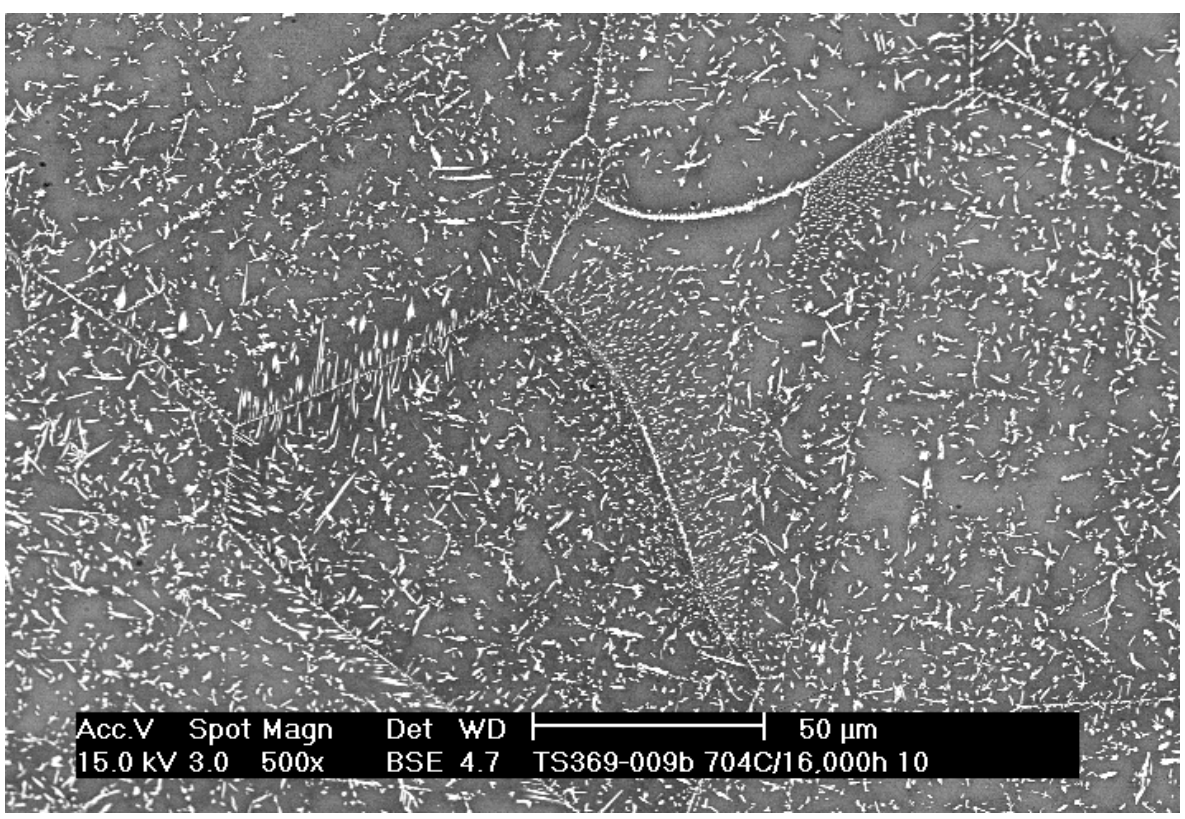

Source: DTN: LL030103712251.007 [DIRS 163014].

NOTE: Due to higher temperature, precipitation in the bulk matrix is more pronounced than shown in Figure 58 (Sample No. TS369-009b).

Figure 59. Base Metal Aged at $704^{\circ} \mathrm{C}$ for 16,000 Hours 


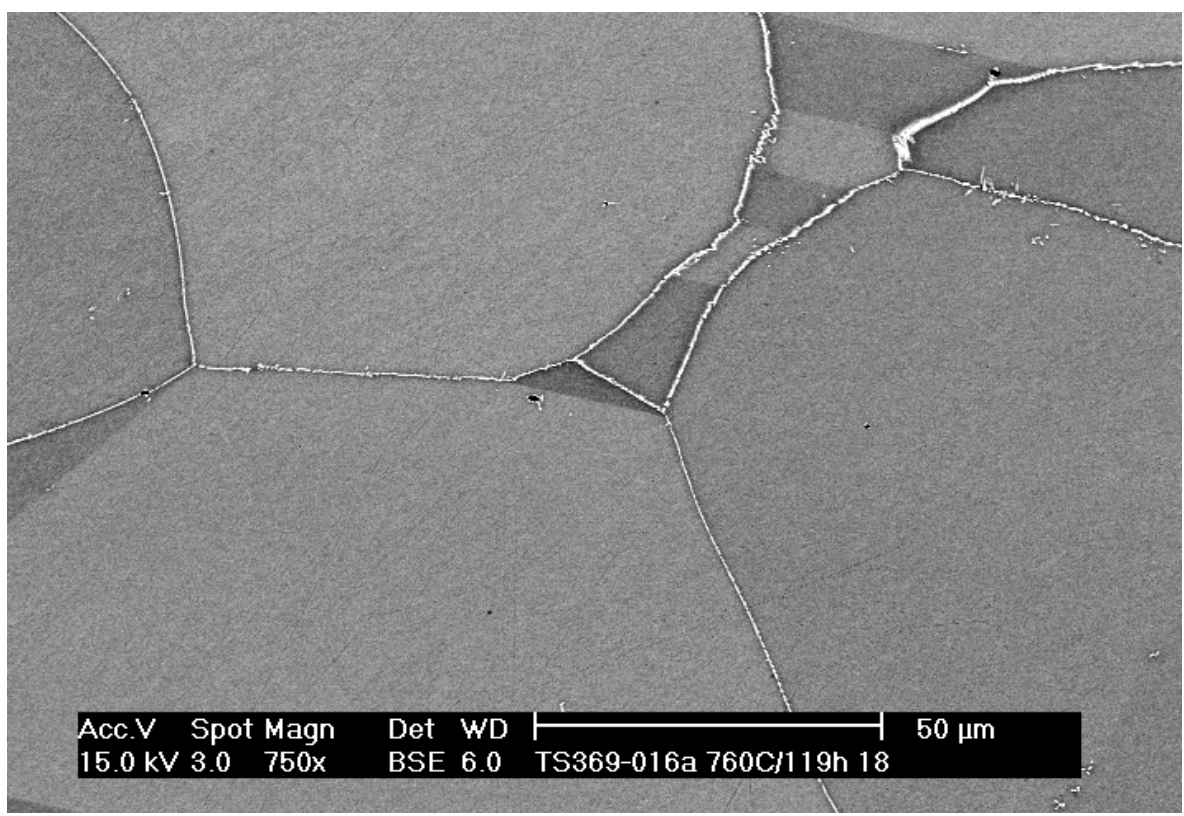

Source: DTN: LL030103712251.007 [DIRS 163014].

NOTE: Few precipitates in the bulk matrix are evident at this temperature after short time (Sample No. TS369 016a).

Figure 60. Base Metal Aged at $760^{\circ} \mathrm{C}$ for 119 Hours

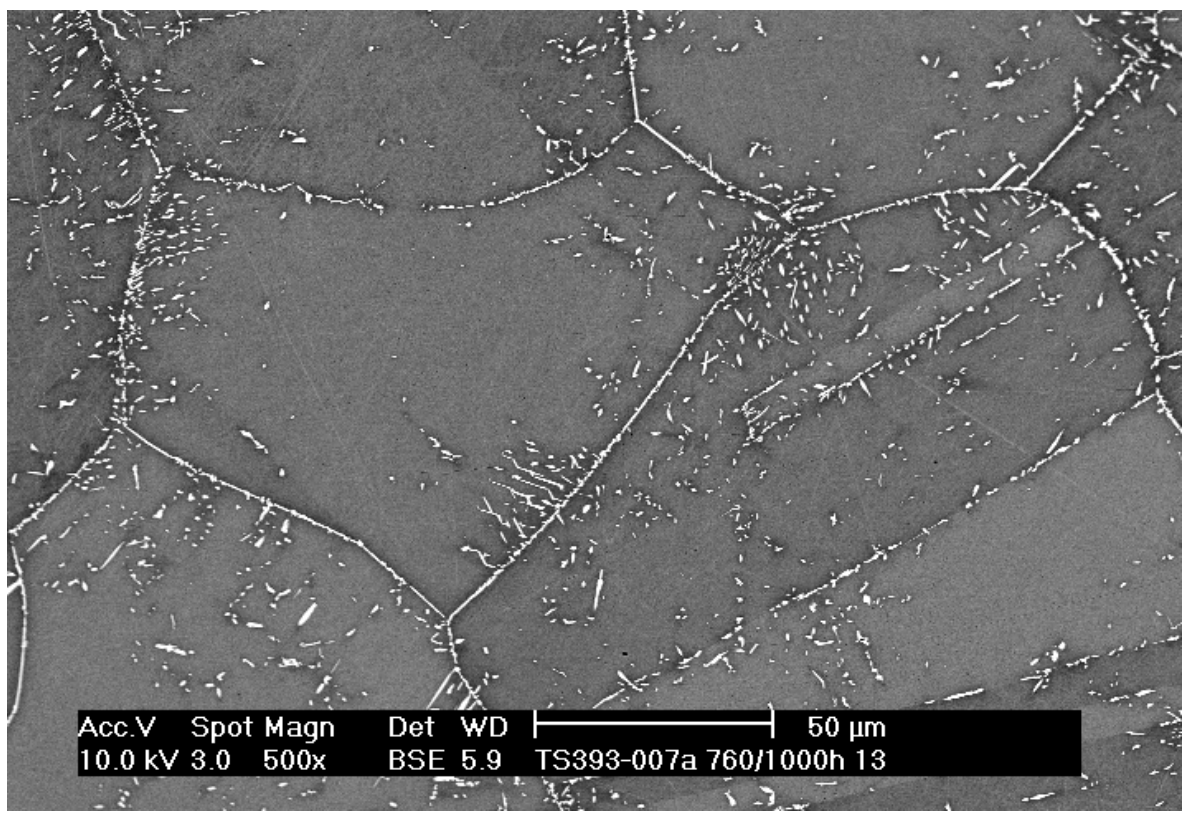

Source: DTN: LL030103712251.007 [DIRS 163014].

NOTE: More precipitation is evident after a longer aging time than was used as shown in Figure 60 (Sample No. TS393-007a).

Figure 61. Base Metal Aged at $760^{\circ} \mathrm{C}$ for 1,000 Hours 


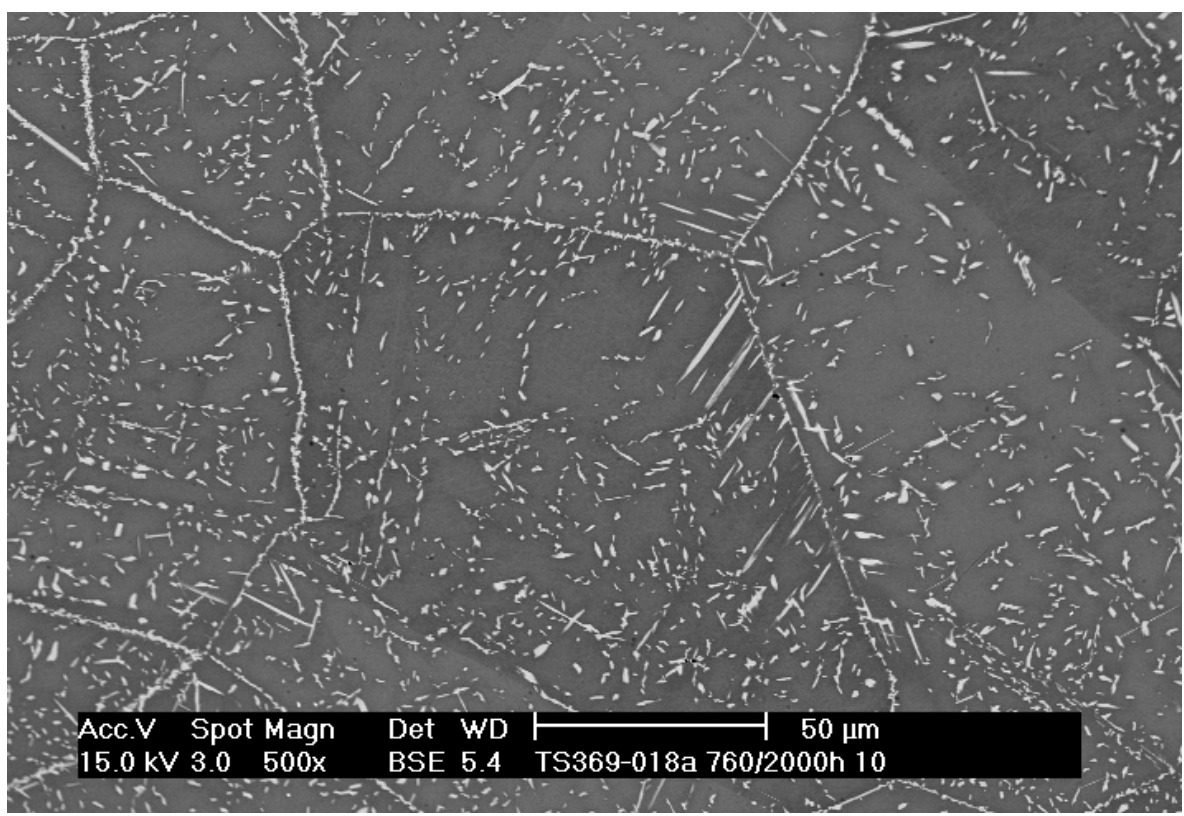

Source: DTN: LL030103712251.007 [DIRS 163014].

NOTE: Significant precipitation is evident in the bulk matrix at the longer aging time, as compared to that shown in Figure 61 (Sample No. TS369-018a).

Figure 62. Base Metal Aged at $760^{\circ} \mathrm{C}$ for 2,000 Hours

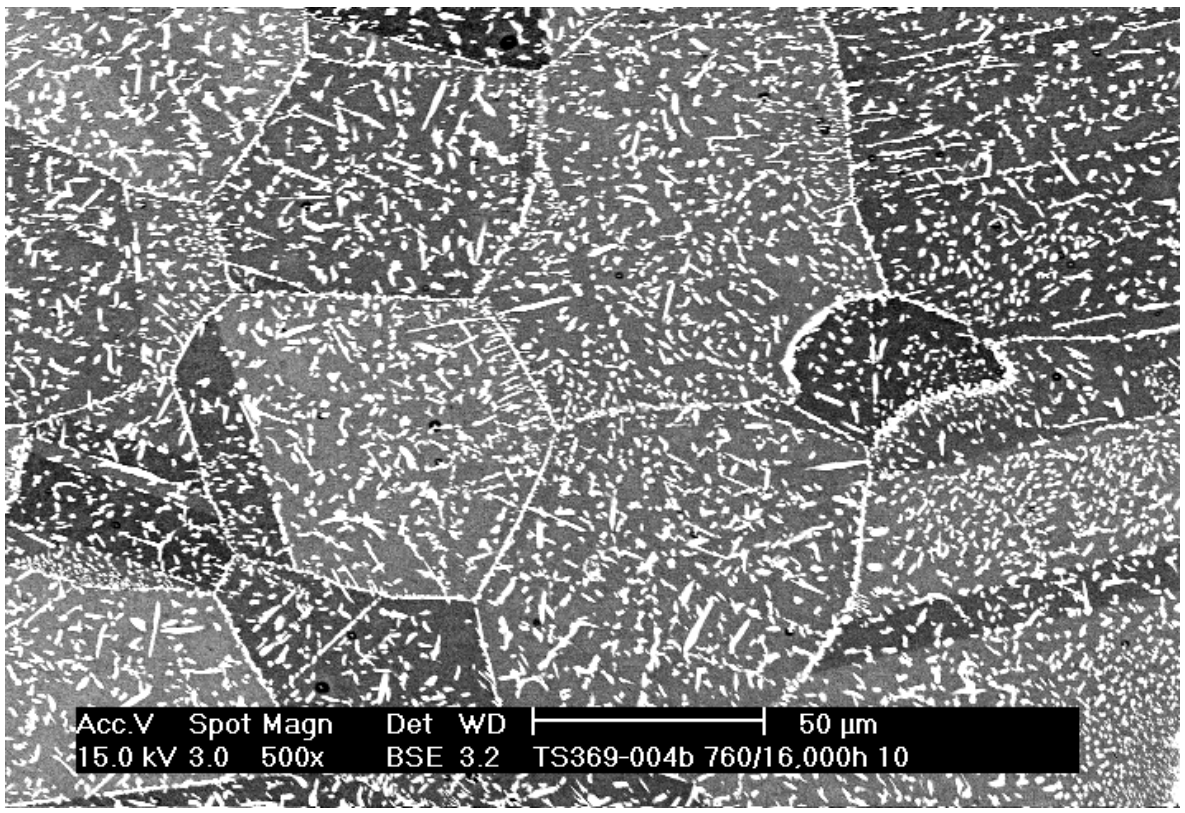

Source: DTN: LL030103712251.007 [DIRS 163014].

NOTE: Precipitation is extensive in the bulk matrix at this temperature and long aging time (Sample No. TS369-004b).

Figure 63. Base Metal Aged at $760^{\circ} \mathrm{C}$ for 16,000 Hours 


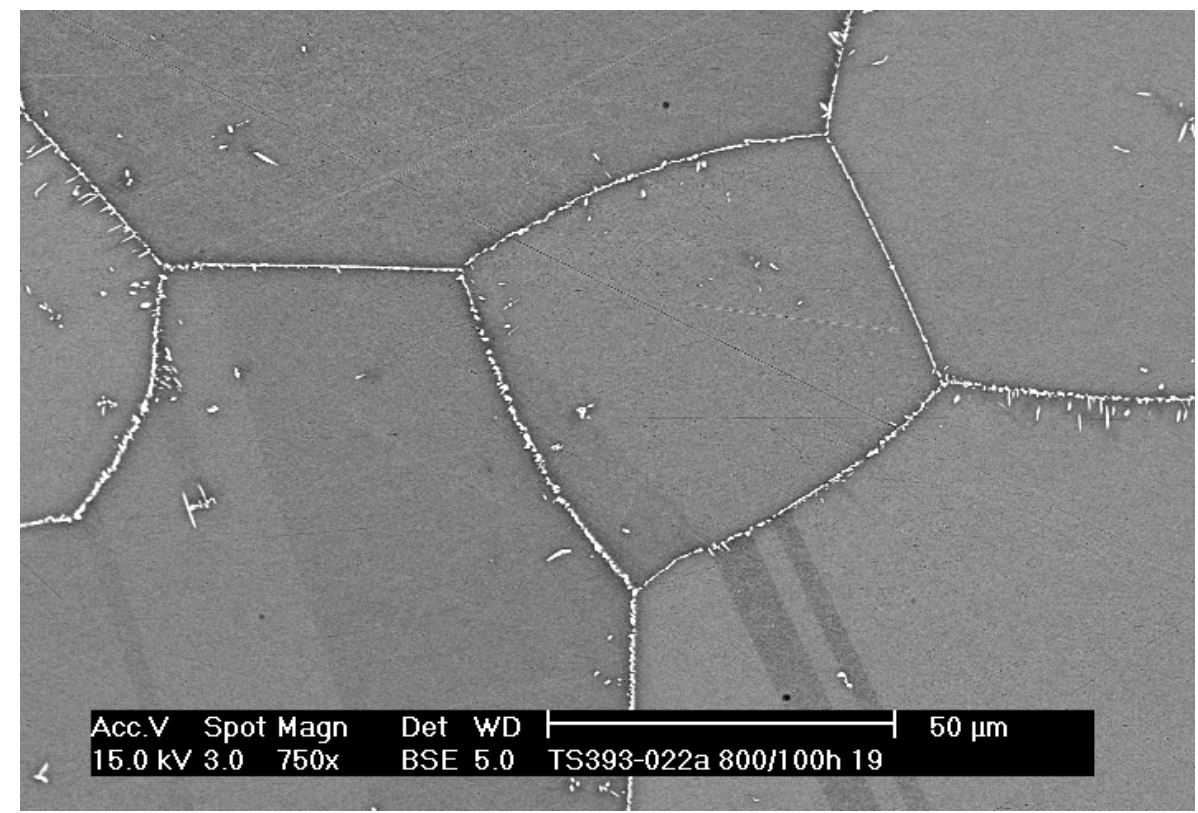

Source: DTN: LL030103712251.007 [DIRS 163014].

NOTE: Precipitation in the bulk matrix is minimal at this high temperature, but short aging time (Sample No. TS393-022a).

Figure 64. Base Metal Aged at $800^{\circ} \mathrm{C}$ for 100 Hours

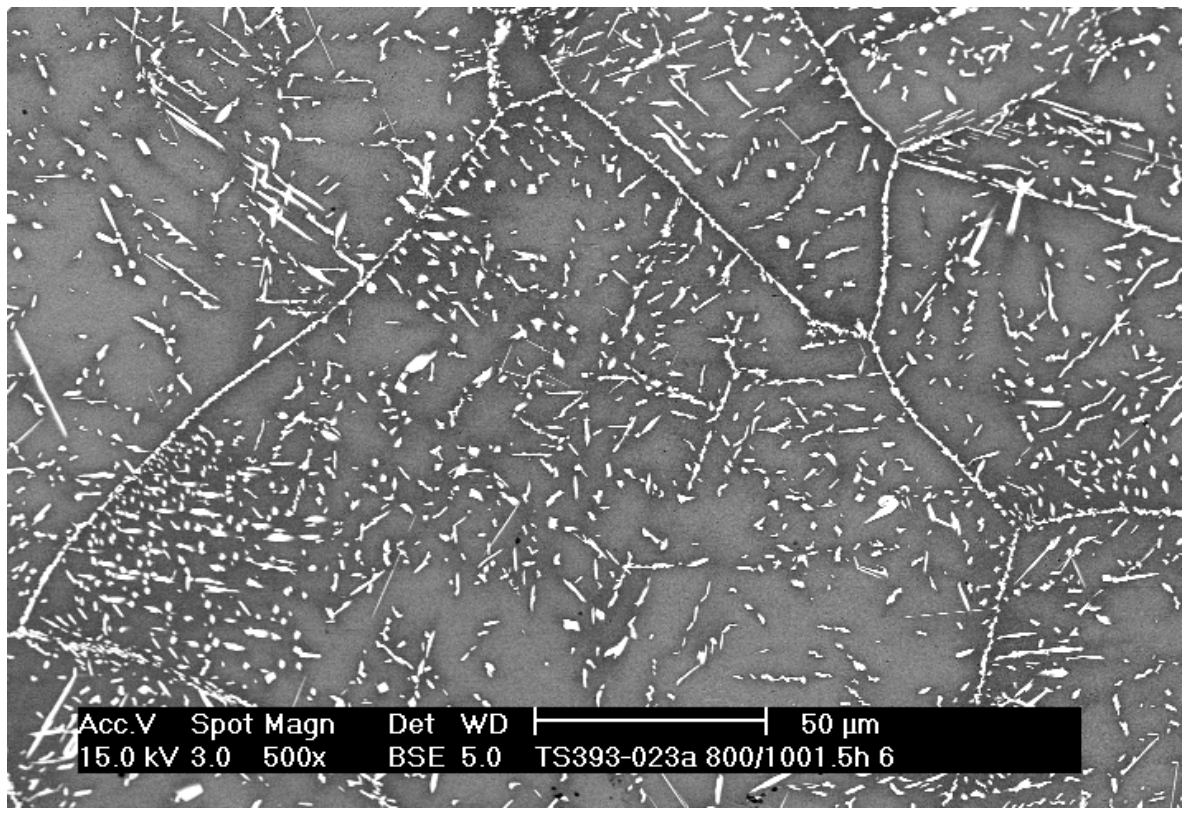

Source: DTN: LL030103712251.007 [DIRS 163014].

NOTE: Precipitation in the bulk matrix is more extensive at this temperature due to the longer aging time, as compared to that shown in Figure 64 (Sample No. TS393-023a).

Figure 65. Base Metal Aged at $800^{\circ} \mathrm{C}$ for 1,002 Hours 


\subsubsection{SEM Micrographs Showing Precipitation in Weld Metal}

Similar to the procedure described for base metal (Section 4.1.6), the micrographs in this section (Figure 66 through Figure 73) are representative of SEM micrographs that are used as input to determine area-fraction coverage in the weld metal as a function of time and temperature. Again, the software package Image-Pro Plus analyzes the micrographs to determine area coverage. The volume fraction of precipitates (as function of time and temperature) is equivalent to the area-fraction measurement (Section 6.6.3) (Vander Voort 2000 [DIRS 161300], Hilliard and Cahn 1961 [DIRS 161454]). The area-fraction measurements on weld metal are presented in Table 4.

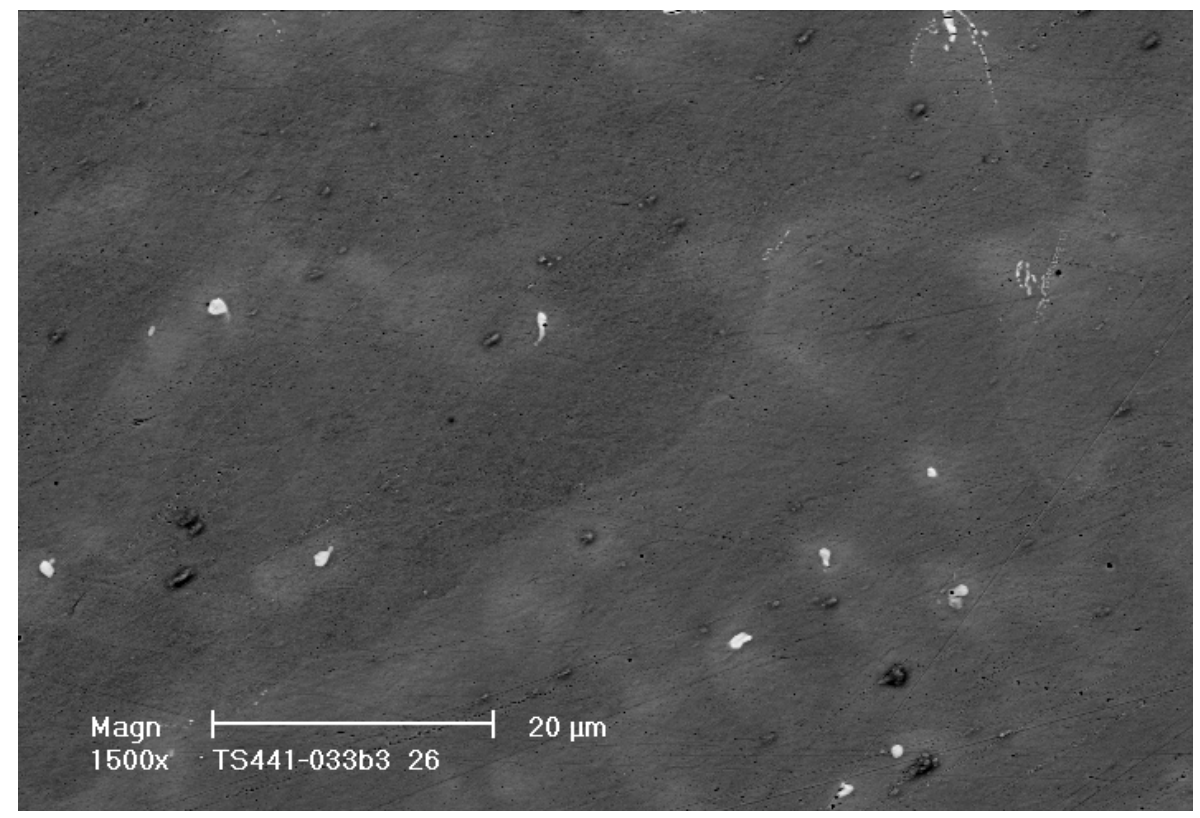

Source: DTN: LL021009912251.003 [DIRS 163013].

NOTE: (Sample No. TS441-033b3).

Figure 66. Weld Metal, As-Welded Condition 


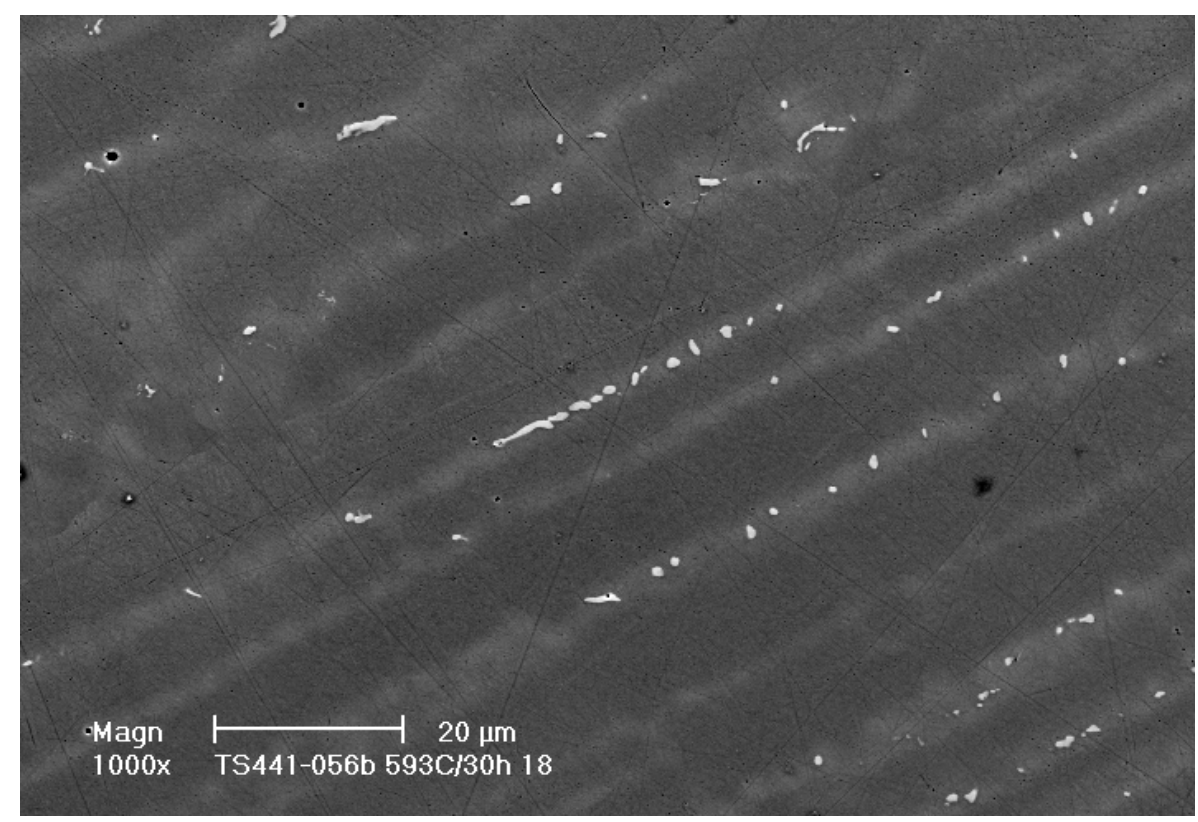

Source: DTN: LL021009912251.003 [DIRS 163013].

NOTE: A minimal amount of precipitates are noticeable along the interdendritic regions (Sample No. TS441-056b).

Figure 67. Weld Metal Aged at $593^{\circ} \mathrm{C}$ for 30 Hours

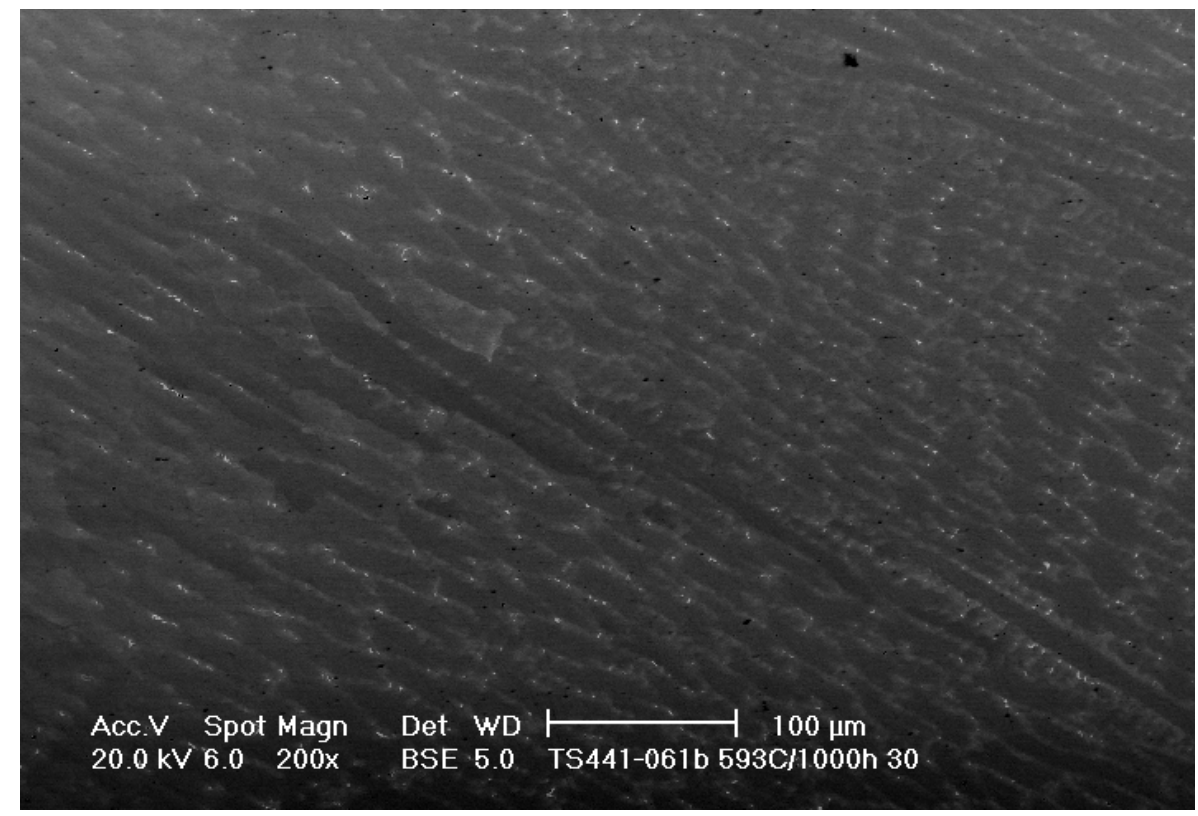

Source: DTN: LL030104212251.012 [DIRS 162009].

NOTE: Using a lower magnification, a minimal amount of precipitation can be seen to align with the interdendritic regions (Sample No. TS441-061b).

Figure 68. Weld Metal Aged at $593^{\circ} \mathrm{C}$ for 1,000 Hours 


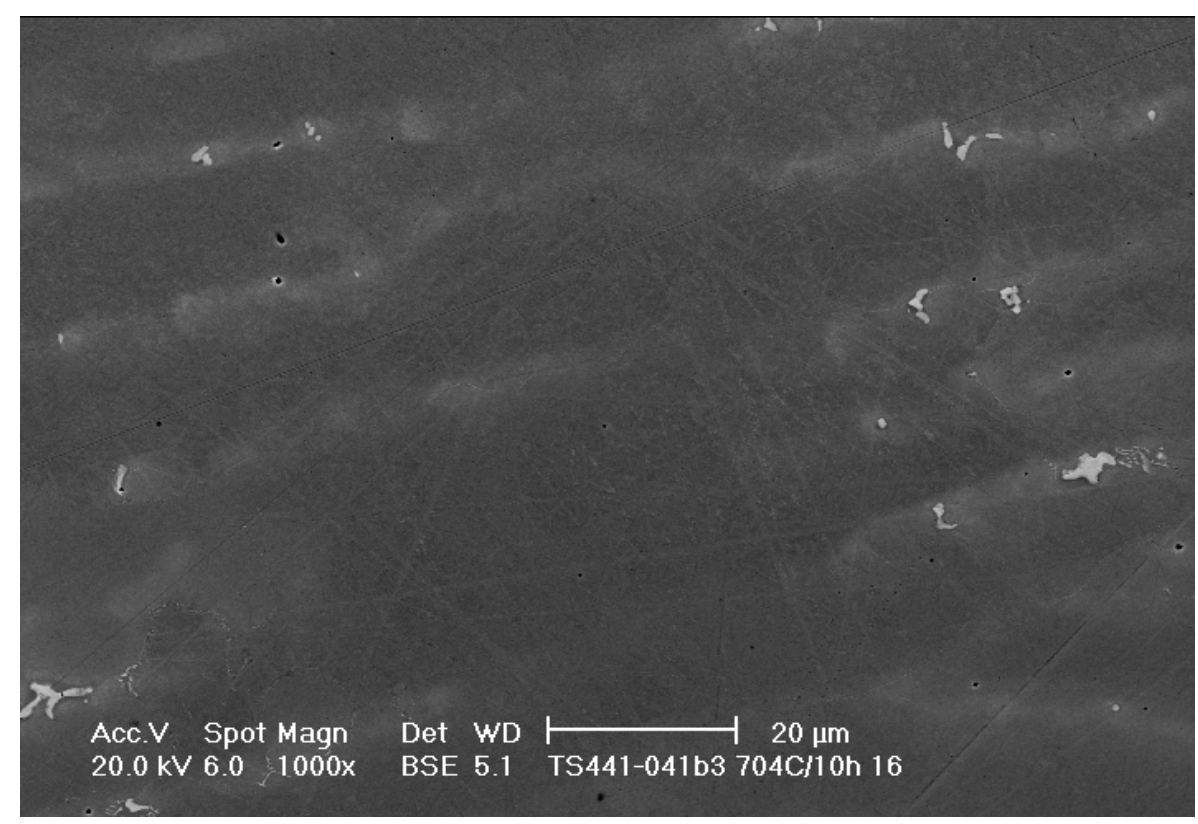

Source: DTN: LL021009912251.003 [DIRS 163013].

NOTE: Due to higher temperature, precipitates are evident in the weld metal (Sample No. TS441-041b3).

Figure 69. Weld Metal Aged at $704^{\circ} \mathrm{C}$ for 10 Hours

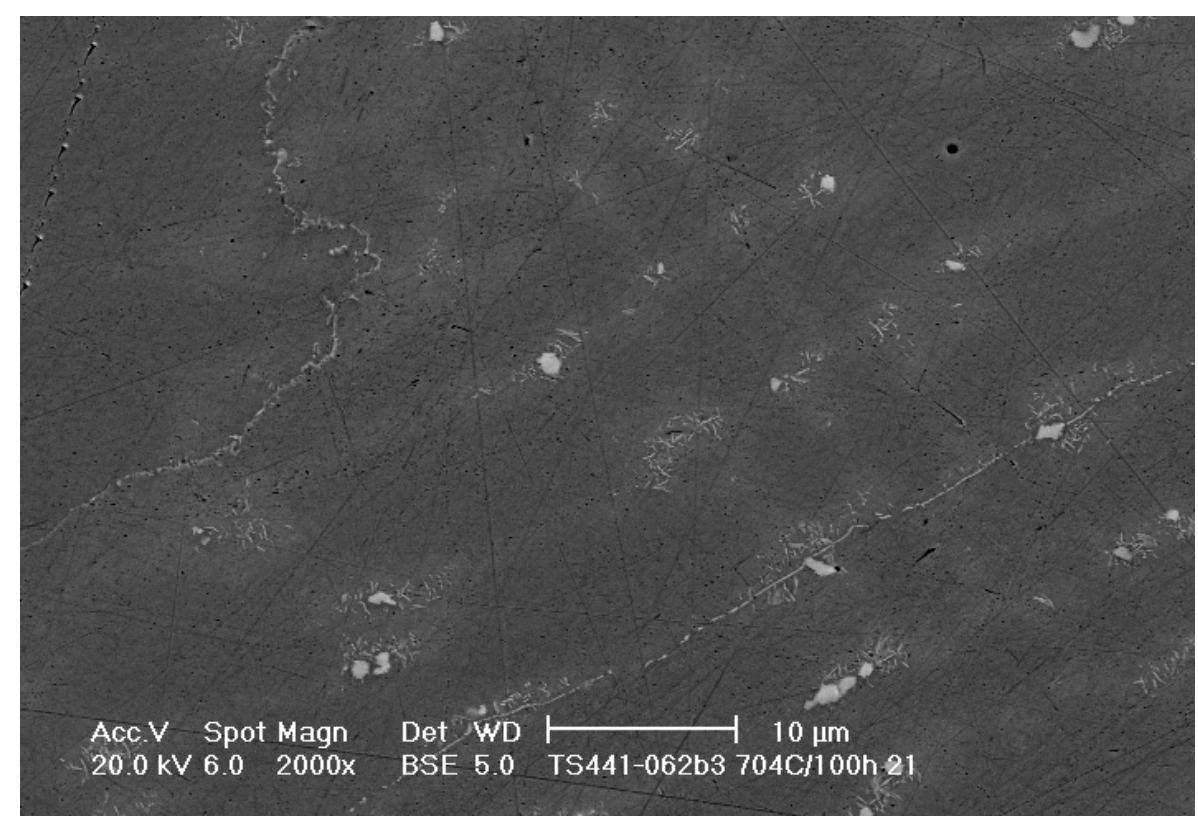

Source: DTN: LL021009912251.003 [DIRS 163013].

NOTE: Due to longer aging time, precipitation along the interdendritic regions is more evident (Sample No. TS441-062b3).

Figure 70 . Weld Metal Aged at $704^{\circ} \mathrm{C}$ for 100 Hours 


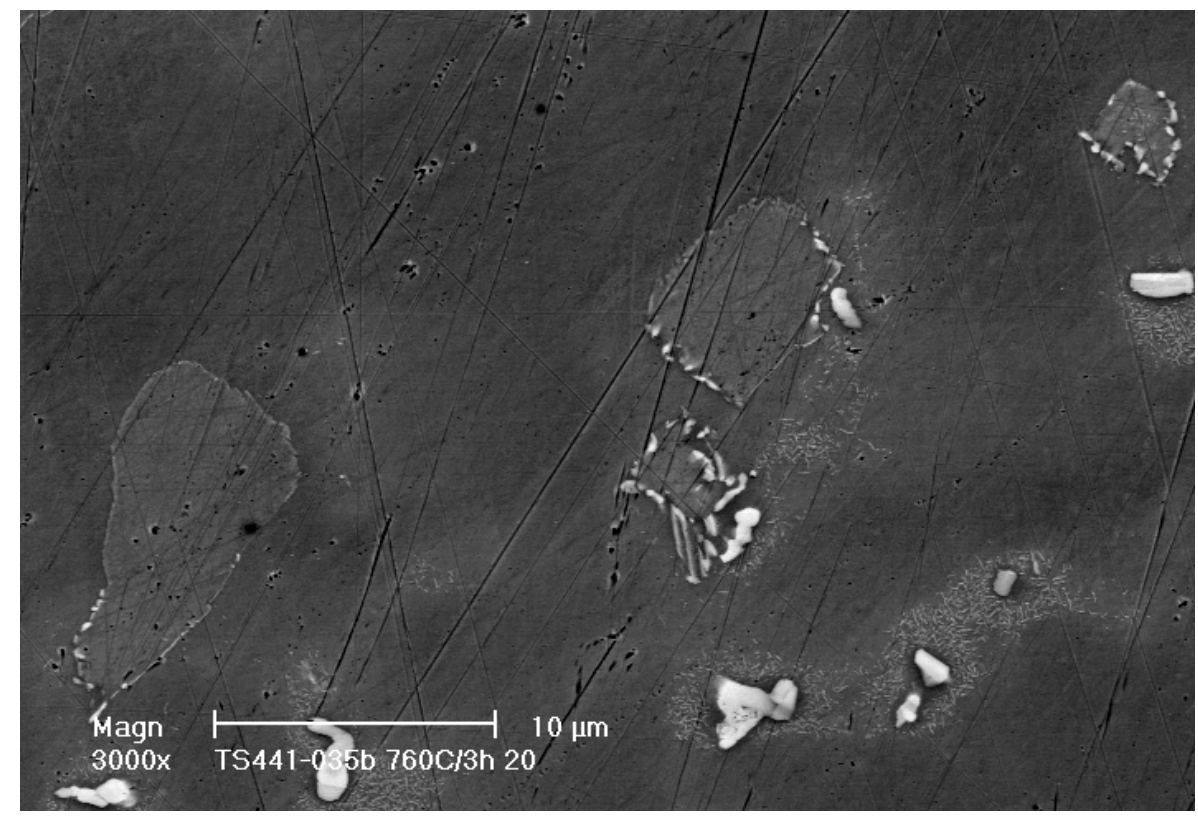

Source: DTN: LL021009912251.003 [DIRS 163013].

NOTE: Close-up micrograph of precipitates evident in weld metal at this higher temperature (Sample No. TS441-035b).

Figure 71. Weld Metal Aged at $760^{\circ} \mathrm{C}$ for 3 Hours

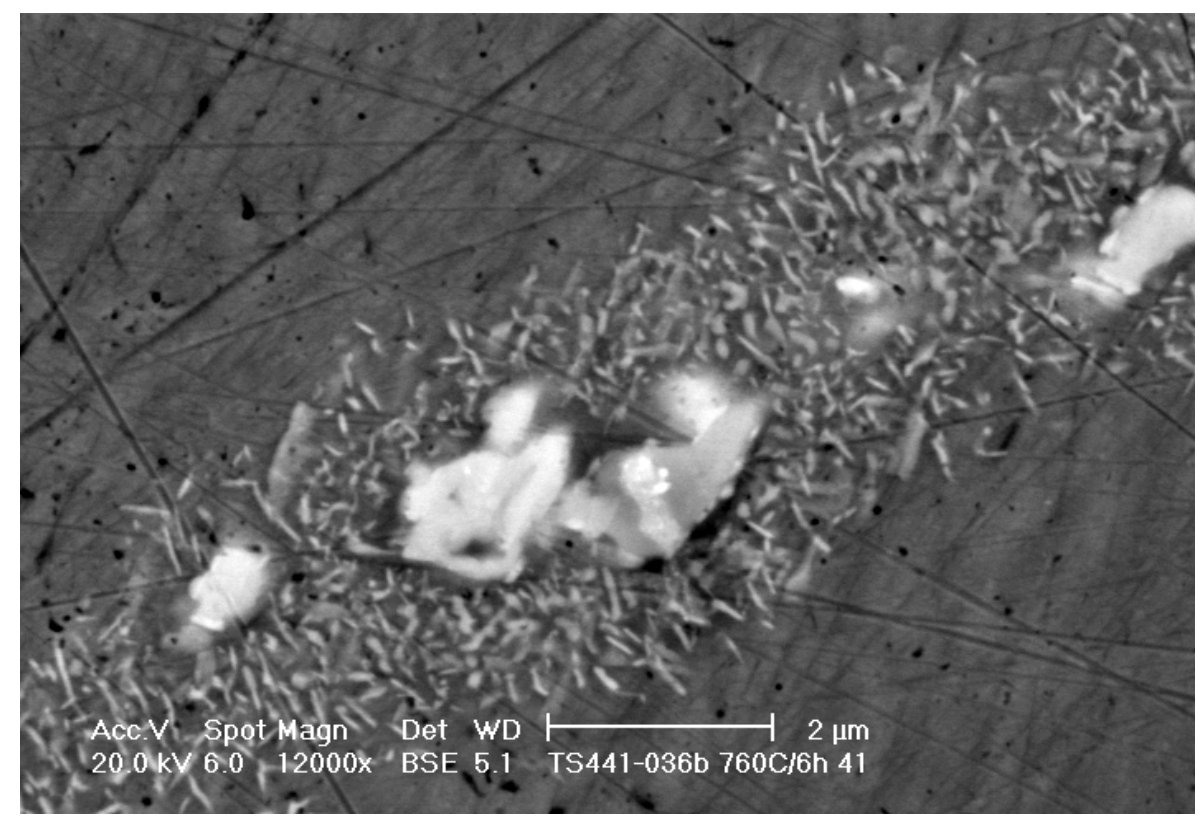

Source: DTN: LL030104212251.012 [DIRS 162009].

NOTE: High magnification image of precipitates formed at higher temperature in weld metal (Sample No. TS441-036b).

Figure 72. Weld Metal Aged at $760^{\circ} \mathrm{C}$ for 6 Hours 


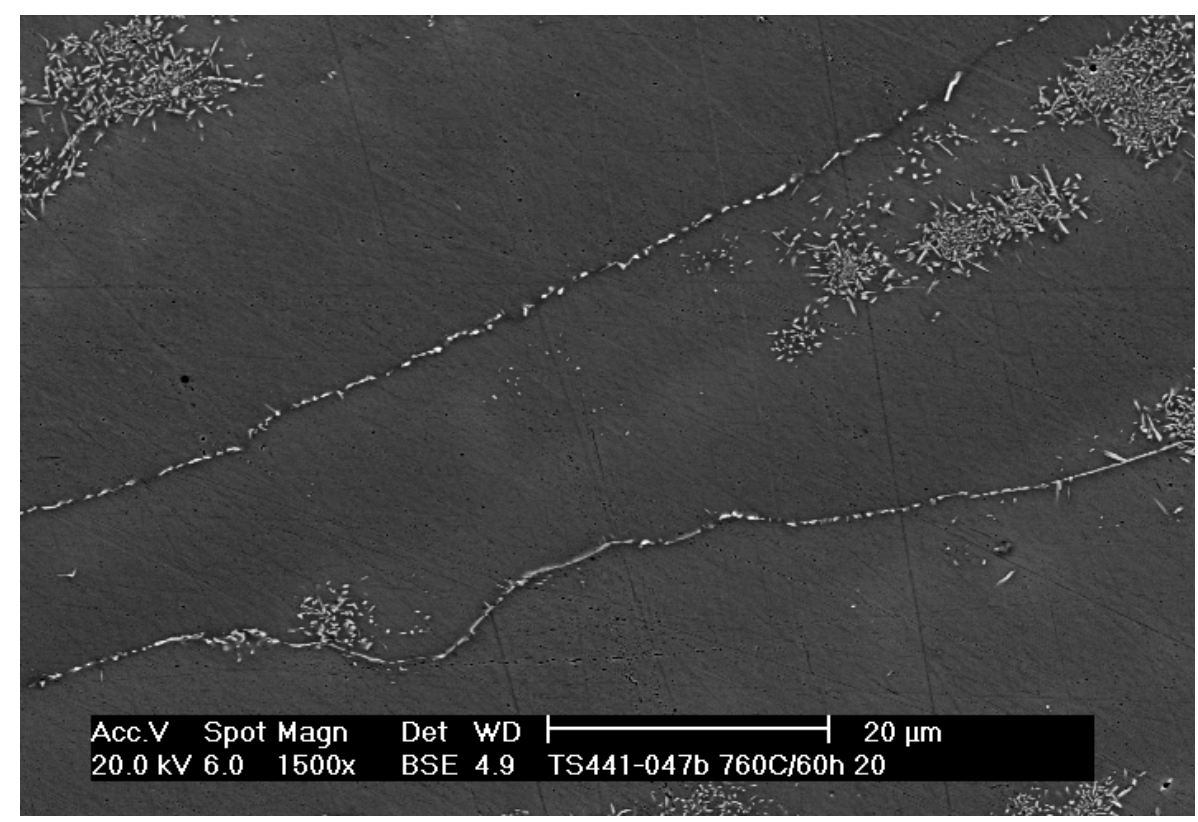

Source: DTN: LL021009912251.003 [DIRS 163013].

NOTE: At this temperature and longer aging time, the precipitates are shown to be more extensive and align along the interdendritic regions in the weld metal (Sample No. TS441-047b).

Figure 73. Weld Metal Aged at $760^{\circ} \mathrm{C}$ for 60 Hours

\subsubsection{Volume-Fraction Measurements}

Volume fraction measurements are used to determine the extent of phase precipitation as function of time and temperature. As a result, the volume fraction measurements are used as inputs to the aging and phase stability model to estimate phase precipitation along grain boundaries and in weld metal. The volume fraction data used in the aging and phase stability model for grain boundary coverage and weld metal are shown in Table 3 and Table 4 . Details of the volume-fraction measurements can be found in the scientific notebooks associated with DTNs: LL030104012251.010 [DIRS 162468] and LL030103612251.006 [DIRS 162012].

As mentioned previously, the micrographs shown in Sections 4.1.5 through 4.1 .7 are a representative sampling of the multitude of micrographs used for volume fraction measurements. As a result, there is not a direct correspondence between the representative micrographs and values shown in Table 3 and Table 4.

The standard deviations and 95\% confidence intervals are calculated per ASTM E 562-95 [DIRS 161301], Standard Test Method for Determining Volume Fraction by Systematic Manual Point Count. 
Table 3. Grain Boundary Precipitation Measurements (Grain Boundary Coverage Fraction)

\begin{tabular}{|c|c|c|c|c|}
\hline $\begin{array}{c}\text { Temperature } \\
\left({ }^{\circ} \mathbf{C}\right)\end{array}$ & $\begin{array}{c}\text { Time } \\
(\mathbf{h r})\end{array}$ & $\begin{array}{c}\text { Grain Boundary } \\
\text { Coverage Fraction }\end{array}$ & $\begin{array}{c}\text { Standard } \\
\text { Deviation }\end{array}$ & $\begin{array}{c}\text { 95\% Confidence } \\
\text { Interval }\end{array}$ \\
\hline 427 & 40,000 & 0 & 0 & 0 \\
\hline 649 & 6 & 0 & 0 & 0 \\
\hline 649 & 600 & 0.84 & 0.05 & 0.04 \\
\hline 704 & 10 & 0.5 & 0.13 & 0.07 \\
\hline 704 & 60 & 0.92 & 0.06 & 0.03 \\
\hline 760 & 0.5 & 0.51 & 0.16 & 0.085 \\
\hline 760 & 3 & 0.79 & 0.06 & 0.03 \\
\hline
\end{tabular}

Source: DTN: LL030104012251.010 [DIRS 162468]

Table 4. Precipitation Area-Fraction Measurements on Weld Metal

\begin{tabular}{|c|c|c|c|c|}
\hline $\begin{array}{c}\text { Temperature } \\
\left({ }^{\circ} \mathrm{C}\right)\end{array}$ & $\begin{array}{c}\text { Time } \\
\text { (hr) }\end{array}$ & $\begin{array}{c}\text { Area Fraction } \\
(\%)\end{array}$ & $\begin{array}{l}\text { Standard } \\
\text { Deviation }\end{array}$ & $\begin{array}{c}95 \% \text { Confidence } \\
\text { Interval }\end{array}$ \\
\hline As-Welded & 0 & 0.16 & 0.15 & 0.047 \\
\hline 593 & 30 & 0.24 & 0.27 & 0.091 \\
\hline 593 & 60 & 0.29 & 0.24 & 0.074 \\
\hline 593 & 100 & 0.21 & 0.21 & 0.060 \\
\hline 593 & 300 & 0.36 & 0.28 & 0.091 \\
\hline 593 & 600 & 0.28 & 0.21 & 0.063 \\
\hline 593 & 1,000 & 0.24 & 0.21 & 0.071 \\
\hline 649 & 10 & 0.24 & 0.24 & 0.077 \\
\hline 649 & 30 & 0.27 & 0.24 & 0.085 \\
\hline 649 & 60 & 0.17 & 0.23 & 0.092 \\
\hline 649 & 100 & 0.34 & 0.24 & 0.085 \\
\hline 649 & 300 & 1.27 & 0.92 & 0.268 \\
\hline 649 & 600 & 1.99 & 1.46 & 0.494 \\
\hline 704 & 3 & 0.21 & 0.27 & 0.081 \\
\hline 704 & 6 & 0.29 & 0.34 & 0.096 \\
\hline 704 & 10 & 0.26 & 0.18 & 0.073 \\
\hline 704 & 30 & 0.73 & 0.76 & 0.222 \\
\hline 704 & 60 & 1.01 & 0.76 & 0.243 \\
\hline 704 & 100 & 2.64 & 2.03 & 0.718 \\
\hline 760 & 1 & 0.21 & 0.22 & 0.072 \\
\hline 760 & 3 & 0.69 & 0.63 & 0.190 \\
\hline 760 & 6 & 0.97 & 1.09 & 0.286 \\
\hline 760 & 10 & 1.10 & 0.87 & 0.341 \\
\hline 760 & 30 & 3.24 & 1.53 & 0.559 \\
\hline 760 & 60 & 4.17 & 1.3 & 0.467 \\
\hline 760 & 100 & 7.77 & 1.92 & 0.659 \\
\hline
\end{tabular}

Source: DTN: LL030103612251.006 [DIRS 162012]

NOTE: Confidence interval values rounded to three decimal places 
As expected, there is more uncertainty in the volume fraction measurements on specimens subjected to lower temperatures and/or shorter aging times. At lower temperatures or shorter aging times, the amount of TCP-phase precipitated can be very small, and as a result, the volume fraction measurements have been performed on minimally detectable levels of precipitates (near zero). Thus, it is not surprising that for lower temperatures or shorter aging times, the standard deviations would be large. As expected, the uncertainty is considerably reduced in measurements where significant amounts $(>5 \%)$ of precipitation have occurred. A more detailed discussion of uncertainty is given in Section 6.7.

\subsection{CRITERIA}

Technical Work Plan for: Regulatory Integration Modeling and Analysis of the Waste Form and Waste Package (BSC 2004 [DIRS 171583]) has identified the following acceptance criteria (AC) based on the requirements mentioned in Project Requirements Document (Curry et al. 2002 [DIRS 157916]) and Yucca Mountain Review Plan, Final Report (NRC 2003 [DIRS 163274]):

- Degradation of Engineered Barriers (NRC 2003 [DIRS 163274], Section 4.2.1.3.1.3; PRD-002/T-015).

Specific requirements include describing deterioration or degradation of engineered barriers and modeling degradation processes using data for performance assessment, including TSPA-LA. Consideration of uncertainties and variabilities in model parameters and alternative conceptual models are also required. To fulfill these requirements, the following acceptance criteria are identified in Technical Work Plan for: Regulatory Integration Modeling and Analysis of the Waste Form and Waste Package (BSC 2004 [DIRS 171583]):

\section{Description and Demonstration of Multiple Barriers Acceptance Criteria}

The following acceptance criteria are from Section 2.2.1.1.3 of Yucca Mountain Review Plan, Final Report (NRC 2003 [DIRS 163274]):

- Acceptance Criterion 1 - Identification of Barriers is Adequate

- Acceptance Criterion 2 - Description of Barrier Capability to Isolate Waste is Acceptable

- Acceptance Criterion 3 - Technical Basis for Barrier Capability is Adequately Presented.

\section{Degradation of Engineered Barriers}

The following acceptance criteria are from Section 2.2.1.3.1.3 of Yucca Mountain Review Plan, Final Report (NRC 2003 [DIRS 163274]):

- Acceptance Criterion 1 - System Description and Model Integration are Adequate

- Acceptance Criterion 2 - Data Are Sufficient for Model Justification 
- Acceptance Criterion 3 - Data Uncertainty is Characterized and Propagated through the Model Abstraction

- Acceptance Criterion 4 - Model Uncertainty is Characterized and Propagated Through the Model Abstraction

- Acceptance Criterion 5-Model Abstraction Output is Supported by Objective Comparisons.

\subsection{CODES AND STANDARDS}

The codes and standards applicable to this report are:

- Standard Specification for Low-Carbon Nickel-Molybdenum-Chromium, Low-Carbon Nickel-Chromium-Molybdenum, Low-Carbon Nickel-Chromium-Molybdenum-Copper, Low-Carbon Nickel-Chromium-Molybdenum-Tantalum, and Low-Carbon NickelChromium-Molybdenum-Tungsten Alloy Plate, Sheet, and Strip (ASTM B 575-99a [DIRS 147465])

- Standard Practice for Prediction of the Long-Term Behavior of Materials, Including Waste Forms, Used in Engineered Barrier Systems (EBS) for Geological Disposal of High-Level Radioactive Waste (ASTM C 1174-97 [DIRS 105725])

- Standard Test Method for Determining Volume Fraction by Systematic Manual Point Count (ASTM E 562-95 [DIRS 161301]). 


\section{ASSUMPTIONS}

\subsection{KINETICS THE SAME FOR THE TCP AND CARBIDE PHASES IN ALLOY 22}

The relative amounts of $\mu, \mathrm{P}, \sigma$, and carbide phases have not been quantified; therefore, the kinetics of formation of these phases cannot be calculated independently at this time. It is reasonable to assume that their rates of formation are similar. This assumption is based on the following observations. The amounts of carbide and $\sigma$ phase tend to be low in the samples examined thus far. Therefore, the rates of formation of these phases are not likely to contribute significantly to the overall performance of the waste package outer barrier, nor are they likely to affect the transformation rates calculated based on volume fraction measurements, which include these phases in the total precipitate volume. The $\mu$ and P phases are very similar (Leonard 1969 [DIRS 104970], p. 225; Raghavan et al. 1982 [DIRS 146956], p. 983, Conclusions, point 2), and the rates at which they form are likely to be similar. It also appears that $\mathrm{P}$ phase is a precursor to $\mu$ phase (Leonard 1969 [DIRS 104970], p. 223, Figure 1). This would also explain why more $\mathrm{P}$ phase (relative to the amount of $\mu$ phase) has been observed at the lower temperatures than at the higher temperatures. If $\mathrm{P}$ phase is a precursor to $\mu$ phase, including the total amount of $\mathrm{P}+\mu$ as input to the kinetic model is appropriate. For the reasons described above, this assumption does not require confirmation. This assumption is used in the preliminary kinetic observations discussed in Section 6.3.1.

\subsection{TRANSFORMATION MECHANISMS OPERATING AT THE HIGHER TEMPERATURES INVESTIGATED ALSO OPERATE AT THE LOWER EXPECTED REPOSITORY TEMPERATURES}

For a waste package lifetime expected to be, at a minimum, 10,000 years, it is impossible to test directly in the laboratory the behavior of waste package outer barrier materials under expected repository conditions. The changes that may occur in these materials must be accelerated. For phase-stability studies, phase transformations are accelerated by increasing test temperatures above those anticipated in the repository $\left(\sim 200^{\circ} \mathrm{C}\right)$. Extrapolation to low temperatures of kinetic data taken at high temperatures assumes that the mechanism by which phases form at high temperatures also operates at lower temperatures. The lower the temperature from which the extrapolation is made, the more likely the validity of these assumptions. Theoretical modeling aimed at calculating the Alloy 22 phase diagram and precipitation kinetics has been performed that further support the use of this assumption. This assumption is used in Sections 6.1.2 and 6.6 and does not require confirmation. 


\section{INTENTIONALLY LEFT BLANK}




\section{MODEL DISCUSSION}

\subsection{MODEL OBJECTIVES}

\subsubsection{Goal of Model}

In the mill-annealed condition, Alloy 22 is primarily a single-phase, fcc solid solution with excellent corrosion resistance in a wide range of environmental conditions. Over time, other phases can precipitate out and degrade both the mechanical properties and corrosion resistance of the alloy. The goal of this model is to determine whether the single-phase solid solution is stable under repository conditions, and if not, how fast other phases may precipitate. Precipitation kinetics in the annealed base metal, as well as in the annealed and stress-mitigated welds, must be modeled. The aging and phase stability model, which is based on fundamental thermodynamic and kinetic concepts and principles, is used to provide predictive insight into the long-term metallurgical stability of Alloy 22 under relevant repository conditions. Thus, there are no direct inputs from this model to TSPA-LA.

\subsubsection{Background}

The time required for these precipitation reactions to occur increases as the temperature decreases. At the expected repository temperatures, the kinetics of these precipitation reactions are too slow to measure experimentally. For this reason, the rates at which they occur are measured at temperatures that are high in comparison to expected repository temperatures and then extrapolated to lower temperatures. Extrapolation from the relatively short laboratory time frame (tens of years) to the long repository time frame (tens of thousands of years) must be performed over durations spanning orders of magnitude. Calculations are used to establish confidence in such extended extrapolations.

Several of the phases that form in Alloy 22 are Frank-Kasper, TCP phases (Shoemaker and Shoemaker 1988 [DIRS 154989], pp. 19 to 45, Section 4): $\mu, \mathrm{P}$, and $\sigma$. These phases tend to be rich in Mo and/or Cr (Raghavan et al. 1984 [DIRS 154707], p. 789, Tables III and IV). Since these elements are largely responsible for the corrosion resistance of Alloy 22, precipitation of TCP phases can lead to the degradation of the corrosion properties. The TCP phases are also very brittle and tend to precipitate (at least initially) on grain boundaries, leading to a reduction in the toughness and, to a lesser extent, the ductility of Alloy 22 (Summers et al. 1999 [DIRS 146915], pp. 922 to 923, Figures 2 and 3).

Welding produces a cast microstructure with chemical segregation regardless of the alloy used. In Alloy 22, segregation of primarily molybdenum causes TCP phases to precipitate during welding (Cieslak et al. 1986 [DIRS 104966], p. 2041). The chemical segregation of an as-welded structure, as well as these TCP phases, can result in the degradation of the mechanical and corrosion properties of Alloy 22 welds when compared to the base metal.

The growth of TCP phases in Alloy 22 welds due to thermal aging causes a further reduction of the corrosion resistance and mechanical properties of the weld. The kinetics of the reactions that occur in the weld may be different than those discussed above for the base metal because the precipitates are already nucleated in the weld and there is chemical segregation. New data 
(Section 6.6.5.3.2) do not indicate that further nucleation and growth of TCP phases in Alloy 22 welds will occur at temperatures below about $200^{\circ} \mathrm{C}$.

\subsection{FEATURES, EVENTS, AND PROCESSES (FEPS) INCLUDED IN MODEL}

This report does not provide a direct basis for the inclusion of FEP 2.1.11.06.0A (Thermal sensitization of waste packages) in the TSPA-LA. Rather, the results of this report are used by another document, General Corrosion and Localized Corrosion of Waste Package Outer Barrier, as reference-only information. This report provides results that show that an extrapolation of the aging and phase stability data (TTT diagrams) indicates that the phase stability of Alloy 22 base metal will not be a concern for temperatures less than $300^{\circ} \mathrm{C}$ for 500 years followed by a period of at least 9,500 years of less than $200^{\circ} \mathrm{C}$ (BSC 2004 [DIRS 169565], Figure 6.3-57).

Table 5 indicates that only a single FEP is related to this subject and has been evaluated for inclusion in or exclusion from consideration in the TSPA-LA model. The same table provides a specific reference to the section within this report where that FEP is discussed. The detailed discussion of the FEP exclusionary argument is documented in FEPs Screening of Processes and Issues in Drip Shield and Waste Package Degradation (BSC 2004 [DIRS 169997]).

Table 5. Features, Events, and Processes Excluded (Screened Out) in This Report

\begin{tabular}{|c|c|c|}
\hline FEP No. & FEP Name & Sections Where Disposition is Described \\
\hline $2.1 .11 .06 .0 \mathrm{~A}$ & Thermal sensitization of waste package & 6.6 .4 \\
\hline
\end{tabular}

\subsection{AGING AND PHASE STABILITY CONCEPTUAL MODEL}

\subsubsection{Phase Identification and Preliminary Kinetic Observations in Alloy 22}

Alloy 22 samples were aged for 40,000 hours at $260^{\circ} \mathrm{C}, 343^{\circ} \mathrm{C}$, and $427^{\circ} \mathrm{C}$; for 30,000 hours at $427^{\circ} \mathrm{C}$; for 1,000 hours at $482^{\circ} \mathrm{C}, 538^{\circ} \mathrm{C}$ and $593^{\circ} \mathrm{C}$; and for 16,000 hours at $593^{\circ} \mathrm{C}, 649^{\circ} \mathrm{C}$, $704^{\circ} \mathrm{C}$, and $760^{\circ} \mathrm{C}$ before examination in TEM. A weld sample aged at $427^{\circ} \mathrm{C}$ for 40,000 hours was also observed in the weld metal, in the HAZ, and in the base metal removed from the weld. The other samples used for the subsequent kinetic arguments were not examined in TEM. Several phases were observed to form in Alloy 22: $\mathrm{P}, \mu, \sigma$, carbide, and $\mathrm{Ni}_{2}(\mathrm{Cr}, \mathrm{Mo}) \mathrm{LRO}$. At $593^{\circ} \mathrm{C}$, P phase was observed only on the grain boundaries. This is shown in Figure 1 through Figure 6. At the higher aging temperatures (up to $760^{\circ} \mathrm{C}$ ), both $\mu$ and $\mathrm{P}$ phases precipitated on grain boundaries (Figure 9 through Figure 15). As the aging temperature increased, more $\mu$ and $\mathrm{P}$ phase precipitation occurred within the grains. Grain boundary carbide precipitation was observed in samples aged at $593^{\circ} \mathrm{C}$ and $704^{\circ} \mathrm{C}$ (Figure 7 and Figure 8; micrographs of only samples aged at $593^{\circ} \mathrm{C}$ are shown here). Because of the small amount of carbide present in these samples and the small volume examined in TEM, it is likely that carbides also form at $649^{\circ} \mathrm{C}$. They may or may not form at $760^{\circ} \mathrm{C}$. Because of the similarity between the $\mathrm{M}_{6} \mathrm{C}$, the $\mathrm{M}_{12} \mathrm{C}$, and the $\mathrm{M}_{23} \mathrm{C}_{6}$-type carbide crystal structures, the specific carbide forming in these samples was not identified; however, it is a cubic carbide with a lattice parameter of 10 to $11 \AA$. A $\sigma$ phase was observed in the samples aged at $704^{\circ} \mathrm{C}$ and $760^{\circ} \mathrm{C}$ (Figure 16 and Figure 17; micrographs of only samples aged at $760^{\circ} \mathrm{C}$ are shown here). The amount of $\sigma$ observed in these samples was small 
compared to the amount of $\mu$ and P. LRO was observed in the samples aged at $593^{\circ} \mathrm{C}$ for 16,000 hours (Figure 45 through Figure 47) and for 1,000 hours and in the samples aged at $427^{\circ} \mathrm{C}$ for 40,000 hours (Figure 48 through Figure 56). These observations are summarized in Table 6.

The results of this section have been published (Summers et al. 1999 [DIRS 110249]) and are consistent with other published results. For example, in Hastelloy Alloy C-276, an alloy in the same class as Alloy 22, mostly $\mu$ and $\mathrm{P}$ phases were seen after aging (Leonard 1969 [DIRS 104970], p. 228, Conclusions, point 5). Also, more $\mu$ relative to $\mathrm{P}$ was seen in C-276 as aging temperature was increased (Leonard 1969 [DIRS 104970], p. 224, Table 2; Raghavan et al. 1982 [DIR 146956], Conclusions). In the earlier papers, $\mu$ phase had not been named; it was called the $\mathrm{Ni}_{7} \mathrm{Mo}_{6}$-type phase. By the time of the Raghavan et al. (1982 [DIRS 146956]) paper, this phase had been identified as $\mu$. The presence of carbides is also consistent with previously published results for C-276 (Raghavan et al. 1982 [DIRS 146956], Conclusions). The observance of LRO after aging between $427^{\circ} \mathrm{C}$ and $593^{\circ} \mathrm{C}$ is consistent with previously published occurrences of LRO in C-276 and in Alloy 22 (Tawancy et al. 1983 [DIRS 104991], p. 40; Rebak and Koon 1998 [DIRS 102797], Figure 9 and Conclusions, Point 5). The presence of $\sigma$ phase after aging above $700^{\circ} \mathrm{C}$ has not been previously reported in Alloy 22. The amount of $\sigma$ phase in these samples is small, and its presence is currently ignored (Section 5.1).

The TEM micrographs from the samples in Section 4.1.1 were taken from samples aged for 16,000 hours at $593^{\circ} \mathrm{C}, 649^{\circ} \mathrm{C}, 704^{\circ} \mathrm{C}$, and $760^{\circ} \mathrm{C}$ and for 1,000 hours at $593^{\circ} \mathrm{C}$. Samples aged for shorter time intervals have not been examined in TEM; therefore, the evolution of the phases during aging is not known. Also, when numerous precipitates are involved, TEM diffraction analysis is a cumbersome method of phase identification. This is especially true when the crystal structures of the various phases are similar. A single SAD pattern is often not enough to distinguish the phases that form in Alloy 22. Instead, two patterns with a known tilt between them frequently must be analyzed. For this reason, little quantitative data exist for the relative amounts of each phase as a function of temperature.

For this preliminary investigation, no distinction has been made between the various TCP and carbide phases that form. It is very difficult to distinguish these phases in SEM. It is generally accepted that $\mathrm{P}$ and $\mu$ phases are similar (Leonard 1969 [DIRS 104970], p. 225; Raghavan et al. 1982 [DIRS 146956], p. 983, Conclusions, Point 2), and, therefore, the kinetics of their formation is expected to be similar. 
Table 6. Phases Observed in Alloy 22 in TEM

\begin{tabular}{|c|c|}
\hline Aging Condition & Phases Observed to Form in Alloy 22 \\
\hline $260^{\circ} \mathrm{C}$ for 40,000 hours & $\begin{array}{l}\text { No LRO } \\
\text { No signs of grain boundary precipitation in base metal }\end{array}$ \\
\hline $343^{\circ} \mathrm{C}$ for 40,000 hours & $\begin{array}{l}\text { No LRO } \\
\text { No signs of grain boundary precipitation in base metal }\end{array}$ \\
\hline $427^{\circ} \mathrm{C}$ for 30,000 hours & $\begin{array}{l}\text { LRO } \\
\text { No signs of grain boundary precipitation in base metal }\end{array}$ \\
\hline $427^{\circ} \mathrm{C}$ for 40,000 hours & $\begin{array}{l}\text { LRO } \\
\text { No signs of grain boundary precipitation in base metal }\end{array}$ \\
\hline $482^{\circ} \mathrm{C}$ for 1,000 hours & $\begin{array}{l}\text { No LRO } \\
\text { No signs of grain boundary precipitation in base metal }\end{array}$ \\
\hline $538^{\circ} \mathrm{C}$ for 1,000 hours & $\begin{array}{l}\text { LRO } \\
\text { No signs of grain boundary precipitation in base metal }\end{array}$ \\
\hline $593^{\circ} \mathrm{C}$ for 1,000 hours & $\begin{array}{l}\text { LRO } \\
\text { Grain boundary films of } P \text { phase }\end{array}$ \\
\hline $593^{\circ} \mathrm{C}$ for 16,000 hours & $\begin{array}{l}\text { LRO } \\
\text { Grain boundary films of } P \text { phase } \\
\text { Carbide precipitates at grain boundaries }\end{array}$ \\
\hline $649^{\circ} \mathrm{C}$ for 16,000 hours & $\begin{array}{l}\text { No LRO } \\
\text { Precipitation of } \mathrm{P} \text { and } \mu \text { phases mainly at grain boundaries }\end{array}$ \\
\hline $704^{\circ} \mathrm{C}$ for 16,000 hours & $\begin{array}{l}\text { No LRO } \\
\text { Precipitation of } P \text { and } \mu \text { phases at grain boundaries and within the grains } \\
\text { Carbide and } \sigma \text { precipitation at grain boundaries }\end{array}$ \\
\hline $760^{\circ} \mathrm{C}$ for 16,000 hours & $\begin{array}{l}\text { No LRO } \\
\text { Precipitation of } P \text { and } \mu \text { phases at grain boundaries and within the grains } \\
\sigma \text { precipitation at grain boundaries }\end{array}$ \\
\hline
\end{tabular}

Source: DTN: LL010107712251.012 [DIRS 155299].

\subsubsection{Kinetics of Phase Transformations in Alloy 22}

Modeling was performed to determine the phase diagrams and other thermodynamic properties of the phases that form in Alloy 22 and to calculate the rate at which the relevant phase transformations occur (Turchi 2001 [DIRS 154934]).

The stability of the binary alloys (nickel-chromium, nickel-molybdenum, and molybdenumchromium) and the stability of the ternary nickel-chromium-molybdenum alloys was investigated. The study also focused on the role of additional solutes (i.e., silicon, carbon, cobalt, neodymium, tantalum, and tungsten) on stability, ordering, and precipitation in Alloy 22. These results indicate that the TCP phases ( $\mathrm{P}$ and probably $\mu$ ) are stable at repository temperatures and will form if they are not kinetically inhibited (Section 6.6.4). It is also apparent that preparing samples for measurements of the corrosion and mechanical properties must be done considering the temperature range at which the relevant phases form. The phases that would be stable under proposed repository conditions form at temperatures below approximately $800^{\circ} \mathrm{C}$. The $\sigma$ phase forms at higher temperatures, but it is not stable at the lower temperatures expected in the proposed repository. 
Kinetic and thermodynamic modeling are combined and applied to the study of diffusioncontrolled transformations. These kinetic studies were focused on the time-dependent formation of complex TCP phases and LRO in terms of phase evolution from the fcc matrix for times up to 10,000 years. The approach used in the kinetic and thermodynamic modeling involved simulating the Ni-Cr-Mo-W alloy system with a series of increasingly more complex calculations. A first series of calculations has been performed to predict the TTT diagram for the case of the $10 \%$ transformation of an fcc-based nickel-chromium matrix in the ordered $\mathrm{Ni}_{2} \mathrm{Cr}$ phase where experimental results were available for comparison (Karmazin 1982 [DIRS 154881]). A second series of simulations were conducted with a pseudo-binary $\mathrm{Ni}_{\mathrm{X}}\left(\mathrm{Cr}_{3} \mathrm{Mo}\right)_{1-\mathrm{X}}$ alloy in which kinetic data are available for comparison from the experimental work of Karmazin et al. (1994 [DIRS 161444]). A third series of simulations was performed for the case of a ternary nickel-chromium-molybdenum alloy with a nominal composition of $\mathrm{Ni}-21.1 \mathrm{Cr}-13.5 \mathrm{Mo}$ (wt \%). The transformations of P, $\sigma$, and oP6 (ordered) phases from the fcc-based matrix ranging from $2 \%$ to $15 \%$ were each considered as a function of time and temperature. In these simulations, grain boundary formation is not considered. Precipitation on grain boundaries, which is observed, occurs at a faster rate than bulk precipitation, which was treated here. The results of these simulations are given in Section 6.6.4, and the validation of these simulations is described in Sections 7.1 through 7.4.

\subsubsection{Weld Characteristics}

The HAZ of a weld is the region of the base metal near the weld that is subjected to a significant thermal pulse during the welding process. TCP-precipitation kinetics in the HAZ will be similar to those in the base metal, but the actual rates of precipitation may be different. The high temperatures (approaching the melting point) seen in the HAZ of welds may trigger nucleation of TCP and carbide precipitates. If nuclei are already present, precipitation will proceed much faster than in the base metal where they are not present.

Very few precipitates have been observed in the HAZ of weld samples thus far (Figure 41), but only two weld samples have been examined: one in the as-welded condition and one after aging at $427^{\circ} \mathrm{C}$ for 40,000 hours. These precipitates may simply be carbides that were present in the mill-annealed (i.e., as-received) condition. Carbides are known to be present in Ni-base alloys similar to Alloy 22, but they are usually within the grains and are generally called primary carbides to distinguish them from other secondary phases that form, often on grain boundaries, after an aging treatment (Tawancy et al. 1983 [DIRS 104991], p. 40). The particle in Figure 44 was not identified but could be one of these primary carbides.

Welding causes melting of the alloy and the development of an as-cast structure upon cooling. The dendritic structure typical of welds can be seen in Figure 35 through Figure 40 . As an Alloy 22 weld solidifies, $\mathrm{Mo}$ and $\mathrm{Cr}$ are rejected from the solid phase, causing their concentration to increase in the liquid (Figure 74). Therefore, the interdendritic regions, which are the last solids to form in a weld, tend to have high concentrations of these elements relative to typical values for Alloy 22 (Cieslak et al. 1986 [DIRS 104966], p. 2,039, Figure 7). Because formation of the TCP phases, which are also enriched in Mo or Cr, is favored by higher Mo and $\mathrm{Cr}$ concentrations, these phases are present in the interdendritic regions of Alloy 22 welds. TCP particles can be seen in Figure 37. $P$ phase is primarily seen in the as-welded condition of Alloy 22 welds, but $\sigma$ and $\mu$ phases are also seen (Cieslak et al. 1986 [DIRS 104966], p. 2,041). 
Only one particle was seen in TEM in an Alloy 22 weld (Figure 42 and Figure 43); this particle could be indexed as either $\mathrm{P}$ or $\sigma$ phase.

Because precipitates are present in Alloy 22 welds from the beginning, kinetics of precipitation is not an issue as it is in the base metal and HAZ. Whether these precipitates are stable and grow, or are unstable and dissolve with aging at repository-relevant temperatures must also be determined. In addition, for weld regions where stress mitigation techniques are used, these techniques may result in areas of increased cold work and, hence, dislocation density. As a result, the increase in dislocation density may result in faster diffusion rates for phase precipitation, and the effect of such faster diffusion rates under repository-relevant temperatures on phase kinetics must be evaluated.

\subsection{CONSIDERATION OF ALTERNATIVE CONCEPTUAL MODELS}

The martensite transformation reaction was considered as a potential alternative conceptual model (Table 7). The martensitic transformation is primarily driven by the difference in free energy as an alloy is cooled from a higher to a lower temperature. During martensitic transformation, the atoms in the parent-phase lattice structure are realigned into the martensiticphase lattice (Reed-Hill 1973 [DIRS 162684], p. 636). During the formation of martensite, no compositional changes occur as the parent-phase lattice is realigned into the martensitic phase. In addition, for the transformation reaction to proceed, diffusion in either the parent phase or martensitic phase is not required (Reed-Hill 1973 [DIRS 162684], p. 636). As a result, martensitic-transformation reactions are usually referred to as diffusionless phase transformations.

Table 7. Alternative Conceptual Model Considered

\begin{tabular}{|l|l|l|}
\hline Alternative Conceptual Model & \multicolumn{1}{|c|}{ Key Assumption } & Screening Assessment and Basis \\
\hline Martensitic transformation & $\begin{array}{l}\text { Analogous phase- } \\
\text { transformation reaction }\end{array}$ & No martensite observed in Alloy 22 \\
\hline
\end{tabular}

Another typical characteristic of the martensitic-transformation reaction is that it primarily depends on temperature change. For example, the faster the alloy is cooled, the faster the parent-martensitic interface moves, since the progress of the martensitic reaction is dependent on temperature changes that affect the free energy of the reaction (Reed-Hill 1973 [DIRS 162684], p. 642).

The speed of the martensitic transformation is very rapid. It has been shown that a martensitic plate in steel grows in $10^{-5}$ to $10^{-7}$ seconds to its full size, at near sonic velocities (Porter and Easterling 1997 [DIRS 163028]). In iron-nickel alloys, speeds of 800 to $1,100 \mathrm{~m} / \mathrm{s}$ were measured in the growth of plate martensite (Porter and Easterling 1997 [DIRS 163028]).

The martensitic-transformation reaction is widely used in industry to increase the mechanical properties of a variety of steels. In the family of controlled-transformation steels, the typical microstructure of fine lath martensite with a possible fine network of $\delta$-ferrite, in combination with work hardening and tempering, provides these steels with strengths up to 1,500 $\mathrm{MPa}$ (Pickering 1976 [DIRS 161275]). Examples of controlled-transformation steels are known as "transformation-induced plasticity" (TRIP) steels, where deformation induces the martensitic 
transformation (Porter and Easterling 1997 [DIRS 163029]). Common uses of TRIP steels include high-impact barriers or shields and automotive crash safety components (e.g., door impact bars).

The "shape memory" alloy, Nitinol (TiNi), has a microstructure of very fine twinned martensite, which allows this alloy to undergo large amounts of deformation. For example, the alloy may be "formed" in a fully reversible manner when deformation occurs below the martensite initiation temperature. Subsequent heating of the alloy above the martensite initiation temperature restores the deformed structure back to its original shape (Porter and Easterling 1997 [DIRS 163029]). Commercial applications of Nitinol include cellular phone antennas, heart valve sizer tools, eyeglass frames, and spinal vertebrae spacers.

The martensitic-transformation reaction is a well-understood and widely used model for phase transformation. Thus, it has been considered as an alternative conceptual model for the phase transformation for Alloy 22. However, in experimental results that span a wide range of temperatures and time periods, no martensite has been observed to form in Alloy 22. Due to its inherent characteristics (e.g., temperature change-dependent reaction and extreme rapid formation times), if martensite were to form in Alloy 22, it would have been easily observed in the tests conducted. As a result, the martensitic phase is not applicable to Alloy 22 phase transformations and, therefore, the alternative conceptual model using the martensitictransformation reaction is screened out from further consideration.

\subsection{MODEL FORMULATION}

\subsubsection{Background and Methodology}

Thermo-Calc and DICTRA are based on the so-called CALPHAD (CALculation of PhAse Diagrams) approach (Saunders and Miodownik 1998 [DIRS 104975]; Spencer 1999 [DIRS 161436]; Small 1999 [DIRS 163389]; Sundman and Agren 1999 [DIRS 163391]; Tanaka et al. 1999 [DIRS 163393]), introduced in the 1970s by Larry Kaufman, that involves the coupling of phase diagrams calculations for multicomponent alloy systems with other forms of thermo-chemical inputs to determine phase formation, proportions, and transformations.

Even in binary alloy systems, difficulties often occur in determining phase formation characteristics solely by reference to an experimentally determined phase diagram. These difficulties arise from kinetic limitations on reaching equilibrium at low temperatures and from inherent limitations on the accuracy of some of the available experimental techniques. One of the major steps in the Thermo-Calc application is a full characterization of a phase diagram that includes all available thermodynamic information. This, in turn, offers a reliable overall assessment that also allows the calculation of ancillary properties from the same database. In analyzing higher-order multicomponent alloys, the Thermo-Calc application avoids thermodynamic inconsistencies with built-in safeguards, which ensure phase boundaries are developed in accordance with the fundamental rules of classical thermodynamics.

DICTRA fulfills the need to provide critical modeling and analysis of data by solving the diffusion equations, calculating thermodynamic equilibrium (with Thermo-Calc), solving the flux-balance equations, and finally predicting the displacement of phase-interface positions. 
This application is used to analyze the kinetics of phase evolution in alloys selected for the barriers of the waste package by predicting TTT diagrams for relevant phases forming as functions of time. This application also will help determine the solidification path and the effect of welding, and eventually post-annealing, on the stability and long-term aging of alloys selected for the waste package. Kinetics studies are focusing on the time-dependent formation of complex Frank-Kasper phases (such as $\mathrm{P}$ and $\sigma$ phases), and the long-range ordering in terms of phase evolution from the fcc matrix with times of at least 10,000 years. The DICTRA application can also be applied to the study of grain boundary formation of carbides, silicides, and TCP phases and phase evolution under non-isothermal conditions, as is the case during welding.

Starting with the thermo-chemical database provided by the SGTE (Scientific Group Thermodata Europe) data group, a detailed analysis of the stability of the binary alloys $\mathrm{Ni}-\mathrm{Cr}, \mathrm{Ni}-\mathrm{Mo}$, and $\mathrm{Mo}-\mathrm{Cr}$, and of the ternary Ni-Cr-Mo alloys was undertaken, since the databases included with the software were not optimally configured for Ni-Cr-Mo-W alloy studies. The study then focused on the role of additional solutes such as $\mathrm{Si}, \mathrm{C}, \mathrm{Co}, \mathrm{Nb}, \mathrm{Ta}$, and $\mathrm{W}$ on stability, ordering, and precipitation in $\mathrm{Ni}-\mathrm{Cr}-\mathrm{Mo}-$ based alloys. Finally, kinetic and thermodynamic modeling have been combined and applied to the study of diffusion-controlled transformations with the use of the DICTRA software linked to Thermo-Calc.

\subsubsection{Solidification According to the Scheil-Gulliver Approach}

In all practical cases, solidification during most processing routes occurs in a non-equilibrium manner and gives rise to significant variations in the chemistry and the occurrence of secondary phases. Using a CALPHAD approach based on Scheil-Gulliver simulations, solidification can be studied, and predictions on the amount of undercooling can be made (Saunders and Miodownik 1998 [DIRS 104975]). Within this approach, a liquid of composition $c_{0}$ is cooled to a small amount below its liquidus temperature $T_{1}$. The solid precipitates out of the liquid with a composition $c_{1}^{\mathrm{S}}$ whereas the composition of the liquid becomes $c_{1}^{\mathrm{L}}$. On further cooling to the temperature $T_{2}$, the initial solid cannot change its composition (since back-diffusion in the solid phase in neglected in this approach). A local equilibrium is then established, and the liquid of composition $c_{1}^{\mathrm{L}}$ transforms to a liquid of composition $c_{2}^{\mathrm{L}}$, and a solid with composition, and the process is repeated upon further cooling (Figure 74). As solidification proceeds, the solid becomes lean in solute in the center of the dendrite whereas the liquid is enriched in solute until the composition of the liquid reaches the eutectic composition, and solidification is finally completed. Within the Thermo-Calc application software, the Scheil module is available to perform these simulations. 


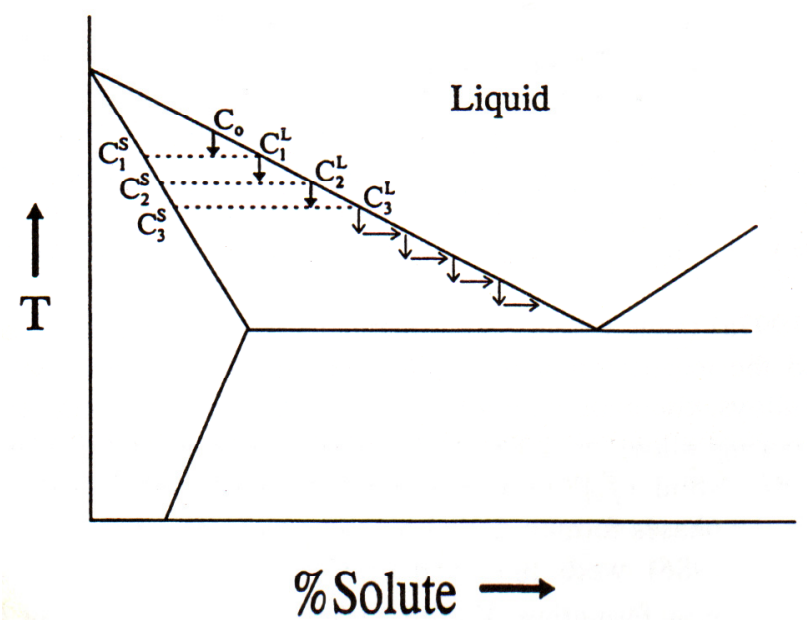

Source: Saunders and Miodownik 1998 [DIRS 104975].

Figure 74. Schematic Description of Solidification According to the Scheil-Gulliver Approach

\subsubsection{Computer Coupling of Phase Diagrams and Thermochemistry}

Computer coupling of phase diagrams and thermochemistry (CALPHAD) is capable of predicting the phase behavior in experimentally uninvestigated regions of a multicomponent system by extrapolating from their lower-order systems.

The equations and diagram presented in this section have been formulated and formatted for clarity by Turchi (2003 [DIRS 162974]) and are a synthesis of information from the cited references and the Thermo-Calc and DICTRA software documentation. These equations and diagrams are included here to aid in understanding the CALPHAD approach to computational thermodynamics and phase kinetics.

In the CALPHAD approach, the Gibbs energy of individual phases is modeled, and the model parameters are collected in a thermodynamic database. It is the modeling of the Gibbs energy of individual phases and the coupling of phase diagram and thermochemistry that make the CALPHAD a powerful technique in computational thermodynamics of multicomponent materials. Models for the Gibbs energy are based on the crystal structures of the phases. For pure elements and stoichiometric compounds, the most commonly used model is the one suggested by the Scientific Group Thermodata Europe (SGTE) and has the following form as presented by Saunders and Miodownik (1998 [DIRS 104975], Equation 5.3) (for simplicity, the pressure dependence and the magnetic contribution are not shown here),

$$
G_{\mathrm{m}}-H_{\mathrm{m}}^{\mathrm{SER}}=a+b T+c T \ln (T)+\sum d_{i} T^{i}
$$

The left-hand side of the equation is defined as the Gibbs energy relative to a standard element reference (SER) state, where $H_{\mathrm{m}}^{\mathrm{SER}}$ is the enthalpy of the element in its stable state at $298.15^{\circ} \mathrm{C}$. Coefficients, $a, b, c$, and $d_{i}$ are the model parameters. The SGTE data for pure elements have been compiled by Dinsdale (1991 [DIRS 161439]). 
For multicomponent solution phases, the Gibbs energy has the following general formula, as presented by Saunders and Miodownik (1998 [DIRS 104975], Equation 5.1):

$$
G=G^{\mathrm{o}}+G_{\mathrm{mix}}^{\mathrm{ideal}}+G_{\mathrm{mix}}^{\mathrm{xs}}
$$

where

$G^{\circ}$ is the contribution from the mechanical mixing of pure components

$G_{\mathrm{mix}}^{\text {ideal }}$ the ideal mixing contribution

$G_{\text {mix }}^{\mathrm{xs}}$ is the excess Gibbs energy of mixing due to non-ideal interactions

Sublattice models have been widely used to describe solution phases (Sundman and Agren 1981 [DIRS 161460]; Andersson et al. 1986 [DIRS 161461]; Ansara et al. 1998 [DIRS 161462]). For example, for a simple phase with two sublattices in an A-B binary system where both components enter both sublattices, the sublattice model is written as $(\mathrm{A}, \mathrm{B})_{p}(\mathrm{~A}, \mathrm{~B})_{q}$, where the subscripts $p$ and $q$ denote the number of sites of each sublattice, respectively. The three terms in Equation 2 are written as (based on the formulation presented by Saunders and Miodownik 1998 [DIRS 104975], Equations 5.30, 5.29, 5.33, and 5.34):

$$
\begin{gathered}
G^{\mathrm{o}}=y_{\mathrm{A}}^{\mathrm{I}} y_{\mathrm{A}}^{\mathrm{II}} G_{\mathrm{A}: \mathrm{A}}^{\mathrm{o}}+y_{\mathrm{A}}^{\mathrm{I}} y_{\mathrm{B}}^{\mathrm{II}} G_{\mathrm{A}: \mathrm{B}}^{\mathrm{o}}+y_{\mathrm{B}}^{\mathrm{I}} y_{\mathrm{A}}^{\mathrm{II}} G_{\mathrm{B}: \mathrm{A}}^{\mathrm{o}}+y_{\mathrm{B}}^{\mathrm{I}} y_{\mathrm{B}}^{\mathrm{II}} G_{\mathrm{B}: \mathrm{B}}^{\mathrm{o}} \\
G_{\text {mix }}^{\text {ideal }}=p R T\left(y_{\mathrm{A}}^{\mathrm{I}} \ln y_{\mathrm{A}}^{\mathrm{I}}+y_{\mathrm{B}}^{\mathrm{I}} \ln y_{\mathrm{B}}^{\mathrm{I}}\right)+q R T\left(y_{\mathrm{A}}^{\mathrm{II}} \ln y_{\mathrm{A}}^{\mathrm{II}}+y_{\mathrm{B}}^{\mathrm{II}} \ln y_{\mathrm{B}}^{\mathrm{II}}\right) \\
G_{\text {mix }}^{\mathrm{xs}}=y_{\mathrm{A}}^{\mathrm{I}} y_{\mathrm{B}}^{\mathrm{I}}\left(y_{\mathrm{A}}^{\mathrm{II}} \sum_{k=0} L_{\mathrm{A}, \mathrm{B}: \mathrm{A}}^{k}\left(y_{\mathrm{A}}^{\mathrm{I}}-y_{\mathrm{B}}^{\mathrm{I}}\right)^{k}+y_{\mathrm{B}}^{\mathrm{II}} \sum_{k=0} L_{\mathrm{A}, \mathrm{B}: \mathrm{B}}^{k}\left(y_{\mathrm{A}}^{\mathrm{I}}-y_{\mathrm{B}}^{\mathrm{I}}\right)^{k}\right) \\
+y_{\mathrm{A}}^{\mathrm{II}} y_{\mathrm{B}}^{\mathrm{II}}\left(y_{\mathrm{A}}^{\mathrm{I}} \sum_{k=0} L_{\mathrm{A}: \mathrm{A}, \mathrm{B}}^{k}\left(y_{\mathrm{A}}^{\mathrm{II}}-y_{\mathrm{B}}^{\mathrm{II}}\right)^{k}+y_{\mathrm{B}}^{\mathrm{I}} \sum_{k=0} L_{\mathrm{B}: \mathrm{A}, \mathrm{B}}^{k}\left(y_{\mathrm{A}}^{\mathrm{II}}-y_{\mathrm{B}}^{\mathrm{II}}\right)^{k}\right)
\end{gathered}
$$

where

$y^{\mathrm{I}}$ and $y^{\mathrm{II}}$ are the site fractions of $\mathrm{A}$ or $\mathrm{B}$ in the first and second sublattices, respectively $G_{\mathrm{I}: \mathrm{J}}^{\mathrm{o}}$ is the Gibbs energy of the compound $\mathrm{I}_{p} \mathrm{~J}_{q}$, expressed by Equation 1 $L_{\mathrm{A}, \mathrm{B}: *}^{k}\left(L_{*: \mathrm{A}, \mathrm{B}}^{k}\right)$ is the $k^{\text {th }}$ order interaction parameter between component $\mathrm{A}$ and $\mathrm{B}$ in the first (second) sublattice

In this notation, a colon separates components occupying different sublattices, and a comma separates interacting components in the same sublattice. These equations can be generalized for phases with multicomponents and multisublattices, and they reduce to a random substitutional model when there is only one sublattice. 
For a multicomponent solution in a particular phase $\Phi$ described with a single sublattice model, the three contributions to the total Gibbs energy reduce to (based on the formulation by Saunders and Miodownik 1998 [DIRS 104975], Equation 5.21):

$$
\begin{aligned}
& { }^{\Phi} G^{o}=\sum_{I} c_{I}{ }^{\Phi} G_{I}^{o} \\
& { }^{\Phi} G_{\text {mix }}^{\text {ideal }}=R T \sum_{I} c_{I} \ln c_{I} \\
& { }^{\Phi} G_{\text {mix }}^{x s}=\sum_{I} \sum_{J>I} c_{I} c_{J} \sum_{k}{ }^{\Phi} L_{I, J}^{k}\left(c_{I}-c_{J}\right)^{k}
\end{aligned}
$$

where the molar Gibbs energy of mixing is expressed by a Redlich-Kister expansion (Redlich et al. 1948 [DIRS 161464]). In these expressions $c_{I}$ is the composition of the alloy in species $I$, and $L_{I, J}^{k}$ is the $\mathrm{k}^{\text {th }}$-order binary interaction parameter between species $I$ and $J$ expressed as a polynomial in temperature, $T$. Note in both sets of expressions the excess Gibbs energy due to nonideal contributions is given by the Muggianu equation (Saunders and Miodownik 1998 [DIRS 104975], Eq. 5.22).

Thermodynamic modeling begins with the evalution of thermodynamic descriptions of unit and binary systems. By combining the thermodynamic descriptions of consititutive binary systems and ternary experimental data, the thermodynamic descriptions of ternary systems are developed and so forth. These descriptions cover the whole composition and temperature ranges, including the experimentally uninvestigated regions. For this work, the original SSOL thermodynamic database has been developed using the CALPHAD technique. Thermo-Calc, the most general and powerful program in computational thermodynamics of multicomponent alloys (Saunders and Miodownik 1998 [DIRS 104975], Spencer 1999 [DIRS 161436]; Small et al. 1999 [DIRS 163389]; Bernard et al. 1999 [DIRS 163390]; Sundman et al. 1999 [DIRS 163391]; Spear et al. 1999 [DIRS 163392]; Tanaka et al. 1999 [DIRS 163393]), is then used.

The CALPHAD approach is, in fact, the most successful method to address specific materials questions of practical importance to industry and technology (Spencer 1999 [DIRS 161436]; Small et al. 1999 [DIRS 163389]; Bernard et al. 1999 [DIRS 163390]; Sundman et al. 1999 [DIRS 163391]; Spear et al. 1999 [DIRS 163392]; Tanaka et al. 1999 [DIRS 163393]).

\subsubsection{Diffusion Modeling in Phase Transformations}

Process simulations require the development of the kinetic description of alloy systems, that is, the mobility of species in individual phases (Saunders and Miodownik 1998 [DIRS 104975]; Spencer 1999 [DIRS 161436]; Small et al. 1999 [DIRS 163389]; Sundman et al. 1999 [DIRS 163391]; Engström et al. 1994 [DIRS 161442]; Agren 1992 [DIRS 161440]). The models relating the mobility and diffusivity are based on the generalized Onsager flux equation.

For example, for a phase consisting of a substitutional sublattice and an interstitial sublattice, the intrinsic diffusion coefficient, $D_{k j}$ (the diffusivity of component $k$ with respect to the gradient of 
component $j$ ), is related to the atomic mobility $M_{i}$ ( $i$ for all the elements in a phase) with the following formula (based on the formulation by Agren (1992 [DIRS 161440])):

$$
\begin{gathered}
D_{k j}=\sum_{i \in S}\left(\delta_{i k}-u_{k}\right) u_{i} M_{i} \frac{\partial \mu_{i}}{\partial u_{j}}+\sum_{i \notin S} \delta_{i k} u_{i} y_{V a} M_{i} \frac{\partial \mu_{i}}{\partial u_{j}} \\
\text { with } u_{k}=\frac{x_{k}}{\sum_{i \in S} x_{i}} \text { and } \delta_{i k}=\left\{\begin{array}{cc}
1 & i=k \\
0 & i \neq k
\end{array}\right.
\end{gathered}
$$

where

$i \in S$ denotes that component $i$ is substitutional and $i \notin S$ denotes that component $i$ is interstitial

$x_{k}$ is the mole fraction of component $k$

$\mu_{i}$ is the chemical potential of component $i$ derived from the Gibbs energy of the phase

$y_{V a}$ represents the site fraction of vacancy in the interstitial sublattice

$\delta_{i k}$ is the Kronecker delta

The mobility $M_{i}$ associated with species $i$ is further related to a frequency factor $M_{i}^{0}$ and composition with the following equations, as presented in the DICTRA User's Guide (ThermoCalc Software 1998 [DIRS 162973]):

$$
\begin{gathered}
M_{i}=\frac{M_{i}^{0}}{R T} \exp \left(\frac{\Delta G_{i}}{R T}\right) \\
\Delta G_{i}=\sum_{j} \sum_{m} y_{j}^{\mathrm{I}} y_{m}^{\mathrm{II}} \Delta G_{i}^{j: m}+\sum_{j} \sum_{k>j} \sum_{m} y_{j}^{\mathrm{I}} y_{k}^{\mathrm{I}} y_{m}^{\mathrm{II}} \Delta G_{i}^{j, k: m}+\sum_{j} \sum_{n} \sum_{m>n} y_{j}^{\mathrm{I}} y_{n}^{\mathrm{II}} y_{m}^{\mathrm{II}} \Delta G_{i}^{j: n, m}
\end{gathered}
$$

where

$\Delta G_{i}$ is the activation Gibbs energy of component $i$

$\Delta G_{i}^{j: m}$ is the activation Gibbs energy of component $i$ with components $j$ and $m$ on the first and second sublattices, respectively

This formulation for a ternary system is based on the binary system formulation presented in Equation 5.37 of CALPHAD, Calculation of Phase Diagrams: A Comprehensive Guide (Saunders and Miodownik 1998 [DIRS 104975]). The interaction terms, $\Delta G_{i}^{j, k: m}$ and $\Delta G_{i}^{j: n, m}$, are expressed with a polynomial similar to the summations in Equation 3. The individual parameters are evaluated from chemical and tracer diffusion data.

By combining thermodynamic and kinetic descriptions of alloy systems, phase transformations can then be simulated. The schematic flow chart of the DICTRA simulation is shown in Figure 75 (Turchi 2003 [DIRS 162974]). The most significant feature of this simulation procedure is the simultaneously coupling of thermodynamics and kinetics. 


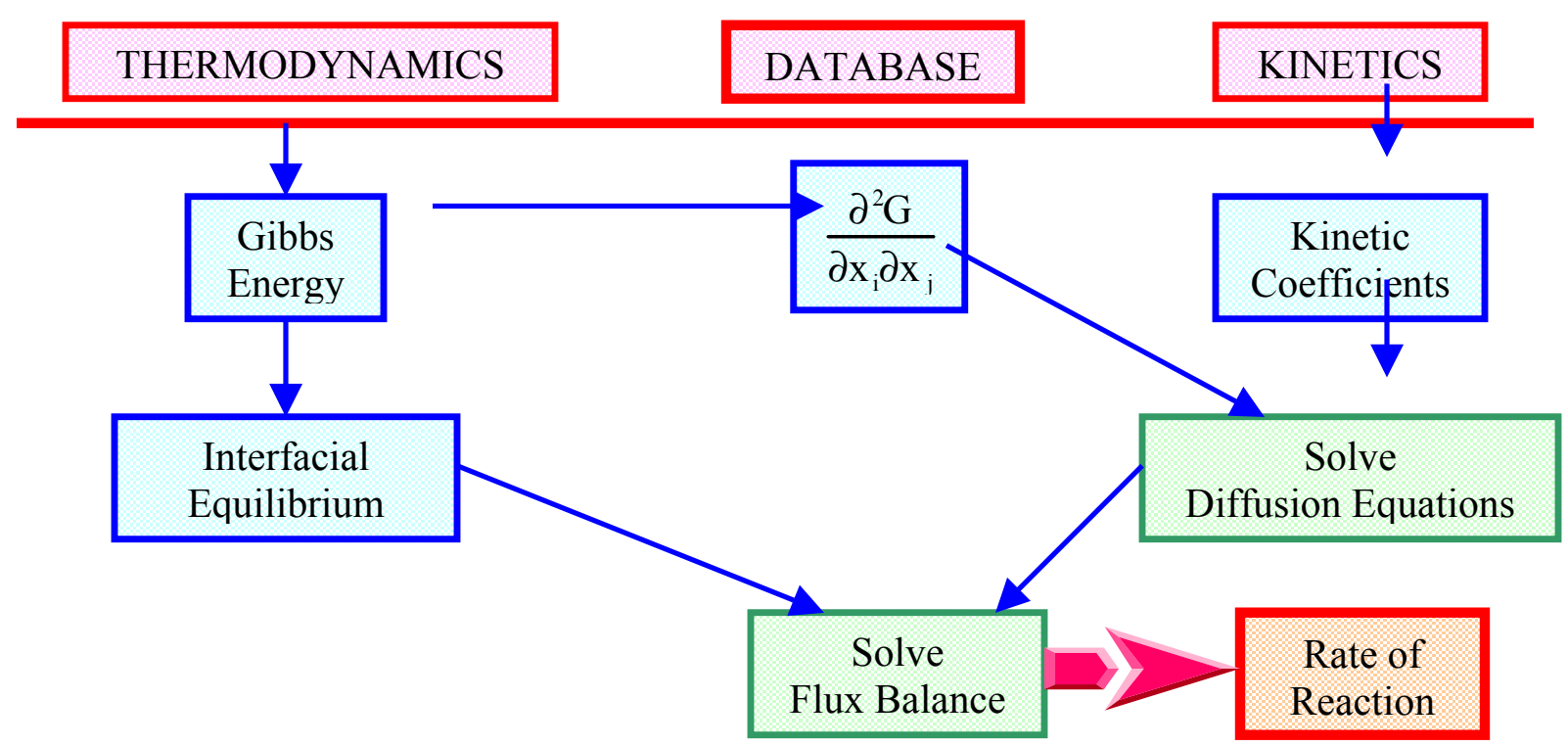

Figure 75. Schematic Flow Chart of Numerical Simulation of Phase Transformations

\subsection{MODEL RESULTS}

The model results are presented in two parts: computational and experimental. The computational results were conducted in three general steps: (1) development of the Thermo-Calc results for the alloy systems and components of interest (Sections 7.1 through 7.4), (2) determination of the property diagrams for the Ni-based alloys of interest (Section 6.6.1), and (3) determination of the kinetic properties (TTT diagrams) of the Ni-based alloys of interest (Section 6.6.2). The experimental results are presented in three areas: (1) volume-fraction measurements in Alloy 22 base metal, including grain boundaries (Section 6.6.5.1); (2) volumefraction measurements in Alloy 22 weld metal (Section 6.6.5.2); and (3) microhardness measurements in Alloy 22 base metal, which are indicative of LRO (Section 6.6.4).

The validation of the computational phase diagrams and kinetic results with published data measured are described in detail in Sections 7.1 through 7.4.

\subsubsection{Property Diagrams of the Ni-Based Alloys}

The property diagrams of various Ni-based alloys were calculated using Thermo-Calc at their nominal alloy composition as indicated in Table 8 . These diagrams display the phase (or volume) fractions as a function of temperature. 
Table 8. Nominal Chemical Compositions of Ni-Cr-Mo Alloys

\begin{tabular}{|c|c|c|c|c|c|c|c|c|}
\hline Alloy & $\begin{array}{c}\mathbf{N i} \\
\text { (balance) }\end{array}$ & $\begin{array}{c}\mathbf{C r} \\
\text { (wt \%) }\end{array}$ & $\begin{array}{c}\text { Mo } \\
\text { (wt \%) }\end{array}$ & $\begin{array}{c}\mathbf{F e} \\
\text { (wt \%) }\end{array}$ & $\begin{array}{c}\mathbf{w} \\
\text { (wt \%) }\end{array}$ & $\begin{array}{c}\text { Mn } \\
\text { (wt \%) }\end{array}$ & $\begin{array}{c}\mathbf{C} \\
\text { (wt \%) }\end{array}$ & $\begin{array}{c}\text { Other } \\
\text { (wt \%) }\end{array}$ \\
\hline C-276 & 57 & 14.5 to 16.5 & 15 to 17 & 4 to 7 & 3 to 4.5 & 1.0 & 0.02 & Co: 2.5 (max) \\
\hline C-4 & 53 & 14 to 18 & 14 to 17 & $3(\max )$ & - & 1.0 & 0.015 & Co: 2.0 (max) \\
\hline 59 & 59 & 22 to 24 & 15 to 16.5 & $\begin{array}{c}1.5 \\
\text { (max) }\end{array}$ & - & 0.5 & 0.01 & Al: 0.1 to 0.4 \\
\hline 22 & 56 & 20 to 22.5 & 12.5 to 14.5 & 2 to 6 & 2.5 to 3.5 & 0.5 & 0.015 & Co: 2.5 (max) \\
\hline
\end{tabular}

Source: Turchi 2003 [DIRS 162974].

\subsubsection{Alloy 22}

In the case of Alloy 22, the Thermo-Calc results shown in Figure 76 (left and central panels) confirm, that at equilibrium and low temperature, a three-phase field that includes the $\mathrm{Ni}_{2} \mathrm{Cr}$-type of ordered phase (or oP6), a complex TCP structure (P phase, or similar such as $\mu$ ), and the fcc matrix should exist. It is interesting to note in Figure 76 (right panel) if the $\mathrm{P}$ phase is suspended during the calculation of the property diagram (suspending a phase is analogous to assuming that the phase is not kinetically favored), the domain of stability of the $\sigma$ phase extends in a broader range of temperatures towards low temperatures from $930^{\circ} \mathrm{C}$ to $448^{\circ} \mathrm{C}$ (instead of $802^{\circ} \mathrm{C}$ ). Also, the ordered phase of $\mathrm{Ni}_{2} \mathrm{Cr}$-type (oP6) competes with the $\mathrm{P}$ phase, as illustrated in Figure 77. Whereas oP6 is itself stable up to $566^{\circ} \mathrm{C}$ (all phases suspended except fcc and oP6), the complete property diagram indicates a maximum temperature of stability at about $408^{\circ} \mathrm{C}$. Finally, at low phase fraction, a number of carbides and silicides are stable, namely: $\mathrm{M}_{7} \mathrm{C}_{3}, \mathrm{~V}_{3} \mathrm{C}_{2}$, and $\mathrm{Cr}_{3} \mathrm{Si}$. It is likely that these precipitate phases will preferably form in the proximity of the grain boundaries, where $\mathrm{C}$ and $\mathrm{Si}$ are usually observed.
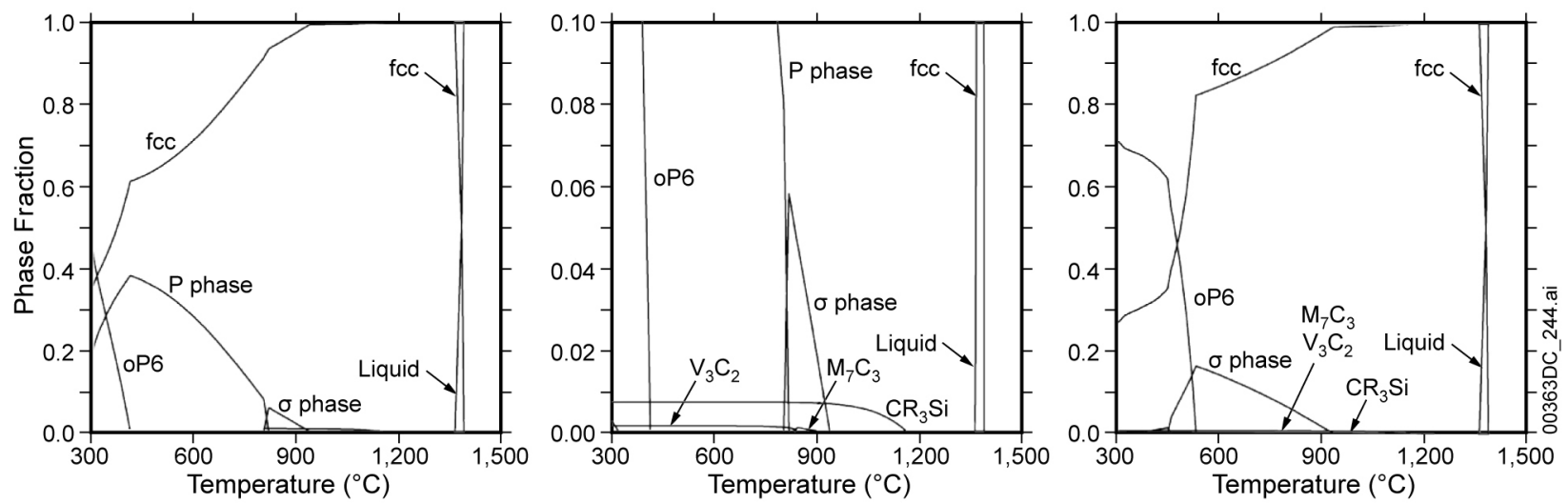

Source: DTN: LL030106312251.013.

NOTE: In the left panel, the diagram in the whole range of phase fraction is displayed, whereas in the central panel a detailed description of the diagram clearly shows the phases that occur at low phase fraction. The right panel is the property diagram of Alloy 22 in the case the P phase is not considered in (i.e., suspended during) the calculations.

Figure 76. Calculated Property Diagrams of Alloy 22 

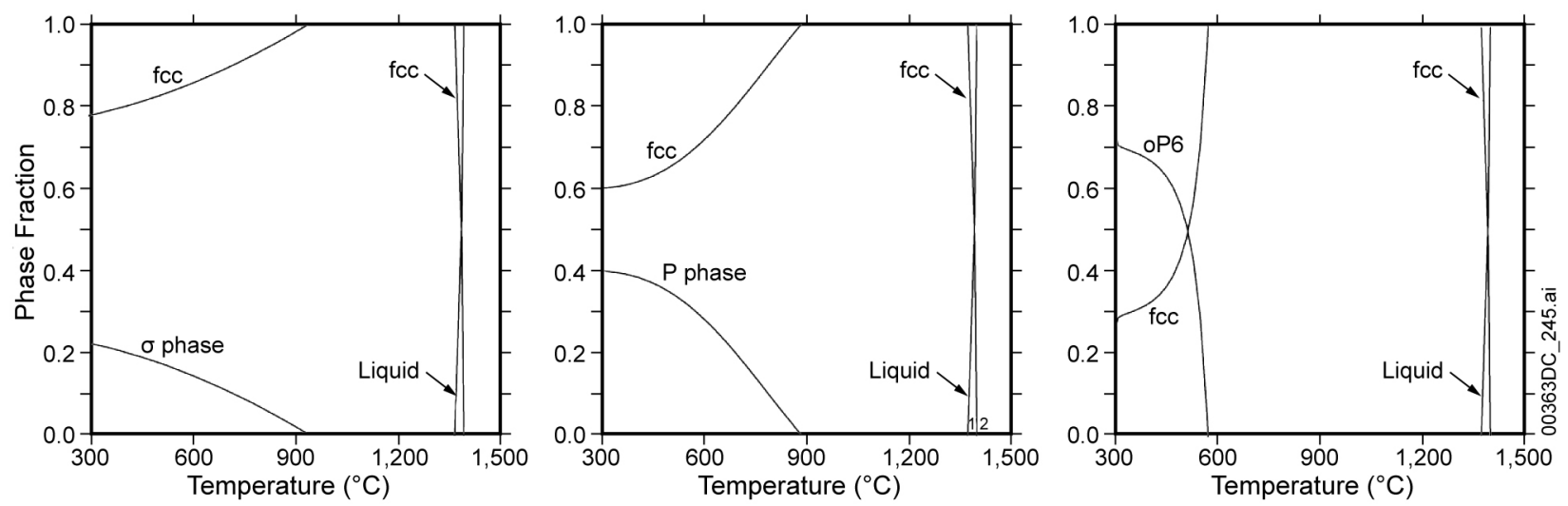

Source: DTN: LL030106312251.013.

Figure 77. Calculated Property Diagrams of Alloy 22 with the Liquid, the fcc Matrix, and the $\sigma$ Phase (Left Panel), the P Phase (Central Panel), and the oP6-ordered Phase (Right Panel) Considered in the Calculations

By retaining the liquid phase and the fcc matrix, and $\sigma$ phase, $\mathrm{P}$ phase, or oP6-ordered phase during the calculation of the property diagram, the domain of existence of $\sigma, \mathrm{P}$ or oP6 with respect to fcc can be easily evaluated, as shown in Figure 77. For example, with no other competing phases than the fcc, the $\sigma$ phase exhibits a broad domain of stability that is limited at low temperature when the oP6 is reintroduced in the calculations (Figure 76, right panel), and even more so when the $\mathrm{P}$ phase is allowed (Figure 76, left panel). Hence, it can be concluded that under particular circumstances where metastability can be promoted, the $\sigma$ phase can be found at temperature lower than the one predicted at equilibrium.

In Figure 78, the analysis in terms of weight fraction as a function of temperature of each major element ( $\mathrm{Ni}, \mathrm{Cr}$, or $\mathrm{Mo}$ ), and $\mathrm{W}$ and $\mathrm{Fe}$ (when present) for each individual phase, namely the fcc matrix, the oP6-ordered phase, and the two TCP phases, $\mathrm{P}$ and $\sigma$, confirms the expectation. Indeed, in the TCP phases, a noticeable depletion in $\mathrm{Ni}$ and an enhancement in $\mathrm{Cr}$ in the $\mathrm{P}$ phase or Mo in the $\sigma$ phase in their temperature range of stability (indicated by the horizontal line with arrows on both ends) are observed in Figure 78 (bottom panels). In the case of the oP6-ordered phase, a depletion in $\mathrm{Ni}$ and a noticeable departure from the nominal $\mathrm{Cr}$ and $\mathrm{Mo}$ compositions are observed (Figure 78, top right panel). It may be necessary to revisit these predictions in the case of welding where alloy stability can be affected by the presence of TCP phases and of the oP6-ordered phase at compositions that strongly depart from the nominal composition of Alloy 22. 

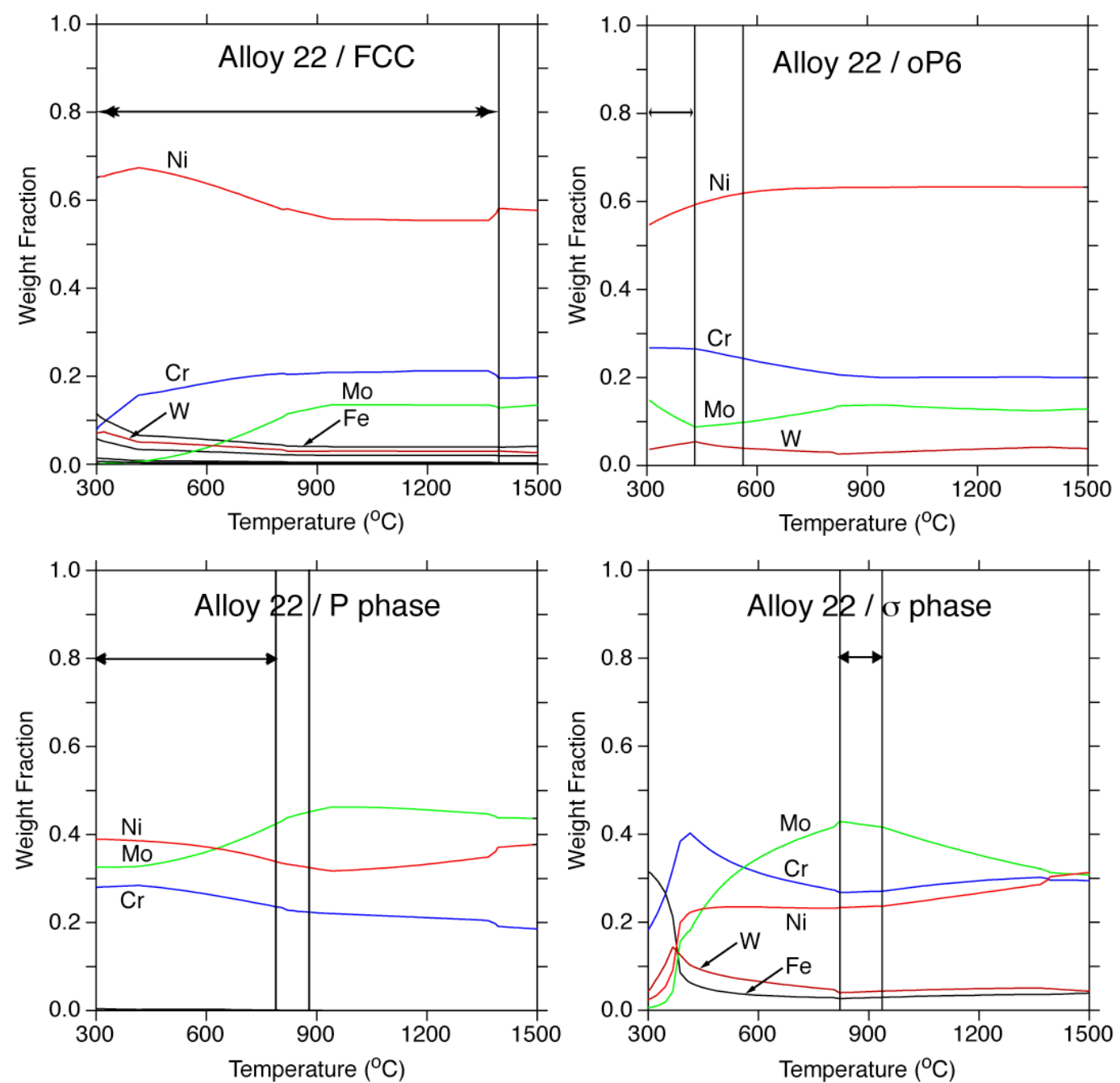

Source: DTN: LL030106312251.013.

NOTE: The horizontal line with arrows on both ends indicates the domain of stability of the phase whereas the stand-alone vertical line indicates the temperature at which the phase starts occurring.

Figure 78. Weight Fraction of $\mathrm{Ni}$ (Red), $\mathrm{Cr}$ (Blue), Mo (Green), W (Brown), and Fe (Black), Versus Temperature in the fcc Matrix, the oP6, and the P and $\sigma$ Phases for Alloy 22 at its Nominal Composition

\subsubsection{Alloy C-4}

The calculated property diagram for Alloy C-4 is shown in Figure 79. In the case of alloy C-4, the main phases forming, besides the fcc matrix, are the $\mathrm{P}$ and the $\mathrm{Ni}_{2} \mathrm{Cr}$-type (oP6) phases. In addition, the $\mathrm{M}_{23} \mathrm{C}_{6}$ and the $\mathrm{A} 15 \mathrm{Cr}_{3}$ Si-type phases form at very low phase fraction. The relatively low $\mathrm{Cr}$ content in this alloy excludes the formation of the $\sigma$ phase. 

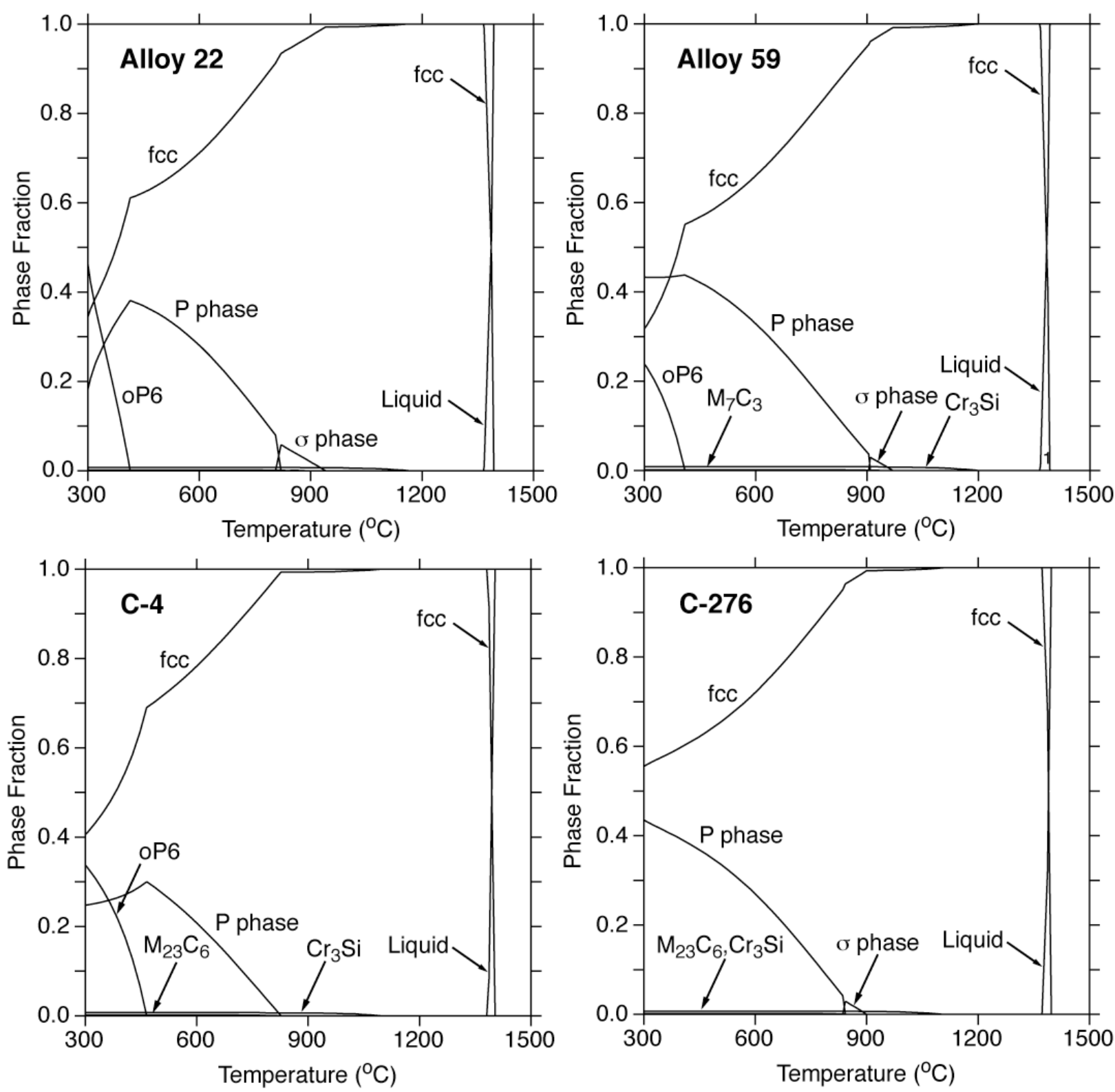

Source: DTN: LL030106312251.013.

NOTE: Additional phases (mostly carbides and silicides) predicted with a phase fraction less than 0.01 are not reported.

Figure 79. Calculated Property Diagrams (Phase Fraction Versus Temperature) of Alloy 22, Alloy 59, C-4, and C-276 at Their Nominal Composition

\subsubsection{Alloy C-276}

The calculated property diagram for Alloy C-276 is shown in Figure 79 . In the case of Alloy 276, as in the case of Alloy C-4, the low $\mathrm{Cr}$ and Mo content significantly reduces the formation of the $\sigma$ phase and prevents the formation of the $\mathrm{Ni}_{2} \mathrm{Cr}$-type (oP6) ordered phase. Because of the presence of $\mathrm{C}$ and $\mathrm{Si}$, the A15 $\mathrm{Cr}_{3}$ Si-type and $\mathrm{M}_{23} \mathrm{C}_{6}$ phases are found in this alloy. 


\subsubsection{Alloy 59}

The calculated property diagram for Alloy 59 is shown in Figure 79. In the case of Alloy 59, the $\mathrm{P}$ phase forms in a broader range of temperature (up to about $900^{\circ} \mathrm{C}$ ) than in Alloy $22\left(811^{\circ} \mathrm{C}\right.$ ); this can be attributed to a higher $\mathrm{Cr}$ and Mo content in Alloy 59 than in Alloy 22. Once again, at very low phase fraction, the $\mathrm{A} 15 \mathrm{Cr}_{3} \mathrm{Si}$-type and $\mathrm{M}_{7} \mathrm{C}_{3}$ phases are stable.

\subsubsection{Equivalent Alloys 22, 59, C-4, and C-276}

A definition for the equivalent composition of $\mathrm{Ni}, \mathrm{Cr}$, and Mo has been used (Section 7.3) that is usually considered when discussing alloy stability in Ni-based alloys (Cieslak et al. 1982 [DIRS 104966]. Using these equivalents, compositions of the property diagrams of the equivalent Alloy 22, 59, C-4, and C-276 compositions have been calculated and the results are displayed in Figure 80. The results are directly comparable to those displayed in Figure 79. Significant differences are noted. For example, in all cases the alloys at their equivalent compositions display an oP6-ordered phase with a larger volume fraction and stabilize at much higher temperature than in the corresponding alloys at their nominal composition. This enhanced stability of the oP6 phase is due to a destabilization of the P phase at low temperature. Also, the $\sigma$ phase is no longer stable in all four cases. Hence, extreme caution must be taken when basing arguments based on $\mathrm{Cr}$, Mo, and Ni equivalents. 

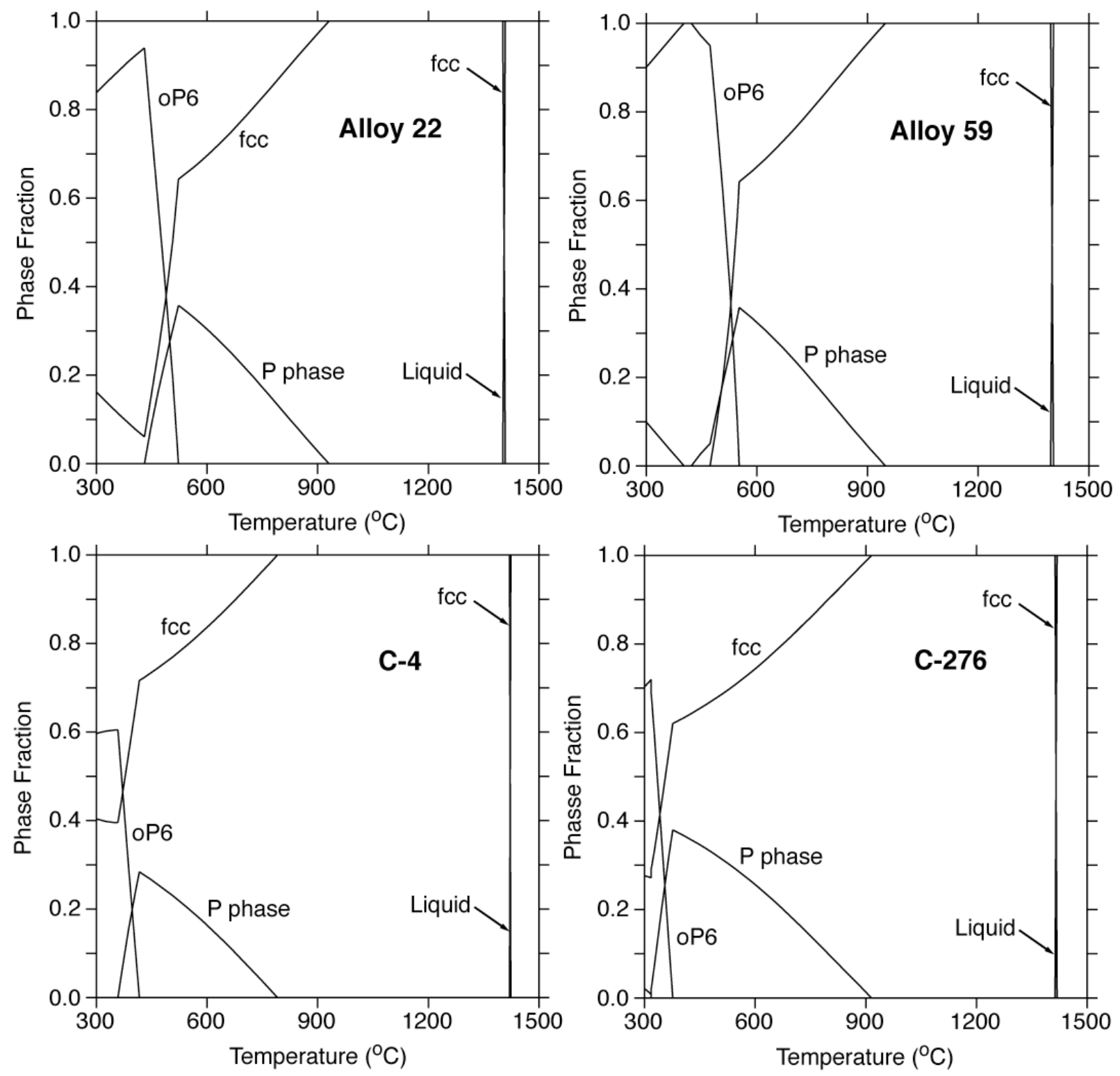

Source: DTN: LL030106312251.013.

NOTE: Additional phases (mostly carbides and silicides) predicted with a phase fraction less than 0.01 , are not indicated in the diagrams.

Figure 80. Property Diagrams (Phase Fraction Versus Temperature) of the Equivalents of Alloy 22, 59, C-4, and C-276 at their Nominal Composition

\subsubsection{Scheil-Gulliver Simulation of Solidification Processes in Ni-Based Alloys}

Most of the Ni-based alloys display a fair amount of under-cooling, of the order of $140^{\circ} \mathrm{C}$ (e.g., $133^{\circ} \mathrm{C}, 127^{\circ} \mathrm{C}, 150^{\circ} \mathrm{C}$, and $150^{\circ} \mathrm{C}$ for Alloy 22 , Alloy $59, \mathrm{C}-4$, and C-276, respectively), and this result has been confirmed with Scheil-Gulliver simulations (Figure 81). From the liquid phase, the first solid phase to occur in all alloy cases is the fcc matrix, and then a small fraction of A15-based $\mathrm{Cr}_{3} \mathrm{Si}$ compound starts forming. The last phase to form under the Scheil-Gulliver conditions (that assume local equilibrium, infinite diffusion in the liquid phase, and no back 
diffusion in the solid phase) is the $\sigma$ phase (except for C-4 and C-276), and the under-cooling is accompanied by a decrease in $\mathrm{Ni}$ content and an increase in $\mathrm{Mo}$ and $\mathrm{Cr}$ contents from the nominal composition (Figure 78, bottom right panel in the base-metal case) and Figure 82. These results clearly indicate that the alloys of this series (at their nominal compositions) can be properly annealed in a relatively broad region of temperature and quenched to retain the single fcc phase.

The transition temperatures are determined during the execution of the Scheil-Gulliver simulations and have been added onto the plots of Figure 81 for clarity.
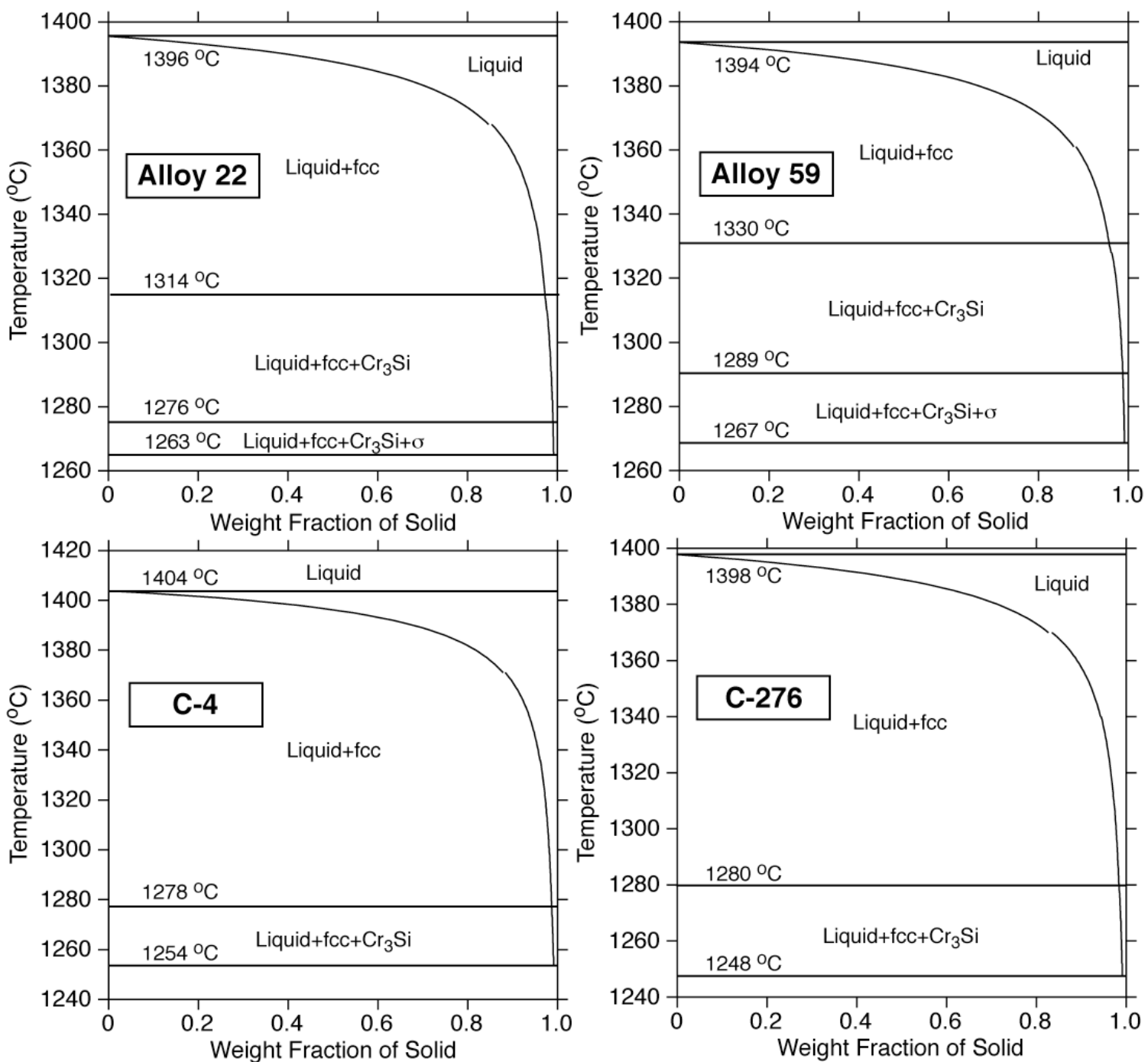

Source: DTN: LL030106312251.013.

Figure 81. Scheil-Gulliver Simulation Results for Alloy 22, Alloy 59, C-4, and C-276: Temperature Versus Weight Fraction of Solid Phase that Describes the Amount of Under-Cooling and the Succession of Phases During Cooling 

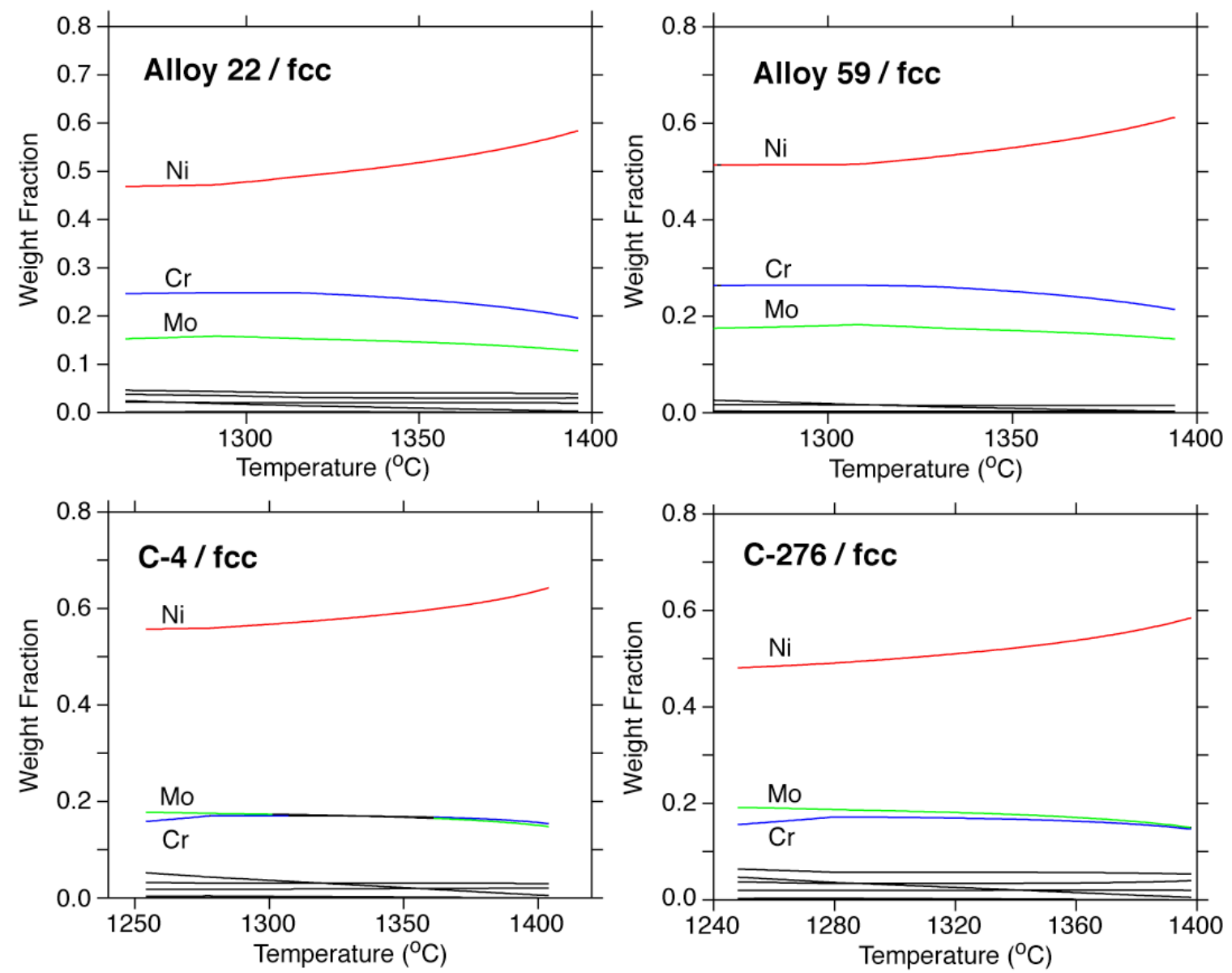

Source: DTN: LL030106312251.013.

Figure 82. Scheil-Gulliver Simulation Results of Weight Fraction of Ni (Red), Cr (Blue), and Mo (Green) in the fcc Matrix for Alloy 22, Alloy 59, C-4, and C-276 as Functions of Temperature, During Solidification

\subsubsection{Kinetic Properties of Nickel-Based Alloys}

Kinetic and thermodynamic modeling have been combined and applied to the study of diffusioncontrolled transformations with the use of the DICTRA application linked with Thermo-Calc. Simulations have been performed on three alloy systems, in order of increasing complexity: (1) a binary $\mathrm{Ni}-\mathrm{Cr}$ alloy, (2) a pseudo-binary $\mathrm{Ni}_{\mathrm{X}}\left(\mathrm{Cr}_{3} \mathrm{Mo}\right)_{1-\mathrm{X}}$ alloy, and (3) a ternary $\mathrm{Ni}-\mathrm{Cr}-\mathrm{Mo}$ alloy that can be considered as a surrogate for Alloy 22, with the following nominal composition: $\mathrm{Ni}$, $21.1 \mathrm{Cr}$, and 13.5 Mo (in wt \%). The TTT diagrams resulting from these simulations are described below.

\subsubsection{TTT Diagram for the fec to $\mathrm{Ni}_{2} \mathrm{Cr}$-Type (oP6) Ordered Phase in $\mathrm{Ni}_{2} \mathrm{Cr}$}

A first series of calculations have been performed to predict the TTT diagram in the case of a $10 \%$ transformation of an fcc-based $\mathrm{Ni}-\mathrm{Cr}$ solid solution to the ordered $\mathrm{Ni}_{2} \mathrm{Cr}$ (oP6) phase for which case experimental results were available (Karmazin 1982 [DIRS 154881]). The results are displayed in Figure 84 . The MOB database that contains the mobility and the diffusion coefficient of the $\mathrm{Cr}$ species in an fcc-Ni matrix has been adjusted to account for the kinetics of 
transformation studied experimentally by Karmazin (1982 [DIRS 154881]). The variation of the fcc lattice parameter as a function of time at various annealing temperatures (Figure 83) is formulated to be directly proportional to the amount of ordered phase formed in the disordered fcc matrix. Based on this relation, three points of the TTT diagram have been obtained at $450^{\circ} \mathrm{C}$, $500^{\circ} \mathrm{C}$, and $530^{\circ} \mathrm{C}$ (Karmazin 1982 [DIRS 154881], Figure 6) in the case of a $10 \%$ transformation from fec to oP6 of the Ni-rich solid solution with 33.3 at \% Cr. The location of the nose of the experimental TTT curve has been used to determine the kinetic parameters that are defined in the MOB database for subsequent DICTRA calculations. The DICTRA results for the same rate of transformation $(10 \%)$ are also displayed in Figure 84, and the shape of the C-curve compares very favorably with the experimentally deduced one. From the stability studies (Section 7.1), the value of the critical order-disorder temperature (that positions the asymptote in the TTT diagram), $553^{\circ} \mathrm{C}$, compares very well to the experimentally assessed value of $540^{\circ} \mathrm{C}$. The transformation is rather sluggish and is initiated after about 200 hours. Extrapolation of the TTT curve to lower temperatures clearly indicates that in this binary alloy, the formation of oP6-ordered phase out of the fcc solid solution will not be a concern for conditions of less than $300^{\circ} \mathrm{C}$ for a period of 500 years followed by temperatures of less than $200^{\circ} \mathrm{C}$ for a period of 9,500 years, conditions that bound the repository time-temperature profiles (BSC 2004 [DIRS 169565], Figure 6.3-57).

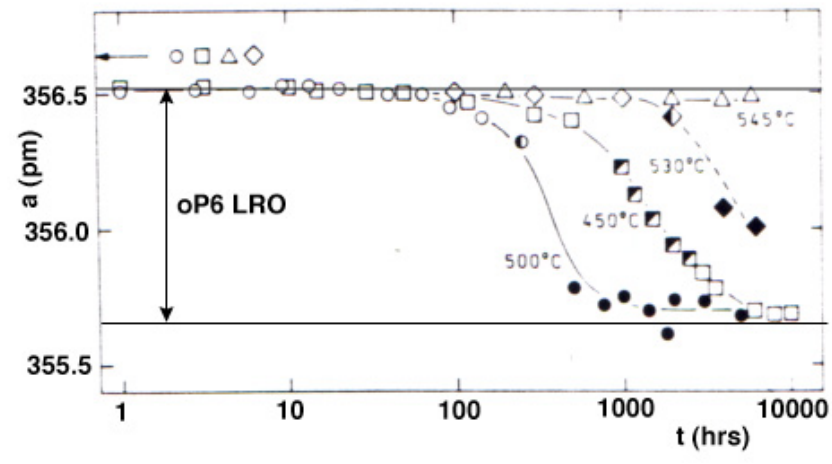

Fig. 6. Kinetics of changes in the lattice parameter $a$ of the nickel-rich solid solution with 33.7 at.\% $\mathrm{Cr}$ during isothermal heating at $450{ }^{\circ} \mathrm{C}(\square, \mathbf{\square}), 500{ }^{\circ} \mathrm{C}$ $(\circ, \bullet, \bullet), 530^{\circ} \mathrm{C}(\diamond, \diamond, \diamond)$ and $545^{\circ} \mathrm{C}(\triangle)$ after an initial heat treatment by quenching from $1100^{\circ} \mathrm{C}$. Sharp $(\square, \diamond, \diamond, \Delta)$, partially diffuse $(\square, \mathbf{D}, \diamond)$ and markedly diffuse $(\bullet, \bullet)$ diffraction lines were found. The arrows $(\leftarrow)$ indicate the initial values after the samples had been quenched from $1100^{\circ} \mathrm{C}$.

Source: Karmazin 1982 [DIRS 154881], Fig. 6.

NOTE: The horizontal lines delineate the range of existence of the oP6 long-range order (LRO) from the disordered phase (top line) to the fully ordered phase (bottom line).

Figure 83. Experimental Variation of the Lattice Parameter with Time at Fixed Isothermal Annealing for $\mathrm{Ni}_{2} \mathrm{Cr}$ Alloy 


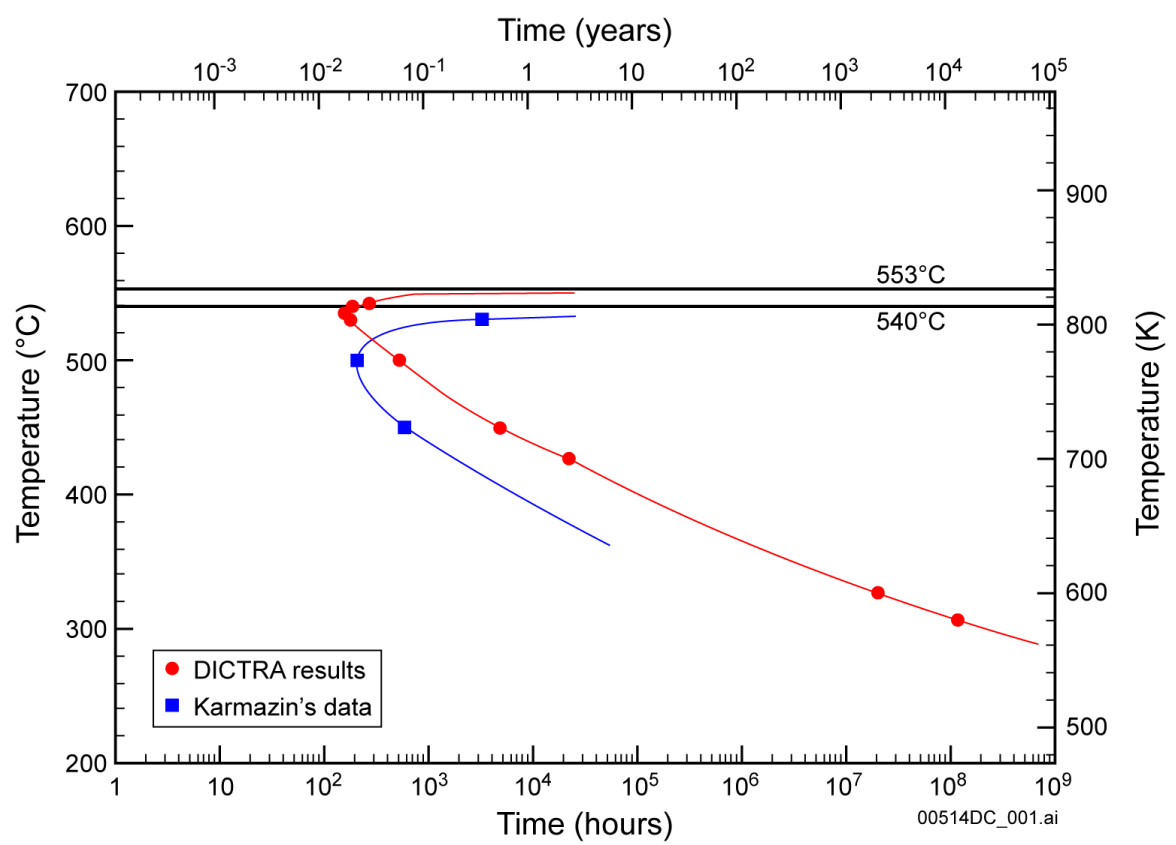

Source: DTN: LL030106312251.013.

NOTE: The experimentally deduced TTT diagram (blue solid squares) (Karmazin 1982 [DIRS 154881]) for the same transformation rate is also shown for comparison.

Figure 84. Calculated Isothermal TTT Diagrams (Red Solid Circles) for an fcc-Based Matrix of a Binary $\mathrm{Ni}_{2} \mathrm{Cr}$ Alloy Transforming into the oP6-Ordered Phase, with Transformation Rate of $10 \%$

\subsubsection{TTT Diagram for the fec to $\mathrm{Ni}_{2} \mathrm{Cr}$-type (oP6) Ordered Phase in a Pseudo-Binary $\mathrm{Ni}_{\mathbf{X}}\left(\mathrm{Cr}_{3} \mathrm{Mo}\right)_{1-\mathrm{X}}$ Alloy}

To make further comparisons with experimental results, a pseudo-binary $\mathrm{Ni}_{\mathrm{X}}\left(\mathrm{Cr}_{3} \mathrm{Mo}\right)_{1-\mathrm{X}}$ alloy is considered in which kinetic data are available from the experimental work of Karmazin et al. (1994 [DIRS 161444]). In this study, the kinetic parameters (diffusion coefficient and mobility) for $\mathrm{Mo}$ in $\mathrm{Ni}$ are formulated to be identical to those of $\mathrm{Cr}$ in $\mathrm{Ni}$. As in the previous case (Section 6.6.4.1), there is a linear relation between the variation of the lattice parameter and the amount of fcc matrix transformed into the oP6-ordered phase. In Figure 85, the property diagram of this alloy is displayed with only the fcc and oP6 phases included in the calculation. It is shown that the ordered phase is stable below $627^{\circ} \mathrm{C}$. Based on this assumption, the DICTRA results for $5 \%, 10 \%$, and $15 \%$ transformation from the fcc-solid solution to oP6 for Ni-24 at \% $\mathrm{Cr}-8$ at \% Mo (or $20.78 \mathrm{wt} \% \mathrm{Cr}$ and $12.78 \mathrm{wt} \% \mathrm{Mo}$ ) are reported in Figure 86 . The experimental point (solid square) indicated in Figure 86, representing 5\% transformation, has been deduced from the experimental study of the variation of the lattice parameter with time under isothermal annealing condition shown in Figure 3 by Karmazin et al. (1994 [DIRS 161444]; Figure 96c). The results show that, (1) the thermodynamic driving force at this alloy composition and the kinetic factors account fairly well for the kinetics of transformation and (2) although Mo enhances the stability of the ordered phase (increased critical order-disorder temperature at about $627^{\circ} \mathrm{C}$ ), the extrapolation of the TTT curves to lower temperatures confirms the observation already made in the binary case that the formation of the oP6-ordered phase out of the fcc-solid solution will not be a concern for conditions of less than $300^{\circ} \mathrm{C}$ for a period of 
500 years followed by temperatures of less than $200^{\circ} \mathrm{C}$ for a period of 9,500 years, conditions that bound the repository time-temperature profiles (BSC 2004 [DIRS 169565], Figure 6.3-57).

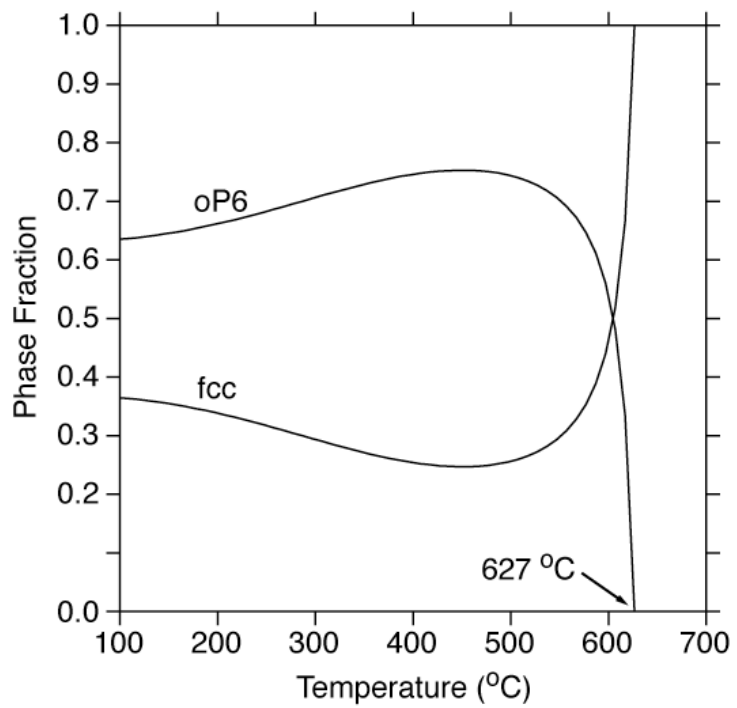

Source: DTN: LL030106312251.013.

NOTE: The fcc and oP6-ordered phases are considered. All other phases are suspended during the calculations.

Figure 85. Property Diagram of Ni-24 at \% Cr-8 at \% Mo (or 20.78 wt \% Cr and 12.78 wt \% Mo)

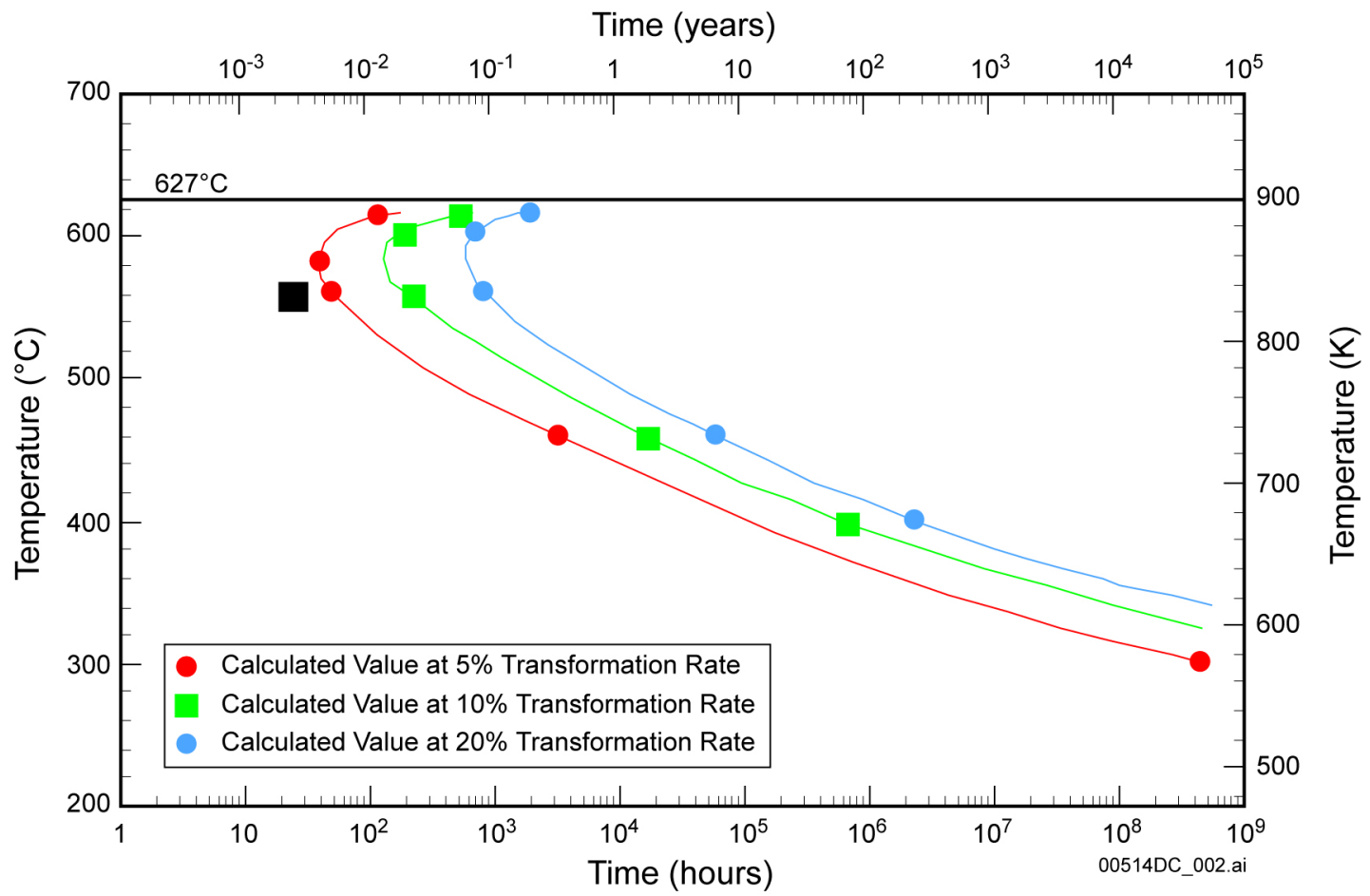

Source: DTN: LL030106312251.013.

NOTE: The black solid square indicates the results deduced from annealing experiments performed on a $\mathrm{Ni}-\mathrm{Cr}-$ Mo alloy at the same composition presented by Karmazin et al. (1994 [DIRS 161444]).

Figure 86. Calculated Isothermal TTT Diagrams for an fcc-Based Matrix of a Ternary Ni-20.78Cr$12.78 \mathrm{Mo}$ (in wt \%) Cr Alloy Transforming into the oP6-Ordered Phase, with Transformation Rates of $5 \%, 10 \%$, and $20 \%$ 


\subsubsection{Kinetics of Transformation in a Ni-21.1 wt \% Cr-13.5 wt \% Mo Alloy}

For this series of calculations, the nominal composition, Ni, 21.1 Cr, and 13.5 Mo (in wt \%), was used for the ternary Ni-Cr-Mo- alloy that can be considered as a surrogate for Alloy 22.

Three transformations were considered: the fcc matrix to the oP6-ordered phase, the fcc matrix to the $\mathrm{P}$ phase and the fcc matrix to the $\sigma$ phase. The corresponding property diagrams associated only with the fcc matrix and the transformed phase (oP6, $\mathrm{P}$, or $\sigma$ ) were considered in the calculations are displayed in Figure 87. In the study of the kinetics of phase formation of the oP6-ordered phase, $7.5 \mathrm{wt} \%$ Mo is used instead of $13.5 \mathrm{wt} \%$. This reduction in Mo accounts for the role of $\mathrm{W}$ in destabilizing the ordered phase, and the relative contribution of $\mathrm{W}$ is approximately twice that of Mo $(1 \mathrm{wt} \% \mathrm{~W} \approx 2 \mathrm{wt} \% \mathrm{Mo})$. Details of this treatment are discussed in Section 7.4.
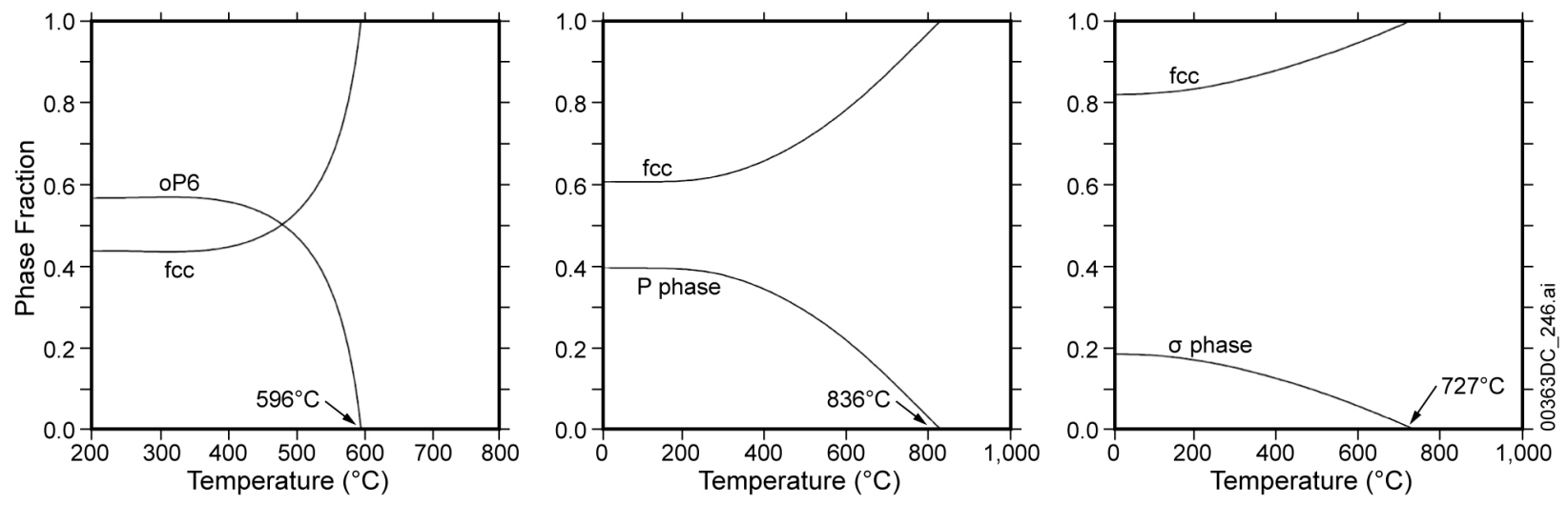

Source: DTN: LL030106312251.013.

NOTE: $\quad$ The fcc Matrix and the Op6-Ordered Phase (Left Panel; in This Case, $7.5 \mathrm{Wt} \%$ Mo Was Considered Instead of $13.5 \mathrm{Wt} \%$, P Phase (Middle Panel), and $\sigma$ Phase (Right Panel) are Considered. All Other Phases are Suspended During the Calculations.

Figure 87. Property Diagram of Ni-21.1 wt \% Cr-13.5 wt \% Mo

In Figure 88, the TTT diagram associated with the fcc to oP6 transformation is displayed with $2 \%, 10 \%$, and $15 \%$ transformation rates. When compared with the results for the binary $\mathrm{Ni}_{2} \mathrm{Cr}$ alloy, the combined role of Mo and $\mathrm{W}$ has the effect of enhancing the critical order-disorder temperature from $553^{\circ} \mathrm{C}$ to $596^{\circ} \mathrm{C}$. 


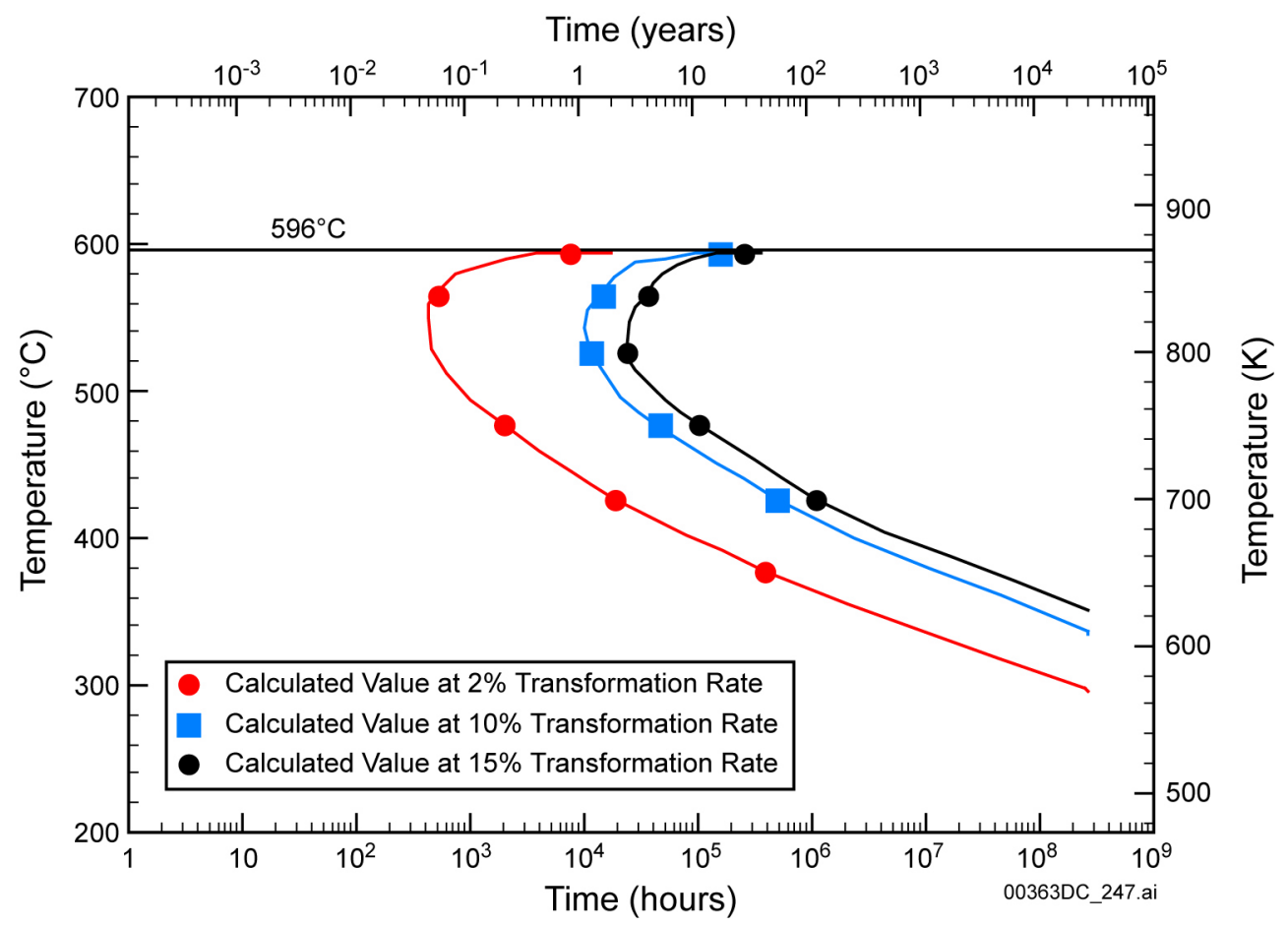

Source: DTN: LL030106312251.013.

Figure 88. Calculated Isothermal TTT Diagram for an fcc-Based Matrix of a Ternary Ni-21.1Cr-7.5Mo (in wt \%) Alloy (Surrogate for Alloy 22) Transforming into the oP6-Ordered Phase, with Transformation Rates of $2 \%, 10 \%$, and $15 \%$

The transformation from the fcc-based matrix to the $\mathrm{P}$ phase with $2 \%, 10 \%$, and $15 \%$ transformation rates was considered (from left to right in Figure 89) as a function of time and temperature. The results are comparable with the qualitative observations cited by Turchi 2001 ([DIRS 154934]).

The transformation from the fcc-based matrix to the $\sigma$ phase with $2 \%, 5 \%$, and $10 \%$ transformation rates was simulated (from left to right in Figure 90) as a function of time and temperature. In contrast to the formation from the fcc-matrix to the oP6-ordered phase that is rather slow, the incipient formation of the $\mathrm{P}$ phase is quite fast (a few hours in the bulk). However, as was concluded previously, the extrapolation of these TTT curves to lower temperatures clearly indicates that formation of the $\mathrm{P}$ phase out of the fcc-solid solution will not be a concern for conditions of less than $300^{\circ} \mathrm{C}$ for a period of 500 years followed by temperatures of less than $200^{\circ} \mathrm{C}$ for a period of 9,500 years, conditions that bound the repository time-temperature profiles (BSC 2004 [DIRS 169565], Figure 6.3-57). 


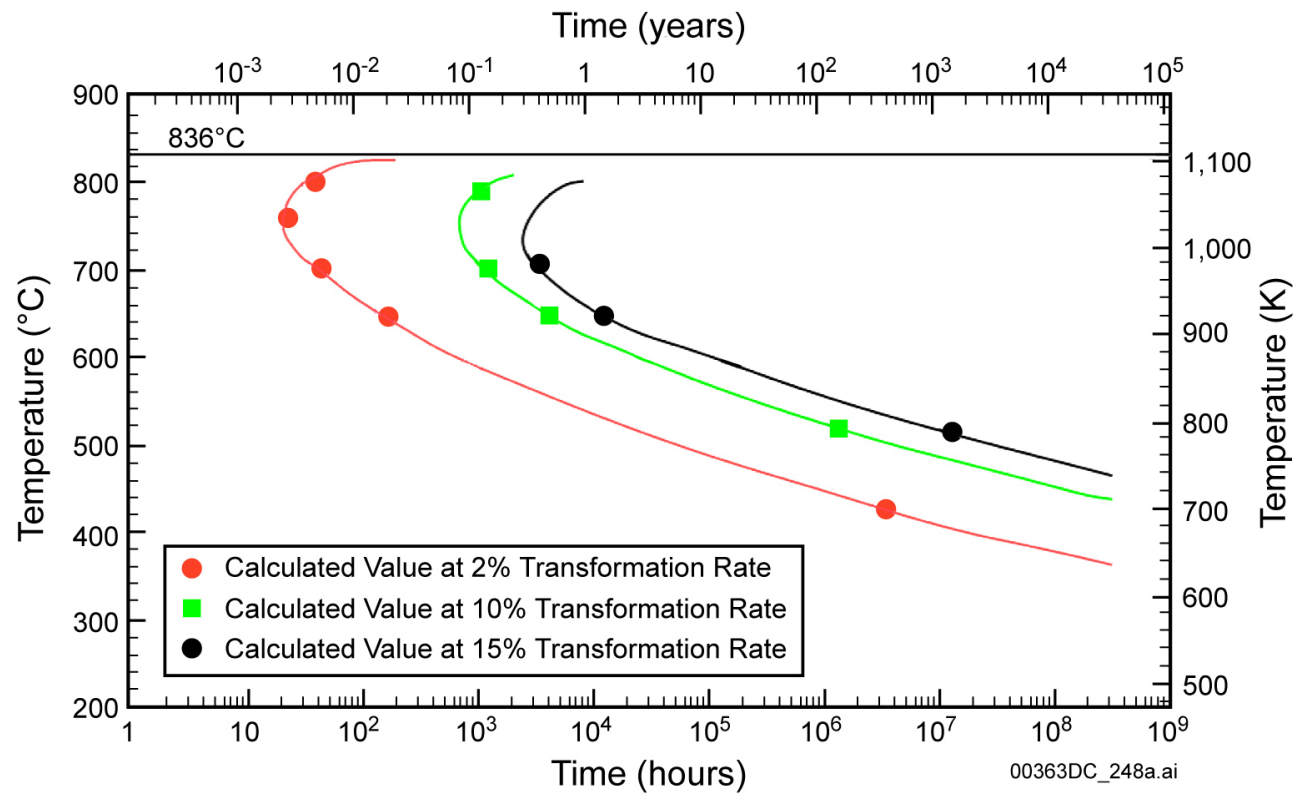

Source: DTN: LL030106312251.013.

Figure 89. Calculated Isothermal TTT Diagram for an fcc-Based Matrix of a Ternary Ni-21.1Cr-13.5Mo (in wt \%) Alloy (Surrogate for Alloy 22) Transforming into the P Phase, with Transformation Rates of $2 \%, 10 \%$, and $15 \%$

It should be noted that in the computational TTT diagrams presented in this section using the ternary Ni-Cr-Mo alloy (a surrogate for Alloy 22), the effects of $\mathrm{Ni}, \mathrm{Cr}, \mathrm{Mo}$, and $\mathrm{W}$ (the elements that contribute most significantly to Alloy 22 phase stability) are included in the computational simulations. Although other elements in the Alloy 22 compositional specification may affect Alloy 22 phase phenomena, these elements are presently not modeled in the ternary Ni-Cr-Mo alloy. Also, in these calculations, grain boundary formation is not considered; that is, the results only apply to bulk formation and homogeneous-phase evolution. 


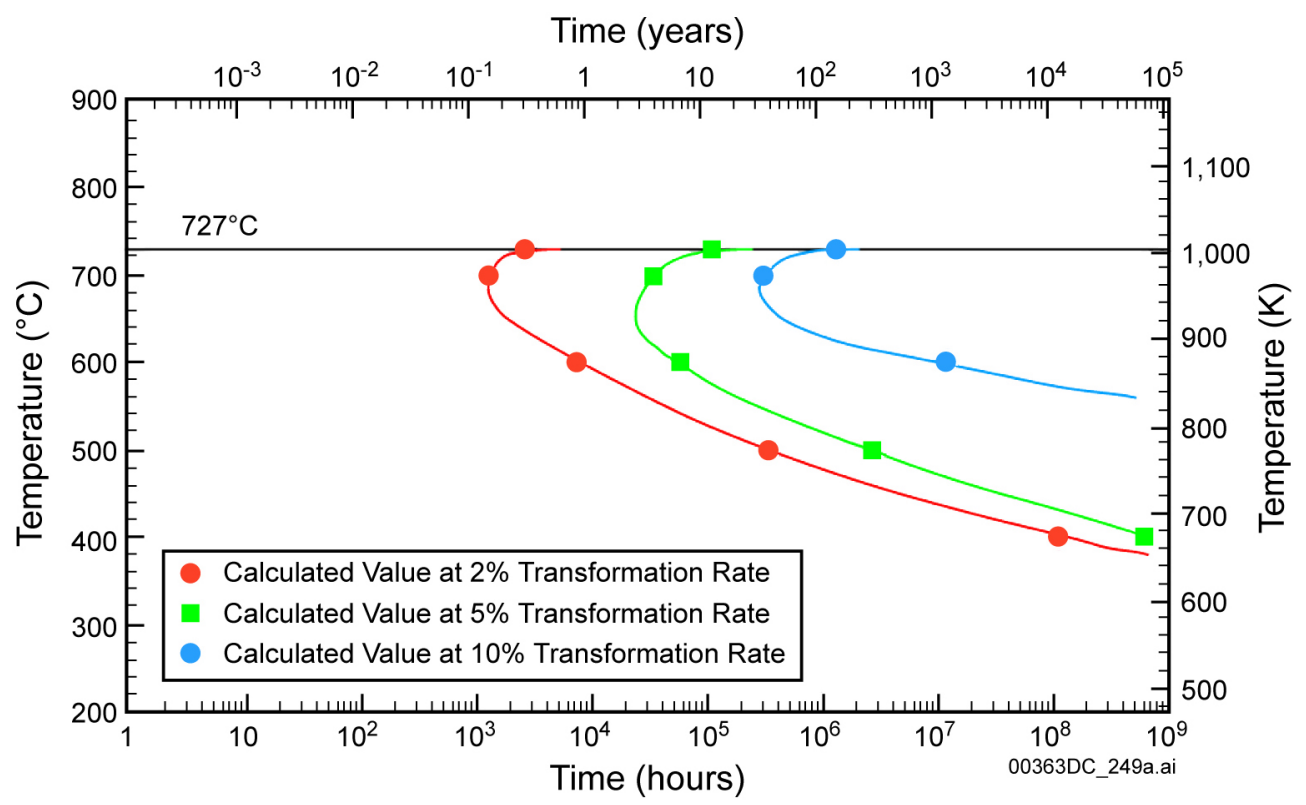

Source: DTN: LL030106312251.013.

Figure 90. Calculated Isothermal TTT Diagrams for an fcc-Based Matrix of a Ternary $\mathrm{Ni}-21.1 \mathrm{Cr}-13.5 \mathrm{Mo}$ (in wt \%) Alloy (Surrogate for Alloy 22) Transforming into the $\sigma$ Phase, with Transformation Rates of $2 \%, 5 \%$, and $10 \%$

\subsubsection{Volume-Fraction Measurements in Alloy 22}

In order to measure the amount of TCP-phase precipitation in Alloy 22 base metal and welds, area-fraction measurements have been made, using SEM image analyses, as a function of aging time and temperature. Using standard methods of quantitative stereology, it has been shown that area-fraction measurements (and correspondingly, linear-fraction measurements on grain boundaries) are mathematically equivalent to volume-fraction measurements (Vander Voort 2000 [DIRS 161300]; Hilliard and Cahn 1961 [DIRS 161454]). Thus, the area-fraction measurements presented in this report are equivalent to the volume-fraction values in Alloy 22 as a function of time and temperature.

The SEM image analyses that were performed measured gross TCP-phase precipitation in the samples as a function of time and temperature. No TCP-phase extraction was conducted to differentiate the types of TCP phases that may be present (e.g., $\mu$ or P phases) in these measurements.

\subsubsection{Area-Coverage Measurements on Grain Boundaries}

Similar to the area-fraction measurements on base metal samples, area-coverage measurements (linear-fraction measurements) on grain boundaries have been performed using SEM image analyses. Again, using standard methods of quantitative stereology, these linear-fraction measurements of TCP-phase precipitation on grain boundaries are mathematically equivalent to volume-fraction measurements (Vander Voort 2000 [DIRS 161300]; Hilliard and Cahn 1961 [DIRS 161454]). Figure 91 summarizes the grain-boundary measurements shown in Table 3. 


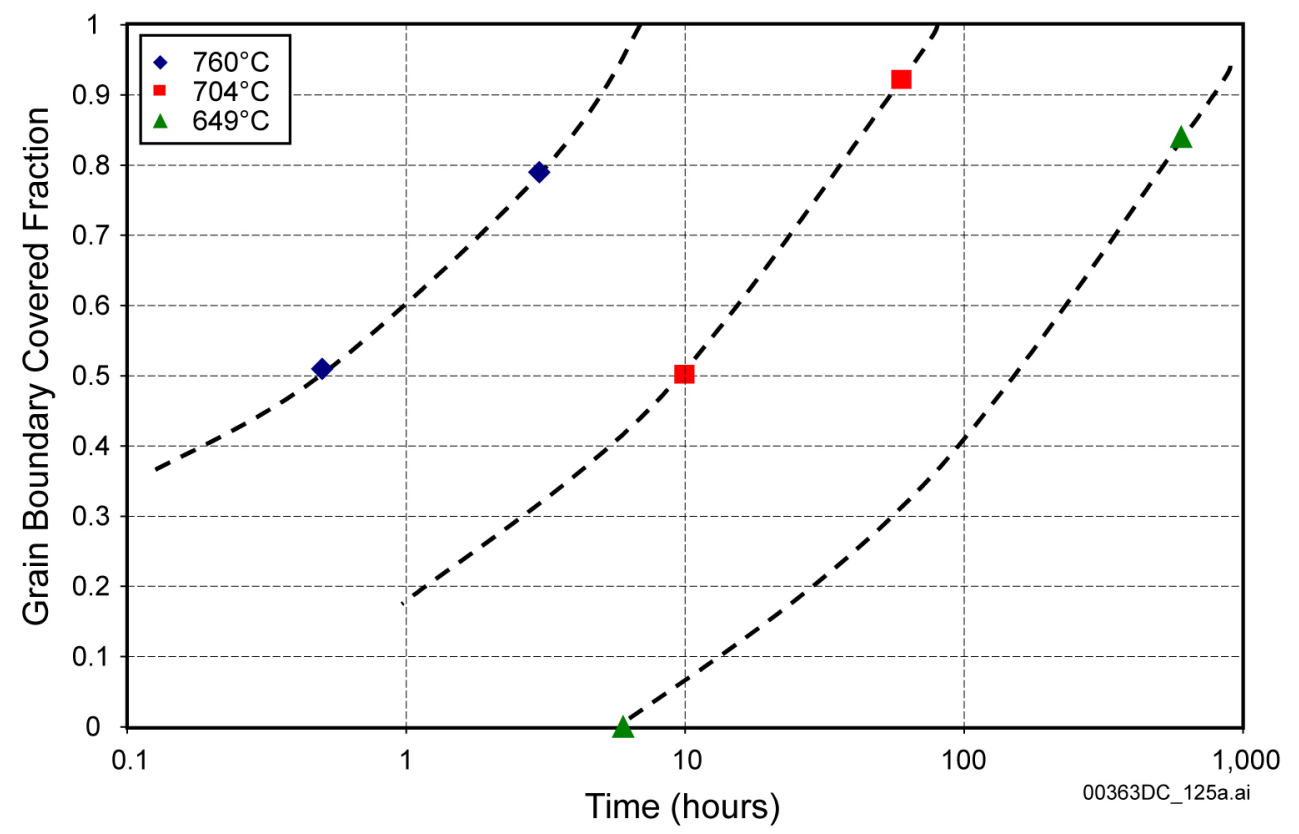

Source: DTN: LL030606912251.020.

Figure 91. TCP Phase Precipitation on Alloy 22 Grain Boundaries as a Function of Time and Temperature

Due to the paucity of available grain coverage data (as shown in Figure 91), only a few observations regarding TCP phase precipitation on grain boundaries are noted. Similar to TCP-phase precipitation in base metal, TCP-phase precipitation on grain boundaries is dependent on temperature. The onset of TCP-phase precipitation on grain boundaries appears to be delayed with decreasing temperature.

\subsection{Estimation of Bounding Case for TCP Phase Precipitation on Grain Boundaries}

Until more measurements of TCP-phase precipitation on grain boundaries or the corresponding results from computational modeling are available, a bounding case of TCP-phase precipitation on grain boundaries can be formulated from the grain-boundary precipitation measurements.

Nucleation and growth kinetics can often be represented by an equation of the following form:

$$
f=1-\exp \left(-k t^{n}\right)
$$

where $f$ is the volume fraction of the precipitating phase, $t$ is the time at the aging temperature, and $k$ and $n$ are constants (Christian 1981 [DIRS 104964], p. 19, Equation 4.11). The value of $k$ depends on nucleation and growth rates and therefore depends very strongly on temperature, usually of the following form:

$$
k=C_{1} \exp \left(-C_{2} / T\right)
$$

where $C_{1}$ and $C_{2}$ are constants and $T$ is the temperature (e.g., Christian 1981 [DIRS 104964], p. 438, Equation 49.2, where the exponentials representing atomic vibrational frequency and 
activation energy for an elementary atomic movement have been combined). Ideally, the volume fraction of precipitation would be measured as a function of time and temperature and would be fit to Equation 9. Precipitation times can be fit to Equation 9 if it is modified for a constant volume fraction. Combining Equations 9 and 10 at constant volume fraction yields:

$$
\ln \left(t_{f}\right)=\frac{C_{2}}{n} \cdot \frac{1}{T}+C_{f}
$$

where $C_{f}$ is a constant containing the constant volume fraction term, $f$, from Equation 9. Equation 11 is of the usual linear form, $y=m x+b$, representing $\ln \left(t_{f}\right)$ as a function of $1 / T$. Plots of $\log$ (time) versus reciprocal temperature for $20 \%$ and $80 \%$ grain boundary coverage are shown in Figure 92.

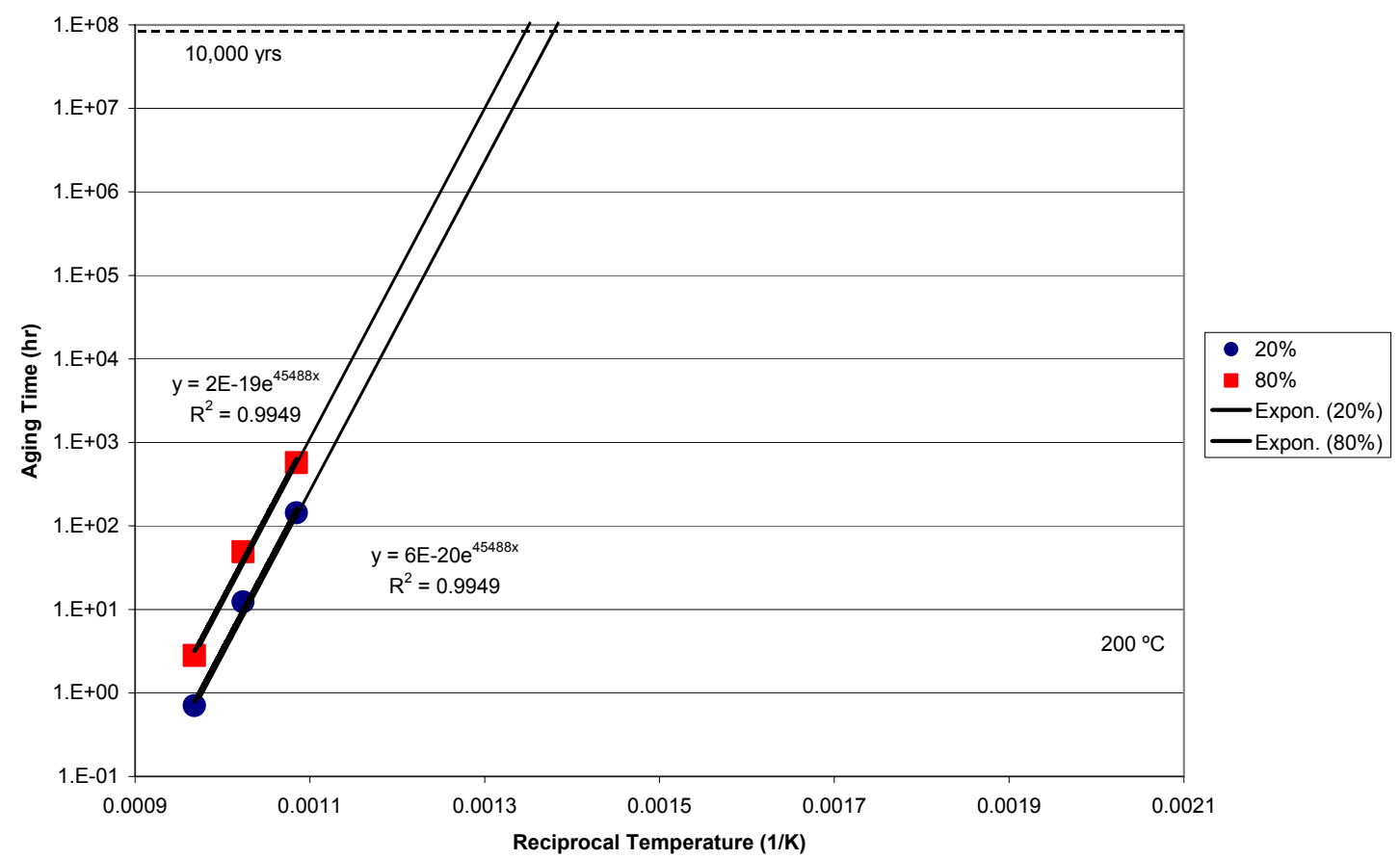

Source: DTN: LL030606912251.020.

Figure 92. Time to Form $20 \%$ and $80 \%$ Grain Boundary Coverage of TCP Phases in Alloy 22 Base Metal as a Function of Aging Temperature

\subsubsection{Volume-Fraction Measurements in Weld Metal}

\subsection{Background}

Gas-tungsten-arc welds, which were made from 0.5-in. thick Alloy 22 base metal in a single V-groove configuration using nine passes, were examined using optical microscopy at magnifications of 200 and 400 times. These welds were produced and aged at $593^{\circ} \mathrm{C}, 649^{\circ} \mathrm{C}$, $704^{\circ} \mathrm{C}$, and $760^{\circ} \mathrm{C}$ for times up to 1,000 hours at Haynes International, Inc. in Kokomo, Indiana (Summers et al. 2000 [DIRS 154854]). Volume fraction measurements were also made. The amount and size of precipitates in the welds vary with position in the weld. For example, 
relatively few and smaller precipitates tend to be present near weld pass boundaries, while many larger precipitates tend to be present at the top of the last weld pass (Figure 42). The measurements presented here represent averages over several positions in the weld. These welds are also much thinner than those called out in the current waste package design. Welding conditions, such as heat input, that may affect the starting weld structure and the subsequent precipitation kinetics will be different for thicker welds. Also, several phases are expected in Alloy 22 welds; $\sigma, \mu$, and P have been observed (Cieslak et al. 1986 [DIRS 104966], p. 2,041). The growth kinetics for each of these phases may be different. In the base metal, it is likely that the amount of $\sigma$ phase precipitating is small at temperatures below about $750^{\circ} \mathrm{C}$ and that $\mu$ and $\mathrm{P}$ phases are similar. In the weld, however, the amount of $\sigma$ phase may be quite high due to chemical segregation.

\subsection{Tetrahedrally Close-Packed Phase Kinetics in Alloy 22 Welds}

As observed by Cieslak et al. (1986 [DIRS 104966]), TCP phases are present in the interdentritic regions of the as-welded structure. After aging, the amount and size of TCP precipitates increases with both time and temperature up to $760^{\circ} \mathrm{C}$. Nucleation of precipitation was also observed to form possibly along grain boundaries in some areas of these samples. The volume fraction of precipitates is shown as a function of time in Figure 93. Each of the data points (Table 4) in Figure 93 represents the average of 20 to 40 measurements. In the as-welded condition, there is approximately 0.02 vol. \% TCP phase.

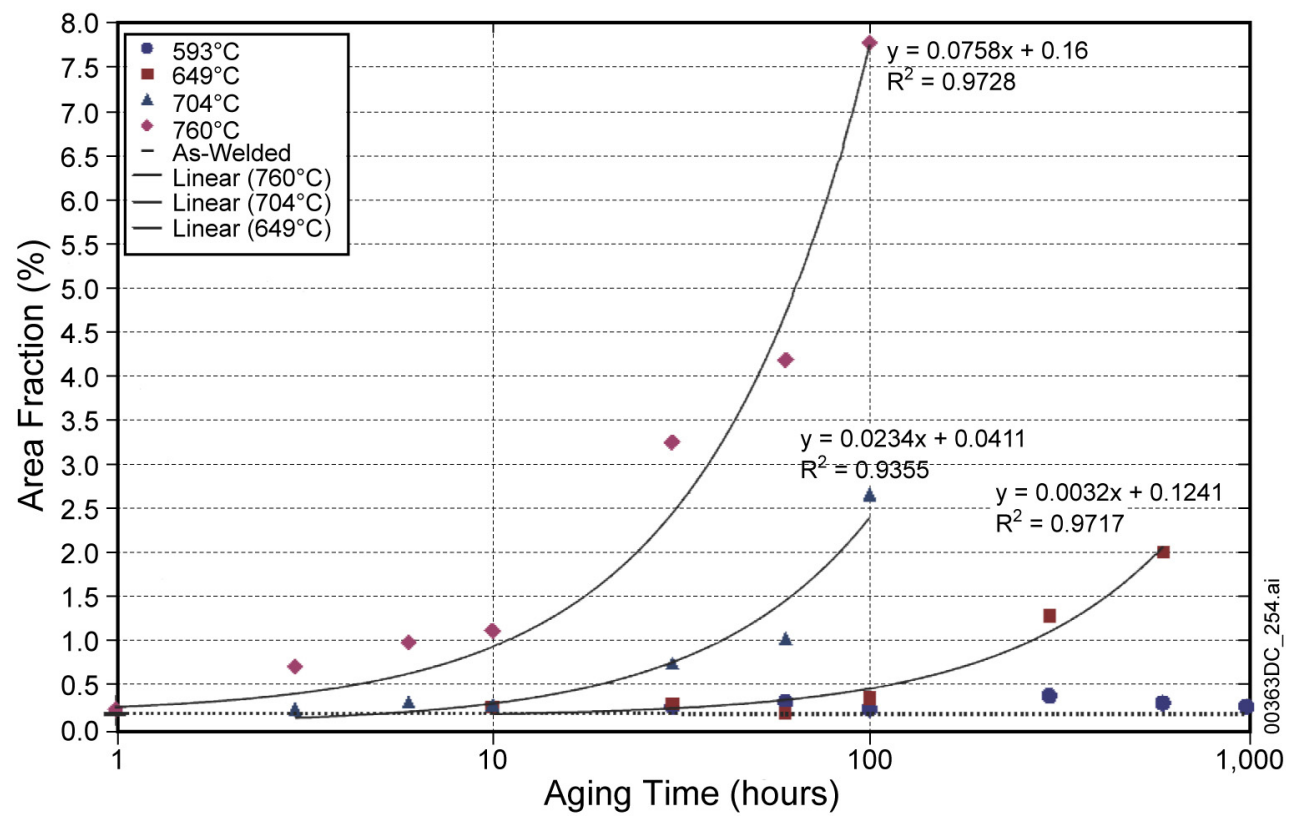

Source: DTN: LL030606912251.020.

Figure 93. TCP-Phase Precipitation Kinetics in C-22 GTAW Welds as a Function of Temperature

The volume fraction data of Figure 93 were fit, for each aging temperature with a trend line, using Equation 11 (Section 6.6.5.2.1). From these curve fits, the times to give 1\% and 5\% volume fraction were calculated. These times are plotted in Figure 94 as a function of reciprocal temperature. The average activation energy calculated from the slopes of these plots 
is $241 \mathrm{~kJ} / \mathrm{mol}$. Extrapolations of these data indicate that precipitate nucleation and growth in the welds will not occur to a significant extent at temperatures below approximately $200^{\circ} \mathrm{C}$, and also significant margin for temperatures below $300^{\circ} \mathrm{C}$ is also evident.

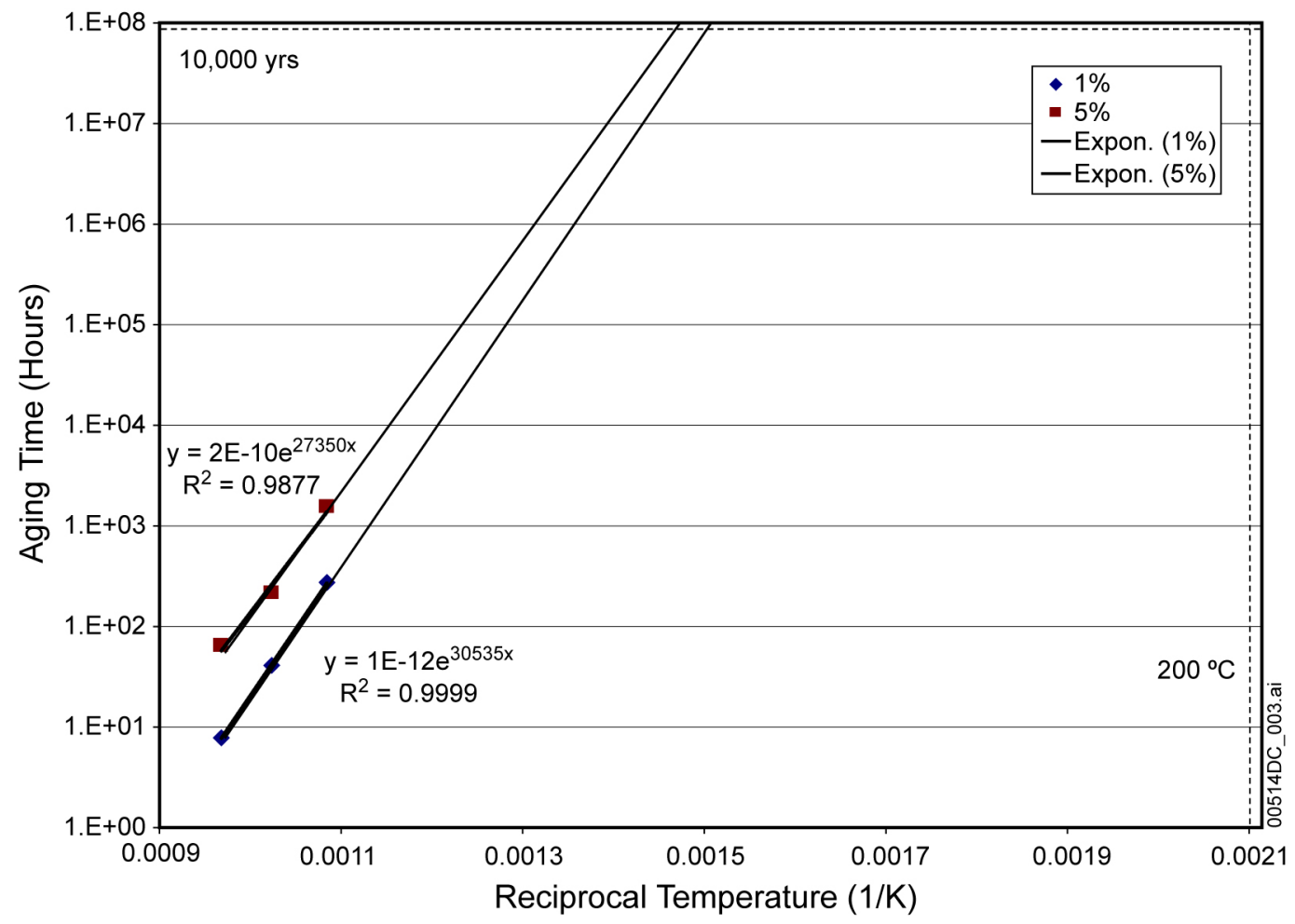

Source: DTN: LL030606912251.020.

Figure 94. Time to Form 1 and 5 vol \% TCP Phase in C-22 Welds as a Function of Aging Temperature

\subsection{MODEL UNCERTAINTY AND CONFIDENCE}

\subsubsection{Model Uncertainty}

\subsubsection{Experimental Uncertainty}

When experimentally determining the extent of phase precipitation, uncertainty in the experimental results is primarily due to measurement uncertainties in the image analysis process. In order to determine the area-fraction coverage (\%) resulting from phase precipitation, imageanalysis software (Image-Pro Plus) is used. Each value representing the area-fraction coverage at a specific time and temperature is the result of approximately 40 to 50 measurements. Electron microscopy images used in the image analyses are digitized using an 8-bit pixel depth, which corresponds to 256 shades of gray per pixel.

The measurement uncertainty in the area-fraction-coverage values is quantified in the standard deviation and 95\% confidence interval values for each series measurements at a particular time and temperature. The standard deviations and 95\% confidence intervals (shown in Table 3 through Table 4) are computed per ASTM E 562-95, Standard Test Method for Determining Volume Fraction by Systematic Manual Point Count ([DIRS 161301], Section 4.1.8). 
As described in Section 4.1.8, there is more uncertainty (larger standard deviation values) in the volume fraction measurements on specimens subjected to lower temperatures or shorter aging times, or both. At these temperatures and times, the volume fraction measurements have been performed on minimally detectable levels of precipitates (near zero). This uncertainty at nearzero levels of precipitation has no impact on the aging and phase stability model because the model predicts the extent, not initiation, of phase precipitation as a function of time and temperature. The initiation of precipitation (where the uncertainty is large) is of no consequence to the aging and phase stability model and has no impact on its results. As shown in Section 4.1 .8 , the uncertainty is considerably reduced in measurements where significant amounts $(>5 \%)$ of precipitation have occurred.

\subsubsection{Accuracy of the Thermo-Calc and DICTRA Results}

The analysis of the results on stability and aging is based on calculations made with the ThermoCalc and DICTRA application software packages, respectively. These software codes use databases.

In the case of Thermo-Calc, the original thermo-chemical database that contains information on the energetics of all phases made of the ten elements: C, Co, Cr, Fe, Mn, Mo, Ni, Si, V, and W, has been extracted from the SSOL database normally called by Thermo-Calc. The database has been reevaluated based on experimental data specifically available for the Ni-based class of alloys. This reevaluation accounted for output information such as assessed-phase diagram, measured heat of formation, and transformation for binary and ternary alloys. Once the database has been validated, predictions are made on phase-stability information, such as property diagrams, isopleths, and Scheil-Gulliver results on solidification. Hence, the accuracy of the output information is mostly based on the machine accuracy of the calculations, once the thermochemical database has been validated.

In the case of DICTRA, two databases are used: the thermo-chemical database used by Thermo-Calc and a database that contains information on diffusion coefficients and mobilities. The original MOB database that is normally called by DICTRA has been validated with experimental information on TTT diagrams available for binary and ternary alloys. Again, once validation has been achieved (Section 7), predictions are made for the aging properties of various phases exhibited by multicomponent alloys, and the accuracy of the TTT results is mostly based on the machine accuracy associated with the numerical resolution of the equations.

Validation of the databases used in this study is described in detail in Section 7. 


\section{INTENTIONALLY LEFT BLANK}




\section{VALIDATION}

The goal of this model is to determine whether the single-phase solid solution of Alloy 22 is stable under repository conditions, and if not, how fast other phases may precipitate. The aging and phase stability model, which is based on fundamental thermodynamic and kinetic concepts and principles, is used to provide predictive insight into the long-term metallurgical stability of Alloy 22 under relevant repository conditions.

During the course of developing the aging and phase stability model, the Thermo-calc and DICTRA databases were modified to more accurately simulate and analyze the thermodynamic and kinetic behavior of Alloy 22. As a result, the first step in model validation was to validate the database modifications (in order of increasing complexity) by comparing the calculated phase diagrams with those in published literature. These comparisons build confidence in demonstrating that the computational model is accurately simulating the phase phenomena associated with Alloy 22. Having validated the calculated phase diagrams, it was then prudent to proceed with developing the alloy property and TTT diagrams of the aging and phase stability model. This validation of the calculated phase diagrams is in addition to the model validation activities described in Technical Work Plan for: Regulatory Integration Modeling and Analysis of the Waste Form and Waste Package (BSC 2004 [DIRS 171583]).

The Thermo-Calc results used in analyzing Alloy 22 along with several other Ni-based alloys have been validated using comparisons of calculated phase diagrams with published literature for (1) the binary sub-systems, (2) the pseudo-binary section $\mathrm{Ni}_{\mathrm{x}}\left(\mathrm{Cr}_{3} \mathrm{Mo}\right)_{1-\mathrm{x}}$, and (3) the ternary Ni-Cr-Mo alloy (a surrogate for Alloy 22). Agreement of the calculated phase diagrams with published literature is excellent and described below.

In this section, the validation of the calculated phase diagrams is discussed first followed by the discussion of the model validation criteria of Technical Work Plan for: Regulatory Integration Modeling and Analysis of the Waste Form and Waste Package (BSC 2004 [DIRS 171583]).

Sensitivity analyses (BSC 2003 [DIRS 168796]) indicate that estimated dose at the regulatory compliance point is not sensitive to the aging and phase stability model. As a result, and as indicated in Table 2-1 of Technical Work Plan for: Regulatory Integration Modeling and Analysis of the Waste Form and Waste Package (BSC 2004 [DIRS 171583]), Level I model validation is required for the aging and phase stability model. 


\section{Confidence-Building During Model Development to Establish Scientific Basis and Accuracy for Intended Use-}

Section 2.2.1 of Technical Work Plan for: Regulatory Integration Modeling and Analyses of the Waste Form and Waste Package (BSC 2004 [DIRS 171583]) specifies several steps for confidence building during model development. The model will contain documentation of decisions and activities implemented during the model development process to build confidence and verify a reasonable, credible, technical approach using scientific and engineering principles. The development of the model should be documented in accordance with AP-SIII.10Q (Section 5.3.2(b)) requirements. The development of the aging and phase stability model has been conducted according to these criteria, as follows:

(1) Selection of input parameters and/or input data, and a discussion of how the selection process builds confidence in the model. (AP-SIII.10Q, 5.3.2(b) (1); AP-2.27Q, Attachment 3 Level I (a)).

The bases for selecting the input data that are used to determine and develop the aging and phase stability model are documented in Section 4.1. Model assumptions have been described in Section 5. Detailed discussion about the computational model concepts can be found in Section 6.5. Thus, this requirement is satisfied.

(2) Description of calibration activities, and/or initial boundary condition runs, and/or run convergences, simulation conditions set up to span the range of intended use and avoid inconsistent outputs, and a discussion of how the activity or activities build confidence in the model. Inclusion of a discussion of impacts of any non-convergence runs. (AP-SIII.10Q, 5.3.2(b)(2); AP-2.27Q, Attachment 3 Level I (e)).

Model formulations for the aging and phase stability model are discussed in Sections 6.5. Kinetic and thermodynamic modeling have been combined and applied to the study of diffusioncontrolled transformations with the use of the DICTRA application linked with Thermo-Calc. Simulations have been performed and validated on three alloy systems, in order of increasing complexity: (1) a binary $\mathrm{Ni}-\mathrm{Cr}$ alloy, (2) a pseudo-binary $\mathrm{Ni}_{\mathrm{X}}\left(\mathrm{Cr}_{3} \mathrm{Mo}\right)_{1-\mathrm{X}}$ alloy, and (3) a ternary $\mathrm{Ni}-\mathrm{Cr}-\mathrm{Mo}$ alloy that can be considered as a surrogate for Alloy 22 (Sections 6.6.4, 7.1, 7.2, 7.3, and 7.4). Thus, this requirement is also satisfied.

(3) Discussion of the impacts of uncertainties to the model results including how the model results represent the range of possible outcomes consistent with important uncertainties. (AP-SIII.10Q, 5.3.2(b)(3); AP-2.27Q, Attachment 3 Level 1 (d) and (f)).

Accuracy of the Thermo-calc and DICTRA results and the uncertainties associated with the experimental data supporting the computational model are described in Section 6.7. Thus, this requirement is satisfied. 
(4) Formulation of defensible assumptions and simplifications. (AP-2.27Q, Attachment 3 Level I (b)).

Discussion of assumptions and simplifications and their rationale are provided in Section 5. Thus, this requirement is satisfied.

(5) Consistency with physical principles, such as conservation of mass, energy, and momentum. (AP-2.27Q, Attachment 3 Level I (c))

The computational model employs Thermo-Calc and DICTRA and is based on the so-called CALPHAD (CALculation of PhAse Diagrams) approach. This approach involves the coupling of phase diagrams calculations for multicomponent alloy systems with other forms of thermochemical inputs to determine phase formation, proportions, and transformations (Section 6.5). Thus, the aging and phase stability model is based on fundamental thermodynamic and kinetic concepts and principles and, thus this requirement is satisfied.

Confidence-Building After Model Development to Support the Scientific Basis of the Model-The specific validation criteria (from AP-SIII.10Q) to be applied to the aging and phase stability model after model development are:

(1) Corroboration of model results with data acquired from the laboratory, field experiments, analog studies, or other relevant observations, not previously used to develop or calibrate the model (AP-SIII.10Q, Section 5.3.2).

Confidence in the accuracy of the models is addressed by evaluating the consistency of the models with data published in refereed journals or industrial literature and data from laboratory tests not used to develop the models (Sections 7.1 through 7.4). In Section 7.4, confidence in the developed computational aging and phase stability model is established by comparing the model to available project data that were not used in the models' development, and this comparison showed that the model is conservative. Thus, this requirement is satisfied.

(2) Corroboration with information published in refereed journals or literature (AP-SIII.10Q, Section 5.3.2).

Confidence in the accuracy of the models is addressed by evaluating the consistency of the models with data published in refereed journals (Sections 7.1 through 7.3). In these sections, published data is used to build confidence in the developed computational aging and phase stability model by comparing these data with the results from three alloy systems, in order of increasing complexity: (1) a binary $\mathrm{Ni}-\mathrm{Cr}$ alloy, (2) a pseudo-binary $\mathrm{Ni}_{\mathrm{X}}\left(\mathrm{Cr}_{3} \mathrm{Mo}\right)_{1-\mathrm{X}}$ alloy, and (3) a ternary Ni-Cr-Mo alloy that can be considered as a surrogate for Alloy 22. Thus, this requirement is satisfied. 
The specific validation criteria applicable to the aging and phase stability model, as described in the technical work plan (BSC 2004 [DIRS 171583], Table 2-1), are:

(VA 1) Do comparisons of Topologically Close-Pack Phases (TCP) and Longrange ordering (LRO) formations in base metal from THERMOCALC / DICTRA agree with experimental data on base metal?

(VA 3) Do experimental data on TCP formations on base metal grain boundaries and TCP and LRO formations in weld metal corroborate with data in peerreviewed literature or fundamental metallurgical phenomena?

(VA 3) Do comparisons of volume fraction measurements agree with peerreviewed published literature (where applicable) and lor fundamental metallurgical phenomena?

Corroborating data must match qualitatively.

Section 7.5 describes in detail the application of these validation activities to the aging and phase stability model.

\subsection{VALIDATION OF THE THERMO-CALC RESULTS FOR THE BINARY SUB- SYSTEMS}

The calculated phase diagrams, as obtained from Thermo-Calc for $\mathrm{Cr}-\mathrm{Ni}$, Mo-Ni, $\mathrm{Cr}-\mathrm{Mo}$, $\mathrm{Cr}-\mathrm{W}, \mathrm{Mo}-\mathrm{W}$, and $\mathrm{Ni}-\mathrm{W}$ are presented in Figure 95 together with the experimentally determined phase diagrams extracted from Binary Alloy Phase Diagrams (Massalski 1990 [DIRS 118757]). These results indicate that the thermo-chemical database is able to account for the stability of most phases encountered experimentally in the composition and temperature domains in the Ni-Mo binary alloy, namely $\mathrm{Ni}_{4} \mathrm{Mo}, \mathrm{Ni}_{3} \mathrm{Mo}$, and $\mathrm{NiMo}$, and in the Ni-W binary alloy, namely $\mathrm{Ni}_{4} \mathrm{~W}, \mathrm{NiW}$, and $\mathrm{NiW}_{2}$. The results also account for the phase separation tendency in the body centered cubic (bcc) solid phase that is observed in the case of Cr-Mo and Cr-W. The binary Mo-W alloy displays an ideal solid solution based on the bcc phase with no particular tendency toward compound formation or phase separation. Also, in the case of the binary $\mathrm{Ni}-\mathrm{Cr}$ alloy, the ordered phase that is experimentally observed at low temperatures around the stoichiometry $\mathrm{Ni}_{2} \mathrm{Cr}$ (referred to as oP6 or $\mathrm{C} 11_{b}$ ) is not accounted for with the initial SSOL database. 


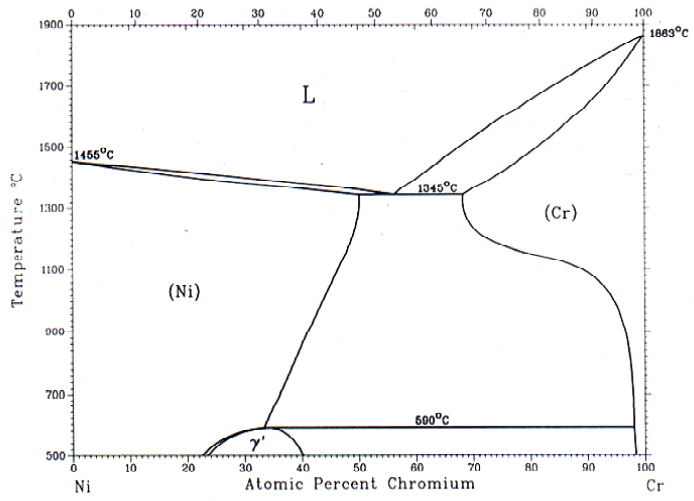

$\mathrm{Ni}-\mathrm{Cr}$
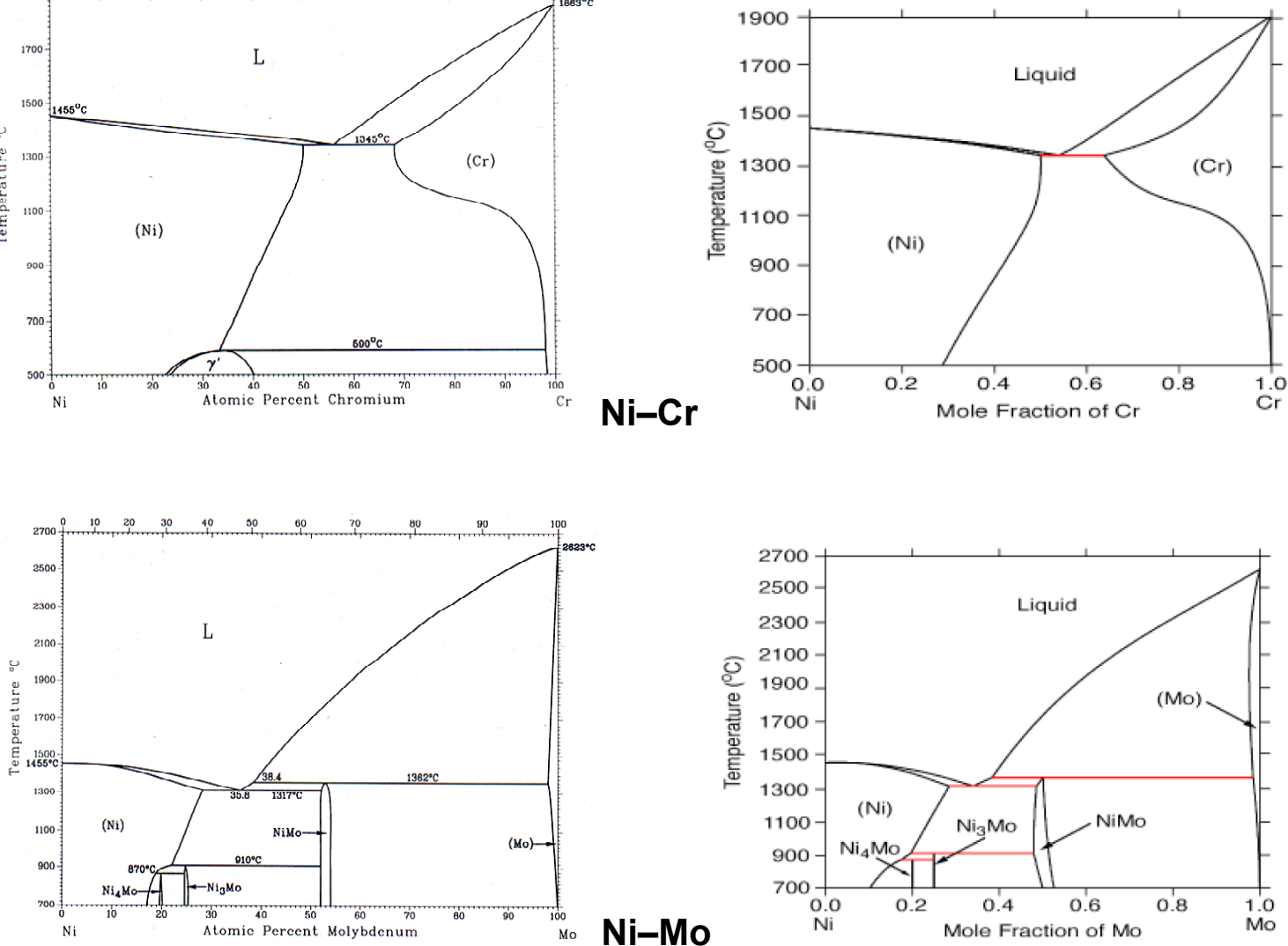

Ni-Mo
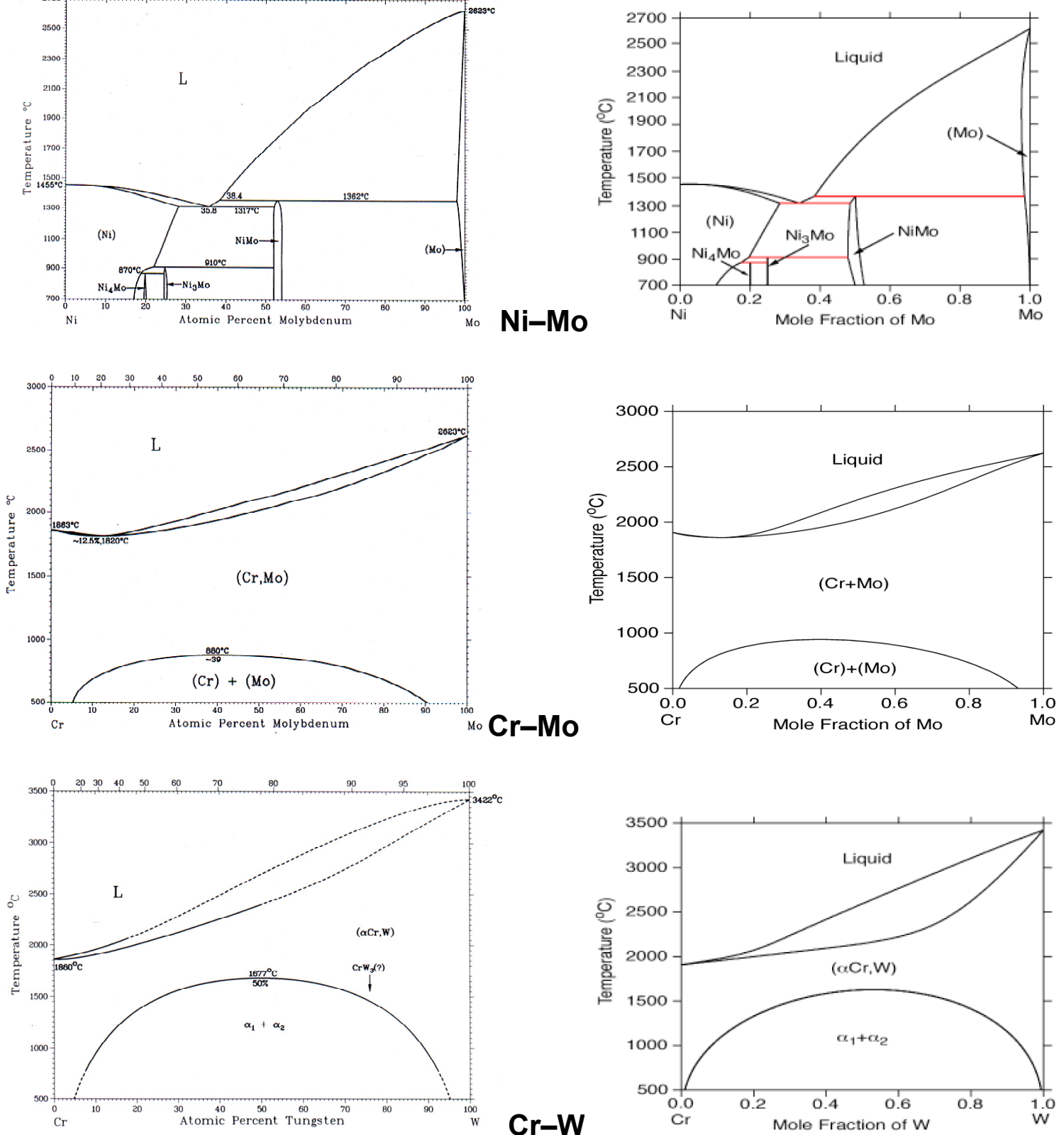

Cr-W

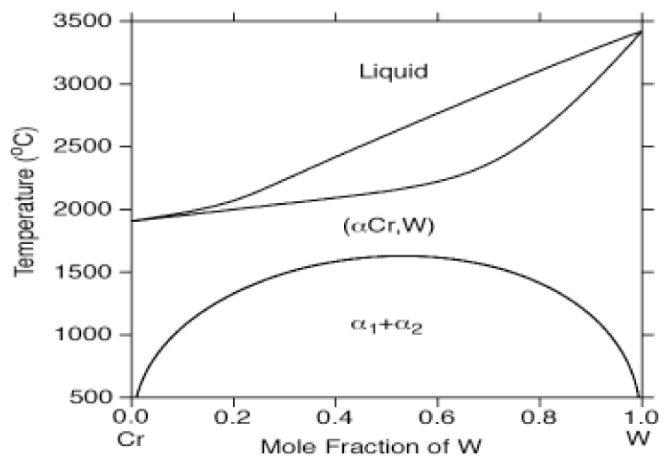




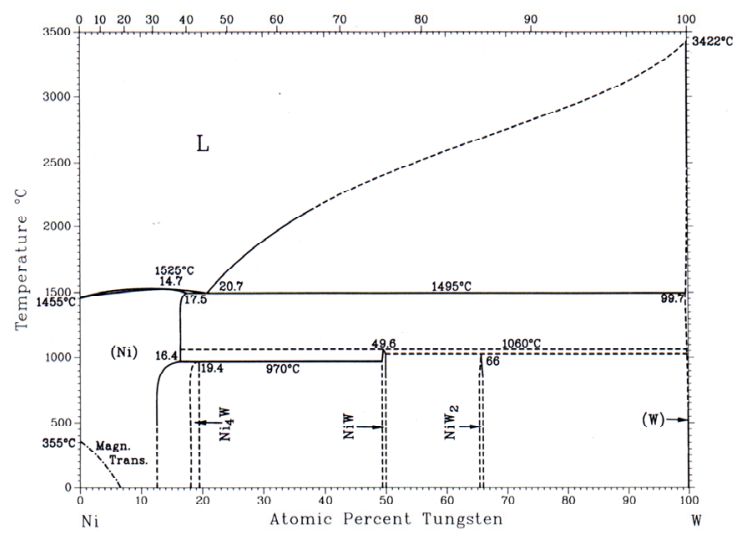

$\mathrm{Ni}-\mathbf{W}$
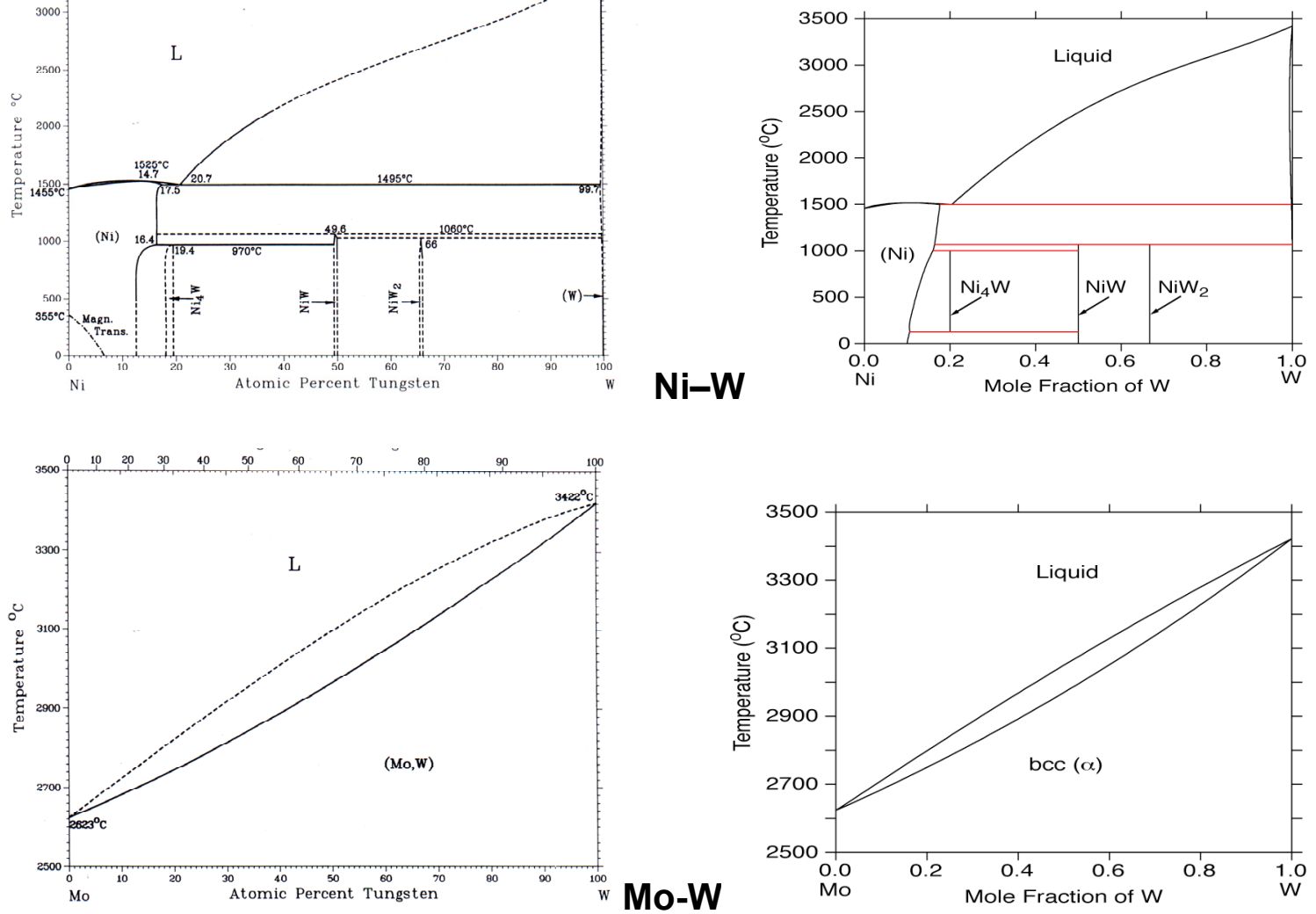

Source: (left) Massalski et al. [DIRS 118757]; (right) DTN: LL030106412251.014.

Figure 95. Comparison Between Experimentally Determined (Left) and Calculated (Right) Phase Diagrams of $\mathrm{Ni}-\mathrm{Cr}$, Ni-Mo, $\mathrm{Ni}-\mathrm{W}, \mathrm{Cr}-\mathrm{Mo}, \mathrm{Cr}-\mathrm{W}$, and $\mathrm{Mo}-\mathrm{W}$ alloys, as Obtained with Thermo-Calc

\subsubsection{Modeling of the Ordered Phase oP6}

To introduce the relevant data that define the Gibbs energy for the ordered phase $\mathrm{C} 11_{\mathrm{b}}$ (or oP6) made of $\mathrm{Ni}, \mathrm{Cr}, \mathrm{Mo}$, and $\mathrm{W}$, the following information was used. First, the experimental work performed by Hirabayashi et al. (1969 [DIRS 161452]) suggests a heat of formation for the $\mathrm{Ni}_{2} \mathrm{Cr}$ ordered phase of approximately $-4,200 \mathrm{~J} / \mathrm{g}$.at (or approximately $-1,000 \mathrm{cal} / \mathrm{g}$.at). Second, the experimental work by Karmazin et al. (1994 [DIRS 161444]), carried out for the oP6-ordered phase in Ni-rich Ni-Cr-Mo alloys, indicates that Mo can be located on two sublattices. Third, $a b$ initio electronic-structure calculations based on the tight-binding linear muffin-tin orbital (TB-LMTO) method (Turek et al. 2000 [DIRS 163109]) allows the estimation of the heat of formation of the oP6-ordered phase for $\mathrm{Ni}_{2} \mathrm{Cr}, \mathrm{Ni}_{2} \mathrm{Mo}$, and $\mathrm{Ni}_{2} \mathrm{~W}$. The results of total energyversus-lattice parameter for the ordered phase based on the fcc lattice are plotted in Figure 96 for the three compounds. 


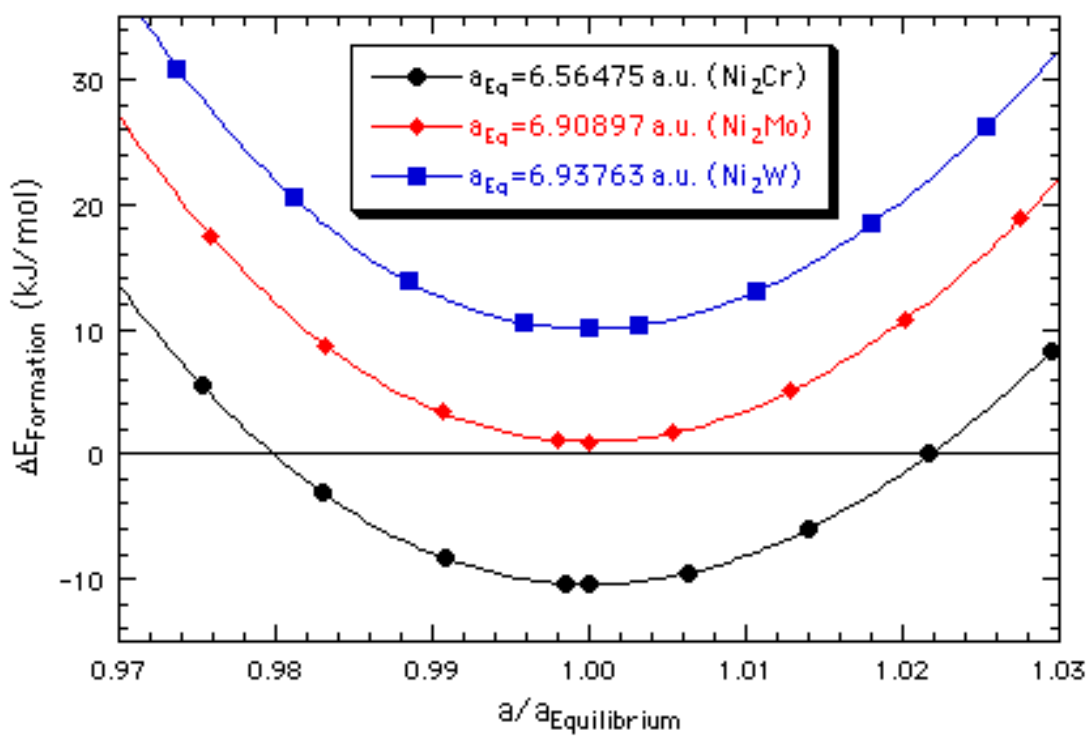

Source: DTN: LL030106412251.014.

NOTE: The zero of energy is taken as the concentration weighted average of the total energies of fcc $\mathrm{Ni}$ and bcc $\mathrm{Cr}$ (or Mo, W).

Figure 96 Total Energy (In kj/mol) Versus Normalized Lattice Parameter (i.e., a/a $\mathrm{a}_{\mathrm{eq}}$, Where a is the Lattice Parameter and $a_{\text {eq }}$ is the Equilibrium Lattice Parameter) for the Three Ordered Compounds $\mathrm{Ni}_{2} \mathrm{Cr}, \mathrm{Ni}_{2} \mathrm{Mo}$, and $\mathrm{Ni}_{2} \mathrm{~W}$ Of $\mathrm{Ni}_{2} \mathrm{Cr}$-Type (C11b or oP6)

Hence, in the following, the ordered phase is treated within a two-sublattice model (Section 6.5.3) with Cr, Mo, and $\mathrm{W}$ on one sublattice and Mo and Ni on the other sublattice. The compound phase parameters (computed with temperature $\mathrm{T}$ in $\mathrm{K}$, and the energies in $\mathrm{J} / \mathrm{g}$.at) are defined as follows (note that the parameters not included in the following are set to zero):

fcc-oP6 2-sublattice model $(\mathrm{Cr}, \mathrm{Mo}, \mathrm{W})_{1}(\mathrm{Mo}, \mathrm{Ni})_{.2}$, i.e., with $p=1$ and $q=2$

$$
\begin{array}{cc}
\Delta G_{\mathrm{Cr}: \mathrm{Mo}}^{\mathrm{fcc} 6}=\Delta G_{\mathrm{Mo}: \mathrm{Mo}}^{\mathrm{fcc}-\mathrm{P} 6}=\Delta G_{\mathrm{W}: \mathrm{Mo}}^{\mathrm{fcc} 6}=6000 & \Delta G_{\mathrm{Cr}: \mathrm{Ni}}^{\mathrm{fcc} 6}=-7095-5.6^{*} T \\
\Delta G_{\mathrm{Mo}: \mathrm{Ni}}^{\mathrm{fcc} 6 \mathrm{Pi}}=+1,000 & \Delta G_{\mathrm{W}: \mathrm{Ni}}^{\mathrm{fcc} 6}=10,000 \\
{ }^{0} L_{\mathrm{Cr}: \mathrm{Mo}, \mathrm{Ni}}^{\mathrm{fcc}-\mathrm{O} 6}=-80,000 \quad{ }^{0} L_{\mathrm{Cr}, \mathrm{Mo}: \mathrm{Ni}}^{\mathrm{fcc}-\mathrm{P} 6}=-11,000 & { }^{0} L_{\mathrm{Cr}: \mathrm{W}, \mathrm{Ni}}^{\mathrm{fcc}-\mathrm{PP} 6}=-55,000 \quad{ }^{0} L_{\mathrm{Cr}, \mathrm{WP}: \mathrm{Ni}}^{\mathrm{fcc}-\mathrm{ob}}=-8,000
\end{array}
$$

Based on the above discussion, these parameters were incorporated into the Thermo-Calc database to more properly model the oP6-ordered phase (Turchi 2003 [DIRS 162974]).

To adjust the experimental information on $\mathrm{Ni}_{2} \mathrm{Cr}$-ordered phase with already available thermodynamic data in the SSOL database, the heat of formation of $\mathrm{Ni}_{2} \mathrm{Cr}$ became $-7,095 \mathrm{~J} / \mathrm{mole}$ (instead of $-4,187 \mathrm{~J} / \mathrm{mol}$ ). The data for Mo-Ni and $\mathrm{W}-\mathrm{Ni}$ account for the ab initio results that indicate that $\mathrm{Ni}_{2} \mathrm{Mo}$ is barely stable, whereas $\mathrm{Ni}_{2} \mathrm{~W}$ is unstable (leading to a positive heat of formation of $10,000 \mathrm{~J} /$ mole). Finally the description of particular species on both sublattices is contained in the two Redlich-Kister parameters ${ }^{0} L^{\mathrm{fcc}-\mathrm{oP} 6}$ (Redlich et al. 1948 [DIRS 161464]). Their values have been adjusted to allow Mo to be located on the two sublattices, to spread the domain of stability of the ordered phase in accordance with Karmazin et al.'s (1994 
[DIRS 161444]) results and, at the same time, to account for the effect of Mo addition on the order-disorder transition temperature (Karmazin et al. 1994 [DIRS 161444]). Although $\mathrm{Ni}_{2} \mathrm{Mo}$ is barely stable, the magnitude of the critical order-disorder temperature for the oP6-ordered phase goes through a maximum as a function of Mo composition. This nonlinear effect of Mo is captured in the energetic description of the ordered compound.

The results of this reassessment are displayed in Figure 97 and are in agreement with the accepted phase diagram of $\mathrm{Ni}-\mathrm{Cr}$.
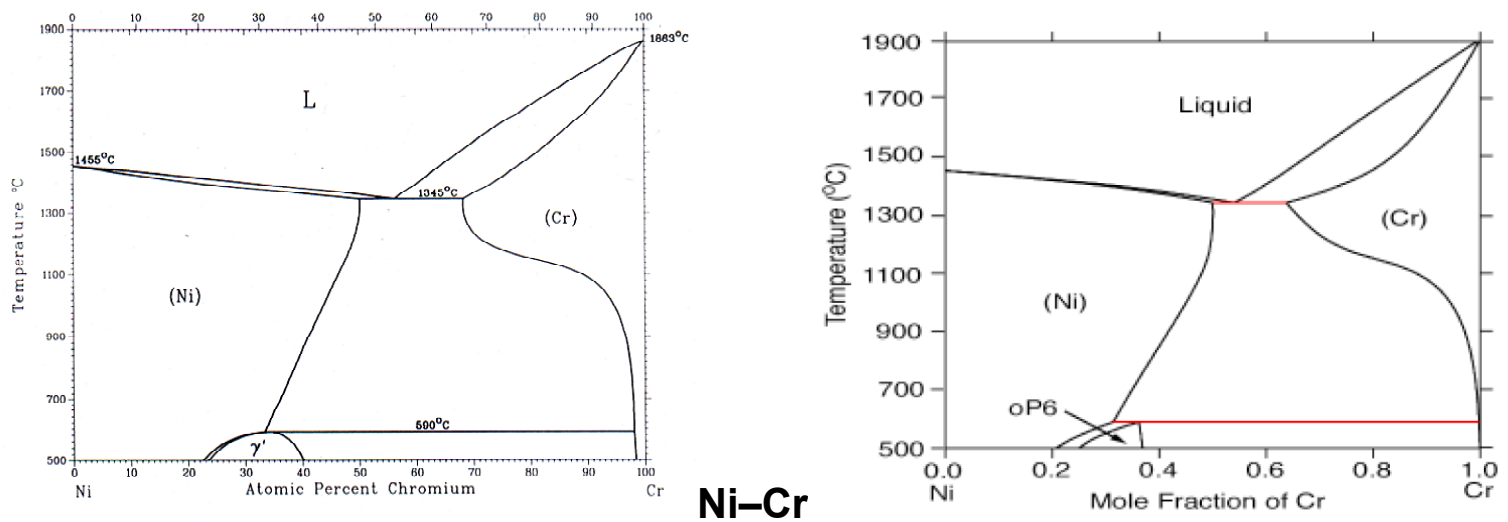

Source: DTN: LL030106412251.014.

NOTE: The domain of stability of the ordered phase of $\mathrm{Ni}_{2} \mathrm{Cr}$-type (oP6 or $\mathrm{C} 11_{b}$ ).

Figure 97. Comparison of the Reference Ni-Cr-Phase Diagram (Left) with the Calculated Ni-Cr-Phase Diagram as Obtained with the Ordered Phase Modeled (Right)

\subsection{VALIDATION OF THE THERMO-CALC RESULTS FOR THE PSEUDO-BINARY $\mathrm{Ni}_{\mathbf{x}}\left(\mathrm{Cr}_{3} \mathrm{Mo}\right)_{1-\mathrm{x}}$ ALLOY}

To further validate the database, the experimental determination of the phase boundaries in the terminal Ni-rich $\gamma$-solid solution in the pseudo-binary section $\mathrm{Ni}_{\mathrm{x}}\left(\mathrm{Cr}_{3} \mathrm{Mo}\right)_{1-\mathrm{x}}$, (with $c_{\mathrm{Cr}+\mathrm{Mo}}=c_{\mathrm{Cr}}+c_{\mathrm{Mo}}$ varying from 13.5 to 44 at \%) (Karmazin et al. 1994 [DIRS 161444]) were considered. It was shown experimentally that the boundary of the terminal $\gamma$-solid solution was increasing with $c_{\mathrm{Cr}+\mathrm{Mo}}$ as indicated in Figure 98a. Calculations were performed with the reassessed database for the same section of the ternary phase diagram with all the phases considered except the P phase. The calculated phase diagram, shown in Figure 98b, compares favorably with the experimental counterpart, displayed in Figure 98a, as far as the boundary of the $\gamma$-solid solution (indicated by a thick black line) is concerned. A two-phase region ( $\mathrm{fcc}+\sigma$ ) is also predicted in the temperature range $620^{\circ} \mathrm{C}$ to $1,370^{\circ} \mathrm{C}$ at lower Ni content. However, since the experimental study did not include the structural characterization of these phases at high temperature in this stability region, the predicted two-phase region could not be confirmed. In retrospect, the "suspension" of the $\mathrm{P}$ phase during the calculation of the phase diagram is equivalent to modeling that the kinetics of P-phase formation is much slower than the phase diagram associated with the formation of the $\sigma$ phase. This approach has been described in Section 6.6.1 where the property diagram of Alloy 22 showed that that the stability of the $\sigma$ phase can be extended at low temperatures when the P phase is suspended. This is a result that is confirmed experimentally. 

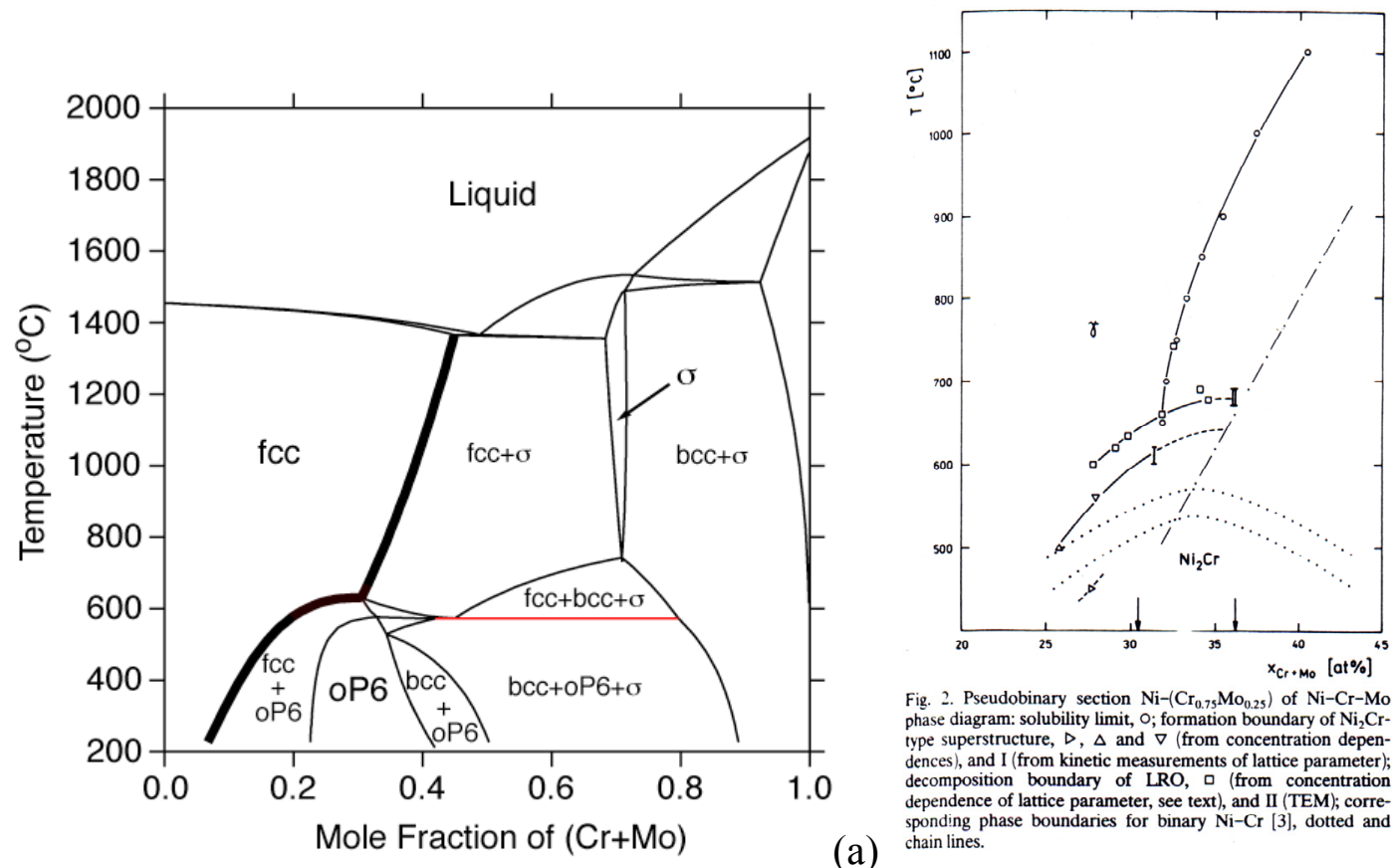

Fig. 2. Pseudobinary section $\mathrm{Ni}-\left(\mathrm{Cr}_{0.75} \mathrm{Mo}_{0.25}\right)$ of $\mathrm{Ni}-\mathrm{Cr}-\mathrm{Mo}$ phase diagram: solubility limit, $O$; formation boundary of $\mathrm{Ni}_{2} \mathrm{Cr}$ type superstructure, $\nabla, \Delta$ and $\nabla$ (from concentration dependences), and I (from kinetic measurements of lattice parameter), decomposition boundary of LRO, a (from concentration dependence of lattice parameter, see text), and II (TEM); corre-
sponding phase boundaries for binary $\mathrm{N} i-\mathrm{Cr}[3]$, dotted and

(a)

(b)

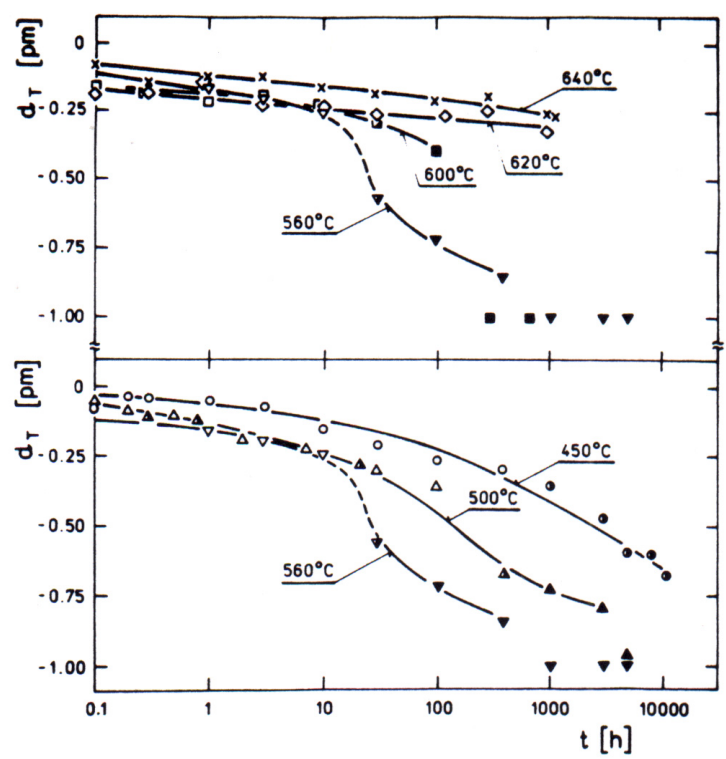

Fig. 3. Dependences of $d_{T}$ vs. time (see text) for isothermal annealing of $\mathrm{Ni}-24 \% \mathrm{Cr}-8 \%$ Mo alloy. Empty, half-filled and filled symbols correspond to sharp, slightly diffuse and diffuse diffraction lines respectively.

(c)

Source: (a) DTN: LL030106412251.014 (b), (c) Karmarzin et al. 1994 [DIRS 161444].

NOTE: The evolution of $\mathrm{d}_{\mathrm{T}}$ given by the difference between the lattice parameter measured at temperature $\mathrm{T}$ and the $a_{1100}$, its initial value obtained after quenching samples from $1,100^{\circ} \mathrm{C}$ is displayed in (c) for several isothermal anneals as a function of time.

Figure 98. Comparison Between the (a) Calculated (with Thermo-Calc) and (b) the Experimental Phase Diagrams of the Pseudo-Binary Alloy Ni- $\left(\mathrm{Cr}_{0.75} \mathrm{Mo}_{0.25}\right)$ 


\subsection{VALIDATION OF THE THERMO-CALC RESULTS FOR THE TERNARY Ni-Cr- Mo ALLOY}

Isothermal sections of the $\mathrm{Ni}-\mathrm{Cr}-\mathrm{Mo}$ phase diagram were calculated and compared with the experimental results (Gdowski 1991 [DIRS 100859]; Jena et al. 1989 [DIRS 161441]; Rideout et al. 1951 [DIRS 161445]; Bloom et al. 1954 [DIRS 161463]; Raghavan et al. 1984 [DIRS 154707]; Cieslak et al. [DIRS 104966]). For example, the results reported by Bloom et al. [DIRS 161463] are shown in Figure 99. The Ni-Cr-Mo system in the entire composition range has been thoroughly reviewed by Jena et al. (1989 [DIRS 161441]) (see also Gdowski 1991 [DIRS 100859]). Here, all the alloys of interest (Table 8) are located in the high-Ni rich portion of the phase diagram (Ni content above $50 \mathrm{wt} \%$ ), and more specific studies have been reported in this limited region of the phase diagram (Rideout et al. 1951 [DIRS 161445], Bloom et al. 1954 [DIRS 161463], Raghavan et al. 1984 [DIRS 154707]). In this region, the single fcc $(\gamma)$-phase is stable at high temperatures and the domain of $\gamma$ stability diminishes toward the Ni-rich corner with decreasing temperature, as illustrated in Figure 101. This study confirms the fact that at equilibrium and at low temperature, all the alloys indicated in Table 8 should display a multiphase field that includes the fcc structure and one or two complex phases, such as $\sigma, \mu$, or P (Frank et al. 1958 [DIRS 161437], Frank and Kasper 1959 [DIRS 161438]; Shoemaker and Shoemaker 1988 [DIRS 154989]). In Figure 99, the thermodynamic calculations performed at $1,523 \mathrm{~K}\left(1,250^{\circ} \mathrm{C}\right)$ reproduce fairly well the lenticular shape of the domain of stability of the $\sigma$ phase. In the following, since the TCP, P, and $\mu$ phases are closely related, a distinction will not be made between them as far as the energetics and the kinetics of formation are concerned. The results of the calculations also confirm that the fccphase field is shrinking in the Ni-rich corner of the phase diagram as the temperature is lowered, as shown in Figure 100. 

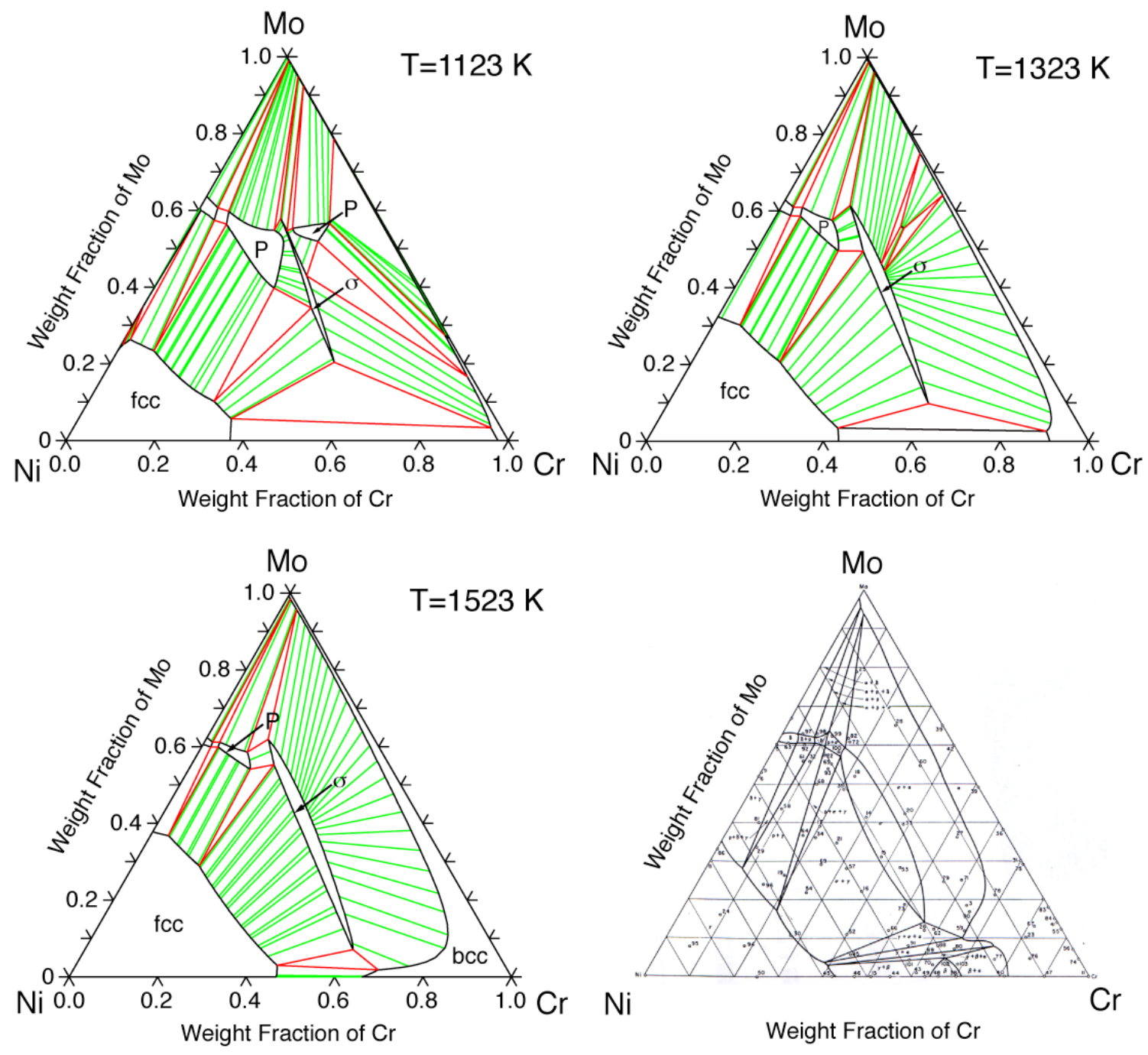

Source: DTN: LL030106412251.014.

NOTE: The bottom right figure shows the experimentally assessed isothermal section of the ternary-phase diagram from Bloom et al. 1954 [DIRS 161463] at 1,523 K.

Figure 99. Calculated Isothermal Sections of the $\mathrm{Ni}-\mathrm{Cr}-\mathrm{Mo}$ Phase Diagram at 1,123 K, 1,323 K, and $1,523 \mathrm{~K}$ 

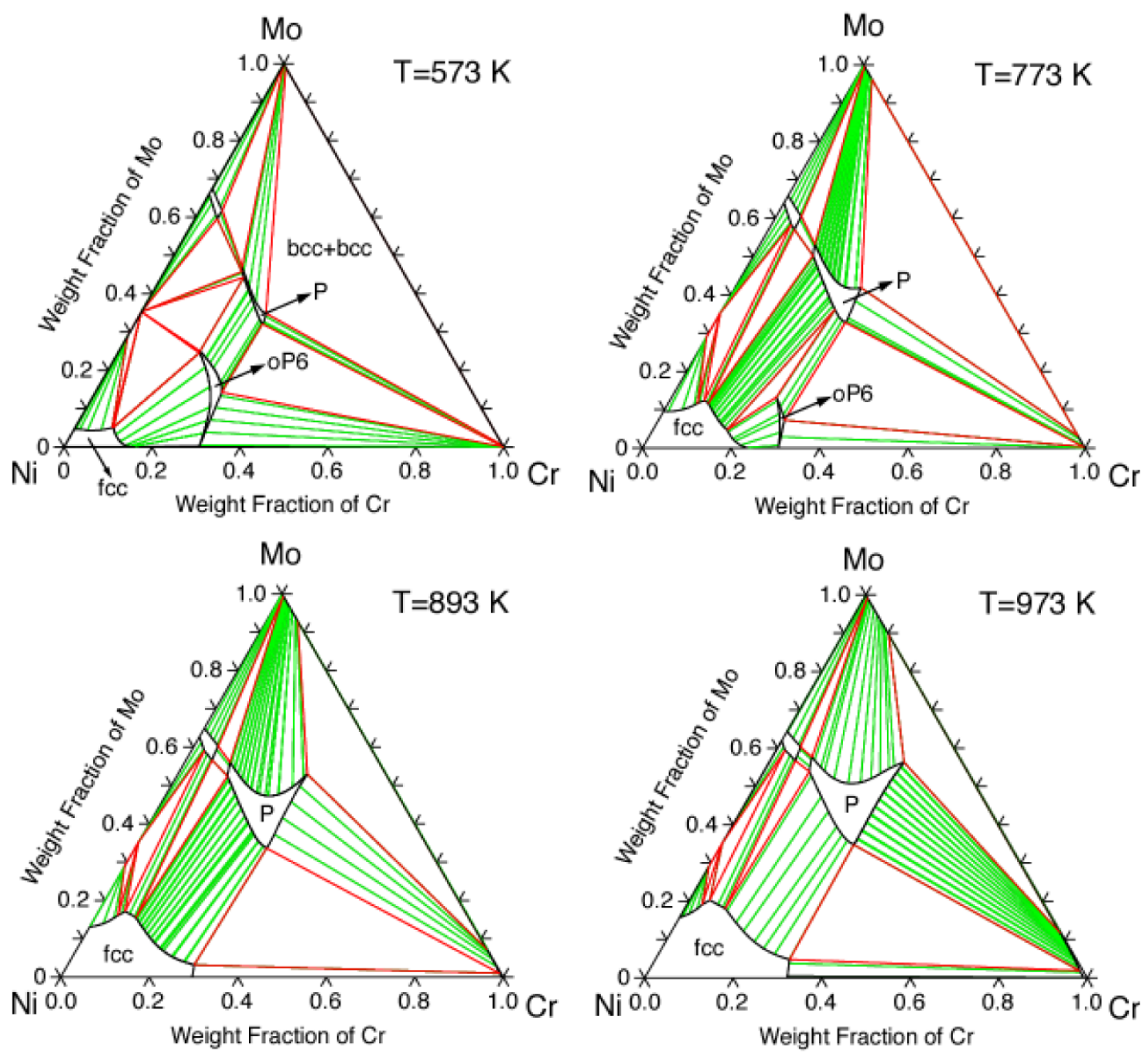

Source: DTN: LL030106412251.014.

Figure 100. Calculated Isothermal Sections of the Ni-Cr-Mo Phase Diagram at $573 \mathrm{~K}, 773 \mathrm{~K}, 893 \mathrm{~K}$, and $973 \mathrm{~K}$

As commercial alloys are not pure ternary alloys, $\mathrm{Cr}$, Mo, and $\mathrm{Ni}$ equivalents have been proposed by correlating the behavior of minor elements (e.g., Co, Fe, Ti, and W) with the major elements $(\mathrm{Cr}, \mathrm{Mo}$, and $\mathrm{Ni}$ ) in the formation of TCP precipitates. Cieslak et al. (1986 [DIRS 104966]) proposed the following relations applicable to Alloys 22, C4, and C-276:

$$
\begin{aligned}
& \mathrm{Mo}_{\text {eq }}=\mathrm{wt} \% \mathrm{Mo}+\mathrm{wt} \% \mathrm{~W} \\
& \mathrm{Cr}_{\text {eq }}=\mathrm{wt} \% \mathrm{Cr} \\
& \mathrm{Ni}_{\text {eq }}=(\text { balance; in wt } \%)
\end{aligned}
$$

However, the property diagrams of these commercial alloys bear very little resemblance to those generated for the alloys at their equivalent compositions. Hence, extreme caution must be taken when making arguments based on $\mathrm{Cr}$, Mo, and Ni equivalents. As shown previously, for example, $\mathrm{W}$ and Mo have a direct influence, qualitatively and quantitatively, on the stability of the oP6-ordered phase (Section 7.1). 
By limiting the analysis to the fcc matrix and the $\mathrm{Ni}_{2} \mathrm{Cr}$-type (or oP6) ordered phase (i.e., with all other phases suspended), the isothermal sections at $620^{\circ} \mathrm{C}, 600^{\circ} \mathrm{C}, 500^{\circ} \mathrm{C}$, and $300^{\circ} \mathrm{C}$ of the $\mathrm{Ni}-\mathrm{Cr}-\mathrm{Mo}$ phase diagram were re-calculated. The results presented in Figure 102 show the domain of stability of the oP6 and its extension in the Ni-rich corner of the phase diagram when temperature decreases. The detailed location of the oP6-ordered phase in the ternary Ni-Cr-Mo alloy in the phase diagram and how Mo affects the stability of the ordered phase and the location of the critical order-disorder transition temperature are illustrated in Figure 103 for fixed Ni mole fractions of $0.625,0.645$, and 0.665 . As discussed before, the addition of Mo does not have a simple gradual effect on the stability of the oP6-ordered phase. For example, in the case of a fixed mole fraction of $\mathrm{Ni}$ equal to 0.645 , there is a gradual increase in the stability of the ordered phase by substituting $\mathrm{Cr}$ for Mo up to about 0.20 -mole fraction of $\mathrm{Cr}$ before destabilization of oP6 phase at higher substitution of $\mathrm{Cr}$ for Mo, as shown in Figure 103. This study confirms the fact that at equilibrium and at low temperature, all the alloys indicated in Table 8 should display a multiphase field that includes the fcc structure and one or two complex phases, such as $\sigma, \mu$, or P.

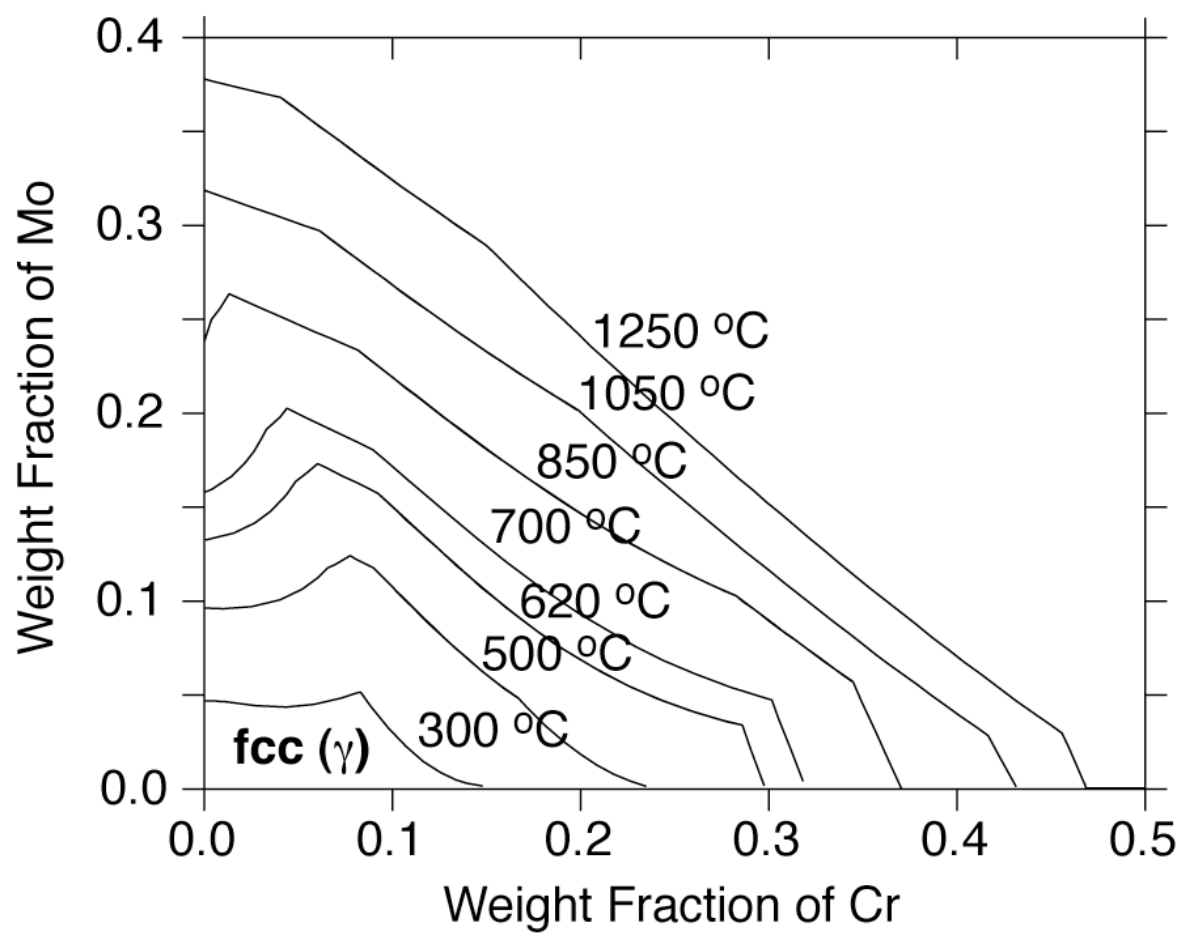

Source: DTN: LL030106412251.014.

Figure 101. Calculated fcc (or y) Domain of Stability of the Ternary Ni-Cr-Mo Phase Diagram as a Function of Temperature from $1,250^{\circ} \mathrm{C}$ to $300^{\circ} \mathrm{C}$ 

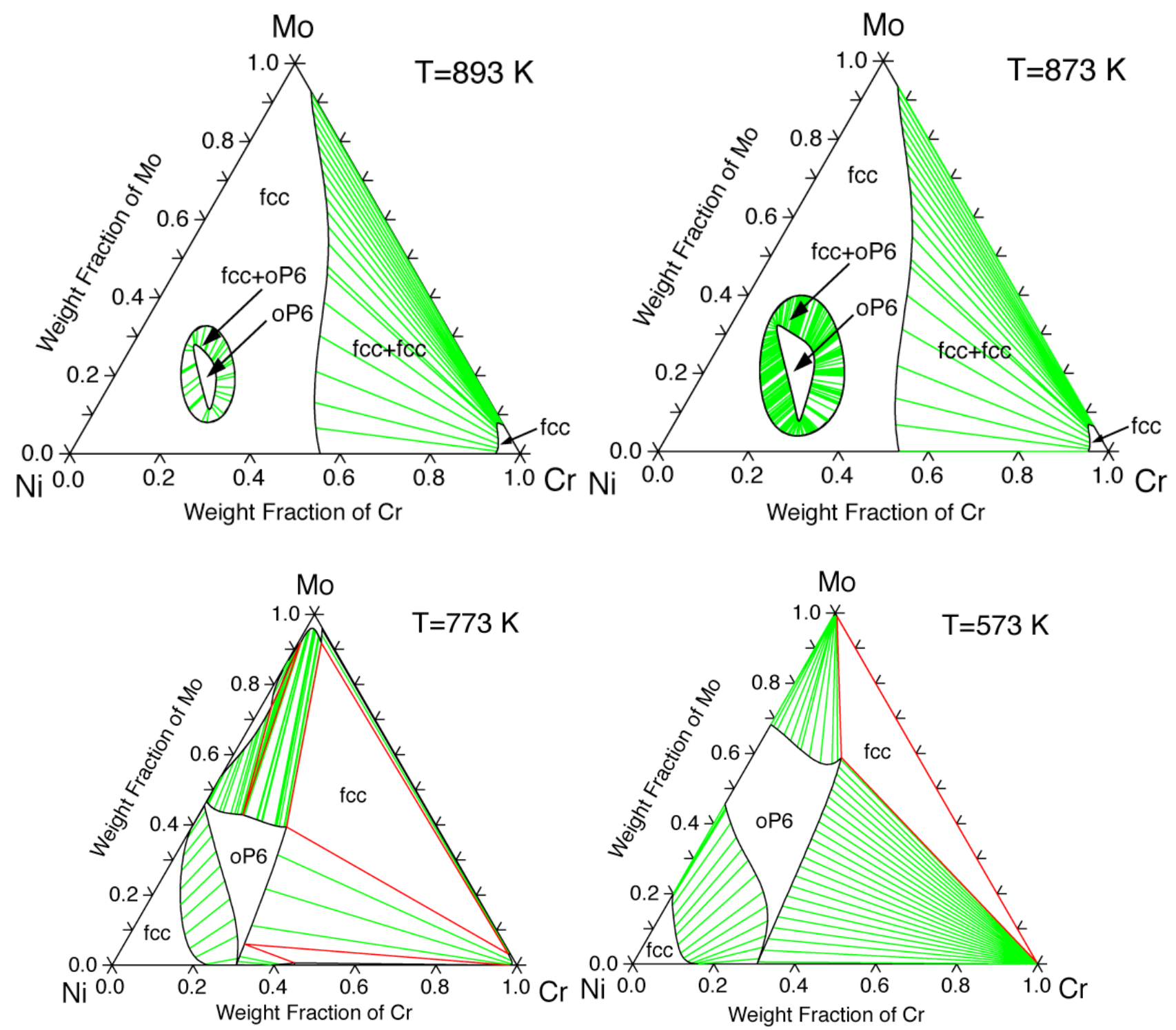

Source: DTN: LL030106412251.014.

NOTE: Only the fcc (or Y) matrix and the oP6-ordered phase are considered for this set of calculations.

Figure 102. Calculated Isothermal Sections of the Ternary Ni-Cr-Mo Phase Diagram at $893 \mathrm{~K}, 873 \mathrm{~K}$, $773 \mathrm{~K}$, and $573 \mathrm{~K}$ 

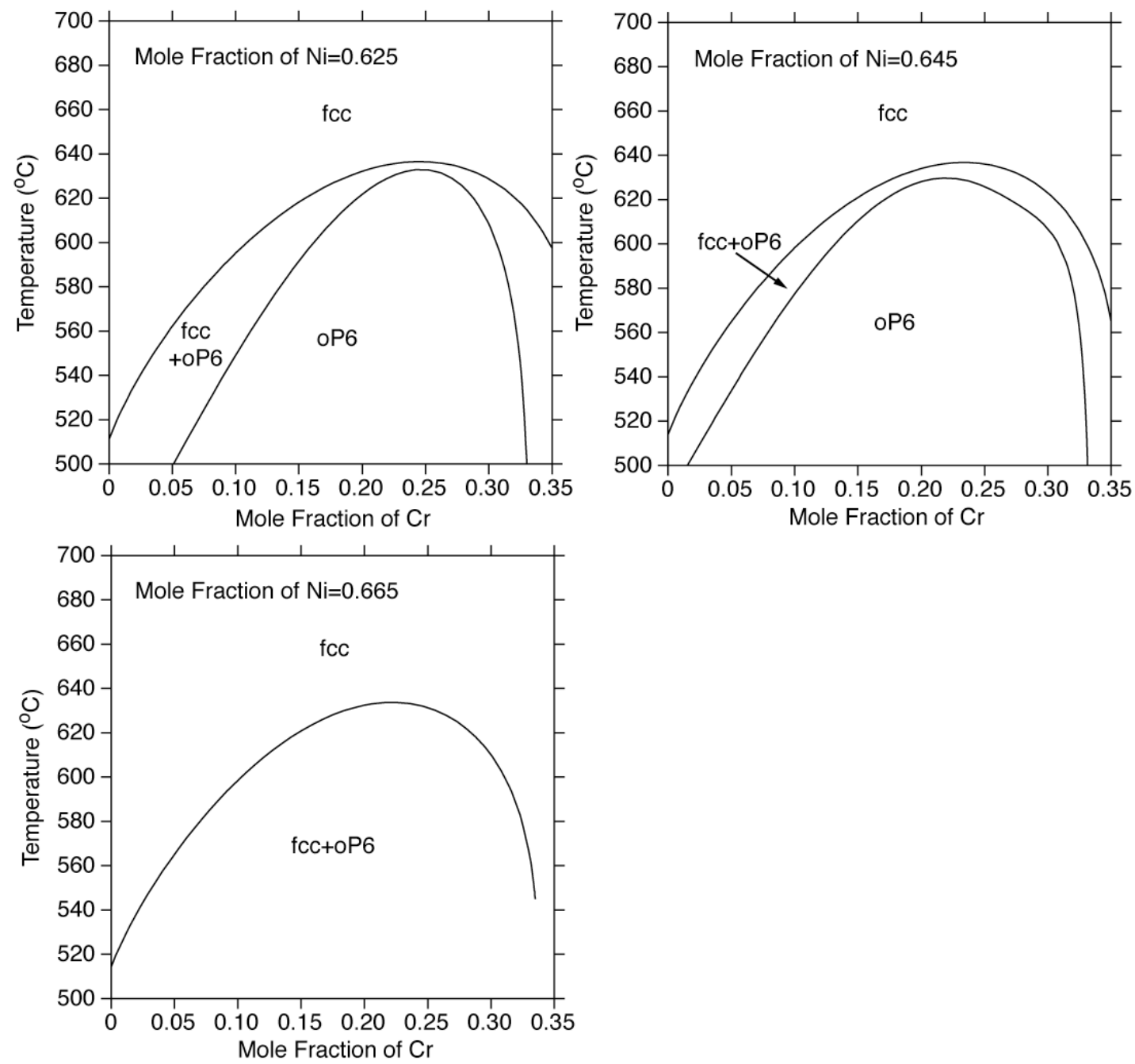

Source: DTN: LL030106412251.014.

NOTE: Only the fcc (or Y) matrix and the oP6-ordered phase are considered for this set of calculations.

Figure 103. Calculated Isopleths of the Ternary Ni-Cr-Mo Alloy at Fixed Mole Fraction of Ni of 0.625, 0.645 , and 0.665

\subsection{VALIDATION OF THE TREATMENT OF MO AND W IN THE TERNARY Ni-Cr-Mo ALLOY}

In the course analyzing the ternary $\mathrm{Ni}-\mathrm{Cr}-\mathrm{Mo}$ alloy as surrogate for Alloy 22, published experimental data for $\mathrm{Ni}-\mathrm{Cr}$ and $\mathrm{Ni}-\mathrm{Cr}-\mathrm{Mo}$ systems have been considered for characterizing the oP6-ordered phase of $\mathrm{Ni}_{2} \mathrm{Cr}$-type. Since Mo and $\mathrm{W}$ play a role in the stability of this ordered phase, it was necessary to include their effects in the alloy energetics.

The ab initio results for the oP6 forms of $\mathrm{Ni}_{2} \mathrm{Cr}, \mathrm{Ni}_{2} \mathrm{Mo}$, and $\mathrm{Ni}_{2} \mathrm{~W}$, and the fcc phases were considered to evaluate the effect of Mo and $\mathrm{W}$ additions, and to compare the calculated results with the experimental findings reported in the literature. $A b$ initio results for the heat of formation of $\mathrm{Ni}_{2} \mathrm{Cr}, \mathrm{Ni}_{2} \mathrm{Mo}$, and $\mathrm{Ni}_{2} \mathrm{~W}$ are $-10,485,+1,014$, and $10,074 \mathrm{~J} / \mathrm{mol}$, respectively (Section 7.1.1, Figure 96). These values were incorporated into the database as $-7,095,+1,000$, 
and 10,000 respectively. The database value for $\mathrm{Ni}_{2} \mathrm{Cr}$ was adjusted from experimental results (Hirabayashi et al. [DIRS 161452]) and phase-diagram calculations while the remaining values for $\mathrm{Ni}_{2} \mathrm{Mo}(+1,000)$ and $\mathrm{Ni}_{2} \mathrm{~W}(+10,000)$ are rounded ab initio results. The most complete data for the effect of Mo on the relative stability of oP6 and fcc in Ni-Cr-Mo alloys is due to Karmazin et al. [DIRS 154881]. This experimental work indicates that a Ni-25 at \% $\mathrm{Cr}-8.33$ at \% Mo alloy has a maximum critical order-disorder temperature for the oP6 to fcc transition on heating of about $670^{\circ} \mathrm{C}$, as compared with a maximum transition temperature of $570^{\circ} \mathrm{C}$ for a $\mathrm{Ni}-33.3$ at $\% \mathrm{Cr}$ alloy. Karmazin (1982 [DIRS 154881]) mentions that Mo can be located on both sublattices that describe the oP6 phase. The role of W on the stability of the oP6 phase is not experimentally documented. Hence, as for Mo, W is allowed to occupy both sublattices. The interaction parameters are smaller than those associated with Mo, since for $\mathrm{Ni}_{2} \mathrm{~W}$, the instability is more significant than for $\mathrm{Ni}_{2} \mathrm{Mo}$.

Ab initio calculations have shown that Mo-W behaves like an ideal solution, because the heat of formation of the alloy in the entire range of composition is practically zero. This result indicates that Mo and W, which belong to the same VIb column of the transition metals, have very similar electronic structure properties. This does not preclude any difference in alloying effect, as shown in Figure 96, when Mo and $\mathrm{W}$ are mixed with other elements such as $\mathrm{Ni}$, due to differences in the manner which atomic orbitals between various elements hybridize.

To account for these observations, the following interaction parameters have been selected:

$$
\begin{array}{cc}
{ }^{0} L_{\mathrm{Cr}: \mathrm{Mo}, \mathrm{Ni}}^{\mathrm{fcc}}=-80,000 & { }^{0} L_{\mathrm{Cr}, \mathrm{Mo}: \mathrm{Ni}}^{\mathrm{fc}-\mathrm{oP} 6}=-11,000 \\
{ }^{0} L_{\mathrm{Cr}: \mathrm{W}, \mathrm{Ni}}^{\mathrm{fcc}}=-55,000 & { }^{0} L_{\mathrm{Cr}, \mathrm{W}: \mathrm{Ni}}^{\mathrm{fcc} 6}=-8,000
\end{array}
$$

Based on the above discussion, these interaction parameters have been included in the ThermoCalc database to model the Mo and $\mathrm{W}$ behavior in the ternary Ni-Cr-Mo alloy system (Turchi 2003 [DIRS 162974]).

With this new description, the oP6-fcc equilibrium shown in Figure 104a and Figure 104c for the $\mathrm{Ni}-\mathrm{Cr}-\mathrm{Mo}$ and $\mathrm{Ni}-\mathrm{Cr}-\mathrm{W}$ systems, respectively, is close to the composition of Alloy 22. These results suggest that in $\mathrm{Ni}-\mathrm{Cr}-\mathrm{Mo}$, the $21.1 \mathrm{wt} \% \mathrm{Cr}-13.5 \mathrm{wt} \%$ Mo composition lies very close to Alloy 22 stoichiometry, and little fcc phase is present when this alloy is cooled below $635^{\circ} \mathrm{C}$, see Figure $104 \mathrm{~b}$. W has a smaller stabilizing effect on oP6 than does Mo, as shown in Figure 104c. Measurements of the kinetics of ordering (oP6) formation conducted at Lawrence Livermore National Laboratory (Shen 1999 [DIRS 161800]) in Alloy 22 $(\mathrm{Ni}-21.1 \mathrm{wt} \% \mathrm{Cr}-13.5 \mathrm{wt} \% \mathrm{Mo}-3 \mathrm{wt} \% \mathrm{~W})$ suggested that the maximum temperature for the oP6/fcc transition is above $593^{\circ} \mathrm{C}$, or some $53^{\circ} \mathrm{C}$ higher than in the $\mathrm{Ni}-\mathrm{Cr}$ case. As $\mathrm{W}$ has mostly a destabilizing effect on the formation of the oP6-ordered phase, several tests performed to account for this fact have shown that to model Alloy 22 with a Ni-Cr-Mo surrogate alloy, $2.0 \mathrm{wt} \%$ Mo for each $1.0 \mathrm{wt} \% \mathrm{~W}$ in the fcc phase provides an acceptable representation of the oP6-fcc phase region. In other words, Alloy 22 with $21.1 \mathrm{wt} \% \mathrm{Cr}-13.5 \mathrm{wt} \% \mathrm{Mo}-3 \mathrm{wt} \% \mathrm{~W}$ can be replaced by $\mathrm{Ni}-21.1$ wt $\%$ Cr-7.5 wt \% Mo. This "equivalent" composition leads to much more fcc phase in the temperature range of precipitation than with the $21.1 \mathrm{wt} \%$ $\mathrm{Cr}-13.5 \mathrm{wt} \%$ Mo composition, as can be concluded from the comparison between Figure 104d (below about $600^{\circ} \mathrm{C}$ ) and Figure $104 \mathrm{~b}$. 

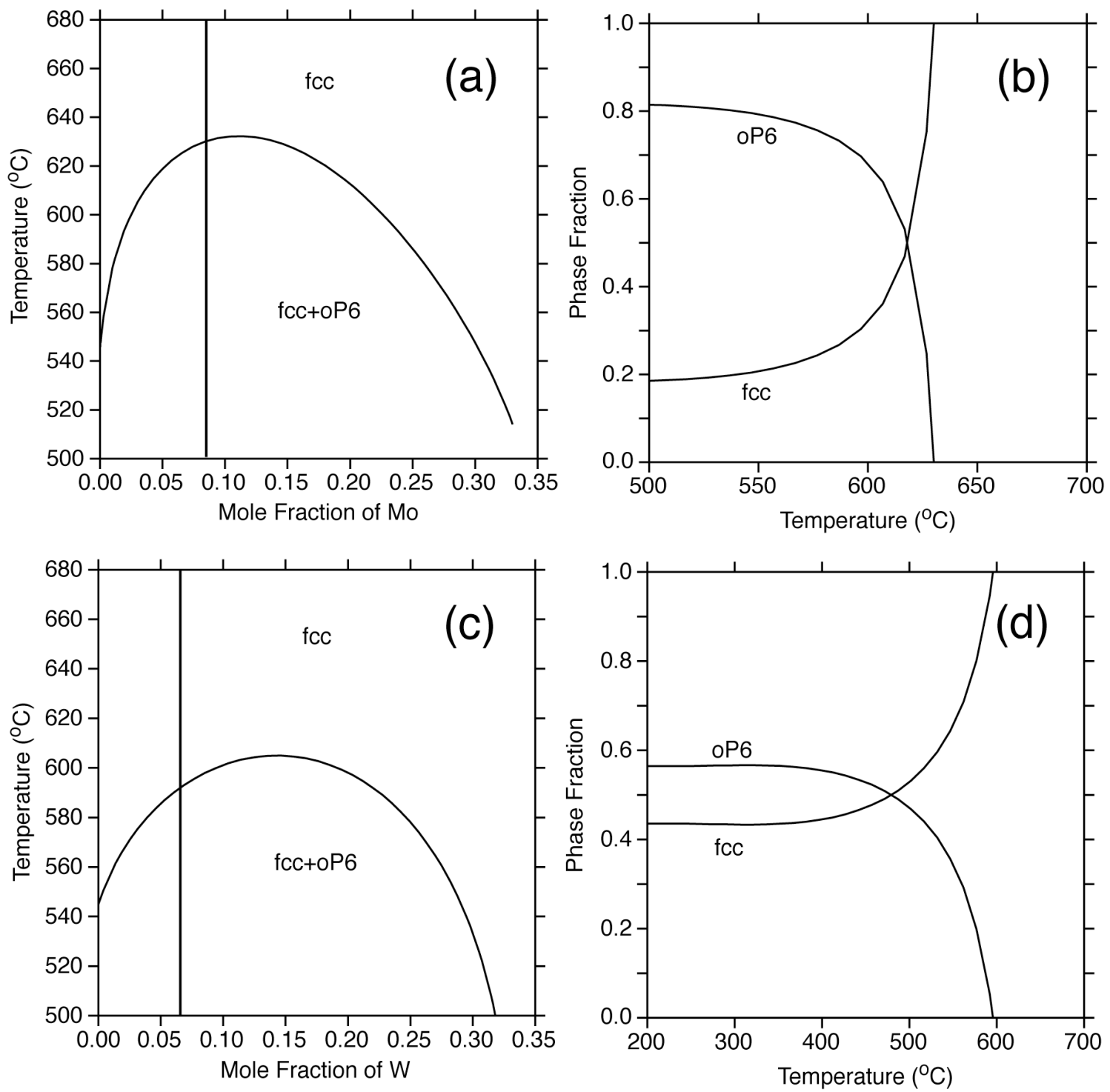

Source: DTN: LL030106412251.014.

NOTE: The vertical lines in (a) and (c) locate the composition of Ni-21.1 Cr-13.5 Mo and Ni-21.1 Cr-1.8 W (in wt \%), respectively. Property diagrams of $\mathrm{Ni}-24.5 \mathrm{Cr}-8.5 \mathrm{Mo}$ (in at \%) or $\mathrm{Ni}-21.1 \mathrm{Cr}-13.5 \mathrm{Mo}$ (in wt \%) (b), and Ni-21.1 Cr-7.5 Mo (in wt \%) (d).

Figure 104. Phase Diagrams of $\mathrm{Ni}-\mathrm{Cr}-\mathrm{X}$, with $\mathrm{c}_{\mathrm{Cr}}+\mathrm{c}_{\mathrm{X}}=0.33$ Being Fixed, Where $\mathrm{X}=\mathrm{Mo}(\mathrm{a}), \mathrm{X}=\mathrm{W}(\mathrm{c})$

To further validate this approach accounting for the role of Mo and $\mathrm{W}$, the experimental results reported by Shen (2000 [DIRS 161801]) are considered. As an example, consider a sample of Alloy 22 with the following composition: 21.1 Cr-13.5 Mo-4.7 Fe-2.9 W-1.74 C-0.21 Mn-0.12 V-0.023 Si-0.003 C (in wt \%) annealed for 16,000 hours at $704^{\circ} \mathrm{C}$. At this annealing temperature, substantial precipitation occurs at grain boundaries and in the fcc-based matrix. These precipitates correspond to the $\mathrm{P}$ (and possibly $\mu$ ) phase, and are identifiable by their platelet shape (Figure 105a). At this annealing temperature of $704^{\circ} \mathrm{C}$, and according to the property diagram presented in Figure 106a, the most likely phase to form is indeed the $\mathrm{P}$ phase with a phase fraction of about $20 \%$. Energy dispersive $\mathrm{X}$-ray (EDS) analysis has been performed using a Philips CM300 equipped with an EDS detector across the TCP 
precipitate along the line indicated in Figure 105a to determine the evolution of elemental weight fractions as functions of distance. As shown in Figure 105b, the alloy composition varies substantially when crossing the precipitate. As expected the P-phase formation is accompanied by a noticeable decrease in Ni content compensated by an increase in Mo content, and to some extent a decrease in $\mathrm{Cr}$ and $\mathrm{Fe}$, and an increase in W. Quantitatively, with the reference set to the composition of the base alloy mentioned above, the composition in $\mathrm{Ni}, \mathrm{Cr}, \mathrm{Mo}, \mathrm{Fe}$, and $\mathrm{W}$ becomes in the P-phase precipitate 30, 18, 45, 3, and 3 (in wt \%), respectively. Calculations have been performed to calculate the property diagram of Alloy 22 at the composition mentioned above, and the weight fractions per element in the fcc matrix and the $\mathrm{P}$ phase have been computed. The results are summarized in Figure 106 . At $704^{\circ} \mathrm{C}$, the temperature at which the isothermal annealing has been performed, the fcc phase qualitatively retains its starting alloy composition. On the other hand, in the $\mathrm{P}$ phase, the composition of each major constituent $\mathrm{Ni}$, $\mathrm{Cr}$, and $\mathrm{Mo}$ is 36,24 , and 39 (in wt \%), respectively. These results are in fairly good agreement with the experimental findings, recognizing that the experiments are conducted on samples that may not have reached their full thermodynamic equilibrium, which is the basis for the calculations. 


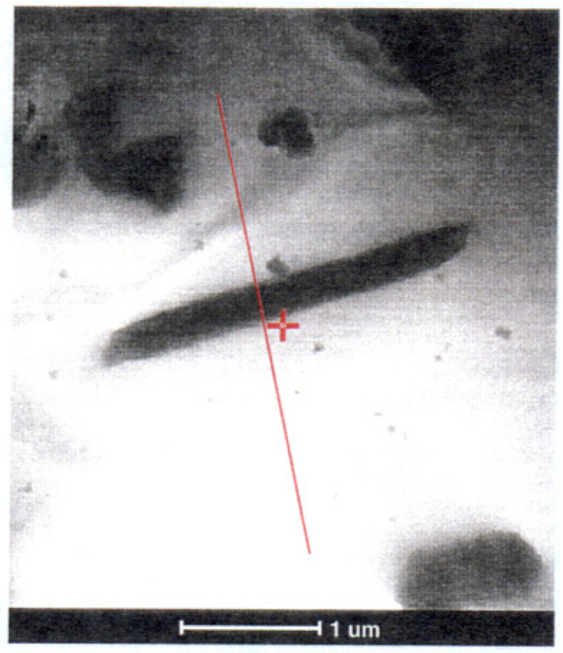

(a)

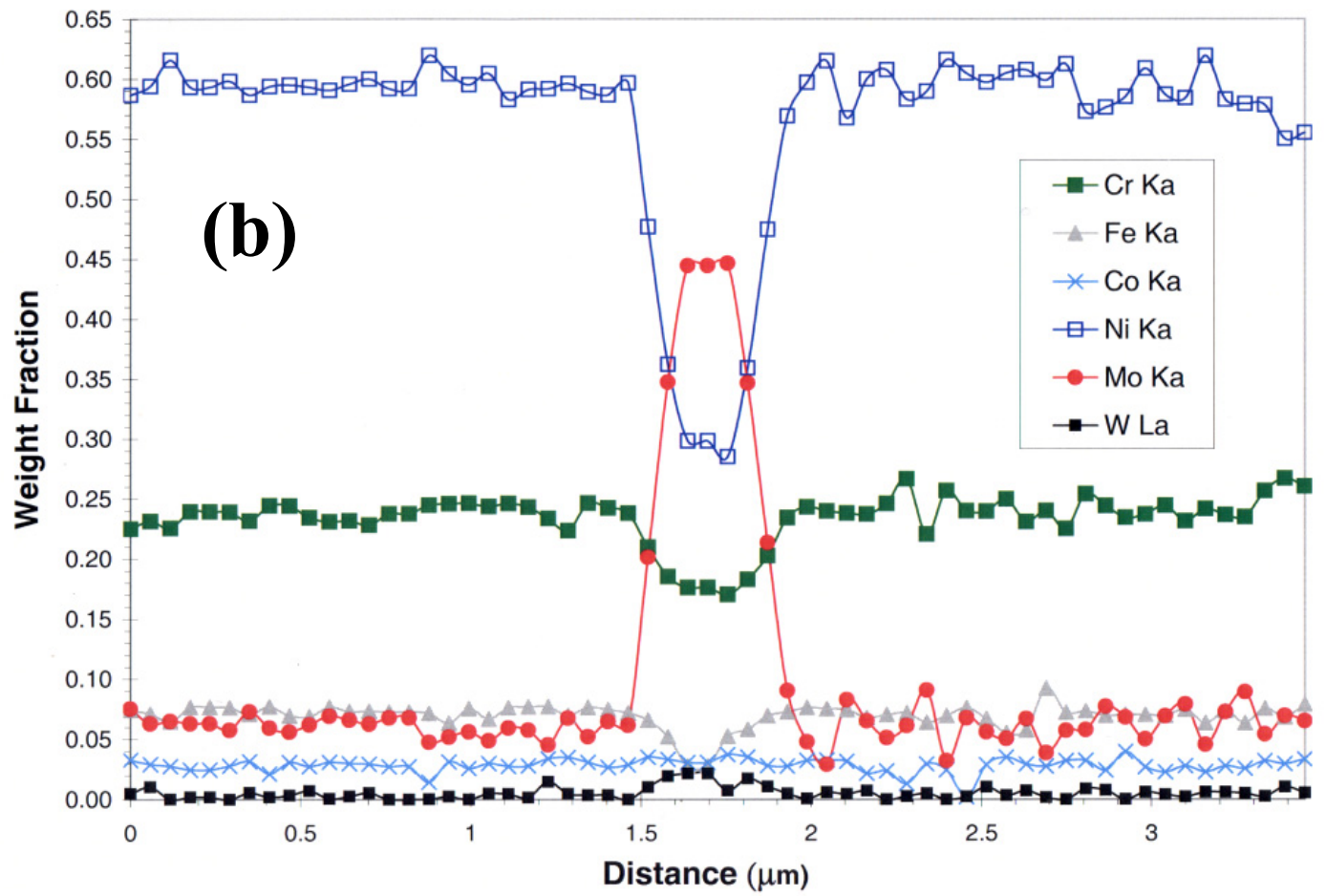

Source: DTN: LL030106412251.014; Shen 2000 [DIRS 161801].

Figure 105. (a) Micrograph of Platelet P-Phase Precipitate in an fcc Matrix, and Location of the (Red) Line Profile Along Which the Energy Dispersive X-ray (EDS) Analysis is Performed. (b) Variation of the Weight Fraction per Element Along the Line Profile, as Obtained from EDX Spectroscopy Analysis for Alloy 22 Annealed at $704^{\circ} \mathrm{C}$ for 16,000 hours. 

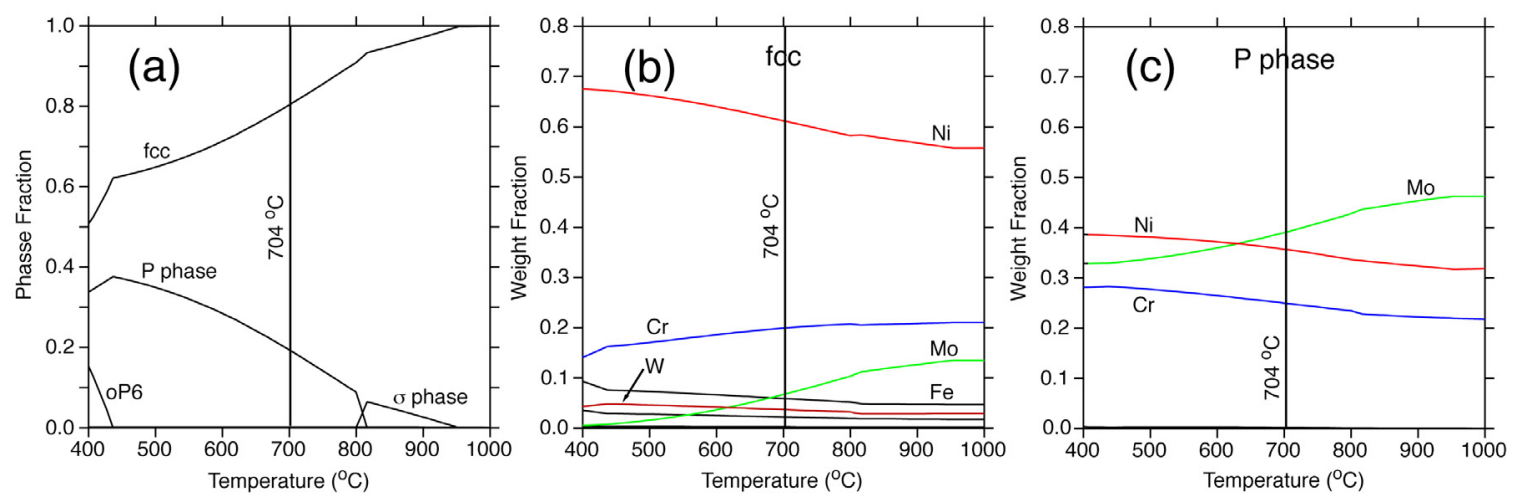

Source: DTN: LL030106412251.014.

NOTE: The vertical line indicates the temperature at which the alloy has been annealed.

Figure 106. (a) Property Diagram of Alloy 22. Weight Fraction of Ni (Red), Cr (Blue), Mo (Green), W (Brown), and Fe (Black), Versus Temperature in the fcc Matrix (b), and the P Phase (c) for Alloy 22

\subsection{MODEL CONFIDENCE: NATURAL ANALOGUES}

Awaruite is a naturally occurring, ordered iron-nickel metallic mineral with an approximate stoichiometry of $\mathrm{Ni}_{3} \mathrm{Fe}$. It was first discovered in Awarua, New Zealand, but has subsequently been found at various locations around the world (Krishnarao 1964 [DIRS 154746], p. 443). Josephinite, a rock found in Josephine County, Oregon, contains grains of awaruite that are larger than other sources of awaruite. Josephinite also has, in some instances, a unique mixture of minerals that has been tied to changes in the local environment and higher temperatures associated with hornblende diorite dikes from igneous intrusions (Dick 1974 [DIRS 154749], p. 297; Göpel et al. 1990 [DIRS 154750], p. 26). The age of these dike intrusions has been measured using $\mathrm{K}$-Ar dating to be approximately 150 to 155 million years (Dick 1974 [DIRS 154749], p. 292). Other nearby rocks also associated with the formation of josephinite have been dated, using $\mathrm{Pb}$ isotopes, at 159 \pm 8 million years (Göpel et al. 1990 [DIRS 154750], p. 24). Thus, the age of josephinite is on the order of 150 million years.

Some samples of josephinite contain taenite (the high-temperature, disordered, FCC Ni-Fe metallic phase) as well as awaruite. The composition and amount of each of these phases in the two-phase mixture have been fit to the Fe-Ni phase diagram, showing that these phases formed in the temperature range of $460^{\circ} \mathrm{C}$ down to about $400^{\circ} \mathrm{C}$ (Botto and Morrison 1976 [DIRS 154716]). The fact that the composition and amount of these phases fit the phase diagram at the higher temperatures indicates that no changes have occurred at lower temperatures. Taenite is not stable below about $350^{\circ} \mathrm{C} ; \alpha-\mathrm{Fe}$ and awaruite are the stable phases at ambient temperatures. The fact that taenite, not $\alpha-\mathrm{Fe}$, is present in josephinite also indicates that no changes have occurred in the 150 million years since these samples formed.

Out of necessity, phase stability is studied at temperatures greater than those expected in the proposed repository so that the rate at which phase changes occur can be measured. These rates are measured as a function of temperature, and the functional relationship is extrapolated to the lower temperatures in the proposed repository. The stability of the metallic structures in josephinite over millions of years suggests that no low-temperature mechanism with rates significantly greater than predicted exists. Thus, this provides confidence in the implicit 
assumption that the high-temperature mechanisms used to extrapolate kinetics are the same as the low-temperature mechanisms that will really be active under repository conditions.

\subsection{DISCUSSION OF MODEL VALIDATION ACTIVITIES}

In this section, each of the model validation criteria described in Technical Work Plan for: Regulatory Integration Modeling and Analysis of the Waste Form and Waste Package (BSC 2004 [DIRS 171583]) are discussed.

Criterion One

Do comparisons of Topologically Close-Pack Phases (TCP) and Long-range ordering (LRO) formations in base metal from THERMOCALC/ DICTRA agree with experimental data on base metal?

Using the TCP precipitation area-fraction measurements for base metal presented in Table 9, Figure 107 summarizes these measurements as a function of time and temperature. A trend line is included for the results at $760^{\circ} \mathrm{C}$, where more than two measurements were made. The trends of the results shown in Figure 107 are consistent with SEM observations and the TTT diagram of Figure 89 . TCP phases are seen to readily form at higher temperatures $\left(760^{\circ} \mathrm{C}\right.$ to $\left.800^{\circ} \mathrm{C}\right)$ in less than 1,000 hours. In general, as the temperature is decreased, the onset of TCP phase precipitation is delayed, and it also appears that the slopes of trend lines at lower temperatures may become shallower, indicating a slower rate of phase precipitation.

Table 9. Bulk Precipitation Area-Fraction Measurements (\% Transformation)

\begin{tabular}{|c|c|c|c|c|}
\hline $\begin{array}{c}\text { Temperature } \\
\left({ }^{\circ} \mathbf{C}\right)\end{array}$ & $\begin{array}{c}\text { Time } \\
(\mathbf{h r})\end{array}$ & $\begin{array}{c}\text { Percent } \\
\text { Transformation }\end{array}$ & $\begin{array}{c}\text { Standard } \\
\text { Deviation }\end{array}$ & $\begin{array}{c}\mathbf{9 5 \%} \\
\text { Confidence Interval }\end{array}$ \\
\hline 649 & 16,000 & 2.50 & 1.60 & 0.64 \\
\hline 650 & 600 & 0.00 & 0.00 & N/A \\
\hline 700 & 10,073 & 8.10 & 1.40 & 0.64 \\
\hline 704 & 16,000 & 19.00 & 3.60 & 1.65 \\
\hline 750 & 10,076 & 17.90 & 1.80 & 0.93 \\
\hline 760 & 16,000 & 22.50 & 2.90 & 1.50 \\
\hline 760 & 2,000 & 10.10 & 1.10 & 0.53 \\
\hline 760 & 1,000 & 6.30 & 1.20 & 0.57 \\
\hline 760 & 119 & 0.73 & 0.28 & 0.11 \\
\hline 800 & 1,002 & 12.70 & 0.86 & 0.44 \\
\hline 800 & 100 & 1.50 & 0.47 & 0.19 \\
\hline
\end{tabular}

Source: DTN: LL030103812251.008 [DIRS 162011].

NOTE: Confidence Interval values rounded to two decimal places. 


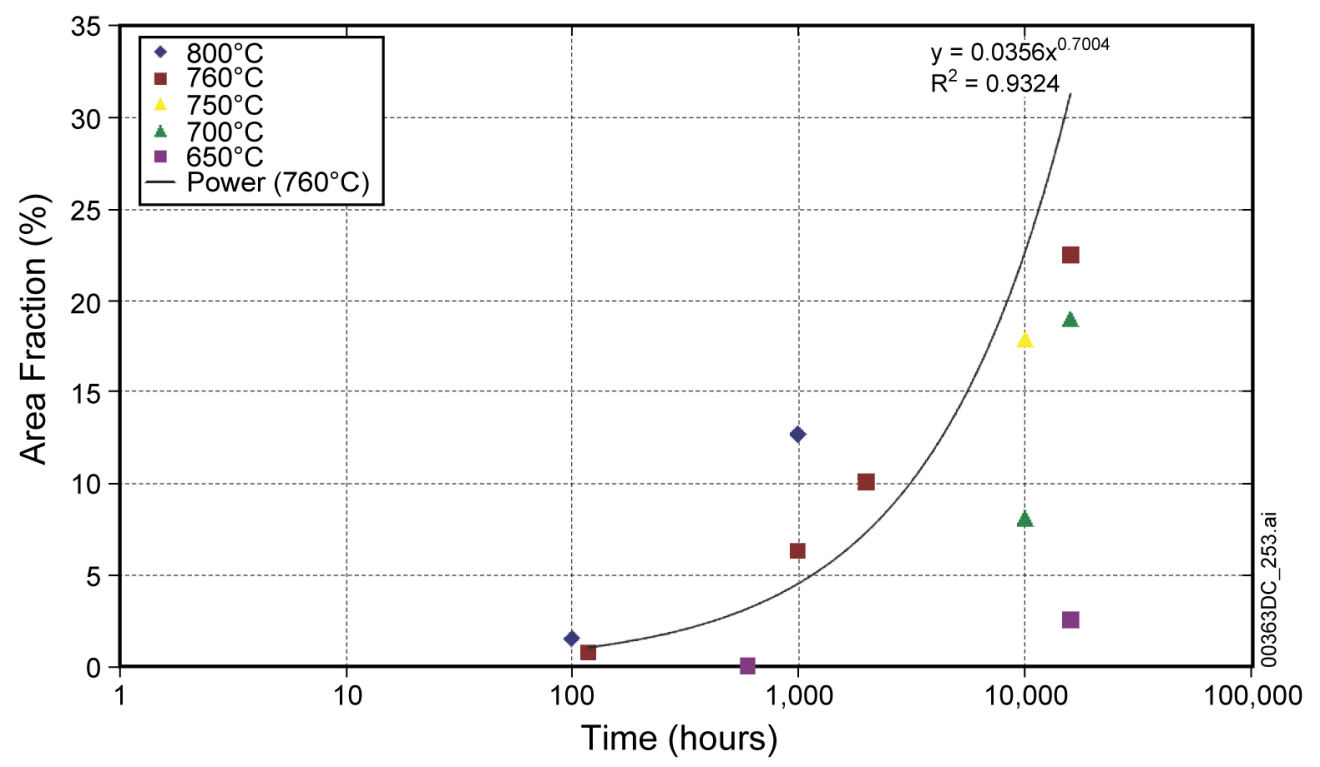

Source: DTN: LL030606912251.020.

Figure 107. TCP-Phase Precipitation in Alloy 22 Base Metal as a Function of Time and Temperature

The computational phase kinetics results (from DICTRA) for the ternary Ni-Cr-Mo alloy (a surrogate for Alloy 22) were compared with volume-fraction measurements on Alloy 22 base metal at temperatures of approximately $700^{\circ} \mathrm{C}$ and $750{ }^{\circ} \mathrm{C}$ (Figure 108 and Figure 109). The computation phase kinetics results are used to construct the computational TTT diagrams for a particular phase (Section 6.6.4). The comparison is not entirely consistent because (1) the volume-fraction measurements do not distinguish among the possible TCP phases $(\mathrm{P}, \mu$, and $\sigma)$ that have formed, and (2) the DICTRA results only display one type of phase fraction at a time. As a result, Figure 108 and Figure 109 compare the $\mathrm{P}$ phase formation results from DICTRA with the TCP volume-fraction measurements, as the P phase is the most likely to form at these temperatures and times. At high temperatures and long aging times, more phases in addition to the $\mathrm{P}$ phase may form, which would increase ambiguity in the comparison. As a result, in order to make the comparisons as consistent as possible, the comparisons presented in Figure 108 and Figure 109 were only able to include a few volume-fraction measurements from Table 9. For this comparison, the few volume-fraction measurements shown in these plots were deemed to most likely contain primarily $\mathrm{P}$ phase at the times and temperature shown.

In both comparisons, the agreement between the computational kinetics results and the volumefraction measurements is reasonable. The comparison shows that the computational results are conservative compared to the measured data, as the measured data points always lie to the right (increasing time) of the DICTRA results. As a result, the computational model predicts slightly earlier phase formation that what is measured at a given temperature. This conservativeness is expected because the DICTRA results are based on a ternary $\mathrm{Ni}-\mathrm{Cr}-\mathrm{Mo}$ alloy, $\mathrm{Ni}-21.1 \mathrm{Cr}-$ 13.5Mo (in wt \%), which is a surrogate for Alloy 22, and the actual composition of Alloy 22 contains less $\mathrm{Ni}$ (the balance of $\mathrm{Ni}$ will be less due to more elements specified in the actual Alloy 22 chemical composition). 


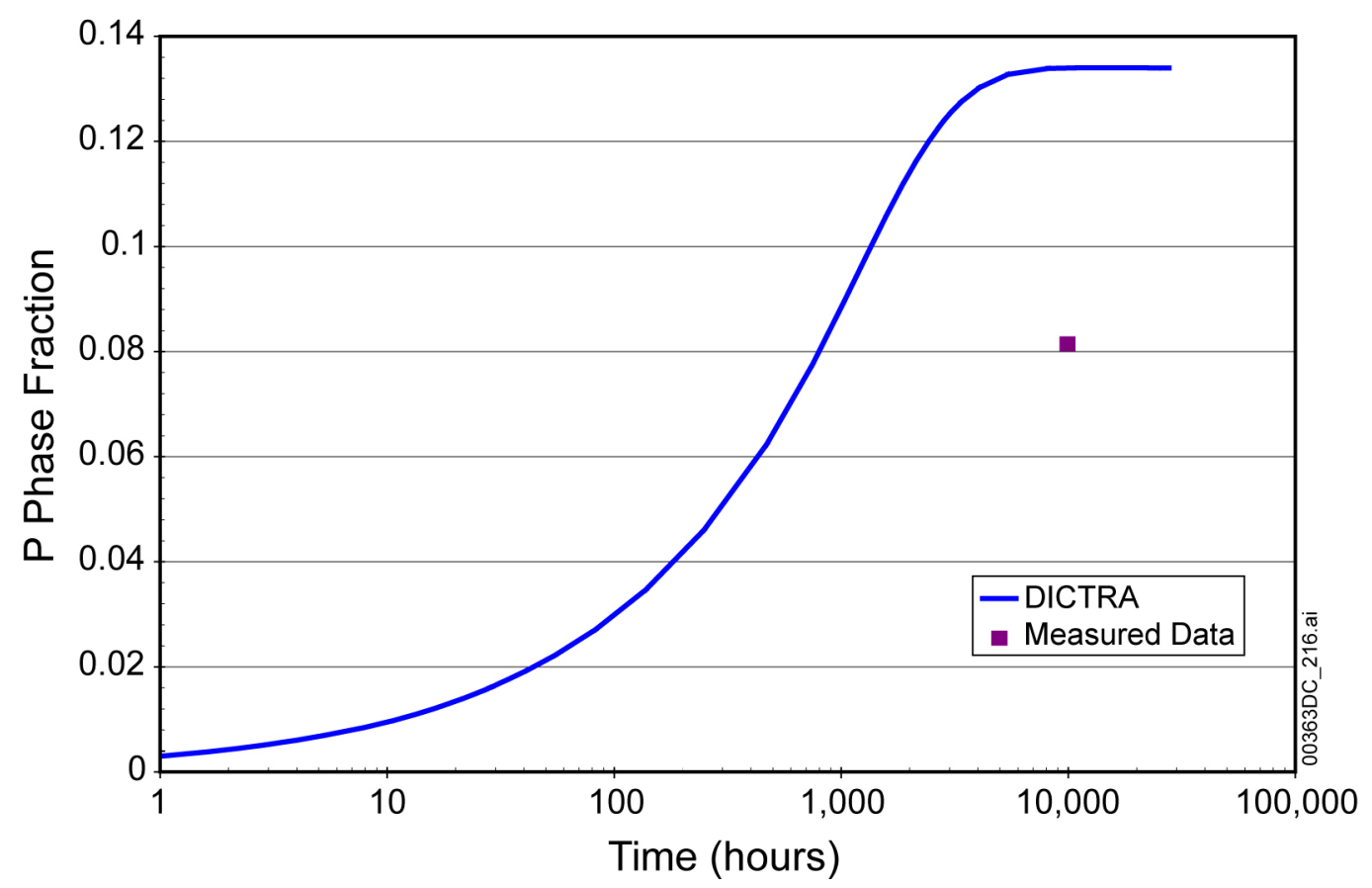

Source: DTN: LL030606912251.020.

Figure 108. Comparison of Phase Formation at $700^{\circ} \mathrm{C}$ for DICTRA Computational Results (P Phase) and Measured Data (TCP Phase) on Alloy 22 Base Metal

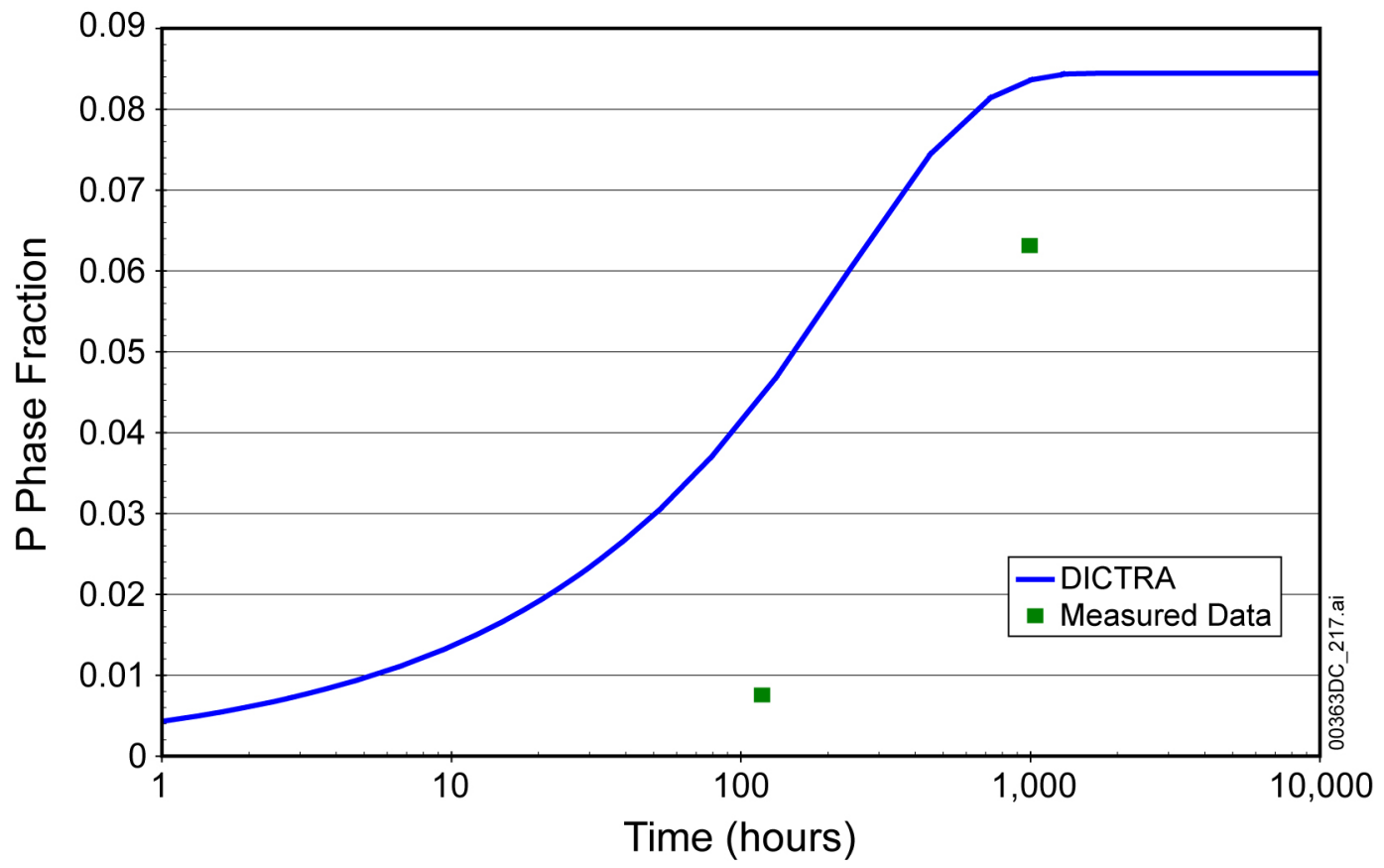

Source: DTN: LL030606912251.020.

NOTE: Measured Data was Obtained at $760^{\circ} \mathrm{C}$.

Figure 109. Comparison of Phase Formation at Approximately $750^{\circ} \mathrm{C}$ for DICTRA Computational Results (P phase) and Measured Data (TCP Phase) on Alloy 22 Base Metal 
The kinetics of LRO are treated in a manner similar to that discussed for TCP phase precipitation. However, very little kinetic data exists for LRO in Alloy 22. A very fine dispersion of ordered domains was seen after aging for 30,000 and 40,000 hours at $427^{\circ} \mathrm{C}$ in Alloy 22 base metal (Figure 48 through Figure 50) and in a weld similarly aged (Figure 51 through Figure 56). The ordering in these cases is so fine that it would be difficult to measure the volume fraction of the ordered domains. LRO was also observed in Alloy 22 base metal aged at $593^{\circ} \mathrm{C}$ for 16,000 hours and at $538^{\circ} \mathrm{C}$ and $593^{\circ} \mathrm{C}$ for 1,000 hours. The volume fraction of ordered domains has not been measured in these samples. Alloy 22 base metal samples aged for 40,000 hours at $260^{\circ} \mathrm{C}$ and $343^{\circ} \mathrm{C}$ and for 1,000 hours at $482^{\circ} \mathrm{C}$ were also examined in TEM, but no LRO was observed.

Unlike TCP-phase precipitates, LRO results in very small and finely dispersed precipitates. As a result, SEM image analysis is not well suited to determine the extent of LRO kinetics. However, due to the uniformly and finely dispersed nature of LRO, microhardness measurements are indicative of LRO, because analogous to precipitation age-hardened alloys, hardness increases with the amount of precipitation (Reed-Hill 1973 [DIRS 162684]). Table 10 summarizes the microhardness (Hv) measurements made on Alloy 22 as a function of time and temperature.

Table 10. Microhardness (Hv) Measurements in Aged Base Metal

\begin{tabular}{|r|r|r|}
\hline $\begin{array}{c}\text { Temperature } \\
\left({ }^{\circ} \mathbf{C}\right)\end{array}$ & \multicolumn{1}{|c|}{$\begin{array}{c}\text { Time } \\
\text { (hr) }\end{array}$} & $\begin{array}{c}\text { Microhardness } \\
(\mathbf{H v})\end{array}$ \\
\hline 600 & 1 & 220 \\
\hline 600 & 4 & 218 \\
\hline 600 & 10 & 223 \\
\hline 600 & 40 & 223 \\
\hline 600 & 100 & 221 \\
\hline 600 & 200 & 223 \\
\hline 600 & 400 & 219 \\
\hline 600 & 600 & 216 \\
\hline 600 & 800 & 222 \\
\hline 593 & 10 & 204 \\
\hline 593 & 30 & 218 \\
\hline 593 & 92 & 215 \\
\hline 593 & 100 & 207 \\
\hline 593 & 300 & 218 \\
\hline 593 & 600 & 218 \\
\hline 593 & 1,000 & 298 \\
\hline 593 & 1,011 & 214 \\
\hline 593 & 16,000 & 265 \\
\hline 550 & 100 & 237 \\
\hline 550 & 300 & 274 \\
\hline 550 & 600 & 301 \\
\hline 550 & 1,000 & 329 \\
\hline 550 & 2,000 & 328 \\
\hline 550 & 4,500 & 346 \\
\hline & & \\
\hline & & \\
\hline 50 & & 210 \\
\hline
\end{tabular}


Table 10. Microhardness (Hv) Measurements in Aged Base Metal (Continued)

\begin{tabular}{|c|c|c|}
\hline \begin{tabular}{|c|}
$\begin{array}{c}\text { Temperature } \\
\left({ }^{\circ} \mathrm{C}\right)\end{array}$ \\
\end{tabular} & $\begin{array}{c}\text { Time } \\
\text { (hr) }\end{array}$ & \begin{tabular}{|c} 
Microhardness \\
(Hv)
\end{tabular} \\
\hline 550 & 6,000 & 364 \\
\hline 550 & 8,000 & 359 \\
\hline 538 & 10 & 210 \\
\hline 538 & 100 & 218 \\
\hline 538 & 1,000 & 300 \\
\hline 500 & 100 & 212 \\
\hline 500 & 300 & 227 \\
\hline 500 & 600 & 252 \\
\hline 500 & 1,000 & 277 \\
\hline 500 & 2,000 & 298 \\
\hline 500 & 4,500 & 307 \\
\hline 500 & 6,000 & 368 \\
\hline 500 & 8,000 & 308 \\
\hline 482 & 10 & 210 \\
\hline 482 & 100 & 204 \\
\hline 482 & 1,000 & 237 \\
\hline 427 & 10,000 & 218 \\
\hline 427 & 20,000 & 223 \\
\hline 427 & 30,000 & 227 \\
\hline 427 & 40,000 & 245 \\
\hline 400 & 1,000 & 215 \\
\hline 400 & 2,000 & 218 \\
\hline 400 & 4,500 & 210 \\
\hline 400 & 6,000 & 211 \\
\hline 400 & 8,000 & 213 \\
\hline 343 & 30,000 & 261 \\
\hline 343 & 40,000 & 212 \\
\hline 260 & 10,000 & 216 \\
\hline 260 & 30,000 & 216 \\
\hline 260 & 40,000 & 210 \\
\hline As-received & & 217 \\
\hline
\end{tabular}

Source: DTN: LL030607112251.021 [DIRS 163927].

These microhardness results are graphically presented in Figure 110. Trend lines have been included for the results at $500^{\circ} \mathrm{C}$ and $550^{\circ} \mathrm{C}$. Some of the temperature values shown in Table 10 have been rounded to one or two significant figures (e.g., $593^{\circ} \mathrm{C} \approx 600^{\circ} \mathrm{C}$ ) when plotted in Figure 110. The microhardness of "as-received" material was $217 \mathrm{Hv}$.

The microhardness measurements indicate that LRO has occurred at temperatures in approximately the $500^{\circ} \mathrm{C}$ to $550^{\circ} \mathrm{C}$ range up to 40,000 hours. In addition, for results up to 40,000 hours, no LRO is evident for temperatures below $400^{\circ} \mathrm{C}$, and little LRO is seen at 
temperatures around $600^{\circ} \mathrm{C}$. The observation of very little LRO near $600^{\circ} \mathrm{C}$ corroborates well with the critical order-disorder temperature of about $596^{\circ} \mathrm{C}$ of the computational model (Section 6.6.4.3). These microhardness measurements add confidence to the observation from the computational TTT diagrams that formation of the oP6-ordered phase from the fcc-solid solution will not be a concern for conditions of less than $300^{\circ} \mathrm{C}$ for a period of 500 years followed by temperatures less than $200^{\circ} \mathrm{C}$ for a period of 9,500 years conditions that bound the repository time-temperature profiles (BSC 2004 [DIRS 169565], Figure 6.3-57).

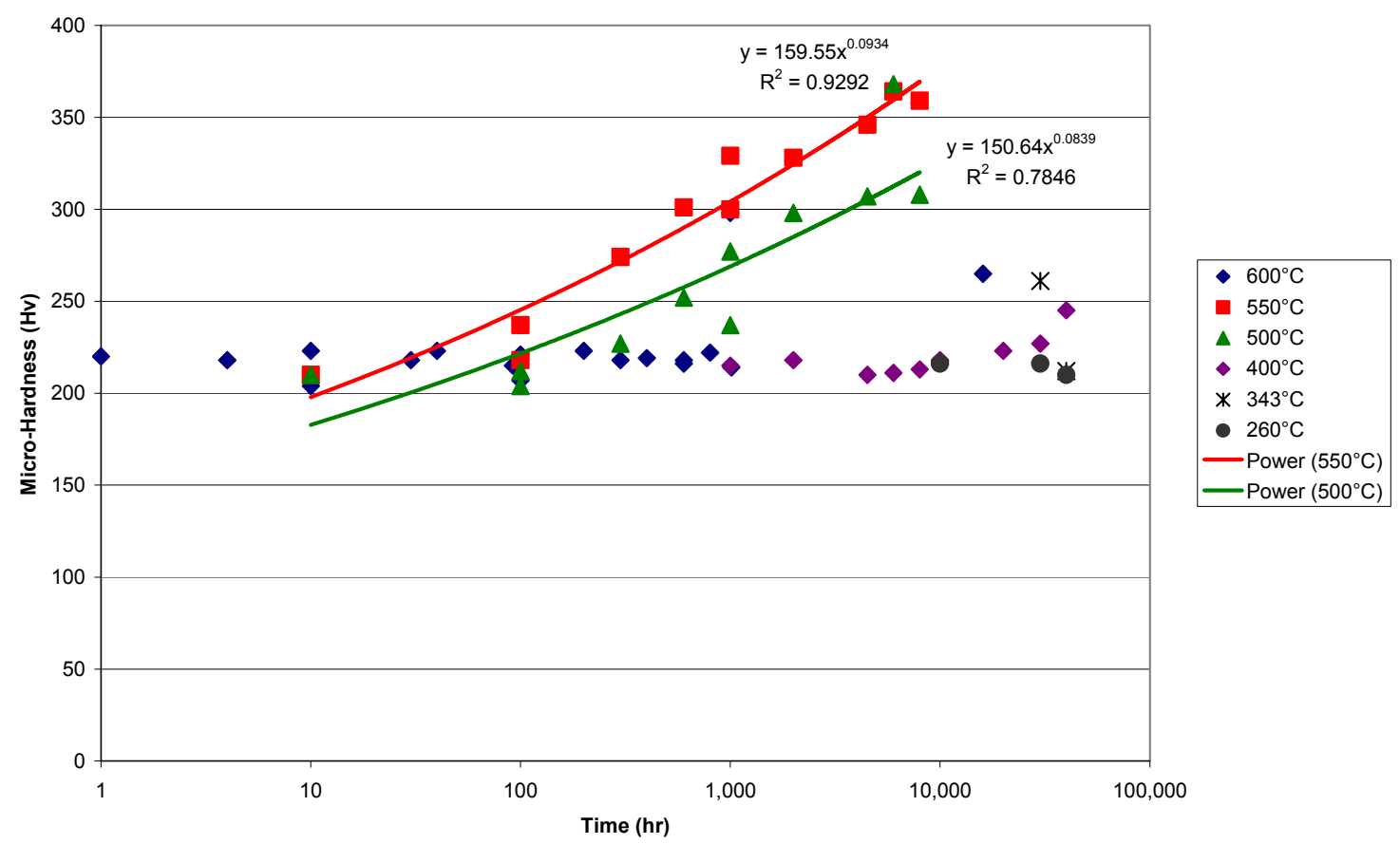

NOTE: Microhardness values are indicative of LRO. Microhardness of "as-received" base metal is $217 \mathrm{Hv}$.

Figure 110. Microhardness (Hv) Measurements on Aged Alloy 22 Base Metal as a Function of Time and Temperature.

For LRO in base metal, the TTT diagram for the oP6 phase of the ternary Ni-Cr-Mo alloy (a surrogate for Alloy 22) was presented in Section 6.6.4.2. In addition, microhardness measurements were used (Figure 110) to provide insight into the extent of LRO at several times and temperatures. In comparing the measurements indicative of LRO and the calculated TTT diagram, it was shown (Section 6.6.4.2) that the calculated order-disorder transition temperature of $620^{\circ} \mathrm{C}$ agreed well with the estimated order-disorder transition temperature of approximately $600^{\circ} \mathrm{C}$ (Figure 88 and Figure 110).

The comparisons of results discussed in this section validate Criterion One and thus, the required level of confidence in the model has been achieved. 


\section{Criterion Two}

Do experimental data on TCP formations on base metal grain boundaries and TCP and LRO formations in weld metal corroborate with data in peer-reviewed literature or fundamental metallurgical phenomena?

In Section 6.6.5.2, the measurements on Alloy 22 grain boundaries were plotted using an Arrhenius fit to conservatively estimate the long-term TCP-phase precipitation on grain boundaries. As a measure of the reasonableness of the data plotted in Figure 92, the activation energy can be calculated. The slopes of the lines in Figure 92 (after accounting for the $\log (\mathrm{e})$ factor) are equal to $C_{2} / n$ in Eq. 11. If these slopes are averaged and $n$ is set to be equal to one, which is a reasonable value for $n$ (Christian 1981 [DIRS 104964], p. 542, Table IX and p. 19), then the activation energy is $378 \mathrm{~kJ} / \mathrm{mol}$ (or $90 \mathrm{kcal} / \mathrm{mol}$ ). This value for activation energy (for Alloy 22 grain boundary precipitation) is higher than the value of $62 \mathrm{kcal} / \mathrm{mol}$ obtained by Hodge (1973 [DIRS 104968], p. 378 paragraph 1) for precipitation in Alloy C-276. It is expected that the activation energy for Alloy 22 would be slightly higher than that of Alloy C-276 primarily due to the differences in chemical composition (alloy C-276 contains more Mo and W) and phases formed. As shown in Section 6.6.1, unlike Alloy 22, Alloy C-276 does not form an oP6-ordered phase. In Alloy 22, it was shown that the formation of the oP6ordered phase competes with the $\mathrm{P}$ phase. As a result, it is reasonable that the activation energy for C-276 would be slightly lower than that observed for Alloy 22. This activation energy value for Alloy 22 grain boundary precipitation is also the within the expected order of magnitude and fairly typical for diffusion of relevant elements in Ni (Brandes et al. 1992 [DIRS 104962], Chapter 13, pp. 13 to 23). For example, the activation energy for diffusion of $\mathrm{Cr}$ in $\mathrm{Ni}$ is $272.6 \mathrm{~kJ} / \mathrm{mol}$, that of $\mathrm{Fe}$ is 253 to $270 \mathrm{~kJ} / \mathrm{mol}$, and that of $\mathrm{W}$ in $\mathrm{Ni}$ is 299 to $308 \mathrm{~kJ} / \mathrm{mol}$. It is expected that these activation energy values in binary alloy systems would be lower than that in Alloy 22, a multicomponent alloy.

The data in Figure 92 represent the precipitation kinetics during an isothermal anneal. The repository temperature is not expected to remain constant. It was shown that even with this activation energy, formation of TCP phases on grain boundaries will not be a concern for conditions of less than $300^{\circ} \mathrm{C}$ for a period of 500 years followed by temperatures less than $200^{\circ} \mathrm{C}$ for a period of 9,500 years, conditions that bound the repository time-temperature profiles (BSC 2004 [DIRS 169565], Figure 6.3-57)).

The comparisons of results discussed in this section validate Criterion Two and, thus, the required level of confidence in the model has been achieved.

Criterion Three

Do comparisons of volume fraction measurements agree with peer-reviewed published literature (where applicable) and/or fundamental metallurgical phenomena?

At present, a computationally based model for phase kinetics in Alloy 22 welds is not available to provide insight into the long-term stability of welds. As a result, in Section 6.6.5.3.2, the measurements on Alloy 22 welds were plotted using an Arrhenius fit to conservatively estimate 
the long-term stability of welds. These Arrhenius plots indicated an average activation energy of $241 \mathrm{~kJ} / \mathrm{mol}$ for TCP phase formation, which is comparable to but lower than the values of 250 and $260 \mathrm{~kJ} / \mathrm{mol}$ reported previously for base metal (Rebak et al. 2000 [DIRS 155013]). It was shown that even with a lower activation energy, formation of TCP phases in welds will not be a concern for conditions of less than $300^{\circ} \mathrm{C}$ for a period of 500 years followed by temperatures less than $200^{\circ} \mathrm{C}$ for a period of 9,500 years, conditions that bound the repository time-temperature profiles (BSC 2004 [DIRS 169565], Figure 6.3-57).

The phase fractions of LRO formations (oP6 phase) in Alloy 22 welds were not measured in this study (LRO was only observed).

The comparisons of results discussed in this section validate Criterion Three and, thus, the required level of confidence in the model has been achieved.

\subsection{VALIDATION SUMMARY}

In light of the above discussion, it may be concluded that the inputs used in the aging and phase stability model and the model output corroborate well with those reported in handbooks and peer-reviewed scientific literature. It is also clear from the above discussion that the validation activities performed for building confidence in the model have sufficiently strong scientific bases, and that the required level of confidence in the model has been achieved, because the model validation criterion described in Technical Work Plan for: Regulatory Integration Modeling and Analysis of the Waste Form and Waste Package (BSC 2004 [DIRS 171583]) has been satisfied (corroborating data match qualitatively). As a result, it has been demonstrated that the aging and phase stability model has been validated for its intended use of providing predictive insight into the long-term metallurgical stability of Alloy 22 under relevant repository conditions.

The aging and phase stability model is complex and validation process involves the use of both Project generated data and peer-reviewed published literature data. The Thermo-Calc results used in analyzing Alloy 22 along with several other Ni-based alloys have been validated using comparisons of calculated phase diagrams with published literature, in order of increasing complexity, for (1) the binary sub-systems, (2) the pseudo-binary section $\mathrm{Ni}_{\mathrm{x}}\left(\mathrm{Cr}_{3} \mathrm{Mo}\right)_{1-\mathrm{x}}$ and (3) the ternary Ni-Cr-Mo alloy (a surrogate for Alloy 22). Agreement of the calculated phase diagrams with published literature is excellent and described in Sections 7.1 through 7.4. In Section 7.5, natural analogues were shown to provide confidence in phase stability of metallic structures over long periods of time. Section 7.6 described comparisons of the aging and phase stability model results and project-generated TCP-phase kinetics data for base metal, and the aging and phase stability model was shown to be conservative. Project generated data on LRO kinetics were also shown to be in good agreement with the computational aging and phase stability model and its estimate of the order-disorder transition temperature (Section 7.6). Comparisons with peer-reviewed published literature were used to demonstrate confidence in the Arrhenius-type extrapolations for the phase kinetics on grain boundaries and welds derived from Project generated data. 


\section{CONCLUSIONS}

The CALPHAD approach has been applied to the study of statics (stability) and kinetics (aging) of phase formation and evolution in Ni-based alloys. At equilibrium, Alloy 22, at its nominal compositions and at low temperatures, should exhibit, besides the fcc matrix, long-range order of $\mathrm{Ni}_{2} \mathrm{Cr}$-type, complex Frank-Kasper phases (here, the $\mathrm{P}$ phase), carbides and silicides. The kinetics of LRO formation occurs at relatively low temperatures, and therefore, does not favor the formation of the ordered phase of $\mathrm{Ni}_{2} \mathrm{Cr}$-type as the phase formation kinetics are primarily driven by diffusion. Alloys homogenized (or annealed) at high temperatures and quenched at relevant repository conditions should not display any deleterious phase. Extrapolation of computationally derived TTT curves to lower temperatures, which bound repository timetemperature profiles (i.e., less than $300^{\circ} \mathrm{C}$ for a period of 500 years followed by temperatures of less than $200^{\circ} \mathrm{C}$ for a period of 9,500 years (BSC 2004 [DIRS 169565], Figure 6.3-57)), indicates that forming the P- or oP6-ordered phases from the fcc solid solution will not be a concern.

After aging for 16,000 hours at $593^{\circ} \mathrm{C}$, P phase was found at Alloy 22 grain boundaries. At higher temperatures (as much as $760^{\circ} \mathrm{C}$ for the same aging time), $\mu$ and $\mathrm{P}$ phases formed on grain boundaries and within the grains. Grain boundary carbides also form at $593^{\circ} \mathrm{C}$ and higher, but the amount of carbide is small compared to the $\mu$ and $\mathrm{P}$ phases. A small amount of $\sigma$ phase forms in Alloy 22 after 16,000 hours at $704^{\circ} \mathrm{C}$ and $760^{\circ} \mathrm{C}$. LRO was seen after aging for 1,000 hours at $538^{\circ} \mathrm{C}$ and $593^{\circ} \mathrm{C}$ and for 30,000 hours at $427^{\circ} \mathrm{C}$ (shown in Table 6), but ordering most likely begins at shorter times.

The experimental analyses previously discussed assume that the kinetics of formation of the $\mu$ and $\mathrm{P}$ phases are similar and that the amount of carbide and $\sigma$ phase present is too small to affect the measured rates of precipitation (Assumption 5.1). Minor compositional changes in Alloy 22 are also expected to have little or no effect on the rate of precipitation. The amounts of carbide and $\sigma$ phase tend to be low in the samples examined thus far. Therefore, the rates of formation of these phases are not likely to contribute significantly to the overall performance of the waste package. Studies from existing literature (Section 5.1) showed that the $\mu$ and $P$ phases are very similar, and the rates at which they form are likely to be similar.

The experimental analyses previously discussed also assume that the precipitation mechanism operating at the high temperatures studied also operates at the lower temperatures expected in the proposed repository and that the phases seen at the higher temperatures are stable at the lower temperatures (Assumption 5.2). Information from natural analogues (Section 6.7.2) showed that the stability of the metallic structures in josephinite over millions of years suggests that no lowtemperature mechanism with rates significantly greater than predicted exists. Thus, this provides confidence in the implicit assumption that the high temperature mechanisms used to extrapolate kinetics are the same as those at lower temperatures that are expected under repository conditions.

The present study shows that formation of TCP or ordered oP6 phases in Alloy 22 base metal and welds (which are deemed to be similar to base metal) will not be a concern for conditions of less than $300^{\circ} \mathrm{C}$ for a period of 500 years followed by temperatures less than $200^{\circ} \mathrm{C}$ for 9,500 years, conditions that bound the repository time-temperature profiles (BSC 2004 [DIRS 169565], Figure 6.3-57). 


\subsection{THE ROLE OF W IN THE STABILITY OF NICKEL-BASED ALLOYS}

From experiments and the results of the present study, it is apparent that $\mathrm{Cr}$ and $\mathrm{Mo}$ favor the formation of TCP phases $(\sigma, \mathrm{P}$, and $\mu)$. It was also noted that in the pure binary forms, $\mathrm{Cr}$ is the only element that favors the formation of the oP6-ordered phase $\mathrm{Ni}_{2} \mathrm{Cr}$. The effect of Mo on oP6-phase formation is more subtle, as revealed from the study. Indeed, in the pure binary form, $\mathrm{Ni}_{2} \mathrm{Mo}$ is barely stable (Section 7.1). However, it was shown experimentally (Karmazin et al. 1994 [DIRS 161444]) that at a low mole fraction of Mo, the substitution of Cr by Mo enhances the formation of the oP6-ordered phase, as indicated by an increase in the critical order-disorder temperature. The gradual substitution of $\mathrm{Cr}$ by $\mathrm{Mo}$ from $\mathrm{Ni}_{2} \mathrm{Cr}$ to $\mathrm{Ni}_{2} \mathrm{Mo}$ does not lead to a gradual instability of the order phase as was initially anticipated. The role of $\mathrm{W}$ on the stability of oP6-ordered phase is more obvious. The gradual substitution of Cr by $\mathrm{W}$ gradually leads to a destabilization of the ordered phase, and the oP6 $\mathrm{Ni}_{2} \mathrm{~W}$ ordered phase is clearly unstable. It is worth recalling that Alloy 22 has (in wt \%) $21.2 \mathrm{Cr}-13.5 \mathrm{Mo}-3 \mathrm{~W}$, whereas in Alloy 59 has $23 \mathrm{Cr}-16 \mathrm{Mo}$, with no W. From the above observations, it is concluded that the oP6-ordered phase will occur at higher temperature (i.e., will be more stable) in Alloy 59 than in Alloy 22 (less unstable effect on the ordered phase caused by the absence of $\mathrm{W}$ in Alloy 59). At the same time, because more $\mathrm{Cr}$ and Mo are present in Alloy 59 than in Alloy 22, it is expected that at low temperatures, the stability of the complex TCP phases will be more favored in Alloy 59 than in Alloy 22 (Heino 2000 [DIRS 161799]). Hence, because of this double effect of the absence of $\mathrm{W}$ in Alloy 59, it is believed that Alloy 22 is a more promising alloy than Alloy 59, at least when in operation at low temperatures (below $800^{\circ} \mathrm{C}$ ), as is the case under expected repository conditions.

\subsection{APPLICABILITY OF RANGES OF ALLOY 22 CHEMICAL COMPOSITION}

In the computational analyses and measurements conducted on Alloy 22 samples presented here, the Alloy 22 chemical composition was within that specified by ASTM specification B575 (UNS N06022). In addition, five heats of Alloy 22 base metal were used in performing the measurements on test specimens, and the chemical composition of these heats are summarized in Table 11. In all heats, the Alloy 22 chemical composition was more restricted than that specified in ASTM specification B575 (UNS N06022) as shown in Table 12. The nominal chemical composition of the ternary $\mathrm{Ni}-\mathrm{Cr}-\mathrm{Mo}$ alloy that was used as a surrogate for Alloy 22 in the Thermo-Calc/DICTRA simulations also agreed well with the range of chemical compositions from these five heats (also shown in Table 12). This comparative summary shows that the chemical compositions of ASTM specification B575, the five heats tested, and the nominal composition of the ternary surrogate for Alloy 22 are consistent and in agreement. Thus, the conclusions presented here are applicable to a narrower range (as compared to the ASTM specification B575) of chemical compositions for $\mathrm{Ni}, \mathrm{Cr}$, Mo, and $\mathrm{W}$, which were modeled with Thermo-Calc and DICTRA. Ni, Cr, Mo, and $\mathrm{W}$ are the most dominant elements in TCP and oP6-ordered phases in Alloy 22. 
Table 11. Summary of Alloy 22 Chemical Composition of Heats Tested

\begin{tabular}{|l|c|c|c|c|c|}
\hline Element & $\mathbf{2 2 7 7 - 0 - 3 2 6 4 ^ { \mathbf { a } }}$ & $\mathbf{2 2 7 7 - 0 - 3 2 7 0}$ & $\mathbf{2 2 7 7 - 8 - 3 1 2 1}^{\mathbf{a}}$ & $\mathbf{2 2 7 7 - 8 - 3 2 3 5}^{\mathbf{b}}$ & $\mathbf{2 2 7 7 - 9 - 3 2 4 3}^{\mathbf{a}}$ \\
\hline $\mathrm{Al}$ & - & - & - & - & - \\
\hline $\mathrm{C}$ & 0.004 & 0.003 & 0.003 & 0.003 & 0.002 \\
\hline $\mathrm{Co}$ & 1.14 & 1.96 & 0.48 & 1.31 & 1.04 \\
\hline $\mathrm{Cr}$ & 21.3 & 21.2 & 21.24 & 21.4 & 21.28 \\
\hline $\mathrm{Cu}$ & - & - & - & - & - \\
\hline $\mathrm{Fe}$ & 4.4 & 4.5 & 3.82 & 3.94 & 3.6 \\
\hline $\mathrm{Mg}$ & - & - & - & - & - \\
\hline $\mathrm{Mn}$ & 0.29 & 0.25 & 0.3 & 0.24 & 0.28 \\
\hline $\mathrm{Mo}$ & 13.4 & 13.3 & 13.43 & 13.47 & 13.29 \\
\hline $\mathrm{N}$ & - & - & - & - & - \\
\hline $\mathrm{Nb}(\mathrm{Cb})$ & - & - & - & - & - \\
\hline $\mathrm{Ni}$ & $\mathrm{BAL}$ & $\mathrm{BAL}$ & $\mathrm{BAL}$ & $\mathrm{BAL}$ & $\mathrm{BAL}$ \\
\hline $\mathrm{P}$ & 0.01 & 0.006 & 0.006 & 0.008 & 0.007 \\
\hline $\mathrm{S}$ & 0.002 & 0.003 & 0.001 & 0.001 & 0.002 \\
\hline $\mathrm{Si}$ & 0.047 & 0.038 & 0.035 & 0.023 & 0.036 \\
\hline $\mathrm{Ta}$ & - & - & - & - & - \\
\hline $\mathrm{Ti}$ & - & - & - & - & - \\
\hline $\mathrm{V}$ & 0.17 & 0.14 & 0.17 & 0.17 & 0.14 \\
\hline $\mathrm{W}$ & 2.9 & 3.0 & 2.85 & 2.87 & 2.8 \\
\hline
\end{tabular}

Sources: ${ }^{a}$ Summers 1999 [DIRS 171396], pp. 9 and 17.

b Summers 2000 [DIRS 171397], p. 1. 
Table 12. Summary of Alloy 22 Chemical Compositions (ASTM B575, Heats Tested, and Ternary Alloy 22 Surrogate)

\begin{tabular}{|l|c|c|c|}
\hline Element & ASTM B575 & $\begin{array}{c}\text { Chemical Compositional } \\
\text { Range of Heats Tested }\end{array}$ & $\begin{array}{c}\text { Nominal Composition of } \\
\text { Ternary Surrogate for Alloy 22 }\end{array}$ \\
\hline $\mathrm{Al}$ & - & - & - \\
\hline $\mathrm{C}$ & $0.015 \mathrm{max}$ & $0.004 \mathrm{max}$ & - \\
\hline $\mathrm{Co}$ & $2.5 \mathrm{max}$ & $2.0 \mathrm{max}$ & - \\
\hline $\mathrm{Cr}$ & 20.0 to 22.5 & 21.2 to 21.4 & - \\
\hline $\mathrm{Cu}$ & - & - & - \\
\hline $\mathrm{Fe}$ & 2.0 to 6.0 & 3.6 to 4.5 & - \\
\hline $\mathrm{Mg}$ & - & - & - \\
\hline $\mathrm{Mn}$ & $0.50 \max$ & $0.30 \max$ & 13.5 \\
\hline $\mathrm{Mo}$ & 12.5 to 14.5 & 13.3 to 13.5 & - \\
\hline $\mathrm{N}$ & - & - & - \\
\hline $\mathrm{Nb}(\mathrm{Cb})$ & - & - & BAL \\
\hline $\mathrm{Ni}$ & BAL & BAL & - \\
\hline $\mathrm{P}$ & $0.02 \max$ & 0.01 max & - \\
\hline $\mathrm{S}$ & $0.02 \max$ & $0.003 \max$ & - \\
\hline $\mathrm{Si}$ & - & - & - \\
\hline $\mathrm{Ta}$ & - & - & - \\
\hline $\mathrm{Ti}$ & - & - & - \\
\hline $\mathrm{V}$ & $0.35 \max$ & $0.2 \max$ & 3.0 \\
\hline $\mathrm{W}$ & 2.5 to 3.5 & 2.8 to 3.0 & \\
\hline
\end{tabular}

\subsection{SUMMARY OF DEVELOPED DATASETS}

The developed data from this report that have been presented and discussed in Sections 6 and 7 have been summarized in Table 13.

Table 13. Summary of Developed Datasets

\begin{tabular}{|l|c|c|}
\hline \multicolumn{1}{|c|}{ Data Name } & DTN & Data Presented in this Report \\
\hline $\begin{array}{l}\text { Property and Phase Kinetics } \\
\text { Diagrams }\end{array}$ & LL030106312251.013 & Sections 6.6.1.1 through 6.6.4.3 \\
\hline Validation of Computational Model & LL030106412251.014 & Sections 7.1 through 7.4 \\
\hline $\begin{array}{l}\text { Developed Data from Alloy 22 } \\
\text { Volume Fraction Measurements }\end{array}$ & LL030606912251.020 & Sections 6.6.5 and 7.5 \\
\hline
\end{tabular}

\subsection{YUCCA MOUNTAIN REVIEW PLAN ACCEPTANCE CRITERIA}

Yucca Mountain Review Plan, Final Report (NRC 2003 [DIRS 163274]) contains Acceptance Criteria that are intended to establish the basis for the review of the material contained in the License Application. As this model report serves, in part, as the basis for the License Application, it is important to show how the information contained herein addresses each of the applicable YMRP Acceptance Criteria. 
The YMRP Acceptance Criteria that are applicable to this report are identified in Technical Work Plan for: Regulatory Integration Modeling and Analysis of the Waste Form and Waste Package (BSC 2004 [DIRS 171583], Table 3-1). For each applicable criterion, the criterion is quoted in italics, followed by pointers to where within the report the information addressing the criterion can be found. In some cases, the criterion is only partially addressed in this report. A demonstration of full compliance requires a review of multiple reports.

\subsubsection{System Description and Demonstration of Multiple Barriers}

The following Acceptance Criteria are from Section 2.2.1.1.3 of Yucca Mountain Review Plan, Final Report (NRC 2003 [DIRS 163274]). Although the criterion pertains to "multiple barriers," only the waste package outer barrier is addressed in this report. As such, the responses below pertain to only that barrier.

\section{Acceptance Criterion 1 - Identification of Barriers Is Adequate}

Barriers relied on to achieve compliance with 10 CFR 63.113(b), as demonstrated in the total system performance assessment, are adequately identified, and are clearly linked to their capability.

The effects of aging and phase stability on waste package outer barrier performance are described in Sections 1, 6.1, and 6.2.

\section{Acceptance Criterion 2 - Description of Barrier Capability to Isolate Waste Is Acceptable}

The capability of the identified barriers to prevent or substantially reduce the rate of movement of water or radionuclides from the Yucca Mountain repository to the accessible environment, or prevent the release or substantially reduce the release rate of radionuclides from the waste is adequately identified and described:

(1) The information on the time period over which each barrier performs its intended function, including any changes during the compliance period, is provided;

(2) The uncertainty associated with barrier capabilities is adequately described;

(3) The described capabilities are consistent with the results from the total system performance assessment; and

(4) The described capabilities are consistent with the definition of a barrier at 10 CFR 63.2.

The effects of aging and phase stability on waste package outer barrier performance are described in Sections 1, 6.1, and 6.2. 


\section{Acceptance Criterion 3 - Technical Basis for Barrier Capability Is Adequately Presented}

The technical bases are consistent with the technical basis for the performance assessment. The technical basis for assertions of barrier capability is commensurate with the importance of each barrier's capability and the associated uncertainties.

The effects of aging and phase stability on waste package outer barrier performance are described in Sections 1, 6.1, and 6.2.

\subsubsection{Degradation of Engineered Barriers}

The following acceptance criteria are from Section 2.2.1.3.1.3 of Yucca Mountain Review Plan, Final Report (NRC 2003 [DIRS 163274]).

\section{Acceptance Criterion 1 - System Description and Model Integration are Adequate}

(1) TSPA adequately incorporates important design features, physical phenomena and couplings and uses consistent assumptions throughout the degradation of engineered barriers abstraction process

The appropriate design features and applicable physical phenomena, as well as environmental factors and their coupling are addressed in Sections 6.1 and 6.3.

(2) Abstraction uses assumptions, technical bases, data and models that are appropriate and consistent with [those used] in other abstractions.

Throughout this report, the performed analyses use assumptions, technical bases, input data and models that appropriately reflect the design and contents of the metallurgical stability of Alloy 22 used in the waste package outer barrier. The assumptions are addressed in Section 5. The data, technical bases and models are addressed in Sections 4.1 and 6. This information is used in a manner that is consistent with other abstractions of processes associated with the degradation of the waste package.

(3) The descriptions of the engineered barriers, design features, degradation processes, physical phenomena, and couplings that may affect the degradation of the engineered barriers are adequate.

Detailed descriptions of the metallurgical stability processes relevant for the Alloy 22 used in the waste package outer barrier (Sections 6.1 and 6.3), and the physical phenomena and their couplings that may affect Alloy 22 metallurgical stability (Sections 6.1 and 6.3) are provided.

(4) Initial and boundary conditions are propagated consistently throughout the abstraction process.

The initial and relevant environmental boundary conditions for the performed analyses (Section 6.5) are described and used in developing the aging and phase stability model. 
(5) Sufficient technical basis for the inclusion and exclusion of FEPs are provided;

This model report provides the basis for the exclusion of FEP 2.1.11.06.0A (Thermal sensitization of waste packages) in TSPA-LA (Total System Performance Assessment for the License Application) as discussed in Section 6.6.4.

(6) In-Package Criticality

Not applicable to this report

(7) Guidance in NUREG 1297 and NUREG 1298 [re: Expert Elicitation] are followed.

Not applicable to this report; expert elicitation is not used.

\section{Acceptance Criterion 2 - Data Are Sufficient for Model Justification}

(1) Parameters used to evaluate the degradation of EBS are adequately justified;

The input data and parameters used for the aging and phase stability model come, primarily, from commercially available thermodynamic and kinetic databases that have been formulated to accurately simulate the metallurgical phenomena of Alloy 22 (Section 7). In addition, Alloy 22 experimental data generated by the project (Section 4.1) is used to support and compare with the results of the computational model. Justification for the use of specific data is typically provided in the section in which the data are initially discussed (Section 4.1) and used (Section 7).

(2) Sufficient data have been collected to establish initial and boundary conditions;

Extensive scientific investigations and experiments have been performed by the project to develop the data necessary to support the analyses provided in this model report (Sections 4.1 and 6.6). All initial and boundary conditions are adequately and appropriately established and justified.

(3) Data on the degradation of the engineered barriers (e.g. - general and localized corrosion, microbially induced corrosion, galvanic interactions, hydrogen embrittlement and phase stability) are based on laboratory measurements, site-specific field measurements, industrial and/or natural analogs and tests designed to replicate anticipated conditions. As appropriate, sensitivity or uncertainty analyses are provided and are shown to be adequate.

Data related to the various potential degradation modes for the metallurgical stability of Alloy 22 are discussed in Sections 6.1 and 6.2.

(4) Degradation models for the applicable processes are adequate. For example, general and localized corrosion, microbially induced corrosion, galvanic 
interactions, hydrogen embrittlement and phase stability are given appropriate consideration and treatment.

The various models related to the potential degradation modes for the metallurgical stability of Alloy 22 are discussed in Sections 6.1 and 6.2.

\section{Acceptance Criterion 3 - Data Uncertainty is Characterized and Propagated through the Model Abstraction}

(1) Models use parameter values, assumed ranges, probability distributions and/or bounding assumptions that are technically defensible, reasonably account for uncertainties and variabilities, and do not result in under-representation of the risk estimate.

The computational model developed in this model report uses parameter values and assumed ranges, that are technically defensible, reasonably account for uncertainties and variabilities, and do not result in under-representation of the risk estimate. Discussion and consideration of the uncertainties associated with specific data are addressed in detail. The effects of data uncertainties and computational accuracy on model results are discussed in Section 6.7.

(2) Appropriate parameters, based on techniques that may include laboratory experiments, field measurements, and industrial analogs are used.

The computational model employed in this model report use data and parameters that have been developed based on the CALPHAD method to simulate the metallurgical phenomena of Alloy 22 (Section 6.5). Peer reviewed and industrial literature, together with project-generated experimental measurements, are used for model validation in Sections 7.1 through 7.5.

(3) Assumed range of values and probability distributions for parameters used in conceptual and process-level models are not likely to underestimate the actual degradation and failure of engineered barriers.

As discussed in Section 7.5, the model validation results indicate the computational model consistently gives results that are conservative compared to experimental measurements.

\section{(4) Nondestructive examination.}

Not applicable; no NDE of Alloy 22 material was involved with the development of this report.

(5) Where sufficient data do not exist, the definition of parameter values and conceptual models is based on appropriate use of other sources, such as expert elicitation.

The available data is generally sufficient to support the definition of parameter values and the Alloy 22 aging and phase stability conceptual model. 


\section{Acceptance Criterion 4 - Model Uncertainty is Characterized and Propagated Through the Model Abstraction}

(1) Alternative modeling approaches are considered and are consistent with available data and current scientific understanding.

Alternative modeling approaches that are consistent with available data and current scientific understanding are considered and discussed in Section 6.4.

(2) Consideration of conceptual model uncertainty is consistent with available site characterization data, laboratory experiments, ... and the treatment of uncertainty does not result in under-estimation of the risk estimate.

Consideration of uncertainties in the models used in this model report is an integral part of the model development and validation processes. Conceptual model uncertainty is consistent with the information that has been developed from computational simulations (Sections 6 and 7). Care is taken to ensure that the treatment of uncertainty does not result in underestimation of the risk estimate. As discussed in Section 7.5, the model validation results show that the computational model consistently gives results that are conservative compared to experimental measurements.

(3) Alternative modeling approaches, consistent with available data and current scientific understanding, are used and the modeling results are evaluated using tests that are sensitive to the processes modeled.

Alternative modeling approaches, consistent with available data and current scientific understanding, are considered (Section 6.4). In all instances, it is determined that the base case model provides a more credible modeling basis than would be achieved through the use of the alternative models. Thus, although due consideration is given to the use of alternative modeling approaches, no alternative models are used in TSPA-LA.

\section{Acceptance Criterion 5 - Model Abstraction Output Is Supported By Objective Comparisons}

(1) Models implemented in this total system performance assessment abstraction provide results consistent with output from detailed process-level models and or empirical observations (laboratory and field testing, and/or natural analogs).

The results of the computational Aging and Phase Stability model developed in this model report (this model is not implemented in a total system performance assessment abstraction) are compared with empirical observations (laboratory) as part of the model validation (Section 7.5).

\section{(2) Corrosion models.}

Not applicable; this report does not include numerical models.

(3) Evidence is sufficient to show that models will not underestimate the actual degradation and failure of engineered barriers. 
In those instances where there is doubt about the appropriateness or accuracy of the models or data, care is taken to select a conservative approach or conservative data that would result in an over-estimation of risk. The model validation results show that the computational model consistently gives results that are conservative compared to experimental measurements (Section 7.5).

(4) Mathematical degradation models are based on the same environmental parameters, material factors, assumptions and approximations shown to be appropriate for closely analogous applications.

The computational model used in this model report is based on the well-established CALPHAD approach that involves the coupling of phase diagrams calculations for multicomponent alloy systems with other forms of thermo-chemical inputs to determine phase formation, proportions, and transformations. As a result, the model is based on the same environmental parameters, material factors, assumptions and approximations that are appropriate for closely analogous applications (Section 6.5).

(5) Accepted and well documented procedures are used to construct and test the numerical models that simulate the EB chemical environment and degradation of $E B$;

The development and testing of the models used to simulate the metallurgical stability of Alloy 22 is performed in accordance with previously established well-documented Yucca Mountain project procedures that are based on industry established norms. These procedures also establish the appropriate quality assurance requirements for such activities and appropriate checking, auditing and other activities performed to ensure the adequacy and appropriateness of the models (Section 2).

(6) $\ldots$

Not applicable to the scope of this report. 


\section{INPUTS AND REFERENCES}

\subsection{DOCUMENTS CITED}

161440 Agren, J. 1992. "Computer Simulations of Diffusional Reactions in Complex Steels." ISIJ International, 32, (3), 291-296. Tokyo, Japan: Iron and Steel Institute of Japan. TIC: 254255.

161461 Andersson, J.-O.; Guillermet, A.F.; Hillert, M.; Jansson, B.; and Sundman, B. 1986. "A Compound-Energy Model of Ordering in a Phase with Sites of Different Coordination Numbers." Acta Metallurgica, 34, (3), 437-445. Elmsford, New York: Pergamon Press. TIC: 253831.

161462 Ansara, I.; Dupin, N.; and Sundman, B. 1998. "Reply to the Paper: 'When is a Compound Energy Not a Compound Energy? A Critique of the 2-Sublattice Order/Disorder Model."' Calphad, 21, (4), 535-542. New York, New York: Elsevier. TIC: 253806.

163390 Bernard, C.; Pons, M.; Blanquet, E.; and Madar, R. 1999. "Thermodynamic Calculations as the Basis for CVD Production of Silicide Coatings." MRS Bulletin, 24, (4), 27-31. Warrendale, Pennsylvania: Materials Research Society. TIC: 254150 .

161463 Bloom, D.S. and Grant, N.J. 1954. "An Investigation of the Systems Formed by Chromium, Molybdenum, and Nickel.” Journal of Metals, 6, (2), 261-268. New York, New York: American Institute of Mining and Metallurgical Engineers. TIC: 253832.

154716 Botto, R.I. and Morrison, G.H. 1976. "Josephinite: A Unique Nickel-Iron." American Journal of Science, 276, (3), 241-274. New Haven, Connecticut: Yale University, Kline Geology Laboratory. TIC: 249797.

104962 Brandes, E.A. and Brook, G.B., eds. 1992. Smithells Metals Reference Book. 7th Edition. Oxford, United Kingdom: Butterworth-Heinemann. TIC: 246620.

168796 BSC (Bechtel SAIC Company) 2003. Risk Information to Support Prioritization of Performance Assessment Models. TDR-WIS-PA-000009 REV 01 ICN 01, with 1 errata. Las Vegas, Nevada: Bechtel SAIC Company. ACC: MOL.20021017.0045; DOC.20031014.0003.

169997 BSC 2004. FEPs Screening of Processes and Issues in Drip Shield and Waste Package Degradation. ANL-EBS-PA-000002, Rev. 03. Las Vegas, Nevada: Bechtel SAIC Company.

169565 BSC 2004. Multiscale Thermohydrologic Model. ANL-EBS-MD-000049 REV 02. Las Vegas, Nevada: Bechtel SAIC Company. 
168361 BSC 2004. Q-List. 000-30R-MGR0-00500-000-000 REV 00. Las Vegas, Nevada: Bechtel SAIC Company. ACC: ENG.20040721.0007.

170992 BSC 2004. Safety Classification of SSCs and Barriers. 000-00C-MGR0-01000-00000A. Las Vegas, Nevada: Bechtel SAIC Company. ACC: ENG.20040721.0005.

171583 BSC 2004. Technical Work Plan For: Regulatory Integration Modeling and Analysis of the Waste Form and Waste Package. TWP-WIS-MD-000009, REV 00, ICN 01. Las Vegas, Nevada: Bechtel SAIC Company. ACC: DOC.20040910.0001.

104964 Christian, J.W. 1981. "Equilibrium and General Kinetic Theory." Part I of The Theory of Transformations in Metals and Alloys. 2nd Edition. Pages 19, 438, 542. New York, New York: Pergamon Press. TIC: 245378.

104966 Cieslak, M.J.; Headley, T.J.; and Romig, A.D., Jr. 1986. "The Welding Metallurgy of Hastelloy Alloys C-4, C-22, and C-276." Metallurgical Transactions A, 17A, (11), 2035-2047. Warrendale, Pennsylvania: Metallurgical Society of AIME.

TIC: 233952.

157916 Curry, P.M. and Loros, E.F. 2002. Project Requirements Document. TER-MGRMD-000001 REV 00. Las Vegas, Nevada: Bechtel SAIC Company. ACC: MOL.20020806.0027.

154749 Dick, H.J.B. 1974. "Terrestrial Nickel-Iron from the Josephine Peridotite, Its Geologic Occurrence, Associations, and Origin." Earth and Planetary Science Letters, 24, (2), 291-298. Amsterdam, The Netherlands: North-Holland.

TIC: 249849.

161439 Dinsdale, A.T. 1991. "SGTE Data for Pure Elements.” Calphad, 15, (4), 317-425. New York, New York: Pergamon Press. TIC: 253829.

171539 DOE (U.S. Department of Energy) 2004. Quality Assurance Requirements and Description. DOE/RW-0333P, Rev. 16. Washington, D.C.: U.S. Department of Energy, Office of Civilian Radioactive Waste Management. ACC: DOC.20040907.0002.

161442 Engström, A.; Höglund, L.; and Agren, J. 1994. "Computer Simulation of Diffusion in Multiphase Systems." Metallurgical and Materials Transactions A. Physical Metallurgy and Materials Science, 25A, (6), 1127-1134. Warrendale, Pennsylvania: Minerals, Metals, \& Materials Society. TIC: 253804.

161437 Frank, F.C. and Kasper, J.S. 1958. "Complex Alloy Structures Regarded as Sphere Packings. I. Definitions and Basic Principles." Acta Crystallographica, 11, (3), 184-190. Copenhagen, Denmark: Ejnar Munksgaard. TIC: 253800.

161438 Frank, F.C. and Kasper, J.S. 1959. "Complex Alloy Structures Regarded as Sphere Packings. II. Analysis and Classification of Representative Structures." Acta 
Crystallographica, 12, (7), 483-499. Copenhagen, Denmark: Ejnar Munksgaard. TIC: 253835.

100859 Gdowski, G.E. 1991. Survey of Degradation Modes of Four Nickel-ChromiumMolybdenum Alloys. UCRL-ID-108330. Livermore, California: Lawrence Livermore National Laboratory. ACC: NNA.19910521.0010.

154750 Göpel, C.; Manhès, G.; and Allègre, C.J. 1990. "U-Pb Isotope Systematics in Josephinites and Associated Rocks." Earth and Planetary Science Letters, 97, (1/2), 18-28. Amsterdam, The Netherlands: Elsevier. TIC: 249851.

161799 Heino, S. 2000. "Role of Mo and W During Sensitization of Superaustenitic Stainless Steel-Crystallography and Composition of Precipitates." Metallurgical and Materials Transactions A. Physical Metallurgy and Materials Science, 31A, (8), 1893-1905. Warrendale, Pennsylvania: Minerals, Metals \& Materials Society. TIC: 254142.

161454 Hilliard, J.E. and Cahn, J.W. 1961. "An Evaluation of Procedures in Quantitative Metallography for Volume-Fraction Analysis." Transactions of the Metallurgical Society of AIME, 221, (2), 344-352. New York, New York: American Institute of Mining, Metallurgical, and Petroleum Engineers. TIC: 253830.

161452 Hirabayashi, M.; Koiwa, M.; Tanaka, K.; Tadaki, T.; Saburi, T.; Nenno, S.; and Nishiyama, H. 1969. "An Experimental Study on the Ordered Alloy $\mathrm{Ni}_{2} \mathrm{Cr} . "$ Transactions of the Japan Institute of Metals, 10, (5), 365-371. Sendai, Japan: Japan Institute of Metals. TIC: 254259.

104968 Hodge, F.G. 1973. "Effect of Aging on the Anodic Behavior of Ni-Cr-Mo Alloys." Corrosion, 29, (10), 375-383. Houston, Texas: National Association of Corrosion Engineers. TIC: 240167.

161441 Jena, A.K.; Rajendraprasad, S.B.; and Gupta, K.P. 1989. "The Cr-Mo-Ni (Chromium-Molybdenum-Nickel) System.” Journal of Alloy Phase Diagrams, 5, (3), 164-167. Calcutta, India: Indian Institute of Metals. TIC: 253833.

154881 Karmazin, L. 1982. "Lattice Parameter Studies of Structure Changes of Ni-Cr Alloys in the Region of $\mathrm{Ni}_{2} \mathrm{Cr}$." Materials Science and Engineering, 54, 247-256. Lausanne, Switzerland: Elsevier. TIC: 249655.

161444 Karmazin, L.; Krejcí, J.; and Zeman, J. 1994. "y[gamma] Phase and $\mathrm{Ni}_{2}$ Cr-Type Long-Range Order in Ni-rich Ni-Cr-Mo Alloys." Materials Science and Engineering A. Structural Materials: Properties, Microstructure and Processing, A183, (1-2), 103-109. Lausanne, Switzerland: Elsevier. TIC: 253803.

154746 Krishnarao, J.S.R. 1964. "Native Nickel-Iron Alloy, Its Mode of Occurrence, Distribution and Origin." Economic Geology, 59, (3), 443-448. Lancaster, Pennsylvania: Economic Geology Publishing. TIC: 249850. 
104970 Leonard, R.B. 1969. “Thermal Stability of Hastelloy Alloy C-276.” Corrosion, 25, (5), 222-228. Houston, Texas: National Association of Corrosion Engineers.

TIC: 240456.

118757 Massalski, T.B.; Okamoto, H.; Subramanian, P.R.; and Kacprzak, L. 1996. Binary Alloy Phase Diagrams. 2nd Edition. Three volumes. Materials Park, Ohio: ASM International. TIC: 242462.

163274 NRC (U.S. Nuclear Regulatory Commission) 2003. Yucca Mountain Review Plan, Final Report. NUREG-1804, Rev. 2. Washington, D.C.: U.S. Nuclear Regulatory Commission, Office of Nuclear Material Safety and Safeguards. TIC: 254568.

161275 Pickering, F.B. 1976. "Physical Metallurgy of Stainless Steel Developments." International Metals Reviews, 21, 227-268. Metals Park, Ohio: American Society for Metals. TIC: 253801.

161265 Porter, D.A. and Easterling, K.E. 1992. "Diffusion along Dislocations." Section 2.7.2 of Phase Transformations in Metals and Alloys. 2nd Edition. Pages 102-103. New York, New York: Chapman \& Hall. TIC: 254148.

163029 Porter, D.A. and Easterling, K.E. 1997. "Case Studies.” Section 6.7 of Phase Transformations in Metals and Alloys. 2nd Edition. Pages 428-437. New York, New York: Chapman \& Hall. TIC: 254148.

163028 Porter, D.A. and Easterling, K.E. 1997. "Theories of Martensite Nucleation." Section 6.3 of Phase Transformations in Metals and Alloys. 2nd Edition. Pages 397409. New York, New York: Chapman \& Hall. TIC: 254148.

146956 Raghavan, M.; Berkowitz, B.J.; and Scanlon, J.C. 1982. "Electron Microscopic Analysis of Heterogeneous Precipitates in Hastelloy C-276." Metallurgical Transactions A, 13A, 979-984. Warrendale, Pennsylvania: Metallurgical Society of AIME and American Society for Metals. TIC: 240058.

154707 Raghavan, M.; Mueller, R.R.; Vaughn, G.A.; and Floreen, S. 1984. "Determination of Isothermal Sections of Nickel Rich Portion of Ni-Cr-Mo System by Analytical Electron Microscopy." Metallurgical Transactions A, 15A, (5), 783-792. New York, New York: Metallurgical Society of American Institute of Mining, Metallurgical, and Petroleum Engineers. TIC: 240057.

102797 Rebak, R.B. and Koon, N.E. 1998. "Localized Corrosion Resistance of High Nickel Alloys as Candidate Materials for Nuclear Waste Repository. Effect of Alloy and Weldment Aging at $427^{\circ} \mathrm{C}$ for up to 40,000 H." Corrosion 98. Pages 153/1-153/13. Houston, Texas: National Association of Corrosion Engineers. TIC: 245068.

155013 Rebak, R.B.; Summers, T.S.E.; and Carranza, R.M. 2000. "Mechanical Properties, Microstructure and Corrosion Performance of C-22 Alloy Aged at $260^{\circ} \mathrm{C}$ to $800^{\circ} \mathrm{C}$." Scientific Basis for Nuclear Waste Management XXIII, Symposium held November 29-December 2, 1999, Boston, Massachusetts. Smith, R.W. and Shoesmith, D.W., 
eds. 608, 109-114. Warrendale, Pennsylvania: Materials Research Society. TIC: 249052.

161464 Redlich, O. and Kister, A.T. 1948. "Algebraic Representation of Thermodynamic Properties and the Classification of Solutions." Industrial and Engineering Chemistry, 40, (2), 345-348. Easton, Pennsylvania: American Chemical Society. TIC: 253808.

162684 Reed-Hill, R.E. 1973. Physical Metallurgy Principles. 2nd Edition. Boston, Massachusetts: PWS-KENT Publishing Company. TIC: 254402.

161445 Rideout, S.; Manly, W.D.; Kamen, E.L.; Lement, B.S.; and Beck, P.A. 1951. "Intermediate Phases in Ternary Alloy Systems of Transition Elements." Journal of Metals, 3, (10), 872-876. New York, New York: American Institute of Mining and Metallurgical Engineers. TIC: 253802.

162973 Royal Institute of Technology. 1998. "DICTRA \& Diffusivities." DICTRA User's Guide. Version: 20. Pages 54-63. Stockholm, Sweden: Royal Institute of Technology, Department of Materials Science and Engineering. TIC: 254256.

104975 Saunders, N. and Miodownik, A.P. 1998. CALPHAD, Calculation of Phase Diagrams: A Comprehensive Guide. New York, New York: Pergamon Press. TIC: 245913.

161800 Shen, T.H. 1999. "TEM Observation of Ordering in C-22 Alloy.” Technical memorandum from T.H. Shen to T. Summers, September 30, 1999. ACC: MOL.20030422.0333.

161801 Shen, T.H. 2000. "X-ray Microanalysis of Precipitates in Alloy C-22." Technical memorandum from T.H. Shen to T. Summers, March 20, 2000.

ACC: MOL.20030422.0335.

154989 Shoemaker, D.P. and Shoemaker, C.B. 1988. "Icosahedral Coordination in Metallic Crystals." Chapter 1 of Introduction to Quasicrystals. Jaric, M.V., ed. Aperiodicity and Order Volume 1. San Diego, California: Academic Press. TIC: 245244.

163389 Small, C.J. and Saunders, N. 1999. "The Application of CALPHAD Techniques in the Development of a New Gas-Turbine Disk Alloy." MRS Bulletin, 24, (4), 22-26. Warrendale, Pennsylvania: Materials Research Society. TIC: 254150.

163392 Spear, K.E.; Besmann, T.M.; and Beahm, E.C. 1999. "Thermochemical Modeling of Glass: Application to High-Level Nuclear Waste Glass." MRS Bulletin, 24, (4), $37-$ 44. Warrendale, Pennsylvania: Materials Research Society. TIC: 254150.

161436 Spencer, P.J. 1999. "Computer Simulations from Thermodynamic Data: Materials Production and Development." MRS Bulletin, 24, (4), 18-19. Warrendale, Pennsylvania: Materials Research Society. TIC: 254150. 
171396 Summers, T. 2002. Phase Stability Studies - LLNL Aging Studies. SN-LLNL-SCI444-V1. Pages 12-74 ACC: MOL.20020624.0336; MOL.20020624.0337.

171397 Summers, T. 2000. E-20-67 Phase Stability Studies. Scientific Notebook SN-LLNLSCI-393-V1. Pages 1-156 ACC: MOL.20020117.0206; MOL.20020117.0207.

110249 Summers, T. and Turchi, P. 1999. Aging and Phase Stability of Waste Package Outer Barrier. UCRL-ID-134582. Livermore, California: Lawrence Livermore National Laboratory. TIC: 246033.

154854 Summers, T.S.E.; Rebak, R.B.; and Seeley, R.R. 2000. Influence of Thermal Aging on the Mechanical and Corrosion Properties of C-22 Alloy Welds. UCRL-JC137727. Livermore, California: Lawrence Livermore National Laboratory. ACC: MOL.20010517.0257.

146915 Summers, T.S.E.; Wall, M.A.; Kumar, M.; Matthews, S.J.; and Rebak, R.B. 1999. "Phase Stability and Mechanical Properties of C-22 Alloy Aged in the Temperature Range 590 to $760^{\circ} \mathrm{C}$ for 16,000 Hours." Scientific Basis for Nuclear Waste Management XXII, Symposium held November 30-December 4, 1998, Boston, Massachusetts. Wronkiewicz, D.J. and Lee, J.H., eds. 556, 919-926. Warrendale, Pennsylvania: Materials Research Society. TIC: 246426.

161460 Sundman, B. and Agren, J. 1981. "A Regular Solution Model for Phases with Several Components and Sublattices, Suitable for Computer Applications." Journal of Physics and Chemistry of Solids, 42, (4), 297-301. New York, New York: Pergamon Press. TIC: 253807.

163391 Sundman, B. and Agren, J. 1999. "Computer Applications in the Development of Steels.” MRS Bulletin, 24, (4), 32-36. Warrendale, Pennsylvania: Materials Research Society. TIC: 254150.

163393 Tanaka, T.; Hack, K.; and Hara, S. 1999. "Use of Thermodynamic Data to Determine Surface Tension and Viscosity of Metallic Alloys." MRS Bulletin, 24, (4), 45-50. Warrendale, Pennsylvania: Materials Research Society. TIC: 254150.

104991 Tawancy, H.M.; Herchenroeder, R.B.; and Asphahani, A.I. 1983. "HighPerformance Ni-Cr-Mo-W Alloys." Journal of Metals, 35, (6), 37-43. Warrendale, Pennsylvania: The Minerals, Metals \& Materials Society. TIC: 245100.

154934 Turchi, P.E.A. 2001. "Delivery of Property Diagram (Phase Fraction Versus Temperature) of Alloy 22 at Its Nominal Composition." Memorandum from P.E.A. Turchi (BSC) to RPC = 3, May 21, 2001, PROJ.05/01.051, with enclosure. ACC: MOL.20010522.0158.

162974 Turchi, P.E.A. April 2003. Modeling of Stability and Aging of Candidate Alloys for Use In Waste Disposal Canisters. SN-LLNL-SCI-477-V1.

ACC: MOL.20030626.0219. 
163109 Turek, I.; Kudrnovský, J.; and Drchal, V. 2000. "Disordered Alloys and Their Surfaces: The Coherent Potential Approximation." Electronic Structure and Physical Properties of Solids, The Uses of the LMTO Method, Lectures of A Workshop held at Mont Saint Odile, France, October 2-5, 1998. Dreyssé, H., ed. Pages 349-378. New York, New York: Springer-Verlag. TIC: 254254.

161300 Vander Voort, G.F. 2000. "Volume Fraction." Metallography, Principles and Practice. Pages 425-435. Materials Park, Ohio: ASM International. TIC: 254149.

\subsection{CODES, STANDARDS, REGULATIONS, AND PROCEDURES}

AP-2.22Q, Rev. 1, ICN 1. Classification Analyses and Maintenance of the Q-List. Washington, D.C.: U.S. Department of Energy, Office of Civilian Radioactive Waste Management. ACC: DOC.20040714.0002.

AP-2.27Q, Rev. 1, ICN 4. Planning for Science Activities. Washington, D.C.: U.S. Department of Energy, Office of Civilian Radioactive Waste Management. ACC: DOC.20040610.0006.

AP-SIII.10Q, Rev. 2, ICN 7. Models. Washington, D.C.: U.S. Department of Energy, Office of Civilian Radioactive Waste Management. ACC: DOC.20040920.0002.

AP-SV.1Q, Rev. 1, ICN 1. Control of the Electronic Management of Information. Washington, D.C.: U.S. Department of Energy, Office of Civilian Radioactive Waste Management. ACC: DOC.20040308.0001.

147465 ASTM B 575-99a. 1999. Standard Specification for Low-Carbon NickelMolybdenum-Chromium, Low-Carbon Nickel-Chromium-Molybdenum, Low-Carbon Nickel-Chromium-Molybdenum-Copper, Low-Carbon Nickel-ChromiumMolybdenum-Tantalum, and Low-Carbon Nickel-Chromium-Molybdenum-Tungsten Alloy Plate, Sheet, and Strip. West Conshohocken, Pennsylvania: American Society for Testing and Materials. TIC: 247534.

105725 ASTM C 1174-97. 1998. Standard Practice for Prediction of the Long-Term Behavior of Materials, Including Waste Forms, Used in Engineered Barrier Systems (EBS) for Geological Disposal of High-Level Radioactive Waste. West Conshohocken, Pennsylvania: American Society for Testing and Materials. TIC: 246015.

161301 ASTM E 562-95. Standard Test Method for Determining Volume Fraction by Systematic Manual Point Count. Philadelphia, Pennsylvania: American Society for Testing and Materials. TIC: 253834.

LP-SI.11Q-BSC, Rev. 0, ICN 0. Software Management. Washington, D.C.: U.S. Department of Energy, Office of Civilian Radioactive Waste Management. ACC: DOC.20040225.0007. 


\subsection{SOURCE DATA, LISTED BY DATA TRACKING NUMBER}

155299 LL010107712251.012. Transmission Electron Microscopy (TEM), Scanning Electron Microscopy (SEM), and Optical Microscopy of Aged Alloy C22 Base Metal Samples. Submittal date: 01/23/2001.

163013 LL021009912251.003. Scanning Electron Microscope (SEM) Micrographs of GasTungsten Arc-Welded Haynes Alloy 22 Samples (As-Welded) and Aged at Various Times and Temperatures Used for Area Fraction Measurements of Topologically Close-Packed (TCP) Phases. Submittal date: 01/21/2003.

162012 LL030103612251.006. Haynes Weld Data for Alloy 22 Transformation Kinetics and Arrhenius Plots. Submittal date: 01/21/2003.

163014 LL030103712251.007. Scanning Electron Microscope (SEM) Images of Base Metal Alloy 22 Samples Aged at Various Times and Temperatures Used for Area Fraction Measurements of Topologically Close-Packed (TCP) Phases. Submittal date: $01 / 23 / 2003$.

162011 LL030103812251.008. Base Metal Data for Alloy 22 Transformation Kinetics in the Matrix. Submittal date: 01/27/2003.

162468 LL030104012251.010. Grain Boundary Data for Alloy 22 Transformation Kinetics. Submittal date: 03/10/2003.

162009 LL030104212251.012. Scanning Electron Microscope (SEM) Images of Alloy 22 Base Metal and Welds Aged at Various Times and Temperatures. Submittal date: 01/22/2003.

162691 LL030301612251.040. Transmission Electron Microscopy (TEM), Scanning Electon Microscopy (SEM), and Optical Microscopy Micrographs of Aged Alloy 22 Samples. Submittal date: 03/10/2003.

163927 LL030607112251.021. Long-Range Ordering (LRO) of Alloy 22 Base Metal Aged at Various Times and Temperatures Using Vickers Microhardness Measurements. Submittal date: 06/20/2003.

\subsection{OUTPUT DATA, LISTED BY DATA TRACKING NUMBER}

LL030106312251.013. Property and Phase Kinetics Diagrams, Submittal date: $04 / 09 / 2003$.

LL030106412251.014. Validation of Computational Model, Submittal date: $04 / 04 / 2003$.

LL030606912251.020. Development Data from Alloy 22 Volume Fraction Measurements, Submittal date: 06/20/2003. 


\subsection{SOFTWARE CODES}

163153. Software Code: Thermo-Calc. VM. Sun Solaris 26. 10170-M-00.

163154 Software Code: DICTRA. V20. SUN Solaris 2,6. 10391-20-00.

$$
2 \cdot 79 / 30 / 04
$$




\section{INTENTIONALLY LEFT BLANK}

